\title{
BRAND WORLDS IN INDUSTRIAL MARKETING
}

BENJAMIN ÖSTERLE 
BRAND WORLDS IN INDUSTRIAL MARKETING BENJAMIN ÖSTERLE 

DISSERTATION

to obtain

the degree of doctor at the University of Twente, on the authority of the rector magnificus, prof. dr. T.T.M. Palstra, on account of the decision of the Doctorate Board, to be publicly defended on Friday, the $22^{\text {nd }}$ of March 2019 at 14:45 hours

by

BENJAMIN ÖSTERLE

born on the $06^{\text {th }}$ of November 1986

in Leonberg, Germany 
This dissertation has been approved by the Supervisor

Prof. Dr. Ir. J. Henseler

and the Co-supervisor

Prof. Dr. M. M. Kuhn

Cover design: Alexander Grimme

Printed by: ProefschriftMaken BV, proefschriftmaken.nl

Lay-out: Based on classicthesis by André Miede and Ivo Pletikosić

ISBN: 978-90-365-4733-8

DOI: $10.3990 / 1.9789036547338$

(C) Benjamin Österle, 2019, Stuttgart, Germany. All rights reserved. No parts of this thesis may be reproduced, stored in a retrieval system or transmitted in any form or by any means without permission of the author. Alle rechten voorbehouden. Niets uit deze uitgave mag worden vermenigvuldigd, in enige vorm of op enige wijze, zonder voorafgaande schriftelijke toestemming van de auteur. 
GRADUATION COMMITTEE

\begin{tabular}{|c|c|c|}
\hline Prof. Dr. G. P. M. R. Dewulf & University of Twente & Chairman \\
\hline Prof. Dr. Ir. J. Henseler & University of Twente & Supervisor \\
\hline Prof. Dr. M. M. Kuhn & DHBW Stuttgart & Co-supervisor \\
\hline Prof. Dr. Ir. P. C. de Weerd-Nederhof & \multicolumn{2}{|l|}{ University of Twente } \\
\hline Dr. Ir. G. M. Bonnema & \multicolumn{2}{|l|}{ University of Twente } \\
\hline Prof. Dr. E. Nijssen & \multicolumn{2}{|c|}{ Eindhoven University of Technology } \\
\hline Prof. S. Guercini, PhD & \multicolumn{2}{|c|}{ University of Florence } \\
\hline Prof. Dr. G. Christodoulides & \multicolumn{2}{|c|}{ American University of Sharjah } \\
\hline Prof. em. Dr. Ir. A. O. Eger & \multicolumn{2}{|l|}{ University of Twente } \\
\hline
\end{tabular}



In today's world, brands are one of the most valuable, intangible assets for companies (Kotler \& Pfoertsch, 2006). They are ubiquitous and serve several important functions (see for example Kapferer, 2012; Keller, 2013). While in earlier days the relevance of brands was perceived to be limited to consumer markets, nowadays, despite the important role of functional and rational aspects in organizational buying decisions, "branding is just as relevant in $\mathrm{B} 2 \mathrm{~B}$ as it is in $\mathrm{B}_{2} \mathrm{C}^{\prime \prime}$ (Kotler \& Pfoertsch, 2006, p. 12). This can be traced back to the pressures of commoditization, growing customer power, globalization, price, and a decreasing number of personal relationships originating in digital communications (Baumgarth \& Schmidt, 2010; Keränen, Piirainen, \& Salminen, 2012; Kotler \& Pfoertsch, 2007; Leek \& Christodoulides, 2011b; Mudambi, Doyle, \& Wong, 1997; Walley, Custance, Taylor, Lindgreen, \& Hingley, 2007). In this environment, where reliability, functionality, and the quality of products are now assumed as minimum requirements (Lynch \& de Chernatony, 2007), even in the industrial field branding may represent one of the last means by which companies can create a sustainable competitive advantage (Ohnemus, 2009). Therefore, many industrial companies invest in their brands, and in fact some of the most valuable brands today are B2B brands, such as GE, Cisco, or IBM (Interbrand, 2018). Yet, $\mathrm{B} 2 \mathrm{~B}$ branding research is still considered relatively novel (B. P. Brown, Zablah, Bellenger, \& Donthu, 2012; Gomes, Fernandes, \& Brandão, 2016; Keränen et al., 2012; Leek \& Christodoulides, 2011a, 2011b; Mohan, Brown, Sichtmann, \& Schoefer, 2018; Seyedghorban, Matanda, \& LaPlaca, 2016), and especially knowledge on the tactics of actually building and managing brands in this context is scarce (Lindgreen, Beverland, \& Farrelly, 2010).

Meanwhile, industrial marketing practitioners lean on the further developed area of consumer branding, and transfer and implement several brand building instruments and tactics to the $\mathrm{B}_{2} \mathrm{~B}$ area. One of the most powerful instruments of branding in consumer marketing, also called "the apex of branding" (Dolbec \& Chebat, 2013, p. 460) or the "home of the brand" (Moore, Doherty, \& Doyle, 2010, p. 153), are brand worlds. These permanent physical spaces, such as brand museums (e.g. the Mercedes-Benz Museum), flagship stores (e.g. the Apple flagship stores), or brand lands (e.g. the Heineken Experience or the VW Autostadt), use experiential marketing techniques to provide their visitors with emotion-laden, extraordinary, strong, and memorable branded experiences, much stronger than regular advertising (Borghini et al., 2009; Zarantonello \& Schmitt, 2013). Recently, more and more of these spaces have also been implemented in the industrial area. One can for example find the Mack Trucks Customer Center, the John Deere Pavilion, the Caterpillar Visitors Center, the Customer Experience Centers of General Electric and Honeywell Process Solutions, and the Automation and Power Center of ABB in the US. In Europe, there are for example the Innovation Center of logistics provider DHL, the Stahlwelt of Austrian steel producer Voestalpine, or the Brand Stores and Flagship Stores of power tool manufacturer Hilti. In Asia, the Mitsubishi Minatomirai Industrial Museum can be found. 
Given the traditionally more rational and functional approaches in organizational buying and the nuances of branding in $\mathrm{B}_{2} \mathrm{~B}$, this might at first seem counterintuitive. In fact, some of the experiential marketing tactics based on fantasies, feelings, and fun, might not only be ineffective, but even counterproductive in industrial markets (Rinallo, Borghini, \& Golfetto, 2010). And in contrary to their counterparts in consumer marketing, there is so far no evidence for the effectiveness of such experiential marketing instruments in the industrial area (Rinallo et al., 2010). In order to allow for a conscious and targeted use of the, on the one hand potentially very powerful, and on the other hand potentially counter-productive, branding instruments of brand worlds for the strategies and tactics of brand building in industrial markets, the central purpose of this work is therefore to answer two primary research questions:

$R Q_{1}$ : Do brand worlds also work in industrial marketing?

And, if so:

\section{RQ2: How do brand worlds work in industrial marketing?}

Answering these questions with respect to these carefully designed physical artifacts can be seen as the last, crucial step of the design science research process: testing and evaluating whether a design or artifact actually 'works', i.e. whether it is effective in solving a problem (van Aken, Chandrasekaran, \& Halman, 2016). Furthermore, understanding 'how' it works subsequently allows for further improvements of the design and its implementation (Holmström, Ketokivi, \& Hameri, 2009; G. G. Meyer, Buijs, Szirbik, \& Wortmann, 2014; Peffers, Tuunanen, Rothenberger, \& Chatterjee, 2007; van Aken et al., 2016). To provide these information, several steps are taken.

As a first inquiry into experiential marketing and brand worlds in business markets, a thorough understanding is needed of what these instruments are, what characterizes them, and whether these characteristics could be transferred to the industrial marketing area. Due to a lack of research on brand worlds in industrial markets, a systematic literature review on brand worlds in consumer markets is conducted, and the findings are mirrored to the $\mathrm{B}_{2} \mathrm{~B}$ realm.

Subsequently, in order to allow for the investigation whether brand worlds are effective in achieving an intended outcome, this intended outcome must first be known. Therefore, the goals and motives of brand worlds in $\mathrm{B}_{2} \mathrm{~B}$, as well as the expectations and value derived from a visit of $\mathrm{B}_{2} \mathrm{~B}$ visitors are identified in the next step, by means of qualitative expert interviews with operating companies, business visitors, and exhibition designers. Next to providing first qualitative support for their effectiveness in branding, this exploratory step also provides crucial information on what the $\mathrm{B}_{2} \mathrm{~B}$ brand world consists of, and how it works on a micro-level in co-creating experiences. Additionally, based on these information, the differences between brand worlds in $\mathrm{B}_{2} \mathrm{C}$ and $\mathrm{B}_{2} \mathrm{~B}$ are delineated.

The subsequently developed theoretical framework links recent findings on customer experiences and brand experiences, and conceptualizes the overall brand experience as dynamic (Andreini, Pedeliento, Zarantonello, \& Solerio, 2018; Kranzbühler, Kleijnen, Morgan, \& Teerling, 2018; Lemon \& Verhoef, 2016). This allows for its measurement across multiple individual touchpoints and stages, and thus for the investigation of the effect of the experience at one individual touchpoint on the overall brand experience. 
Lastly, to quantitatively investigate whether a visit to a $\mathrm{B}_{2} \mathrm{~B}$ brand world increases the levels of the crucial branding outcomes of brand experience and brand equity, i.e. whether brand worlds work in industrial marketing, a pretest-posttest quasi-experimental study is conducted at a $\mathrm{B}_{2} \mathrm{~B}$ brand world. This step also shows how the brand world works on a macro-level from an experiential marketing perspective, by analyzing how the co-created brand world experience relates to pre-visit and post-visit brand experience and brand equity in a nomological net, using partial least squares structural equation modeling.

In summary, the research conducted within this dissertation shows that brand worlds work in industrial marketing, and that they can help to build brand equity.

Looking at how this instrument works in $\mathrm{B}_{2} \mathrm{~B}$, a core difference between $\mathrm{B}_{2} \mathrm{C}$ and $\mathrm{B}_{2} \mathrm{~B}$ brand worlds is, that $\mathrm{B}_{2} \mathrm{~B}$ visitors expect more functional than hedonic benefits, and the visit has to support them in their own business activities. Yet, emotional and more hedonic factors do also play a role.

On the micro level, the experience at a brand world itself is co-created by the operating company and the visitor. On the one hand, the $\mathrm{B}_{2} \mathrm{~B}$ brand world experiencescape reflects the company's contribution to this co-creation. It is the manifestation of the contents that the company wants to convey in the brand world in physical artifacts and spaces, and in social environments and practices. On the other hand, the embodied cognition of the $\mathrm{B}_{2} \mathrm{~B}$ brand world reflects the visitor's contribution to how he perceives and interacts with the affordances provided within the $\mathrm{B} 2 \mathrm{~B}$ brand world experiencescape, and thus how he experiences it. Through their actions and perceptions on these affordances, the visitors interact with and influence both the physical artifacts and spaces, as well as the social environment. These perceptions of and interactions and relationship-building processes with subjects (i.e. the brands employees), as well as the interactions with, perceptions of, and immersion in the physical environment leads to further engagement, a personalization and co-production of the $\mathrm{B}_{2} \mathrm{~B}$ brand world experience, and facilitates learning and relationship-building in the brand world. It is how the $\mathrm{B}_{2} \mathrm{~B}$ brand world experience itself, and the value in it for both parties, is co-created.

On the macro level, this experience at the $\mathrm{B}_{2} \mathrm{~B}$ brand world is influenced by previous brand experiences. Yet, it is not influenced by levels of pre-visit brand equity. In a complementary mediation, the brand world experience itself in turn influences post-visit brand equity directly and indirectly through post-visit brand experience. The total effect of this experience co-created at the brand world on post-visit brand equity amounts to more than half of the size of the effect of pre-visit brand equity on post-visit brand equity. This means that if the visitor was unaware of the brand, had negative associations with the brand, perceived it as being of low quality, or was disloyal to the brand prior to the visit, one single visit to a $\mathrm{B} 2 \mathrm{~B}$ brand world can compensate for half of these possible preconceptions with respect to the visitors post-visit brand equity evaluation. On the other hand, it also means that visitors who have high levels of brand equity prior to the visit do not necessarily also have a great experience at the brand world. If the visitor is in fact disappointed by the experience at this individual touchpoint, it can also have a negative effect on his levels of post-visit brand experience and brand equity. Thus, to reap the potential benefits of brand worlds in industrial marketing, operating companies 
have to fulfill, if not exceed, the expectations of their visitors. This calls for careful management and an individualization of the brand world experience to each $\mathrm{B}_{2} \mathrm{~B}$ visitor's needs, and is in line with the findings in this thesis about the importance of individualization and the creation of a visit that is relevant for the business visitor in that it supports him in his business activities. The differences between brand worlds in $\mathrm{B}_{2} \mathrm{C}$ and $\mathrm{B}_{2} \mathrm{~B}$ described in this thesis provide further information for their implementation in practice.

To conclude, brand worlds in industrial marketing, the 'living rooms' of B2B brands, might not only be the apexes of branding in $\mathrm{B}_{2} \mathrm{C}$, but also in $\mathrm{B}_{2} \mathrm{~B}$. 
For me, writing this $\mathrm{PhD}$ thesis was an incredible journey - figuratively and literally, given all the beautiful places that I was allowed to visit.

This journey would not have been possible if it were not for all the people who supported me. Therefore, I would like to express my deepest gratitude to everyone I met on this journey and who played a role in it. Yet, besides this general acknowledgment, there are also some very special persons which I would like to thank personally.

First of all, my supervisor and co-supervisor, Jörg and Marc. I know it sounds like a platitude, but I could not have wished for better supervisors! Marc, if you would not have called me on this sunny day in July 2014, completely out of the blue for me, to ask me whether I would not want to quit my full-time job in the industry to pursue a $\mathrm{PhD}$, I would not be writing these lines today. In the time since then, we have experienced a lot of great things together, and you not only became my co-supervisor, but also a friend. Jörg, from the very first time that we met in December 2014 in Stuttgart, with your very empathic, supportive, and esteeming personality - next to the methodological guidance - you gave me the encouragement, confidence and support needed for such a project. It is remarkable how you keep a positive mindset even when something does not go as planned, and see an opportunity for publication in it. Therefore, dear supervisors: Thank you for always dealing with my last minute submissions so patiently, for your invaluable comments, feedback, and advice (which you always provided in basically no time), for your guidance, for your continuing support and belief in me, and for always finding the right words that pushed me to keep going forward. I am deeply grateful for that.

I would also like to thank all members of my graduation committee, Prof. Dr. G. P. M. R. Dewulf, Prof. Dr. Ir. P. C. de Weerd-Nederhof, Dr. Ir. G. M. Bonnema, Prof. Dr. E. Nijssen, Prof. S. Guercini, PhD, Prof. Dr. G. Christodoulides, Prof. em. Dr. Ir. A. O. Eger, for their valued time and effort.

Dear colleagues at the Center for Empirical Research at the DHBW in Stuttgart, dear Vanessa, Anne, Sarah, Kerstin, Julia, Viola, Natalie, Nathalie, Simon, Simon, Milena, Daniel: To be honest, if I would write something personal for each of you, I could probably fill another book. And right now, I am happy with the one I just wrote. Therefore, I just want to thank you for your help in the process of writing this thesis, for your feedback on my work progress in our not so monthly status update meetings, for the serious talks when something did not go as planned, but also for the not so serious talks and especially for the great moments and fun we had together, not only in the office but also on several other occasions outside of it - for example on our trips to Bari, Florida, Enschede, Bruxelles, Berlin, or when we simply went bowling, climbing, or played poker. Just like Marc, you became friends. Thank you!

Furthermore, I want to thank all the members of the Department of Design, Production and Management at the University of Twente, and some people specifically, who were always there for me in case I needed help, and who provided a great framework for an external PhD student like me. Bjorn and Carsten, thank you for the great time I think we always had at the PhD days, 
from the very beginning. I will definitely miss the evenings at the bar with you guys. Florian, thank you for our last minute session after Bjorn's defense, for finding some 'minor' mistakes in my work and for helping me deal with them. Mauricy, thank you for your feedback on one of my papers, for accompanying me on my run during and just as much for the fun party after the batavierenrace. Inge, 'batavierenrace' is your keyword. First of all, thank you for kind of forcing me to be on the team, it was a really great experience. I also want to thank you for your continuing support and the fun talks during the $\mathrm{PhD}$ days or on the phone. Thank you to the entire 'Horsthollers' running crew as well. Annemarie and Inge, thank you for always being supportive, cheerful, and fun when we met at the PhD days or when we talked on the phone. Chris, thank you for your review and feedback on one of my papers, and for the interesting discussion that followed afterwards. Jelle, thank you for taking the time to introduce me to the world of phenomenology.

I would also like to thank all my fellow $\mathrm{PhD}$ candidates of the Chair of Product-Market Relations for the great day- and the just as great eveningsessions at the bar of Drienerburght, which we always had at said PhD days. Christian, special thanks go to you for the long and deep talks on our trips to Enschede. For me, these meetings were always a very strong and valuable source of motivation. Thank you all for that, and I wish you all the best for the rest of your $\mathrm{PhD}$ projects.

From all the people I mentioned, I would like to point out Vanessa and Bjorn. The result of us getting along so well during the past four years is that I gave you some work to do as my paranymphs. Thank you for taking on this task.

Hansi, Thomas, Paddy, Ali, Dani, Hannes, thank you for always being there when I needed some distraction from my PhD thesis, and for your friendship for so many years already.

I also want to thank my entire family for always encouraging me in the pursuit of this thesis.

Tobi and Steffi, I am proud to have a brother and a sister-in-law like you, and I am looking forward to spending time with the addition to the family. Thank you for your support and for letting me off the hook so often when I was busy writing my papers and could not help you build your new home.

Last but not least, I am especially grateful to my parents. Mama and Papa, thank you for your unconditional love and support - not only on the journey to my $\mathrm{PhD}$, but on my entire journey to this point. Without you, I literally would not be writing this. Thank you very much for everything you have done for me.

Dankeschön! 


\section{CONTENTS}

I RESEARCH BACKGROUND AND STRUCTURE OF THIS THESIS I

1.1 Introduction 1

1.2 Research Questions, Design and Objectives 2

1.3 Thesis Outline 4

1.4 Contribution 7

1.5 Guide to the Reader 9

2 AN INQUIRY INTO EXPERIENTIAL MARKETING AND BRAND WORLDS IN INDUSTRIAL MARKETING II

2.1 Introduction 12

2.2 Experiential Marketing, Brand Experience and Brand Worlds in B2C 14

2.3 Experiential Marketing, Branding and Brand Worlds in B2B $\quad 16$

2.4 Methodology 18

2.5 Analysis of Literature on Brand Worlds in Consumer Marketing 19

2.6 Brand Worlds in Industrial Marketing 20

2.7 Conclusions and Implications for Marketing Theory 31

2.8 Implications for Business Marketing Practice 32

3 BRAND WORLDS: INTRODUCING EXPERIENTIAL MARKETING TO B2 B BRANDING 35

3.1 Introduction 36

3.2 Theoretical Background 38

3.3 Methodology 46

3.4 Results 49

3.5 Discussion and Conclusion 56

4 DIFFERENCES BETWEEN BRAND WORLDS IN B2C AND B2B 65

4.1 Introduction 66

4.2 Theoretical Background 67

4.3 Methodology and Sample 69

4.4 Differences between $\mathrm{B}_{2} \mathrm{C}$ and $\mathrm{B}_{2} \mathrm{~B}$ brand worlds $\quad 71$

4.5 Conclusion 74

5 THE DYNAMIC NATURE OF BRAND EXPERIENCE 75

5.1 Introduction $\quad 76$

5.2 Customer Experiences 77

5.3 Touchpoints and Experiences $\quad 79$

$5 \cdot 4$ Brands and Experiences 81

5.5 Conclusion and Implications 82

6 ENTERING B2B BRANDS' LIVING ROOMS: HOW BRAND WORLDS CAN HELP BUILD BRAND EQUITY 85

6.1 Introduction 86

6.2 Background 89

6.3 Empirical Study 97

6.4 Results 108

6.5 Discussion 118

7 SYNOPSIS 125 
7.1 Introduction 125

7.2 Discussion 125

7.3 Limitations 132

$7 \cdot 4$ Implications 133

A APPENDix 139

A.1 Appendix Chapter $2 \quad 139$

A.2 Appendix Chapter 3 and $4 \quad 146$

A.3 Appendix Chapter $6 \quad 170$

BIBLIOGRAPHY 183 
Figure 1.1

Figure 3.1

Figure 3.2

Figure 5.1

Figure 5.2

Figure $5 \cdot 3$

Figure 6.1

Figure 6.2

Figure 6.3

Figure 6.4

Figure 6.5

Figure 6.6

Figure A.1

Figure A.2
Thesis outline 4

A $360^{\circ}$ view on co-created $\mathrm{B} 2 \mathrm{~B}$ brand world experience 47

A comprehensive view on $\mathrm{B} 2 \mathrm{~B}$ brand worlds $\quad 61$

Formation of static and dynamic customer experience $\quad 79$

Process Model for Customer Journey and Experience $\quad 80$

Customer Journey and Dynamic Nature of Brand Experience 82

Conceptual model and hypotheses 96

Sample distribution of visitor groups 102

Sample distribution of age 102

Sample distribution of country 103

Sample distribution of previous visits to the brand world 103

Sample distribution of ownership of the brand's products 104

Minimal model for assessment of composite brand world experience measurement 181

Final second-order model $\quad 182$ 
Table 2.1

Table 2.2

Table 2.3

Table 3.1

Table 3.2

Table $3 \cdot 3$

Table 3.4

Table $3 \cdot 5$

Table 4.1

Table 6.1

Table 6.2

Table 6.3

Table 6.4

Table 6.5

Table 6.6

Table 6.7

Table 6.8

Table 6.9

Table 6.10

Table 6.11

Table 6.12

Table 6.13

Table 6.14

Table A.I

Table A.2

Table A.3

Table A.4

Table A. 5

Table A.6

Table A.7

Table A.8

Table A.9
Overview of main types of brand worlds described in consumer marketing literature $\quad 21$

Differentiating characteristics of brand worlds described in consumer marketing 22

Overview of potential characteristics differentiating brand worlds in industrial marketing $\quad 29$

Main goals for the implementation of brand worlds in $\mathrm{B}_{2} \mathrm{C} \quad 41$

Super-ordinate expectations and demands of $\mathrm{B}_{2} \mathrm{C}$ brand world visitors 42

B2C experiential value dimensions 44

$\mathrm{B} 2 \mathrm{~B}$ experiential value dimensions in networking events

Motives of companies operating $\mathrm{B}_{2} \mathrm{~B}$ brand worlds $\quad 5^{1}$

Differences between $\mathrm{B}_{2} \mathrm{C}$ and $\mathrm{B}_{2} \mathrm{~B}$ brand worlds $\quad 72$

Wilcoxon Test results 109

Model fit first-order pre-visit measurement $\quad 112$

Model fit first-order post-visit measurement $\quad 112$

Final model fit first-order post-visit measurement $\quad 113$

Reliability and validity of final first-order measurement 114

Model fit of the minimal model for assessment of secondorder composite $\quad 115$

Model fit of final second-order model 115

Reliability and validity of second-order constructs $\quad 115$

Loadings and t-values of final second-order model $\quad 116$

Consistent weights, t-values and VIFs of final second-

order model 116

Coefficients of determination $\quad 117$

Direct effects $\quad 117$

Indirect effects $\quad 118$

Total effects 119

Overview of sources and discussed characteristics of B2C brand worlds 140

Company sample overview $\quad 151$

Visitor sample overview $\quad \mathbf{1 5 6}$

Exhibition designer sample overview $\quad 157$

Company informant statements and motive categories

Expectations and demands of $\mathrm{B}_{2} \mathrm{~B}$ brand world business visitors 160

Value of the $\mathrm{B}_{2} \mathrm{~B}$ brand world experience for business visitors 161

Informant statements on the $\mathrm{B}_{2} \mathrm{~B}$ brand world content $\quad 164$

Informant statements on the B2B brand world experiencescape $\quad 167$ 
Table A.10

Table A.11

Table A.12

Table A.13

Table A.14

Table A.15

Table A.16

Table A.17
Brand experience indicators $\quad 170$

Brand equity indicators 171

Brand world experience indicators $\quad 172$

Indicator statistics 173

Reliability and validity of initial first-order measurement $\quad 178$

Removed indicators 179

Loadings and $t$-values of final first-order pre-visit measurement 179

Loadings and $\mathrm{t}$-values of final first-order post-visit measurement 180 


THESIS

\section{I INTRODUCTION}

In today's world, brands are ubiquitous and play an important role in people's lives. This goes so far that brands can even serve as substitute for religiosity in expressing self-worth (Shachar, Erdem, Cutright, \& Fitzsimons, 2011). Since brands are so important for customers, they are also one of the most valuable, intangible assets for companies, which in turn try to build strong brands (Keller, 2013; Kotler \& Pfoertsch, 2006). The culmination of these branding efforts lies in brandscaping, which transforms the brand itself into physical spaces and locations (Riewoldt, 2002). To stay in the picture of brands and religiosity, such physical spaces which embody a brand and make it visible and actually tangible, are seen as the new places of pilgrimage and worship of today (Borghini et al., 2009; Hollenbeck, Peters, \& Zinkhan, 2008; Kozinets et al., 2002; Mikunda, 2004; Riewoldt, 2002). These branded, permanent, physical spaces such as flagship stores, brand museums, customer experience centers, or brand lands, which we summarize under the umbrella term 'brand worlds', facilitate extraordinary experiences related to a brand which are much stronger than regular advertising, based on their direct, highly interactive visitor-brand encounters (Borghini et al., 2009; E. H. Wood, 2009; Zarantonello \& Schmitt, 2013). Adopting a more secular perspective, flagship stores are also termed the "home of the brand" (Moore et al., 2010, p. 153) and the "apexes of branding" (Dolbec \& Chebat, 2013, p. 460), exactly because of this power to evoke strong, unique, and memorable experiences related to a brand (Dolbec \& Chebat, 2013; Kozinets et al., 2002). For the emotional realm of consumer marketing, there can hardly be a greater achievement for a brand than fully materializing in its own successful brand world, such as for example the Walt Disney World, the World of Coca-Cola, the Hershey Park, the VW Autostadt or the Apple Flagship Stores. All these brand worlds employ techniques of experiential marketing, a management area that refers to the strategies and tactics of staging and creating offerings for the purpose of facilitating extraordinary experiences (Carù \& Cova, 2003; Pine \& Gilmore, 1999).

While in earlier days the relevance of brands was perceived to be limited to consumer markets, it is today also acknowledged that brands and branding play an important role in industrial markets. Despite the importance of functional and rational aspects in organizational buying decisions, subjective evaluations, heuristics, and emotions play a role as well (Casidy, Nyadzayo, Mohan, \& Brown, 2018; Iyer, Hong Xiao, Sharma, \& Nicholson, 2015; Mohan et al., 2018; Zablah, Brown, \& Donthu, 2010), and thus "branding is just as relevant in B2B as it is in $\mathrm{B}_{2} \mathrm{C}^{\prime \prime}$ (Kotler \& Pfoertsch, 2006, p. 12). Some of the most valuable brands today are in fact $\mathrm{B} 2 \mathrm{~B}$ brands, such as GE, Cisco, or IBM (Interbrand, 2018). Yet, B2B branding research is still considered relatively novel, and many concepts, frameworks, and theories have been transferred and adapted from the further developed $\mathrm{B}_{2} \mathrm{C}$ branding area to $\mathrm{B}_{2} \mathrm{~B}$ branding (B. P. Brown et al., 2012; 
Gomes et al., 2016; Keränen et al., 2012; Leek \& Christodoulides, 2011a, 2011b; Mohan et al., 2018; Seyedghorban et al., 2016). The unique characteristics of the $\mathrm{B}_{2} \mathrm{~B}$ area need to be taken into account in these transfers for the development of a sound $\mathrm{B}_{2} \mathrm{~B}$ branding theory, and one can not simply rely on thinking that what works for brands in $\mathrm{B}_{2} \mathrm{C}$ also works for brands in $\mathrm{B}_{2} \mathrm{~B}$ (Keränen et al., 2012; Mudambi, 2002; Seyedghorban et al., 2016; Webster \& Keller, 2004). Due to this relative novelty of $\mathrm{B}_{2} \mathrm{~B}$ branding research, only recently a shift has been made from investigating the mere relevance of brands to business buyers towards focusing on the tactics of how brands can actually be built, managed, and refreshed in industrial markets (Lindgreen et al., 2010). This issue of building and maintaining strong brands is seen as a major strategic objective in B2B markets (Seyedghorban et al., 2016).

$\mathrm{B}_{2} \mathrm{~B}$ marketing practitioners have already recognized the potential benefits of brand worlds, these homes of the brand and apexes of branding, for their own companies. All over the world, they have implemented spaces such as the Caterpillar Visitors Center, the Customer Experience Centers of General Electric and Honeywell Process Solutions, or the John Deere Pavilion in the US, the Innovation Center of logistics provider DHL, the Stahlwelt of Austrian steel producer Voestalpine, or the John Deere Forum in Europe, or the Mitsubishi Minatomirai Industrial Museum in Asia, amongst others. Furthermore, these spaces have also been mentioned as possibilities for $\mathrm{B}_{2} \mathrm{~B}$ companies to create strong, memorable customer experiences (Gilmore \& Pine, 2002; Pine \& Gilmore, 1999; Schmitt, 1999b). While this implementation in business marketing practice provides evidence for their mere existence in industrial markets, it does not yet provide scientific evidence for their effectiveness in this different $\mathrm{B}_{2} \mathrm{~B}$ marketing context. In fact, so far there is a complete absence of research on brand worlds in industrial markets, and the understanding of experiential marketing activities in this different, nuanced context is limited, too (Rinallo et al., 2010). Therefore, the effectiveness of such experiential marketing instruments in industrial markets and the determinants of their effectiveness need to be investigated further (Rinallo et al., 2010), in order to allow for a conscious and targeted use of these potentially powerful branding instruments for the strategies and tactics of brand building in industrial markets.

\subsection{RESEARCH QUESTIONS, DESIGN AND OBJECTIVES}

Based on the situation outlined in Section 1.1, namely the importance of branding in industrial markets, the strategic practical issue of how to build and maintain strong brands in this context, and the use of brand worlds in business marketing practice on the one hand, and the complete lack of research on the effectiveness of these apexes of branding in $\mathrm{B} 2 \mathrm{~B}$ on the other hand, the central purpose of this work is to answer two primary research questions:

RQ1: Do brand worlds also work in industrial marketing?

And, if so:

$R Q 2:$ How do brand worlds work in industrial marketing?

In trying to answer these questions, brand worlds can be seen as physical artifacts, designed and built to achieve a certain purpose. As such, they are 
a product of design, like many other marketing communication instruments (Henseler, 2017a). Research on such marketing communication and branding instruments designed by humans, such as in advertising research, is "a design science, aiming to generate a body of knowledge on how to create, improve, orchestrate, and manage specific types of marketing instruments" (Henseler, 2017a, p. 178). Design science research itself is a research strategy that aims to create knowledge that can be used to design and implement actions, processes or systems to achieve desired outcomes in practice (van Aken et al., 2016) Based on a process comprising different steps, such as problem identification and exploration, the search for initial solutions, and the own development of a solution (Holmström et al., 2009; G. G. Meyer et al., 2014; Peffers et al., 2007; van Aken et al., 2016), the goal of design science is to develop a "'means to an end,' an artifact to solve a problem" (Holmström et al., 2009, p. 67) Hence, the question of whether a design actually 'works', i.e. whether it is effective in solving a problem, and therefore testing and evaluating the artifact, is the crucial last step of the design science research process (van Aken et al., 2016). It subsequently allows for further improvements of the design and its implementation (Holmström et al., 2009; G. G. Meyer et al., 2014; Peffers et al., 2007; van Aken et al., 2016).

The intended outcomes or achievements of marketing instruments are often changes in consumer behavior or attitudes (Henseler, 2017a). For a substantial period of time, the dominant metaphor for marketing theory in general was that marketing is a behavioral science, focusing on theories that describe and try to explain the beliefs, attitudes, intentions, and behaviors of consumers and industrial buyers alike (Fishbein \& Ajzen, 1975; Kerin, 1996; Kumar, 2015). Therefore, the aim to investigate whether the marketing instrument 'brand world' 'works' in industrial marketing, i.e. whether operating companies are able to achieve the potentially behavioral outcomes intended with their implementation, places this thesis at the intersection of design and behavioral research. Furthermore, with the aim to describe and explain how brand worlds in industrial marketing function and how they might influence these constructs of behavioral science, this thesis could provide information for practitioners that might help to further improve the design and management of these marketing instruments, and further the theoretical knowledge on experiential marketing instruments and brand building tactics in industrial markets.

Now that the approach applied to answer the guiding research questions is placed in research theory, the structure of this thesis is presented along its different chapters in Section 1.3. Subsequently, in Section 1.4, an overview of the theoretical and practical contributions of this thesis is provided. Section 1.5 provides those readers who wish to read this thesis in its entirety with a hopefully helpful guide, since some of the contents in the various chapters are overlapping and repetitive. This circumstance originates therein, that the then following chapters (Chapters 2, 3, 4, 5, 6) are based on scientific papers, which are initially written to be stand-alone pieces of research and individually submitted to various journals and academic conferences, and are now combined to form the body of this thesis. While all of these papers answer different subordinate research questions, they are connected by the common theme of brand worlds and/or experiences and experiential marketing, and build on each other. The 'red thread' or storyline that links them is described in Section 1.3. Chapter 7 then presents the answers to the main research questions 
of this thesis, which are based on the outcomes of the research carried out within this project. It furthermore discusses the findings, presents limitations, and provides recommendations for further research and for practitioners.

\subsection{THESIS OUTLINE}

This section provides the 'red thread' for this thesis. It explains how the individual papers that are presented in the next chapters of this thesis are linked to each other, and how they contribute to answering the main research questions in multiple steps.

Figure 1.1 summarizes this 'red thread'.

\begin{tabular}{|c|c|c|c|}
\hline \multicolumn{2}{|l|}{$\begin{array}{l}\text { CHAPTER 1: } \\
\text { Research Background and } \\
\text { Structure of This Thesis }\end{array}$} & $\begin{array}{l}\text { RQ 1: } \\
\text { Do brand worlds } \\
\text { also work in } \\
\text { industrial } \\
\text { marketing? }\end{array}$ & $\begin{array}{l}\text { RQ 2: } \\
\text { How do brand } \\
\text { worlds work in } \\
\text { industrial } \\
\text { marketing? }\end{array}$ \\
\hline $\begin{array}{l}\text { CHAPTER 2: } \\
\text { Inquiry Into Exp. } \\
\text { Marketing and Brand } \\
\text { Worlds in Ind. Marketing }\end{array}$ & $\begin{array}{l}\text { APPROACH / DATA: } \\
\text { Systematic literature } \\
\text { review; } \\
38 \text { relevant B2C } \\
\text { contributions }\end{array}$ & \multicolumn{2}{|c|}{$\begin{array}{c}\text { CONTRIBUTION: } \\
\text { First inquiry into experiential marketing and } \\
\text { brand worlds in business markets. What are } \\
\text { these instruments and what characterizes } \\
\text { them? }\end{array}$} \\
\hline $\begin{array}{l}\text { CHAPTER 3: } \\
\text { Brand Worlds: } \\
\text { Introducing Exp. } \\
\text { Marketing to B2B } \\
\text { Branding }\end{array}$ & \multirow{2}{*}{$\begin{array}{l}37 \text { qualitative expert } \\
\text { interviews with } \\
\text { companies, } \\
\text { designers, and } \\
\text { visitors; Qualitative } \\
\text { content analysis }\end{array}$} & $\begin{array}{l}\text { Identification of } \\
\text { goals and motives, } \\
\text { expectations, and } \\
\text { value derived; Qual. } \\
\text { support that B2B } \\
\text { brand worlds work } \\
\end{array}$ & $\begin{array}{l}\text { What B2B brand } \\
\text { worlds consist of; } \\
\text { How they work on a } \\
\text { micro-level in co- } \\
\text { creating experiences }\end{array}$ \\
\hline $\begin{array}{l}\text { CHAPTER 4: } \\
\text { Differences Between } \\
\text { Brand Worlds in B2C and } \\
\text { B2B }\end{array}$ & & & $\begin{array}{c}\text { Differences between } \\
\text { brand worlds in B2C } \\
\text { and B2B; } \\
\text { Considerations for } \\
\text { their practical } \\
\text { implementation } \\
\end{array}$ \\
\hline $\begin{array}{l}\text { CHAPTER 5: } \\
\text { The Dynamic Nature of } \\
\text { Brand Experience }\end{array}$ & Theoretical paper & \multicolumn{2}{|c|}{$\begin{array}{l}\text { Theoretical framework which conceptualizes } \\
\text { the overall brand experience as dynamic and } \\
\text { allows for its measurement across multiple } \\
\text { individual touchpoints and multiple stages }\end{array}$} \\
\hline $\begin{array}{l}\text { CHAPTER 6: } \\
\text { Entering B2B Brands' } \\
\text { Living Rooms }\end{array}$ & $\begin{array}{l}\text { Pretest-posttest } \\
\text { quasi-experiment in } \\
\text { a B2B brand world; } \\
\text { Survey with } 218 \\
\text { business visitors; } \\
\text { Partial least squares } \\
\end{array}$ & $\begin{array}{l}\text { A visit to a B2B } \\
\text { brand world } \\
\text { significantly } \\
\text { increases levels of } \\
\text { brand experience } \\
\text { and brand equity } \\
\end{array}$ & $\begin{array}{l}\text { How B2B brand } \\
\text { worlds work on a } \\
\text { macro-level; } \\
\text { relationships to } \\
\text { brand experience } \\
\text { and brand equity } \\
\end{array}$ \\
\hline $\begin{array}{l}\text { CHAPTER 7: } \\
\text { Synopsis }\end{array}$ & & \multicolumn{2}{|c|}{$\begin{array}{c}\text { Synthesis of the findings } \\
\text { Final answers to the research questions } \\
\text { Discussion } \\
\text { Implications for theory and practice } \\
\text { Conclusion }\end{array}$} \\
\hline
\end{tabular}

Figure 1.1: Thesis outline 


\subsubsection{Chapter 2: An Inquiry Into Experiential Marketing and Brand Worlds in Industrial Marketing}

As a start to the endeavor of finding out whether and how brand worlds work in industrial marketing, one must first gain an understanding of what these instruments are and what characterizes them. Therefore, Chapter 2 serves as a first inquiry into experiential marketing and brand worlds in business markets. Due to the lack of research on both these topics in B2B, it analyzes and synthesizes the findings regarding what different types of brand worlds exist in $\mathrm{B}_{2} \mathrm{C}$, what their goals and special characteristics are, as well as whether these instruments work and how they work in consumer marketing. In order to do so, 38 relevant contributions to the consumer marketing literature were identified using a systematic literature review and analyzed with qualitative content analysis. Seven main types of brand worlds are identified, and 16 characteristics differentiating them from each other. Furthermore, these findings are reflected on examples of brand worlds in the $\mathrm{B}_{2} \mathrm{~B}$ realm, in order to investigate whether they might be transferable. As such, this chapter serves to give an overview on brand worlds and to place this thesis into the research environment of experiential marketing and branding in business markets.

\subsubsection{Chapter 3: Brand Worlds: Introducing Experiential Marketing to B2B Branding}

In the following Chapter 3, this preliminary understanding of brand worlds in industrial markets, which is so far only based on secondary information and a transfer from the consumer marketing area, is deepened further. In line with the two main research questions, the purpose of this chapter is twofold. First, to identify why companies in industrial marketing implement brand worlds, i.e. the goals and motives that they pursue, but also what the expectations of and the values derived for the business visitors are. Understanding this allows for the later investigation of whether these goals are achieved, and whether brand worlds work. Second, with respect to the question of how they work, this chapter investigates the nature of $\mathrm{B} 2 \mathrm{~B}$ brand worlds, what they consist of, and how they are experienced. This chapter is based on a total of 37 qualitative expert interviews with industrial companies operating brand worlds, business visitors, and exhibition designers. The findings show that although $\mathrm{B}_{2} \mathrm{~B}$ brand worlds apply similar experiential marketing techniques than their $\mathrm{B}_{2} \mathrm{C}$ counterparts, they also differ in several important aspects. One similarity is that they are also instruments used for branding purposes and to create brand experiences, and the findings provide first qualitative support for the effectiveness of brand worlds in industrial markets in this respect. But compared to $\mathrm{B}_{2} \mathrm{C}, \mathrm{B}_{2} \mathrm{~B}$ visitors expect more functional than hedonic benefits, and the visit has to support them in their own business activities. Affordances of the brand world experiencescape, consisting of physical artifacts and spaces, and the social environment and practices, and the action-perception between visitor, brand employees, and these physical environments are at the core of the $\mathrm{B}_{2} \mathrm{~B}$ brand world experience. This shows on a micro level how the $\mathrm{B}_{2} \mathrm{~B}$ brand world works, by describing how it is perceived and how the experience at a $\mathrm{B}_{2} \mathrm{~B}$ brand world is co-created. 


\subsubsection{Chapter 4: Differences Between Brand Worlds in $B_{2} C$ and $B 2 B$}

With respect to our second main research question, how brand worlds in industrial marketing work, Chapter 4 highlights the differences between these spaces in $\mathrm{B}_{2} \mathrm{C}$ and $\mathrm{B}_{2} \mathrm{~B}$. It gives a deeper understanding of what the specific characteristics of brand worlds in industrial marketing are, which have to be considered in their practical implementation. This chapter builds on the same sample and methodology as Chapter 3.

\subsubsection{Chapter 5: The Dynamic Nature of Brand Experience}

In order to quantitatively investigate the first main research question, whether the visit to a brand world works, in this case whether it has an influence on the operating company's branding goals, a thorough understanding of experiences is needed, as is a theoretical framework. With respect to the second main research question, such a framework would also allow to investigate how the experience co-created at a brand world in industrial marketing works on a macro level in a nomological net. Chapter 5 links the findings on the distinct concepts of brand experience and customer experience in such a theoretical framework, in order to generalize from those specific experience areas to overarching principles of experiences. This framework argues and allows for the measurement of the overall brand experience, a core aspect in branding research, across multiple individual touchpoints and multiple stages. This theoretical paper sets the foundation for the quantitative evaluation of whether brand worlds in industrial marketing, a single touchpoint, work with respect to an increase in brand experience, which was one goal of the implementation of brand worlds as identified in Chapter 3 .

\subsubsection{Chapter 6: Entering B2B Brands' Living Rooms: How Brand Worlds Can Help Build Brand Equity}

Chapter 6 builds on the findings of Chapter 3 and the framework outlined in Chapter 5. While Chapter 3 has given qualitative support showing that brand worlds work in industrial marketing, and how they work in co-creating an experience for the visitor, this study investigates quantitatively whether brand worlds work in increasing the levels of core branding concepts, namely brand experience and brand equity. Furthermore, while Chapter 3 has shown how brand worlds work on a micro-level to co-create experiences, this chapter investigates how the experience co-created there works on a macro-level by analyzing its relationships with brand experience and brand equity in a nomological net. Data is collected in a quasi-experimental pretest-posttest research design from a sample of 218 visitors of a brand world in industrial marketing. Analyzing this data with a Wilcoxon signed-rank test showed that brand worlds indeed work in industrial marketing, and are effective in increasing the levels of the focal outcome constructs brand experience and brand equity. Furthermore, based on the components of the B2B brand world experience identified in Chapter 3 and using partial least squares structural equation modeling as implemented in ADANCO 2.0.1 (Henseler \& Dijkstra, 2015), this chapter shows that the experience at the individual touchpoint of the brand 
world mediates the relationship between pre- and post-visit brand experience. It is not influenced by pre-visit brand equity. Yet, this brand world experience influences post-visit brand equity directly and indirectly through post-visit brand experience.

\subsubsection{Chapter 7: Synopsis}

In the last Chapter 7 of this dissertation, these individual research papers and their findings are synthesized. The answers to the main research questions of this thesis are presented: 'Do brand worlds also work in industrial marketing?' and, if so, 'how do brand worlds work in industrial marketing?' These answers are based on the findings of the research conducted within this thesis, as outlined above and described in the following Chapters 2-6. Apart from this, these findings are discussed and related back to theory on branding and experiential marketing in industrial markets. Furthermore, a reflection on the limitations of the findings of this research project as a whole, related areas for further research, and implications for theory as well as for practitioners conclude this thesis.

\subsection{CONTRIBUTION}

By addressing the main research questions and the subordinate research questions in each individual chapter, this thesis contributes to marketing theory and practice in several ways. This section briefly describes these contributions.

\subsubsection{Chapter 2: An Inquiry Into Experiential Marketing and Brand Worlds in Industrial Marketing}

Chapter 2 summarizes and synthesizes the research on brand worlds in consumer markets. Seven main types of brand worlds which are discussed in $\mathrm{B}_{2} \mathrm{C}$ marketing literature are identified. Furthermore, 16 characteristics distinguishing these different types of brand worlds in $\mathrm{B}_{2} \mathrm{C}$ were found. Due to its fragmented nature and the at times contradictory use of terms, these findings contribute to a better understanding of brand worlds as marketing instruments in consumer markets, and thus to theory building. Based on this synthesis, the characteristics of brand worlds are reflected on, regarding their possible transfer from the consumer marketing to the industrial marketing area. This chapter is the first academic paper to focus on brand worlds as a possible means of branding and experiential marketing in business markets. It serves as a first introduction to the topic for both marketing academics and practitioners and offers directions for further research.

\subsubsection{Chapter 3: Brand Worlds: Introducing Experiential Marketing to B2B Branding}

By being the first paper to investigate brand worlds in industrial marketing qualitatively, Chapter 3 contributes to a better theoretical understanding of this phenomenon. Answering a general call for further research on experiential marketing activities in business markets, it contributes to the literature on the branding instrument of brand worlds specifically. By investigating it from 
multiple perspectives, namely the operating companies', the business visitors', and the exhibition designers', it expands the literature from merely describing its existence in $\mathrm{B}_{2} \mathrm{~B}$ to a comprehensive and holistic understanding of its nature and components, as well as the why, what, and how of this phenomenon. This chapter thus contributes to the understanding of the industrial marketing equivalent of one of the most powerful branding instruments in consumer markets. It introduces $\mathrm{B}_{2} \mathrm{~B}$ brand worlds as a valuable alternative and addition to existing $\mathrm{B}_{2} \mathrm{~B}$ branding instruments for the operating company, but also as a valuable tool for the business visitor, based on the experience that is co-created there. Therefore, this study also contributes to the frameworks and tactics of brand building and brand management, as well as the customer experience in business markets.

\subsubsection{Chapter 4: Differences Between Brand Worlds in $B_{2} C$ and $B_{2} B$}

Chapter 4 shows that $\mathrm{B}_{2} \mathrm{~B}$ brand worlds share several similarities with their $\mathrm{B}_{2} \mathrm{C}$ counterparts, and that they are using the same principles of experiential marketing, live communication, and branding in order to fulfill their goals and convey their messages. Yet, based on the different priorities of operating companies regarding the goals, and the motivations and expectations of business visitors, also some major differences in brand worlds in $\mathrm{B}_{2} \mathrm{~B}$ compared to $\mathrm{B}_{2} \mathrm{C}$ emerge. The results highlight these differences, which have to be taken into account for the design, implementation, and operation of brand worlds in B2B marketing practice in order for them to be successful. Furthermore, the paper provides interesting areas for future research regarding the role of a $\mathrm{B}_{2} \mathrm{~B}$ brand world in the entire customer journey and the processes of relationship-building and interactions on business markets on the micro-level of individuals. If one of the actors involved possesses a brand world, they often provide the inspiring and stimulating physical environment for a first personal meeting and interaction, and thus the foundation for a future relationship between the operating company and other actors on business markets.

\subsubsection{Chapter 5: The Dynamic Nature of Brand Experience}

Chapter 5 contributes to the discussion on specific experience areas and the generalization from them to overarching principles of experiences by proposing a framework that argues and allows for the measurement of the overall brand experience across multiple touchpoints and multiple stages. This framework enables the measurement and evaluation of the influence of individual touchpoints on the overall brand experience, which is a valuable contribution for both marketing academia and practice.

\subsubsection{Chapter 6: Entering B2B Brands' Living Rooms: How Brand Worlds Can Help Build Brand Equity}

Chapter 6 contributes to the overall understanding of the B2B counterparts of brand worlds as one of the most powerful branding instruments in $\mathrm{B}_{2} \mathrm{C}$. By being, to the best of the author's knowledge, the first study to investigate their effectiveness regarding customer experience and branding outcomes, it 
also contributes to the understanding of industrial customer experiences and experiential marketing in business markets. Furthermore, it contributes to research on brand building tactics and brand management in business markets in general by investigating whether this instrument is actually effective. It also contributes to research on customer and brand experience in $\mathrm{B}_{2} \mathrm{C}$ as well as in $\mathrm{B}_{2} \mathrm{~B}$, by explicating the effect of an experience at an individual touchpoint on the overall brand experience and subsequent experience outcomes, as outlined in the framework developed in Chapter 5. Practically, this study shows that B2B brand worlds are indeed effective in increasing brand experience and brand equity levels, which is not only an important contribution to theory, but also a valuable finding for business marketers.

\subsubsection{Chapter 7: Synopsis}

Finally, Chapter 7 summarizes the findings of the previous chapters and links them back to the main research questions of this thesis. It therefore contributes to the overall understanding of whether and how $\mathrm{B}_{2} \mathrm{~B}$ brand worlds work in industrial marketing.

\subsection{GUIDE TO THE READER}

Simply doing research is not enough. Only by sharing this research with academics and practitioners alike through publishing, one can join the scientific debate, receive feedback, and contribute to the progression of science, as well as ultimately have an impact on practice. Therefore, the goal of this research project was not only to conduct research on brand worlds in industrial marketing, but to present this research on conferences and publish it in conference proceedings and academic journals.

As a result, the different steps undertaken to answer the main research questions of this thesis are presented in individual papers. These papers have been written as stand-alone, independent pieces of research, answering different subordinate research questions on the way to the final answers to our main research questions. As such, they were individually submitted to different academic conferences and journals, as soon as this individual step has been concluded. Together, these individual and independent papers now form the main body of this thesis as the separate Chapters $2-6$. This suits the needs of readers who are only interested in specific pieces of the overall work within this thesis. For readers who want to read through the entirety of this dissertation, a certain degree of repetition and overlap is unfortunately inevitable. This mostly concerns parts of the introduction, theoretical background, and methods sections.

Before you now begin to read the actual outcomes of this $\mathrm{PhD}$ research project, allow me one last remark. I would sincerely like to thank you for your interest in my work and for your time to read it, whether it is the entirety of this dissertation or parts of it. My objective with this research project was to contribute to science and practice. In fact, this project evolved out of a very practical question that posed itself in my former job in marketing and sales practice. The question was whether a flagship store, brand museum, or a different type of brand world would make sense and could also be a useful 
instrument for a company in industrial marketing to provide its (potential) customers or other stakeholders with unique and extraordinary experiences and, as a result of doing so, strengthen their bond to the brand, i.e. whether a brand world would also work in industrial marketing. As it turned out, science did not have an answer to this question. By providing this answer within this thesis, I hope that I have achieved my objective of furthering scientific knowledge on the marketing of industrial goods and services, and also the objective of having an impact on industrial marketing practice. I have enjoyed the process of conducting this research and also writing it up very much, and have gained a lot of new knowledge during the course of this process. I therefore hope that by reading this work you will also gain new knowledge that helps you with your own research or work in industrial marketing or other areas, and that you enjoy reading this thesis at least as much as I did writing it! 
As a first step towards investigating experiential marketing and brand worlds in business markets, a thorough understanding is needed of what these instruments are, what characterizes them, and whether these characteristics could be transferred to the industrial marketing area. This chapter serves as this first step. Due to a lack of research on brand worlds in industrial markets, a systematic literature review on brand worlds in consumer markets is conducted, and the findings are mirrored to the $\mathrm{B}_{2} \mathrm{~B}$ realm.

\section{PUBLICATION HISTORY:}

Previous versions of this chapter, written together with Prof. Dr. Marc Kuhn and Prof. Dr. Jörg Henseler, were submitted to and presented at the Academy of Marketing Science (AMS) World Marketing Congress (WMC) 2016 and the 32nd annual conference of the Industrial Marketing and Purchasing Group (IMP), 2016. Furthermore, a previous version of this chapter was submitted to the special issue on "The Role of Emotions in B2B Marketing" of the Journal of Business \& Industrial Marketing.

\section{REFERENCES TO PREVIOUS PUBLICATIONS:}

Österle, B., \& Kuhn, M. M. (2017). Disneyland in B2B? Toward Physical Brand Worlds in Industrial Marketing. In M. Stieler (Ed.): Developments in Marketing Science, Creating Marketing Magic and Innovative Future Marketing Trends: Proceedings of the 2016 Academy of Marketing Science (AMS) Annual Conference (pp. 729-742). Cham, s.l.: Springer International Publishing.

Österle, B., Kuhn, M. M., \& Henseler, J. (2016). An Inquiry into Brand Worlds in Industrial Marketing. In IMP Group (Ed.), 32nd Annual IMP Conference.

\section{KEYWORDS:}

Brand Worlds, brands, branding, B2B-branding, experiential marketing, industrial marketing, business marketing 
2. AN INQUIRY INTO EXPERIENTIAL MARKETING AND

BRAND WORLDS IN INDUSTRIAL MARKETING

ABSTRACT

The purpose of this paper is to introduce the concept of experiential marketing in 'brand worlds' to the $\mathrm{B}_{2} \mathrm{~B}$ branding area. It analyzes and provides a synthesis of the extant literature on $\mathrm{B}_{2} \mathrm{C}$ brand worlds regarding the different types, their goals and special characteristics. Using existing B2B brand worlds as examples, it mirrors the findings on brand worlds as an instrument of experiential marketing and branding from $\mathrm{B}_{2} \mathrm{C}$ to the $\mathrm{B}_{2} \mathrm{~B}$ realm. Due to a lack of literature, this serves as a first step to further research on this instrument of experiential marketing in $\mathrm{B} 2 \mathrm{~B}$. A systematic literature review and the inductive category formation technique of qualitative content analysis are used to analyze the existing literature on brand worlds in consumer marketing. Despite the proposal that the goal of experiential marketing activities in $\mathrm{B}_{2} \mathrm{~B}$ should be an instrumental experience, rather than an autotelic one as in $\mathrm{B}_{2} \mathrm{C}$, this paper identifies a substantial overlap regarding the characteristics of $\mathrm{B}_{2} \mathrm{C}$ and $\mathrm{B}_{2} \mathrm{~B}$ brand worlds. The major contribution of this paper is twofold. First, it provides a so far non-existent synthesis of the literature on brand worlds in consumer marketing. Second, on this basis, this work is the first piece of literature covering brand worlds as a means of branding and experiential marketing in business markets. It answers a call for more research on experiential marketing instruments in $\mathrm{B}_{2} \mathrm{~B}$, offers directions for future research on brand worlds in industrial marketing, and provides both academics and practitioners with a first introduction to the topic.

\subsection{INTRODUCTION}

Business-to-Business branding research has undergone a development from relative unimportance towards an exclusive field of study. Nowadays, branding is described as being just as relevant in $\mathrm{B}_{2} \mathrm{~B}$ as in $\mathrm{B}_{2} \mathrm{C}$ (Kotler \& Pfoertsch, 2006). In the course of this evolution, $B_{2} B$ branding has adopted many insights and underlying concepts from the more mature consumer branding literature (Seyedghorban et al., 2016).

Interestingly though, a powerful technique of branding in $\mathrm{B}_{2} \mathrm{C}$, which leads to increased interactions and emotional connections between consumers and brands (Schmitt, 1999a), has received almost no academic attention in the B2B area: experiential marketing. This marketing management area is based on the thinking that the understanding and especially the provision of appealing experiences for customers is crucial for positioning and differentiating brands, products, and other offerings in the competitive environment of today's markets (Zarantonello \& Schmitt, 2013). Except for a few references, where for example emotionally charged rather than feature-and-benefit laden advertising (Schmitt, 1999b), or the spectacularization of business products and services (Pine \& Gilmore, 1999) are suggested, only one study takes an experiential approach to business marketing activities. Based on an ethnographic study conducted at ten international trade shows in the textile industry, Rinallo et al. (2010) find that business marketing practitioners have adopted experiential marketing 
techniques in the trade show environment already for decades, simply without applying the experiential marketing label to it. Thus, they call for further investigations of industrial buyer experiences and experiential marketing for business markets, with the focus on other promotional instruments (Rinallo et al., 2010).

In this paper, we argue that next to trade shows, business marketing practitioners also use the concept of experiential marketing in 'brand worlds', an umbrella term for permanent, physical locations dedicated to promote a brand, its products, or offerings. In $\mathrm{B}_{2} \mathrm{C}$, the primary use of brand worlds is to evoke positive brand experiences in the visitors, and the term encompasses for example brandscapes, brand lands, brand museums, and flagship stores. Unfortunately, the amount of research on $\mathrm{B}_{2} \mathrm{C}$ brand worlds is limited, and the definitions and the use of terms are often contradictory. The literature is characterized by a lack of empirical synthesis on the different types of brand worlds and their characteristics (Doyle, Moore, Doherty, \& Hamilton, 2008; Kirchgeorg, Springer, \& Ermer, 2012; Manlow \& Nobbs, 2013).

Brand worlds in the $\mathrm{B} 2 \mathrm{~B}$ context have so far received no academic attention at all, although practical examples can be found at various companies and industries, such as Caterpillar with their Caterpillar Visitor Center, General Electric with various Customer Experience Centers, Mack Trucks with their Customer Center, or Austrian steel manufacturer Voestalpine with their Stahlwelt.

Against this background, the goal and main contribution of this article is to introduce the powerful and so far disregarded concept of experiential marketing to the $\mathrm{B}_{2} \mathrm{~B}$ branding area, based on the example of brand worlds. To provide a sound theoretical foundation, the literature on experiential marketing and brand worlds in $\mathrm{B}_{2} \mathrm{C}$ serves as the starting point for this introduction.

Due to the lack of synthesis in the $\mathrm{B}_{2} \mathrm{C}$ brand world literature, this paper first aims at analyzing which different types of brand worlds are described in the $\mathrm{B}_{2} \mathrm{C}$ literature, and what their goals and special characteristics are, respectively. Subsequently, it investigates whether these goals and special characteristics of $\mathrm{B}_{2} \mathrm{C}$ brand worlds as experiential marketing instruments can be transferred to $\mathrm{B}_{2} \mathrm{~B}$ brand worlds. This transfer is based on information on $\mathrm{B}_{2} \mathrm{~B}$ brand world examples in practice. The remainder of this paper is structured as follows: First, it provides a background on the development of the concept of experience, consumption experiences, experiential marketing, and brand worlds in $\mathrm{B}_{2} \mathrm{C}$. It then describes the use of a systematic literature review to identify the existing and relevant literature on brand worlds in consumer marketing. Because of the lack of synthesis in the $\mathrm{B}_{2} \mathrm{C}$ brand world literature, it subsequently outlines the step of qualitative content analysis to identify different types, characteristics, and functions of $\mathrm{B}_{2} \mathrm{C}$ brand worlds on the basis of this literature. It identifies seven main types of brand worlds in $\mathrm{B}_{2} \mathrm{C}$, and four categories comprising 16 characteristic features on whose attribute levels the types of brand worlds can differentiate from each other. These findings on the special characteristics of the different types of $\mathrm{B}_{2} \mathrm{C}$ brand worlds as instruments of experiential marketing and branding are then transferred from consumer to industrial marketing, based on the inherent characteristics of industrial marketing and practical examples of brand worlds in $\mathrm{B}_{2} \mathrm{~B}$. The final section draws conclusions, acknowledges the study's limitations, and defines areas of future research on the topic of brand worlds in industrial marketing. 


\subsection{EXPERIENTIAL MARKETING, BRAND EXPERIENCE AND BRAND WORLDS IN B2C}

\subsubsection{The concept of experience}

The concept of experience is a very multifaceted one. Two major categories under which the various definitions fall have been identified (Schmitt \& Zarantonello, 2013): the first category of definitions uses the term experience to refer to "ongoing perceptions, feeling, and direct observations". As an example, Webster's Third New International Dictionary can be used, where experience is defined as "'direct observation of or participation in events: an encountering, undergoing, or living through things in general as they take place in the course of time'" is mentioned. The second category of definitions, refers to knowledge and accumulated experiences over time. Again Webster's Third New International Dictionary is used as an example, where experience is also described as "'knowledge, skill, or practice derived from direct observation of or participation in events: practical wisdom resulting from what one has encountered, undergone, or lived'". Depending on the field of science, experience can be seen as either objective (e.g. in the philosophy of science) or subjective (e.g. in psychology), as an individual (e.g. American psychologists) or social process (e.g. European psychologists), and as a group-based concept (anthropology and ethnology), which is why it must be put in cultural context (Schmitt \& Zarantonello, 2013).

\subsubsection{The experiential view in marketing}

All these different perspectives have influenced how marketers understand the concept of experience. Therefore, different streams of research have evolved, such as the very broad and general stream of research on consumer or customer experience, more specific research focusing on the interaction between the customer and the product (product experience), the interaction between the customer and the company when a service is provided (service experience), offline and online experiences and the again broader concept of consumption experience (Schmitt \& Zarantonello, 2013).

The introduction of consumption experience by M. B. Holbrook and Hirschman (1982) has started the academic discussion about experience in general. Since then, consumption is not just described as a logical process to solve a problem which results in a purchase anymore. Instead, consumption involves "a steady flow of fantasies, feelings, and fun encompassed by what we call the 'experiential view"' (M. B. Holbrook \& Hirschman, 1982, p. 132). This development of the experiential view subsequently led to the concept of experience economy, where, as goods and services become increasingly commoditized, customer experiences that companies create matter most (Pine \& Gilmore, 1998). In this commoditized world, customers take product quality, functions and benefits, and a positive brand image for granted - what they long for are "products, communications, and marketing campaigns that dazzle their senses, touch their hearts, and stimulate their minds. They want products, communications and marketing campaigns to deliver an experience. The degree to which a company is able to deliver and provide a desirable customer experience (...) will largely determine its success in the global marketplace of the new millen- 
nium" (Schmitt, 1999b, p. 57). Taking this one step further is the concept of the experience society (Schulze, 2005), in which people define their lives by the sum of their own experiences (van Boven \& Gilovich, 2003). Yet, since experiences are subjectively felt emotions, they cannot be 'made' or 'guaranteed' by the 'provider', e.g. the company offering experiential products or services. Instead, inducing a positive inner feeling, turning the experiential offer into an actually perceived experience, depends on the processing and the reception of each individual customer (Kilian, 2009). This means that for experience providers it is crucial to create an adequate and fitting environment which contributes to the evoking of a desirable customer experience (Schmitt, 1999a).

\subsubsection{Brand experience in $\mathrm{B}_{2} \mathrm{C}$}

Based on the aforementioned works and as another stream of research, more recently the broad concept of brand experience has emerged, partly as a result of the focus on branding and brand management in marketing since the $1990 \mathrm{~s}$ It has been defined as "subjective, internal consumer responses (sensations, feelings, and cognition) and behavioral responses evoked by brand-related stimuli that are part of a brand's design and identity, packaging, communications and environments" (Brakus, Schmitt, \& Zarantonello, 2009, p. 53). The marketing of such experiences in relation to a brand becomes increasingly important for companies in order to create brand equity (Schmitt, 1999b; Zarantonello \& Schmitt, 2013).

\subsubsection{Brand worlds in $\mathrm{B}_{2} \mathrm{C}$}

Given this background of experiential marketing and brand experience in consumer markets, the emergence and success of places and locations which provide unique experiences based on brands is no surprise. Such efforts of 'brandscaping' follow the conviction that "the glamour and power of the brand are the key weapons in the battle for target groups and customers. By staging the brand experience in flagship stores, shop designs or entire theme parks, companies communicate the image of the brand and imprint a characteristic atmosphere on the consumer consciousness" (Riewoldt, 2002, p. 8). Since these locations are so powerful in delivering these branded experiences, they are also called "apex of branding" (Dolbec \& Chebat, 2013, p. 460).

Unfortunately the term brandscape is used ambiguously: as the physical outcome of turning a brand into a location, for an imaginary market landscape linking brands to each other, or the overall experiential reach and engagement of a brand (Sherry, 1998; D. M. Wood \& Ball, 2013). Therefore, we define a 'brand world' as the result of brandscaping, in terms of the physical outcome of turning a brand into a physical space. In this paper, it is thus understood as an umbrella term for permanent, physical locations whose primary use is to promote a brand and evoke brand experiences in the visitors. They encompass for example brand lands, brand museums, brand stores, flagship stores, etc., and are a means to provide customers with a unique brand experience. These locations give the operating companies the opportunity to stage themselves and their products in an environment that they can largely control by themselves, which contributes to this desired outcome of a positive brand experience 
for the customer (Kozinets et al., 2002). A visit to a brand world makes the brand visible, actually tangible, and therefore creates a strong, real, memorable customer experience and relationship between the brand and the customer (Webb, 2012). Such live experiences of actually visiting the brand become part of one's own life and have a higher recollective value than simple advertising or conventional PR (Mikunda, 2004).

Indeed, such brand worlds are not a new phenomenon. Already in 1906, the Hershey's chocolate company established Hershey Park. Initially designed as a picnic and leisure park for employees, it soon developed into an amusement and entertainment theme park based on the Hershey brand and was made accessible to the public. Walt Disney was also a pioneer in brandscaping. He recognized that "entertainment spaces such as amusement parks could be used not only to sell popcorn and candy floss, but toys, collectibles, and motion pictures, as well as - and, we would argue, most importantly - a corporate brand image" (Kozinets et al., 2002, p. 18). The experiences created for visitors at, for example, Disney World, undoubtedly contribute to the image of the operating Walt Disney Company that we have today. Until today, many $\mathrm{B}_{2} \mathrm{C}$ companies like Apple with their flagship stores, Nike with the Nike Town stores and Coca-Cola with their World of Coca-Cola use brandscaping and its manifestations, brand worlds, as an important tool of experiential marketing, live communication, event marketing, brand management, and brand communication. This emergence of brand worlds in consumer marketing has received academic attention from various sectors. Yet, the amount of research is limited, and the definitions and use of terms are often contradictory. There is no empirical synthesis on these ideas and on types or categories of different brand worlds so far (Doyle et al., 2008; Kirchgeorg et al., 2012; Manlow \& Nobbs, 2013)

\subsection{EXPERIENTIAL MARKETING, BRANDING AND BRAND WORLDS IN B2B}

\subsubsection{Experiential marketing in $B 2 B$}

So far, experiential marketing in $\mathrm{B}_{2} \mathrm{~B}$, compared to its counterpart in $\mathrm{B}_{2} \mathrm{C}$, has received almost no academic attention, with only very few exemptions. It is mainly focused on trade shows as an important means of $\mathrm{B}_{2} \mathrm{~B}$ communication (Kirchgeorg, Springer, \& Kästner, 2010; Rinallo et al., 2010). This lack of research is explained with the focus on emotions, feelings and hedonic dimensions as central determinants of consumption behavior in experiential marketing (Addis \& Holbrook, 2001), whereas the industrial buying behavior is described to be more rational and professional (Rinallo et al., 2010). Interestingly though, marketers in a $\mathrm{B}_{2} \mathrm{~B}$ environment have created promotional experiences and used experiential marketing techniques in the context of trade shows for decades already, simply without applying the experiential marketing label to it (Rinallo et al., 2010). However, researchers call for a fundamental distinction between experiences in $\mathrm{B}_{2} \mathrm{C}$ and $\mathrm{B}_{2} \mathrm{~B}$. They propose that in contrast to $\mathrm{B}_{2} \mathrm{C}$ experiences, $\mathrm{B} 2 \mathrm{~B}$ experiences are not autotelic, meaning they end in themselves. Instead they are instrumental, which means they serve some higher goal or are a means to a further end, no matter how fun, spectacular or entertaining they might be (Rinallo et al., 2010). For example, B2B trade show visitors value experiences which result in learning or new knowledge, or give the 
opportunity to socialize and relate to exhibitors and other visitors, in order to gather information which is useful for their own cause (Rinallo et al., 2010). Due to this distinction, some experiential marketing tactics that are based on autotelic activities and involve fantasies, feelings, and fun, and which work well in consumer markets, may prove to be ineffective or even counter-productive in industrial environments (Rinallo et al., 2010). This is why academics call for further investigations on experiences and experiential marketing for business markets, with the focus on other promotional instruments and experiential marketing activities (Rinallo et al., 2010).

\subsubsection{Branding in $B_{2} B$}

Similar to experiential marketing, for a substantial period of time also branding was not even meant to be relevant in $\mathrm{B}_{2} \mathrm{~B}$, and brands were seen purely as a consumer marketing phenomenon (Kotler \& Pfoertsch, 2006). Yet today, the development in academic research (Seyedghorban et al., 2016) and the fact that some of the most valuable brands nowadays are industrial brands (Interbrand, 2018) support the statement that "branding is just as relevant in $\mathrm{B}_{2} \mathrm{~B}$ as it is in $\mathrm{B}_{2} \mathrm{C}^{\prime \prime}$ (Kotler \& Pfoertsch, 2006, p. 12). The purpose of industrial brands is described as exactly the same as for consumer brands (e.g. Kotler \& Pfoertsch, 2007; Wise \& Zednickova, 2009). The brand value in industrial marketing also comprises not only functional components such as quality, technology, and reliability, but emotional components such as risk reduction, reassurance, trust, and credibility (Leek \& Christodoulides, 2012). These emotions play an important role in the relationship between salesperson and customers (Bagozzi, 2006). But branding is also relevant in the relationship with sales channel partners (Anisimova \& Mavondo, 2014), and brands in total can play an important role in the decision making process in $\mathrm{B} 2 \mathrm{~B}$ both for product- and service oriented businesses (Gomes et al., 2016; Walley et al., 2007).

And also in industrial marketing the concept of a brand is a holistic one, as it is in consumer markets. This means that all elements of the marketing communication mix, all customer touchpoints contribute to brand equity in several ways: They create awareness of the brand, link desired associations to the brand image, evoke emotions or judgments, influence the brands reputation, and facilitate a stronger customer-brand relationship (Kotler \& Pfoertsch, 2006; G. Wang, Wang, Long, Hou, \& Ching, 2015; Xie \& Haugland, 2016). Like in $\mathrm{B}_{2} \mathrm{C}$, the experiences that $\mathrm{B}_{2} \mathrm{~B}$ customers have with a brand have a direct effect on $\mathrm{B}_{2} \mathrm{~B}$ brand equity dimensions, such as brand awareness, brand associations, perceived quality and brand loyalty (Biedenbach \& Marell, 2010), or building blocks such as the salience of the manufacturer's brand, its performance, reputation, judgment, sales force relationships and partnership solutions (Kuhn, Alpert, \& Pope, 2008). Therefore it seems only reasonable that also B2B companies make use of brand worlds as one of the most powerful tools in branding to create unique experiences for their visitors.

\subsubsection{Brand worlds in $\mathrm{B}_{2} \mathrm{~B}$}

Brand worlds have been mentioned as a possibility for $\mathrm{B} 2 \mathrm{~B}$ companies to create unique customer experiences (Gilmore \& Pine, 2002), and industrial brands 
have also already invested in brand worlds and the unique experiences and emotions they provide for visitors. Yet, B2B brand worlds have not been subject to academic research so far. Brand worlds in industrial marketing differ from their counterparts in $\mathrm{B}_{2} \mathrm{C}$ first and foremost in the fact, that the target group for the products of the operating company are not consumers, but industrial buyers. In the course of this study, and as a preparation for further inquiries, we conducted extensive online research, checked press releases, connected with business and academic network contacts, and attended practitioner conferences focusing on experiential marketing and brand worlds, to discover information about cases of brand worlds in industrial marketing practice. These efforts led us to the finding that such information is scarce and also difficult to obtain, because in contrast to their $\mathrm{B}_{2} \mathrm{C}$ counterparts, not a lot of $\mathrm{B}_{2} \mathrm{~B}$ companies actively and prominently advertise these locations. Therefore, often only industry experts are familiar with them. But despite that, examples for such brand worlds of companies in industrial marketing can in fact be found all over the world. To just name a few: In the US, there are the Mack Trucks Customer Center, the Caterpillar Visitors Center, the Customer Experience Centers of General Electric and Honeywell Process Solutions, and the Automation and Power Center of ABB. In Europe, there are for example the Innovation Center of logistics provider DHL, the Stahlwelt of Austrian steel producer Voestalpine, or the Brand Stores and Flagship Stores of power tool manufacturer Hilti. In Asia, the Mitsubishi Minatomirai Industrial Museum can be found.

Some of these industrial brand worlds are accessible to the public and even charge entrance fees, others are only accessible to customers or other stakeholders upon invitation. This simple example already shows the wide spread of types and goals of these industrial brand worlds, and a differentiation to $\mathrm{B}_{2} \mathrm{C}$ brand worlds, which in general are all accessible to the public.

Given this background on experiential marketing, branding and brand worlds in $\mathrm{B}_{2} \mathrm{C}$ and $\mathrm{B}_{2} \mathrm{~B}$, it seems especially interesting whether the finding in the trade show environment, that $\mathrm{B}_{2} \mathrm{~B}$ experiences are mostly instrumental instead of autotelic as in $\mathrm{B}_{2} \mathrm{C}$, has an influence on the goals and characteristics of $\mathrm{B}_{2} \mathrm{~B}$ brand worlds compared to their $\mathrm{B}_{2} \mathrm{C}$ counterparts.

Therefore, in this paper we want to provide a synthesis on the literature of brand worlds in $\mathrm{B}_{2} \mathrm{C}$, to identify main types of brand worlds according to this literature and to identify the main characteristics that differentiate them from each other. Because of the complete lack of literature on these experiential locations in business markets, we then transfer our findings on these instruments of branding and experiential marketing to the $\mathrm{B}_{2} \mathrm{~B}$ environment, based on a critical reflection with practical examples of brand worlds in $\mathrm{B}_{2} \mathrm{~B}$.

\subsection{METHODOLOGY}

To identify the relevant academic and scholarly articles related to brand worlds in consumer marketing, we followed the guidelines for systematic literature reviews that Tranfield, Denyer, and Smart (2003) propose, which have been applied in an industrial marketing context before (e.g. Hüttinger, Schiele, \& Veldman, 2012). We searched for peer-reviewed journal articles in English using a total of 27 keywords in the Scopus database. We required that the articles contain at least one of these terms in the title, the abstract or the keywords. The final search resulted in 79 journal articles. Including related papers in 
the references, the sample consisted of 17 relevant articles from 11 journals. This result is consistent with the aforementioned findings in literature, namely that the phenomenon of brand worlds has only received limited academic consideration in terms of journal publications. We then also added monographs, dissertations, or contributions in anthologies that were cited in these journal publications (Tranfield et al., 2003), and searched local university libraries and Google Scholar using the same terms for further contributions in English or German, in order to get a more comprehensive overview of the topic. This yielded another 21 relevant contributions, 16 of them in German. The total of 38 contributions related to the topic of brand worlds in consumer marketing form the foundation of our analysis.

The inductive category formation of Qualitative Content Analysis was then used to arrive directly at summarizing categories coming from the material itself and not from theoretical considerations (Mayring, 2014). The a priori definitions of what the relevant parts of the material are, as well the level of abstraction, are crucial to the analysis and are derived from the research questions (Mayring, 2014). As we wanted to derive a comprehensive classification of brand worlds and their distinctive features, we wanted all possible types and characteristics to be included. We therefore defined the relevant parts of the material as any text passage containing a denomination, description, or definition of any type of physical, permanent brand representation, and as any text passage containing characteristics, specific or distinctive features of any type of physical, permanent brand representation. As the level of abstraction, we chose specific denominations of single types of brand worlds, as well as characteristics of any of these types. We then followed the procedure for inductive category formation as described in the literature, coded the text and developed main categories from our category system as the result of the analysis (Mayring, 2014). By following these established processes and describing our approach, we make our qualitative research as transparent as possible. All the sources included in our analysis are depicted in the Appendix in Table A.1, including the characteristics that were discussed within these sources. The full results are described in the next section.

\subsection{ANALYSIS OF LITERATURE ON BRAND WORLDS IN CONSUMER MAR- KETING}

Mikunda (2004) was the first to use the term 'brand world' to describe permanent exhibitions arranged at corporate locations (Mikunda, 2004). Yet with his description he outlines what we understand as 'brand lands'. In this current paper, 'brand world' is used as an umbrella term for all permanent, physical locations that promote a brand. They are not limited to corporate locations and also comprise venues that are not only exhibitions, but also places of transaction, like brand stores and flagship stores. Unfortunately, there are several definitions and typologies of the various forms of brand worlds in consumer marketing in the examined literature, and there is no consensus on the use of names and definitions for these various types (Kent \& Brown, 2012; Manlow \& Nobbs, 2013).

Following up on one of our research aims, to provide a synthesis of the $\mathrm{B}_{2} \mathrm{C}$ literature on brand worlds, we merge these different typologies under seven main categories and one additional category that comprises numerous 
venues and sub-types which have only been mentioned in single contributions. They are presented in Table 2.1. Furthermore, we identify 16 characteristics distinguishing the main types from each other. Table A.1 in the Appendix gives an overview of the characteristics discussed within each of our sources. An additional summary of the characteristics can be seen in Table 2.2. They are organized into four main categories: goal-related characteristics, content-related characteristics, characteristics describing the physical appearance of the brand world, and characteristics related to its customers. An underlying goal for all of the various types of brand worlds is the provision of unique, memorable experiences to the visitors; in some types, the experience even is the product on sale (Sherry et al., 2001). Similarly, the employees are a fundamental factor for all types of brand worlds in $\mathrm{B}_{2} \mathrm{C}$, since they act as ambassadors for the brand, and, due to their direct interaction with the visitors, they largely contribute to the shaping of the experience (Hollenbeck et al., 2008; Penaloza, 1998). These types and characteristics are the findings of our qualitative content analysis of the relevant literature that covers the topic of brand worlds in consumer marketing. With regard to our third research question and owing to the lack of existing research in that specific field, we now transfer these findings to industrial marketing. To do this, we use information about the aforementioned practical examples and reflect on our findings on brand worlds in consumer marketing.

\subsection{BRAND WORLDS IN INDUSTRIAL MARKETING}

Following our third research aim, whether the aforementioned goals and special characteristics of $\mathrm{B}_{2} \mathrm{C}$ brand worlds as instruments of experiential marketing can be transferred to their $\mathrm{B} 2 \mathrm{~B}$ counterparts, we first shed light on the practice of transferring knowledge from $\mathrm{B}_{2} \mathrm{C}$ to $\mathrm{B}_{2} \mathrm{~B}$.

The transfer and adaption of underlying knowledge and structures from $\mathrm{B}_{2} \mathrm{C}$ to $\mathrm{B}_{2} \mathrm{~B}$ branding is current practice in $\mathrm{B}_{2} \mathrm{~B}$ branding research. These structures may also work in both consumer and industrial marketing, but researchers are simultaneously calling for the consideration of the specific factors inherent to industrial marketing when doing so (Seyedghorban et al., 2016). Additionally, researchers are also trying to renew the debate around the differences between $\mathrm{B}_{2} \mathrm{C}$ and B2B (Cova \& Salle, 2007; Wind, 2006). Cova and Salle's (2007) argument is based on the approach of the Industrial Marketing and Purchasing Group (IMP) to industrial markets and the development of consumer culture theory in consumer marketing. They state that the "significant differences between $\mathrm{B}_{2} \mathrm{~B}$ and $\mathrm{B}_{2} \mathrm{C}$ can be rendered almost null and void," and therefore "we should no longer be frightened of cross-fertilization between $\mathrm{B}_{2} \mathrm{~B}$ and $\mathrm{B}_{2} \mathrm{C}$ marketing" (Cova \& Salle, 2007, p. 9).

Nevertheless, we keep in mind $\mathrm{B}_{2} \mathrm{~B}$ marketing specifics as described in standard B2B textbooks (e.g. R. Grewal \& Lilien, 2012), and also the different, instrumental notion of experiences in $\mathrm{B}_{2} \mathrm{~B}$ (Rinallo et al., 2010) when we transfer the distinguishing features of brand worlds derived from consumer marketing literature to industrial marketing. Also, the functions of brands in $\mathrm{B}_{2} \mathrm{~B}$ differ in their importance from the $\mathrm{B} 2 \mathrm{C}$ sector, the most important being risk reduction, followed by the reduction of information search cost. Image benefits play a minor role, which means that there is a directly inverse ranking of brand 
Table 2.1: Overview of main types of brand worlds described in consumer marketing literature $(n=38)$

\begin{tabular}{|c|c|c|}
\hline MAIN CATEGORY & $\begin{array}{l}\text { QUANTITY } \\
\text { OF SOURCES }\end{array}$ & TEXT EXAMPLE \\
\hline Factory Tours & 6 & $\begin{array}{l}\text { "The increasingly evident appeal of factory tour-type op- } \\
\text { erations will likely come into play in the future, as the } \\
\text { success of the Crayola Factory, Hershey's Chocolate World, } \\
\text { and Kellogg's Cereal City U.S.A. is duplicated." (Kozinets } \\
\text { et al., 2002, p. 25) }\end{array}$ \\
\hline Visitor Centers & 8 & $\begin{array}{l}\text { Attractions of this kind, where a factory tour is com- } \\
\text { bined with extensive gastronomic and entertainment offers. } \\
\text { (Roost 2008, 48, Author's translation) }\end{array}$ \\
\hline Brand Museums & 10 & $\begin{array}{l}\text { "Three key features distinguish brand museums from } \\
\text { other themed retail environments: (a) historical linkages; } \\
\text { (b) museumlike qualities (e.g., galleries, exhibits, paid ad- } \\
\text { mission); and (c) an education-based mission." (Hollen- } \\
\text { beck, Peters, \& Zinkhan, 2008, p. 336) }\end{array}$ \\
\hline Showrooms & 8 & $\begin{array}{l}\text { "Showrooms are the representatives of brands that stage } \\
\text { the products and company philosophies throughout the } \\
\text { world" (Messedat, 2007, p. 6) }\end{array}$ \\
\hline Flagship Stores & 18 & $\begin{array}{l}\text { "Flagship brand stores can be distinguished by three char- } \\
\text { acteristics. First, they carry a single (usually established) } \\
\text { brand of product. Second, that brand's manufacturer owns } \\
\text { them. Finally, they are operated-at least in part-with } \\
\text { the intention of building or reinforcing the image of the } \\
\text { brand rather than operating to sell product at a profit." } \\
\text { (Kozinets et al., 2002, p. 17) }\end{array}$ \\
\hline Brand Stores & 9 & $\begin{array}{l}\text { "A flagship is a store '1) carrying a single brand of product, } \\
\text { 2) owned by that brand's manufacturer, and 3) operated - at } \\
\text { least in part - with the intention of reinforcing the brand rather } \\
\text { than selling a product at a profit' (Kozinets et al. 2002, p. } \\
\text { 17, emphasis added). Only the first two characteristics of } \\
\text { flagships apply to brand stores." (Dolbec \& Chebat, 2013, } \\
\text { pp. 460-461) }\end{array}$ \\
\hline Brand Lands & 18 & $\begin{array}{l}\text { "Within the concept of event-marketing, brand lands are } \\
\text { immobile corporate theme parks that provide an inter- } \\
\text { active mixture of entertainment and information around } \\
\text { brand themes to consumers." (Wohlfeil \& Whelan, 2005, p. } \\
\text { 199) }\end{array}$ \\
\hline Other types & 10 & $\begin{array}{l}\text { "Brandscapes"(Sherry, 1998, p. 112); "themed flagship } \\
\text { brand stores" (Kozinets et al., 2002, p. 18); "retail spec- } \\
\text { tacles" (Hollenbeck, Peters, \& Zinkhan, 2008, p. 334); "con- } \\
\text { sumption spectacle" (Penaloza, 1998, p. 339); etc. }\end{array}$ \\
\hline
\end{tabular}


Table 2.2: Differentiating characteristics of brand worlds described in consumer marketing $(n=38)$

\begin{tabular}{llll}
\hline & & QTY. OF & \\
MAIN CATE- & SUB- & SOURCES & TEXT EXAMPLE \\
GORY & CATEGORY & & \\
\hline
\end{tabular}

Goal related Image

Retail

Content re- Hands-on

lated

Education /

Information

Entertainment

Product

range

Time per-

spective

Additional

Services

Physical Size

characteris-

tics
34 "The flagship was also seen as a branding tool to build and showcase the brand's identity and to position it in the market." (Manlow \& Nobbs, 2013, pp. 59-6o)

28 "Retail orientation reflects the extent to which the flagship brand store environment encourages and emphasizes making the short-term sale (as in traditional retail stores) over longer-term brand building (as in current manifestations such as Nike Town or the Coca Cola Museum)." (Kozinets et al. 2002, p. 24)

21 "These are all so called hands-on, interactive installations beamed immediately from the world of science museums to the world of brand lands." (Mikunda, 2004, pp. 37-38)

24 "One key feature of brand museums is the resemblance to traditional museums, but, in the former, the brand is positioned within historical and educational contexts." (Hollenbeck et al., 2008, p. 334)

24 "Entertainment consultant Wolf (1999) asserts that, as entertainment has seeped into every aspect of the economy, shopping has become blended into entertainment, becoming what he terms 'shoppertainment'." (Kozinets et al., 2002, p. 17)

20 " $(. .$.$) and the majority of the respondents stated$ that a defining feature of a flagship is that it has the widest and most indepth product range out of all the stores in the company, (...)" (Nobbs et al., 2012, p. 930)

15 "Brand museums are slightly different from themed flagship brand stores explored in prior studies (e.g., ESPN Zone) in that they frame their advertising-driven contents as cultural artifacts with historical linkages that connect consumers to both local and international history." (Hollenbeck et al., 2008, p. 336)

18 "In terms of added value services these were not visually advertised inside the flagship store and were therefore not apparent during the observation. However two thirds of interview respondents mentioned this as being a differential aspect of the form of their flagship store, supporting Verdict (2007)." (Nobbs et al., 2012, p. 930)

19 "By way of delineating the physical differences that characterise flagship stores, the findings have identified that these stores are significantly larger in scale than any other format operated by the retailers - either domestically or internationally. Typically, flagships are between five to eight times larger than the typical retail (...)" (Moore et al., 2010, p. 148)

Location

26 "Flagship projects are distinguished by their location and differentiation." (Kent \& Brown, 2012, p. 2)

Architecture / Design
23 "The store is usually furbished to a higher standard than the others and may have its own unique identity in the chain." (Webb, 2012, pp. 20-21) 
Table 2.2: Differentiating characteristics of brand worlds described in consumer marketing $(\mathrm{n}=38)$ ctd.

\begin{tabular}{|c|c|c|c|}
\hline $\begin{array}{l}\text { MAIN CATE- } \\
\text { GORY }\end{array}$ & $\begin{array}{l}\text { SUB- } \\
\text { CATEGORY }\end{array}$ & $\begin{array}{l}\text { QTY. OF } \\
\text { SOURCES }\end{array}$ & TEXT EXAMPLE \\
\hline \multirow{5}{*}{$\begin{array}{l}\text { Customer re- } \\
\text { lated }\end{array}$} & Multisensuality & 11 & $\begin{array}{l}\text { "In other words, shoppers develop a special emo- } \\
\text { tional, sensorial, and cognitive attachment to flag- } \\
\text { ships due to their extraordinary sensorial features } \\
\text { (Kaltcheva, Patino, and Chebat 2010). Such a bond } \\
\text { is less likely in the case of less spectacular brand } \\
\text { stores." (Dolbec \& Chebat, 2013, p. 464) }\end{array}$ \\
\hline & Investment & 19 & $\begin{array}{l}\text { "For more major pursuits, comparable to ESPN } \\
\text { Zone and the World of Coca Cola, an impor- } \\
\text { tant condition for success is considerable finan- } \\
\text { cial backing (...). The development of a suc- } \\
\text { cessful large-scale themed flagship brand store } \\
\text { will require millions of dollars in development } \\
\text { money and millions more to architecturally exe- } \\
\text { cute." (Kozinets et al., 2002, p. 28) }\end{array}$ \\
\hline & Target group & 20 & $\begin{array}{l}\text { "Flagship projects (...) have a marketing commu- } \\
\text { nication role to consumers, employees and a wider } \\
\text { community of stakeholders." (Kent \& Brown, 2012, } \\
\text { p. 2) }\end{array}$ \\
\hline & $\begin{array}{l}\text { Stage in } \\
\text { customer } \\
\text { relationship }\end{array}$ & 6 & $\begin{array}{l}\text { "Flagship stores play a critical role in relationship } \\
\text { development." (Moore et al., 2010, p. 155) }\end{array}$ \\
\hline & $\begin{array}{l}\text { Dialectical / } \\
\text { Co-creation }\end{array}$ & 22 & $\begin{array}{l}\text { "In essence, consumers willfully perform within } \\
\text { the stage created by the producer, resulting in over- } \\
\text { lapping, interdependent consumption and produc- } \\
\text { tion experiences. This view is theoretically consis- } \\
\text { tent with the dialectical relationship between mar- } \\
\text { keters and consumers in the Nike Town context } \\
\text { as described by both Sherry (1998) and Penaloza } \\
\text { (1999)." (Hollenbeck et al., 2008, p. 336) }\end{array}$ \\
\hline
\end{tabular}

functions for the customer as compared with B2C (Backhaus, Steiner, \& Lügger, 2011).

With their business type approach, Backhaus, Steiner, and Lügger (2011) also give a possibility to differentiate various industrial businesses based on the specific investment necessary on the buyer's and the seller's side into product business, project business, systems business and OEM business. This differentiation might also explain some of the different characteristics of industrial brand worlds.

We will now reflect on the characteristics of $\mathrm{B}_{2} \mathrm{C}$ brand worlds in industrial marketing based on the aforementioned practical examples of brand worlds in $\mathrm{B}_{2} \mathrm{~B}$ and the specifics of industrial markets in general.

\subsubsection{Suggested characteristics differentiating types of brand worlds in industrial marketing from each other}

The first category of differentiating characteristics of brand worlds that we identified in consumer marketing was goal-related specifics. It comprises image orientation, the amount of focus on long-term brand building, and retail orientation, the amount of focus on the short-term sales (Kozinets et al., 2002).

Regarding image orientation, we argue that in industrial marketing brand worlds also differ from each other with respect to the extent to which they 
focus on long-term brand building. Especially given the long-term relationships linked to some $\mathrm{B}_{2} \mathrm{~B}$ transactions, the rational transparency of the production process in factory tours and product displays in showrooms are not the only aspects that should be displayed. Brands "that go beyond just functionalism, evoking an emotional association are a further contributor to differentiation and are in a stronger position to attract and retain customers" (Lynch \& de Chernatony, 2007, p.131). In consumer marketing, these emotional associations can be created in more image-oriented brand worlds such as brand museums or entire brand lands (Hollenbeck et al., 2008; Wohlfeil \& Whelan, 2007). As an example of a more image-oriented brand world in industrial marketing, we suggest the Mack Trucks Customer Center, which not only presents current products of the brand but also provides a museum and heritage center for customers to experience the history of the brand.

The direct counterpart of this characteristic in consumer marketing is retail orientation, the extent to which the focus is on short-term sales (Kozinets et al., 2002). Some brand worlds in industrial marketing also serve this goal. Given the usually more complex buying situation in $\mathrm{B}_{2} \mathrm{~B}$, we argue that this characteristic holds true on the one hand for brand worlds that offer branded merchandise and collectibles for the visitor to buy, and on the other hand for brand worlds of companies operating in the product business type. This business type shares the most communalities with the consumer marketing of all four business type approaches mentioned before (Backhaus, Steiner, \& Lügger, 2011). We therefore argue that in this less complex buying situation, brand worlds in industrial marketing can also follow an approach that is more retail- than image-oriented, similar to brand stores or flagship stores in consumer marketing (Dolbec \& Chebat, 2013). The Hilti stores and flagship stores serve as an example of brand worlds in product business with a strong retail orientation.

Looking at the GE Customer Experience Center, we can identify another goal-related characteristic, which has not been mentioned in the $\mathrm{B}_{2} \mathrm{C}$ literature on brand worlds. One goal of this location is to convey theoretical and practical knowledge regarding the use and the function of the products to both customers and employees. In order to do so, GE integrated a special 'learning center' inside their brand world. The provision of services attached to the company's own product, like training customer staff in operation and maintenance, is described as the beginning of a servitization strategy of product-centric businesses in B2B, which can eventually lead to a new revenue stream (Raddats \& Easingwood, 2010). It plays an important role, especially in the implementation phase of new product developments (Ernst, Hoyer, \& Rübsaamen, 2010). This additional knowledge transfer orientation has not been described in the $\mathrm{B}_{2} \mathrm{C}$ literature on brand worlds as an explicit goal, although it is also part of some $\mathrm{B}_{2} \mathrm{C}$ brand worlds. Miele for example, a German manufacturer of home appliances, offers cooking courses in their Miele Centers, where customers can learn how to make the best use of their products. As the GE example proves, it exists as a goal in industrial marketing brand worlds and is supported by $\mathrm{B}_{2} \mathrm{~B}$ literature. Therefore, we suggest knowledge transfer orientation as another goal-related characteristic of special types of brand worlds.

Additionally, the GE Customer Experience Center comprises a "Product Accelerator Lab. This lab is supposed to help improve new product design processes, speeding up development times with 3-D printing and rapid prototyping. It unites customers and engineering teams in an atmosphere that allows 
for fast, hands-on feedback throughout the development process." (General Electric Company, 2015). In $\mathrm{B}_{2} \mathrm{C}$, brand worlds are also described as being dialectical in nature, creating direct interaction between the visitors and the operating company, and providing direct feedback (Hollenbeck et al., 2008; Kent, 2012). In B2B, however, this seems to be one of the primary goals for some types of brand worlds, given the often close relationships and individualized or co-created products (Backhaus, Steiner, \& Lügger, 2011). These brand worlds actively promote and engage collaboration and the co-creation of new products and solutions. Therefore, we suggest collaboration orientation as another goal-related characteristic that could be used to differentiate brand worlds in industrial markets.

The second group of variables we identified to distinguish between brand worlds in $\mathrm{B}_{2} \mathrm{C}$ were content-related characteristics. We describe hands-on orientation as the level of active participation the visitor can have, for example by trying out products or using interactive installations (Mikunda, 2004; Webb, 2012). In some consumer brand worlds, such as brand stores and showrooms, visitors can have a direct, tactile, physical experience with products such as mobile phones or watches and try out these products (Webb, 2012), whereas in brand museums this usually is not the case (Penaloza, 1998). In B2B, researchers highlight the importance of a product trial as a powerful tool to form brand beliefs and attitudes. These beliefs derived from a direct experience are stronger than the indirect experiences created through above-the-line communication such as advertising (Biedenbach \& Marell, 2010). Giving B2B customers the possibility to try the functional qualities of the product in person could reduce perceived risk (Leek \& Christodoulides, 2012). With regard to the buying center members, the possibility for product trial or interaction before the purchase decision could be aimed especially at the users of the product (Kotler \& Pfoertsch, 2006). The performance track at the Mack Trucks Customer Center provides this possibility. Therefore, we suggest hands-on orientation as a variable distinguishing $\mathrm{B}_{2} \mathrm{~B}$ brand worlds as well.

By contrast, the content in brand museums in $\mathrm{B}_{2} \mathrm{C}$ is transported by means of educating and informing visitors, especially about the history of the brand (Hollenbeck et al., 2008). This provision of information about the background of the brand also makes sense in a $\mathrm{B}_{2} \mathrm{~B}$ environment, where the primary purpose of branding is risk reduction. The display of the length of time the company has been in business, its successful history, and the brand's degree of experience gives $\mathrm{B}_{2} \mathrm{~B}$ customers the perception of it being a stable company. This reduces purchasers' perceived risk and provides them with confidence to make their decision (Leek \& Christodoulides, 2012).

Brand worlds in $\mathrm{B}_{2} \mathrm{C}$ include branded theme parks, whose main focus is on entertainment and fun, or flagship stores, which blend entertainment with shopping (Kozinets et al., 2002). Based on these examples, the brand worlds of $\mathrm{B} 2 \mathrm{~B}$ companies provide entertainment only to a lesser extent. This seems logical given the more rational approach in industrial marketing, and the distinction between autotelic experiences in $\mathrm{B} 2 \mathrm{C}$ and instrumental experiences in $\mathrm{B} 2 \mathrm{~B}$. But still, for example at the Caterpillar Visitors Center, there is an interactive, virtual installation of an excavator similar to a computer game, installed in a real excavator cockpit. Mack Trucks also wants to provide the visitors of their customer center with a fun adventure. Both of these brand worlds also target private customers and fans of the brand by expanding the focus from 
buyers to company stakeholders (Wind, 2006). In such cases, the provision of entertainment can help to give consumers - and business visitors, too - an experience similar to the one in consumer brand worlds, where it strengthens the relationship to the brand (Kozinets et al., 2002).

The product range on display also differs in brand worlds in industrial marketing. While flagship stores in consumer marketing usually display a wider or even the entire product range (Manlow \& Nobbs, 2013), the same holds true when we look at the example of Hilti's brand and flagship stores. This display of the capabilities of a brand is suggested as an important functional component of brand value in B2B (Leek \& Christodoulides, 2012), and the wide product range on offer might also reduce search costs. Therefore, we suggest that the product range as differentiating characteristic can also be transferred from $\mathrm{B}_{2} \mathrm{C}$ to $\mathrm{B}_{2} \mathrm{~B}$.

The time perspective identified as a differentiating feature between brand worlds in consumer marketing can also be transferred to the industrial realm. In consumer marketing, brand museums use historical artifacts to evoke emotions and convey brand identity and brand meaning (Hollenbeck et al., 2008). As described before, the image-related aspects play a minor role for the customer with regard to the $\mathrm{B}_{2} \mathrm{~B}$ brand. Yet, the display of a brand's historical features can reduce the perceived risk for the purchaser and increase the relevance of the brand (Backhaus, Steiner, \& Lügger, 2011; Leek \& Christodoulides, 2012). Mack Trucks' brand museum is an example of the presentation of historical features of a company in $\mathrm{B} 2 \mathrm{~B}$. In showrooms, where the current product range is on display, the company's product-related capabilities are presented. These capabilities in product innovation contribute to the identity of brands in industrial marketing and add to brand value (Beverland, Napoli, \& Lindgreen, 2007; Leek \& Christodoulides, 2012). In its Innovation Center, logistics provider DHL offers a view of the future of logistics solutions as the company sees them. This completes the views on the past, the present, and the future that different brand worlds in industrial marketing provide.

Additional services in industrial brand worlds focus on practical use rather than entertainment, accommodation, and gastronomy. More sophisticated locations, such as the DHL Innovation Center, offer workshops, briefings, and conference rooms to increase the customer's brand experience.

Brand worlds in industrial marketing also differ in their physical appearance in a way that is similar to the one in the consumer area. A full brand land is typically larger than flagship stores, which in turn surpass brand stores in size. And while the brand museums and brand lands that we used as examples are usually at locations that have a special meaning for the brand, like the corporate headquarters or founding sites, brand stores or showrooms are closer to the customer and present in various markets. The transfer from $\mathrm{B}_{2} \mathrm{C}$ to $\mathrm{B}_{2} \mathrm{~B}$ of both the size and the location as variables of brand worlds therefore seems valid. In $\mathrm{B}_{2} \mathrm{C}$, research has proven that these two factors are crucial for the success of a brand world, as both contribute to the brand's image (Moore et al., 2010; Nobbs et al., 2012). As there is no research on brand worlds in $B_{2} B$, the only partially comparable type of experiential marketing or brand communication tool in $\mathrm{B}_{2} \mathrm{~B}$ in our opinion are trade shows. Here, the booth location and size have a significant effect on the trade show's image-building performance, sales-related performance, and relation-improvement performance for the supplier (Lee \& Kim, 2008). 
Both architecture and design are important features for brand worlds in $\mathrm{B}_{2} \mathrm{C}$. They distinguish, for example, regular brand stores from the more spectacular flagship stores (Moore \& Doherty, 2007). The design and architecture of corporate buildings are also important features of corporate design in $\mathrm{B}_{2} \mathrm{~B}$ to convey a consistent brand image. Furthermore, in $\mathrm{B}_{2} \mathrm{~B}$, less spectacular forms can be found in brand stores, whereas flagship stores or brand lands are aesthetically more appealing.

The degree of multisensuality also differs in the various types of brand worlds and is linked to the architecture and design features. We argue that brand lands or brand museums with interactive installations offer a more multisensual approach to the brand than less spectacular brand stores, similar to the consumer marketing area (Hollenbeck et al., 2008).

Moreover, similarly to their consumer counterparts, the investment in a brand world will be higher the bigger and the more complex it becomes.

According to the literature on consumer brand worlds, they also differ from each other with respect to some customer-related characteristics. First, there is the difference in the target group, ranging from direct customers to media representatives and other stakeholders (Kent \& Brown, 2012). In industrial marketing, with the background of organizational buying centers and the demand for focus on all stakeholders (Wind, 2006), this differentiation gains importance. The user might have the chance to try out the product or to be trained, with the intention of ensuring the correct usage and maintenance of the product (Raddats \& Easingwood, 2010). Instead, the purchaser might have been invited to visit a brand museum or a factory tour to gain trust in the supplier and its capabilities before making a purchase decision. Additionally, internal branding plays an important role in industrial marketing as well because it determines how the brand is presented externally to the purchasers and other stakeholders (Leek \& Christodoulides, 2012; Lynch \& de Chernatony, 2004).

This differentiation in target groups is inevitably linked to the stage in the customer relationship. Brand worlds play a role in creating, maintaining, and developing an enduring relationship in consumer marketing, yet the different types do so to a different extent (Moore et al., 2010). We argue that in industrial marketing, a brand museum has a stronger impact on prospective customers than a retail-oriented brand store does. This is because the provision of historical linkages can reduce the perceived risk, which might be especially useful in the early stages of the relationship, where the parties have no previous experience doing business with each other (Leek \& Christodoulides, 2012). The visit to a training center is more likely to take place in an already ongoing relationship or as a product trial shortly before the purchase decision than at an earlier stage.

The dialectical and co-creating nature of some types of brand worlds is also of importance in industrial markets, with their more customer-specific and complex products (R. Grewal \& Lilien, 2012). Researchers argue that customers and suppliers in a $\mathrm{B}_{2} \mathrm{~B}$ co-development process are more active in those phases of the process that help them fulfill their individual goals. These are, for suppliers, the possibility to commercialize a new development, while for customers the primary goal is to improve process efficiency (Oinonen \& Jalkala, 2015). As mentioned before, the primary goal of innovation centers is to provide a location to collaborate and co-create. These environments could especially be helpful for the supplier in business approaches with a high specific investment 
on the supplier's side, e.g. in the OEM and the project business. For the customer, it could also be beneficial in buying situations with a high specific investment on their side to create a product that specifically helps them improve their processes, e.g. in the systems business.

Following up on our third research aim, based on the inductive category formation and the examples provided, we suggest that the original 16 characteristics differentiating various types of $\mathrm{B}_{2} \mathrm{C}$ brand worlds can be transferred to their $\mathrm{B}_{2} \mathrm{~B}$ counterparts. The findings suggested to complement them with two additional goal-related characteristics. The full list of 18 characteristics that differentiate the various types of brand worlds in industrial marketing are depicted in Table 2.3.

To conclude, a substantial overlap between the characteristics of $\mathrm{B}_{2} \mathrm{C}$ and $\mathrm{B} 2 \mathrm{~B}$ brand worlds could be identified. Thus, despite the differences of autotelic experiences in $\mathrm{B}_{2} \mathrm{C}$, and instrumental experiences in $\mathrm{B}_{2} \mathrm{~B}, \mathrm{~B}_{2} \mathrm{~B}$ marketing practitioners have acknowledged the positive impact that brand worlds as experiential marketing instruments can have on their branding efforts. 


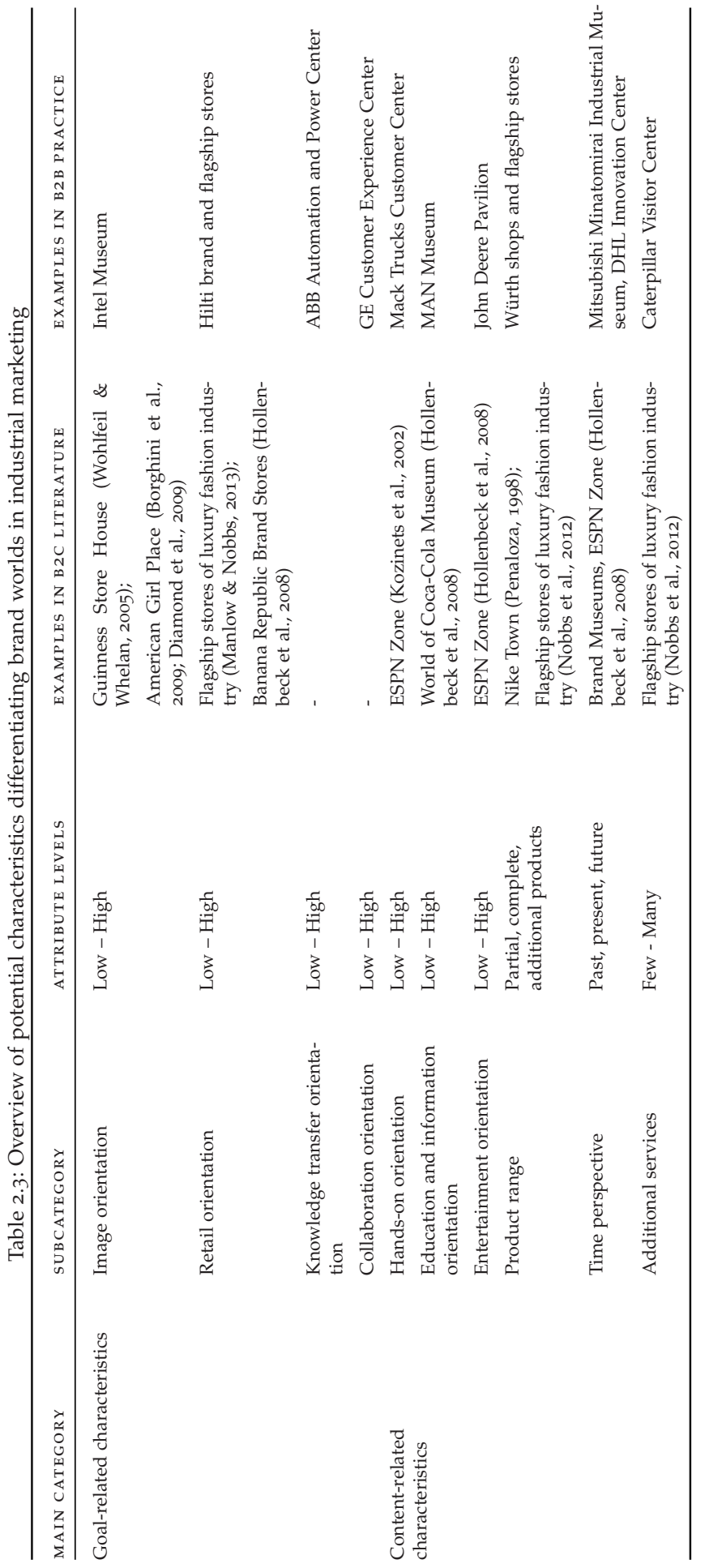




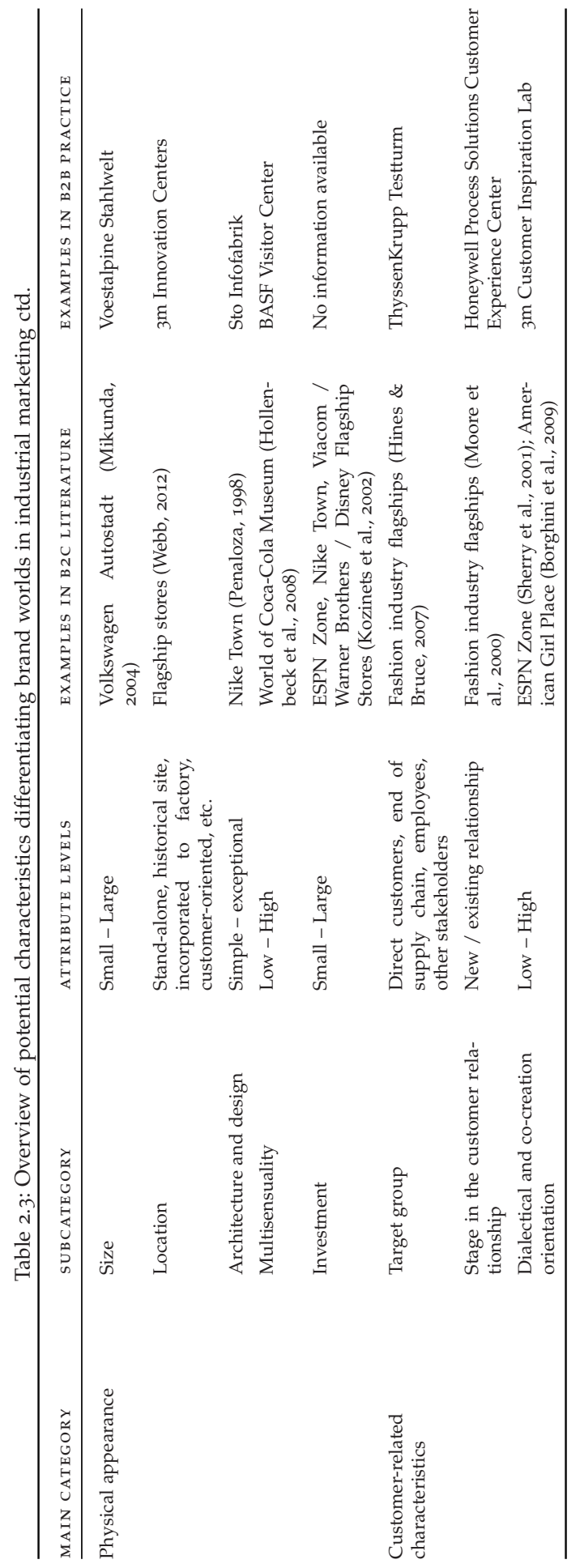


Inherent to the methods used to identify the types and characteristics of brand worlds in $\mathrm{B}_{2} \mathrm{C}$, this study has some limitations. Regarding the systematic literature review, it is possible that publications might be overlooked due to terminological differences, or a lack of citations and availability in databases for recent publications. Nonetheless, after considering the journals and authors included in our list of references, we are confident that the analyzed publications accurately represent the stream of research on brand worlds in consumer marketing. The main critique with respect to the qualitative content analysis is its subjective nature. By closely following accepted guidelines and processes, and by presenting our criteria and definitions in this study, we make our approach more transparent to the reader and also more valid and reliable. The possible limitations of the transfer of findings, knowledge, and structures from $\mathrm{B}_{2} \mathrm{C}$ to $\mathrm{B}_{2} \mathrm{~B}$ have been outlined in this study.

Despite these limitations, we are able to draw several conclusions for $\mathrm{B} 2 \mathrm{~B}$ branding research from this paper. Branding in business markets is essentially a form of communicative interaction; especially the interaction between employees, customers, and stakeholders evokes the co-creation of brand experiences (Ballantyne \& Aitken, 2007). In $\mathrm{B} 2 \mathrm{C}$, experiential marketing and especially the instrument of brandscaping are described as some of the most powerful tools to entail these strong, long-lasting brand experiences (Dolbec \& Chebat, 2013). Despite the difference between autotelic and instrumental experiences in the consumer and business marketing areas (Rinallo et al., 2010), this paper identifies strong parallels between brand worlds in $\mathrm{B}_{2} \mathrm{C}$ and their counterparts in $\mathrm{B}_{2} \mathrm{~B}$. It thus supports the finding from the trade show industry, that business marketing practitioners are already successfully implementing experiential marketing instruments for quite some time (Rinallo et al., 2010). Furthermore, it extends this application of experiential marketing techniques to their successful use in the $\mathrm{B}_{2} \mathrm{~B}$ branding area.

This introduction of the experiential view to $\mathrm{B}_{2} \mathrm{~B}$ branding research provides fruitful areas for future research. In general, B2B branding scholars suggest both more qualitative and more quantitative research (Seyedghorban et al., 2016). Therefore, a qualitative approach to investigate the underlying objectives that $\mathrm{B}_{2} \mathrm{~B}$ companies pursue when investing in experiential marketing techniques in general, and brand worlds in particular, can be considered. As the investment, especially in an extensive brand world, can be considerably high, it could be interesting to determine whether other goals than the ones described in this paper are pursued by operating companies. Additionally, the success factors of the different types of $\mathrm{B}_{2} \mathrm{~B}$ brand worlds from a company perspective form an interesting research opportunity, as does the expectations that potential visitors have of these brand worlds. These insights would prove especially helpful as a basis for recommendations or guidelines for future experiential marketing activities in practice in this area. Based on these qualitative approaches, the body of literature would also benefit from quantitative empirical research. For example, a typology of different types of brand worlds could be developed on the basis of the differentiating characteristics described in this paper, using quantitative data. This would prevent the inconsistent use of terms in the area of brand worlds in industrial marketing. Furthermore, the characteristics suggested here could be subject to quantitative review and could be either 
refined or verified. In fact, only two journal publications on brand worlds in consumer marketing were based on quantitative research, e.g. to evaluate the impact of a visit to a flagship store compared with a brand store on brand attachment, brand attitude, and brand equity from the visitor's perspective (Dolbec \& Chebat, 2013). Similar approaches should be considered to evaluate the qualitative findings on goals and success factors. The investigation of the effect that a visit to a brand world in industrial marketing has on the visitor and his image of the operating company provides an area for research as well. Finally, taking into account experiential marketing and the strong brand experiences it can evoke, and fully integrating it in into the overall communication programs, could significantly contribute to the branding efforts of $\mathrm{B}_{2} \mathrm{~B}$ organizations. More contributions on its implementation and impact can be expected to exploit this so far insufficiently researched field.

\subsection{IMPLICATIONS FOR BUSINESS MARKETING PRACTICE}

The main implication of this paper for business marketing practice is based on the finding that there is a substantial overlap between the characteristics of brand worlds in $\mathrm{B}_{2} \mathrm{C}$ and $\mathrm{B}_{2} \mathrm{~B}$. Seemingly, $\mathrm{B}_{2} \mathrm{C}$ tools, techniques, and conceptual models of experiential marketing can not only be transferred from $\mathrm{B}_{2} \mathrm{C}$ to $\mathrm{B}_{2} \mathrm{~B}$ in the context of trade shows, but also in the context of brand worlds. Keeping in mind the more instrumental nature of the experience for $\mathrm{B}_{2} \mathrm{~B}$ visitors, brand worlds can also create powerful brand experiences in business markets. Often only minimal investments are necessary, to turn factories into theme-parks and museum-like showcases (Kozinets et al., 2002). Such a museum or museal aspects in a $\mathrm{B} 2 \mathrm{~B}$ brand world for example could help to demonstrate the history and experience of the brand in a certain field, resulting in reduced uncertainty on the customer side and a more positive brand perception. Additionally, people learn best through experience. Learning is defined by experiential learning theorists as "the process whereby knowledge is created through the transformation of experience. Knowledge results from the combination of grasping and transforming experience" (Kolb, 1984, p. 41). The direct, hands-on, personal experiences that can be created with experiential marketing activities such as trade shows and brand worlds will most likely leave a deeper impression on the visitor's mind, and create more knowledge than regular advertising instruments such as trade magazines could. So if the goal is to provide a target group with knowledge about a product or a brand, a powerful tool is to let them experience the product or the brand themselves firsthand, be it in the form of product trial or a personal visit to the companies facilities. If these facilities not only comprise of regular meeting rooms or standard plant tours, but well-designed, experiential locations such as their $\mathrm{B}_{2} \mathrm{C}$ brand world counterparts, a long-lasting impression can be expected. With themed experiences, where physical cues such as symbols, signals or stories are used to inspire the senses, the values of the brand can effectfully be conveyed to the visitor. As such, brand worlds also form the ideal venue for business meetings in $\mathrm{B}_{2} \mathrm{~B}$, with its emphasis on personal interactions. Customers, suppliers, or other stakeholders can be invited, and although the reason for the visit might be a purely rational sales negotiation, the personal interaction in the experiential, stimulating environment of a brand world could help to form a memorable and unique experience for the visitors, and subsequently contribute to their 
image of the brand. Therefore, we encourage $\mathrm{B}_{2} \mathrm{~B}$ branding practitioners to take advantage of these strong brand experiences evoked in brand worlds within their branding efforts. 

In order to allow for the investigation whether brand worlds are effective in achieving an intended outcome, this intended outcome must first be known. Therefore, the goals and motives of brand worlds in $\mathrm{B}_{2} \mathrm{~B}$ as well as the expectations and value derived from a visit of $B_{2} B$ visitors are identified in this study, by means of qualitative expert interviews with operating companies, business visitors, and exhibition designers. Next to providing first qualitative support for their effectiveness in branding, this exploratory step also provides crucial information on what the $\mathrm{B} 2 \mathrm{~B}$ brand world consists of, and how it works on a micro-level in co-creating experiences.

PUBLICATION HISTORY:

The earliest version of this chapter was written together with Prof. Dr. Marc Kuhn and Prof. Dr. Jörg Henseler as a conference paper for the International Symposium/Workshop on "Branding in the Business-toBusiness Context" held at Massey University, Albany Campus, Auckland, New Zealand from July 2-5 2017. A full paper was submitted to the special issue on "Branding in the Business-to-Business Context" of Industrial Marketing Management, which was published in 2018. This full paper is presented in this chapter.

REFERENCES TO PREVIOUS PUBLICATIONS:

Österle, B., Kuhn, M. M., \& Henseler, J. (2018). Brand worlds: Introducing experiential marketing to $\mathrm{B}_{2} \mathrm{~B}$ branding. Industrial Marketing Management, 72, 71-98.

https://doi.org/10.1016/j.indmarman.2018.04.015

KEYWORDS:

Brand Worlds, B2B, Branding, Experiential marketing, Relationship, Emotion 
3. BRAND WORLDS: INTRODUCING EXPERIENTIAL MARKETING TO B2B BRANDING

ABSTRACT

Experiential marketing instruments and the extraordinary experiences they provide are one of the strongest means of branding in $\mathrm{B}_{2} \mathrm{C}$. Inter alia as brand worlds, they also exist in $\mathrm{B} 2 \mathrm{~B}$ marketing practice, but have only received limited attention from the $\mathrm{B}_{2} \mathrm{~B}$ branding perspective. Differences between $\mathrm{B}_{2} \mathrm{C}$ and $\mathrm{B}_{2} \mathrm{~B}$ branding raise questions regarding why $\mathrm{B}_{2} \mathrm{~B}$ companies operate brand worlds, what they consist of, what their nature is, and how they are experienced. We build on a rich, comprehensive sample of 37 expert interviews, comprising the perspectives of operating companies, business visitors, and exhibition designers. We find that $\mathrm{B}_{2} \mathrm{~B}$ brand worlds differ substantially from their $\mathrm{B}_{2} \mathrm{C}$ equivalents in several aspects, but they apply similar experiential techniques. Operating companies' motives focus on providing live product experiences to explain complex products and create product awareness. B2B visitors expect more functional than hedonic benefits, and the visit has to support them in their own business activities. Affordances of the experiencescape and the actionperception between visitor, brand employees, and the physical environment are at the core of how the $\mathrm{B} 2 \mathrm{~B}$ brand world experiences are co-created. Our research highlights the important role and nature of $\mathrm{B}_{2} \mathrm{~B}$ brand worlds as three-dimensional 'business cards,' where relationships are initiated and built.

\subsection{INTRODUCTION}

Since the introduction of the idea that consumption involves a "steady flow of fantasies, feelings, and fun encompassed by what we call the experiential view" (M. B. Holbrook \& Hirschman, 1982, p. 132), the concept of customer experience has played a crucial role for both marketing practitioners and academics. Experiential marketing refers to the strategies of staging and creating offerings for the purpose of facilitating extraordinary experiences (Carù \& Cova, 2003; Pine \& Gilmore, 1999). Customer experiences with brands along all touchpoints and branding instruments are crucial to the branding process, whether extraordinary or not (Brakus et al., 2009). The value of the experience is co-created, and the result of interactions between a single firm or a brand - the experience provider - and the customer, but also between a whole network of firms, employees, brands, experts or opinion leaders and this customer (Tynan \& McKechnie, 2009). Reciprocally, brands play an important role in this process of experience co-creation (Tynan \& McKechnie, 2009). Differentiation, a main driver of experiential marketing, is a crucial function of brands in both $\mathrm{B}_{2} \mathrm{C}$ and B2B (Kotler \& Pfoertsch, 2006), and brands themselves are rich sources of "sensory, affective, and cognitive associations that result in memorable and rewarding brand experiences" (Schmitt, 1999a, p. 57). A specific branding instrument which uses experiential marketing techniques, the flagship store, is called the "apex of branding" (Dolbec \& Chebat, 2013, p. 460). But also other instruments of branding, for example permanent, physical branded locations such as brand lands, brand museums, or customer experience centers, which we summarize with flagship stores under the umbrella term 'brand 
worlds', deliver powerful branded experiences much stronger than regular advertising, based on their direct, highly interactive visitor-brand encounters and experiential marketing techniques (Borghini et al., 2009; E. H. Wood, 2009; Zarantonello \& Schmitt, 2013). Indisputably, this holds true for the emotional realm of consumer marketing. There can hardly be a greater achievement for a brand than fully materializing in its own successful brand world, such as the Walt Disney World, the World of Coca-Cola, the Hershey Park, the VW Autostadt or the Apple Flagship Stores.

Since branding in $\mathrm{B}_{2} \mathrm{~B}$ increasingly attracts attention (Keränen et al., 2012; Leek \& Christodoulides, 2011a; Seyedghorban et al., 2016), the question arises which role experiential marketing and its techniques play in this context. Its instruments and techniques have been mentioned as a possibility for B2B companies to create strong, memorable customer experiences (Gilmore \& Pine, 2002; Pine \& Gilmore, 1999; Schmitt, 1999b), but only trade shows have been investigated from an experiential perspective on business markets, and without a branding perspective (Rinallo et al., 2010). This gap in research can be explained with the predominant notion of rational and professional actors in the business context, as opposed to the original experiential value sources of "fantasies, feelings, and fun" (M. B. Holbrook \& Hirschman, 1982, p. 312). Trade show experiences create value first and foremost when they support the B2B visitors in their business activities, "no matter how entertaining or spectacular they may be" (Rinallo et al., 2010, p. 256). This preliminary understanding of experiential marketing in business markets is followed by a call for further research on other experiential marketing instruments and the determinants of their effectiveness (Rinallo et al., 2010). Nevertheless, industrial marketing practitioners have already discovered the branding potential of experiential marketing techniques. B2B brand worlds can in fact be found all over the planet, such as for example the Caterpillar Visitors Center or the Customer Experience Centers of General Electric and Honeywell Process Solutions in the US, the Innovation Center of logistics provider DHL or the Stahlwelt of Austrian steel producer Voestalpine in Europe, or the Mitsubishi Minatomirai Industrial Museum in Asia. But in contrast to their $\mathrm{B}_{2} \mathrm{C}$ counterparts, these instruments of branding, which employ experiential marketing techniques, have not attracted academic attention yet (Österle, Kuhn, \& Henseler, 2016).

Against this background, this article enriches $\mathrm{B}_{2} \mathrm{~B}$ branding research with a new theoretical perspective, experiential marketing, and examines brand worlds as a branding instrument that uses experiential marketing techniques. Given the dyadic nature of experiences (Lemon \& Verhoef, 2016), we adopt both an organizational and a customer perspective, and complement these with the perspective of exhibition designers. In order to understand brand worlds and their use of experiential marketing techniques for $\mathrm{B} 2 \mathrm{~B}$ branding, the goal of this study is threefold. First, to answer the question of why, to investigate the motives of industrial companies to implement brand worlds, to identify expectations $\mathrm{B}_{2} \mathrm{~B}$ visitors have, and the value they derive from the experience of a $\mathrm{B}_{2} \mathrm{~B}$ brand world visit; second, to answer the question of what, to understand the nature of the $\mathrm{B} 2 \mathrm{~B}$ brand world and what it is constituted of; and third, to answer the question of how, to investigate how the $\mathrm{B}_{2} \mathrm{~B}$ brand world is perceived and how the experience is co-created.

This paper contributes in several ways. It provides a theoretical contribution by introducing brand worlds as an instrument of branding, which employs 
experiential marketing techniques, to the $\mathrm{B}_{2} \mathrm{~B}$ context. As such, it also provides a contextual contribution and expands the $\mathrm{B}_{2} \mathrm{~B}$ literature on brand building tactics and brand management. We also identify brand worlds as locations for operating companies and business visitors to personally interact and build relationships during the entire customer journey, contributing to the relationship and interaction approaches in $\mathrm{B}_{2} \mathrm{~B}$. Brand worlds also convey customer value propositions with the hands-on product experiences they evoke, as well as other experiential value dimensions. Thus, our research contributes to the current discussion on value in business markets. Fifth, by taking a phenomenological stance of embodied cognition, our paper also contributes to the understanding of how experiences in brand worlds are perceived and co-created.

The remainder of this paper is structured as follows. To provide the setting for this study, we outline the differences between $\mathrm{B}_{2} \mathrm{C}$ and $\mathrm{B}_{2} \mathrm{~B}$ branding, and elaborate on brand worlds as instruments of branding which employ experiential marketing techniques. We then outline experiential marketing and experiential value, as well as the phenomenological perspective we took in order to understand the nature of $\mathrm{B}_{2} \mathrm{~B}$ brand worlds and how they are experienced. Next, we describe our exploratory research approach, and present an overview of our comprehensive, multi-perspective sample. Subsequently, we present our results. We conclude with a discussion of our findings, provide areas for future research and implications for theory and practice, and outline the limitations of our study, before giving an outlook on brand worlds in B2B.

\subsection{THEORETICAL BACKGROUND}

\subsubsection{Differences between $B_{2} C$ and $B 2 B$ branding}

Key differences of $\mathrm{B}_{2} \mathrm{~B}$ markets relative to $\mathrm{B}_{2} \mathrm{C}$ include the nature of demand (derivative vs. primary); a culture driven by manufacturing and technology, which is related to the complexity of industrial products; more technical and quantifiable value propositions; a small number of customers, but large-unit transactions; complex buying processes involving buying centers and thus group dynamics, resulting in more rational discourse and decision-making; the emphasis on corporate rather than product branding; and the more important role of relationships, interpersonal communication or personal selling (B. P. Brown, Bellenger, \& Johnston, 2007; B. P. Brown et al., 2012; D. Grewal, Krishnan, Baker, \& Borin, 1998; Kotler \& Pfoertsch, 2006; Lilien, 2016; Webster \& Keller, 2004; Zablah et al., 2010). B2B buying decisions are influenced by the buying situation (e.g. Kotler \& Pfoertsch, 2006), a higher perceived risk, and the more economic and performance type of risk (B. P. Brown et al., 2007). These general differences have effects on marketing communications, which are proposed to be more technical and pedagogical, but also more interactive and personal, and thus also on the branding efforts on business markets (B. P. Brown et al., 2007).

When it comes to brands, things were supposed to be different in industrial marketing. For a substantial period of time, branding was not relevant, and a pure $\mathrm{B}_{2} \mathrm{C}$ phenomenon (Kotler \& Pfoertsch, 2006). After about 40 years of research, however, $\mathrm{B}_{2} \mathrm{~B}$ branding has evolved from irrelevance towards being important for business marketing practice, and an established field of study (Gordon, Calantone, \& Di Benedetto, 1993; Interbrand, 2016; Saunders \& Watt, 
1979; Seyedghorban et al., 2016; Shipley \& Howard, 1993; Sinclair \& Seward, 1988; Webster \& Keller, 2004). Nowadays, "branding is just as relevant in B2B as it is in $\mathrm{B}_{2} \mathrm{C}^{\prime \prime}$ (Kotler \& Pfoertsch, 2006, p. 12). In the course of this evolution, many concepts, frameworks, and theories have been transferred and adapted from the further developed consumer to the industrial context (e.g. Beverland et al., 2007; Kuhn et al., 2008; Mudambi et al., 1997). Researchers have to be cautious with this transfer and take into account the unique characteristics of $\mathrm{B}_{2} \mathrm{~B}$ markets for the development of a sound B2B branding theory (e.g. Keränen et al., 2012; Mudambi, 2002; Seyedghorban et al., 2016; Webster \& Keller, 2004).

Both academics as well as practitioners today acknowledge that industrial brands serve similar general purposes as consumer brands (Keränen et al., 2012; Kotler \& Pfoertsch, 2007; Wise \& Zednickova, 2009). They are means of identification, differentiation, and employer branding, ambassadors towards all stakeholders, indicators of origin, quality, and performance, thus reducing risk and complexity of buying decisions, and they are means to communicate the values and benefits of a company's offerings - even increasing the perceived value of a product for a customer (Bengtsson \& Servais, 2005; Cretu \& Brodie, 2007; Davis, Golicic, \& Marquardt, 2008; Kotler \& Pfoertsch, 2006, 2007; Leek \& Christodoulides, 2011a; Leischnig \& Enke, 2011; Michell, King, \& Reast, 2001; Ohnemus, 2009; Wise \& Zednickova, 2009; Zablah et al., 2010). B2B brands also have financial value for the company. They help to attract customers, to get on bid lists, to shift tight purchasing decisions in a desired direction, and increase customer loyalty (Ohnemus, 2009; van Riel, Pahud de Mortanges, \& Streukens, 2005; Wise \& Zednickova, 2009). Brand-loyal industrial buyers in turn promote the brand to other purchasing agents, consider the brand's other products, and even pay a price premium for their favorite brand, leading to higher sales turnovers (Bendixen, Bukasa, \& Abratt, 2004; Hutton, 1997). To summarize, despite their importance is context-dependent (B. P. Brown et al., 2012; Zablah et al., 2010), brands matter to business buyers (Cretu \& Brodie, 2007; Mudambi, 2002). As in $\mathrm{B}_{2} \mathrm{C}$, brand value in $\mathrm{B}_{2} \mathrm{~B}$ comprises not only functional and rational components such as quality, technology, and reliability, but also emotional and hedonic components such as risk reduction, reassurance, trust, and credibility (B. P. Brown et al., 2012; Gomes et al., 2016; Leek \& Christodoulides, 2012; Lynch \& de Chernatony, 2007). Yet, as opposed to B2C, the most important brand values in $\mathrm{B}_{2} \mathrm{~B}$ are functional ones, whereas emotional aspects play a minor role (Backhaus, Steiner, \& Lügger, 2011; Leek \& Christodoulides, 2012).

When it comes to the question of how a $\mathrm{B}_{2} \mathrm{~B}$ brand can be built and communicated, the brand is conceptualized as a holistic and interactive experience, as in B2C (Ballantyne \& Aitken, 2007; Biedenbach \& Marell, 2010; Kotler \& Pfoertsch, 2006; Lynch \& de Chernatony, 2004). Therefore, despite the specific importance of the salesperson and personal interaction (Lynch \& de Chernatony, 2007), all customer touchpoints and elements of the marketing mix contribute to brand equity dimensions, as they do in $\mathrm{B}_{2} \mathrm{C}$ : They create awareness of the brand, link desired associations to the brand image, evoke emotions or judgments of quality, and facilitate a stronger customer-brand relationship (Biedenbach \& Marell, 2010; Kotler \& Pfoertsch, 2006). These differences between - but also the similarities of $-\mathrm{B}_{2} \mathrm{C}$ and $\mathrm{B}_{2} \mathrm{~B}$ branding provide the context of our study of brand worlds as instrument of branding and its use of experiential marketing in $\mathrm{B}_{2} \mathrm{~B}$. 


\subsubsection{Brand worlds}

Due to the lack of research and literature on brand worlds in the $\mathrm{B}_{2} \mathrm{~B}$ context, on which we focus in our study, we provide background information on their $\mathrm{B}_{2} \mathrm{C}$ counterparts in this section as starting point for our investigation. Brandscaping - creating physical locations based on brands - is one of the strongest means in branding in $\mathrm{B}_{2} \mathrm{C}$, based on emotions and a non-rational, experiential approach (Riewoldt, 2002). Practical examples for these physical locations based on brands in $\mathrm{B}_{2} \mathrm{C}$ are the Disney Worlds, the Apple flagship stores, or the World of Coca- Cola in Atlanta, Georgia, to only name a few. They follow the conviction that "the glamour and power of the brand are the key weapons in the battle for target groups and customers. By staging the brand experience in flagship stores, shop designs or entire theme parks, companies communicate the image of the brand and imprint a characteristic atmosphere on the consumer consciousness" (Riewoldt, 2002, p. 8). In such locations, in contrast to most classical advertising instruments, the brand becomes visible, actually tangible, and therefore a strong, real, memorable customer experience and relationship between the brand and the customer is created (Manlow \& Nobbs, 2013; Webb, 2012). The live experience of taking a trip to, for example, a brand park, and actually visiting the brand becomes part of one's own life and has a higher recollective value than simple advertising or conventional PR (Mikunda, 2004). Simply witnessing a product's production in a mere plant tour can lead to higher brand loyalty, based on the identification with the product, the familiarity with the production process, and the interaction with employees (M. A. Mitchell \& Orwig, 2002).

Flagship stores are titled the "apex of branding" because of their branding power (Dolbec \& Chebat, 2013, p. 460). Similar venues have been mentioned and investigated in consumer-centric academic literature, such as customer experience places, brand lands, brand museums, brandscapes, flagship stores etc. (e.g. Borghini et al., 2009; Diamond et al., 2009; Gilmore \& Pine, 2002; Hollenbeck et al., 2008; Joy, Wang, Chan, Sherry, \& Cui, 2014; Kozinets et al., 2002; Sherry, 1998; Sherry et al., 2001). The terms partially overlap and lack clear distinctions and definitions (Österle et al., 2016). Therefore, we use the term 'brand worlds' as an umbrella term for such permanent branded locations that are an instrument of brand communication and experiential marketing. These brand worlds have been subject to a limited amount of academic research in the $\mathrm{B}_{2} \mathrm{C}$ environment already. For example, the goals of different types of brand worlds in various industries have been investigated, which are, to summarize, related to the image of the brand, the presentation, staging and test of products, customer relationship goals, merchandising goals, and knowledge transfer (e.g. Borghini et al., 2009; Diamond et al., 2009; Gilmore \& Pine, 2002; Hollenbeck et al., 2008; Joy et al., 2014; Kozinets et al., 2002; Sherry, 1998; Sherry et al., 2001). Further main goals with different priorities were identified for $\mathrm{B} 2 \mathrm{C}$ brand worlds, as depicted in Table 3.1.

$\mathrm{B}_{2} \mathrm{C}$ visitors' expectations and demands have also been subject to investigation. When they visit brand worlds, they want to experience entertainment, flow, get information about the products and the brand, relax, be distracted and escape from their day-to-day live, experience community with other visitors, and feel well and appreciated by the operating company (Kirchgeorg et al., 
Table 3.1: Main goals for the implementation of brand worlds in $\mathrm{B}_{2} \mathrm{C}$

\begin{tabular}{|c|c|c|}
\hline HIGHEST PRIORITY & MEDIUM PRIORITY & LOWER PRIORITY \\
\hline Brand experience & Information & $\begin{array}{l}\text { Customer integration into } \\
\text { business processes (e.g. co- } \\
\text { creation) }\end{array}$ \\
\hline Brand- and product presence & Raising brand awareness & $\begin{array}{l}\text { Engaging with new, potential } \\
\text { customers }\end{array}$ \\
\hline $\begin{array}{l}\text { Determination of the own po- } \\
\text { sition in the competitive envi- } \\
\text { ronment }\end{array}$ & Internal communication goals & Generating sales turnover \\
\hline \multirow[t]{2}{*}{$\begin{array}{l}\text { Improve, strengthen and fos- } \\
\text { ter the brand image }\end{array}$} & $\begin{array}{l}\text { Management and activation } \\
\text { of existing customer relation- } \\
\text { ships }\end{array}$ & \\
\hline & Building trust & \\
\hline
\end{tabular}

Adapted from Kirchgeorg, Springer, and Ermer (2012), Zentes, Ney, and Keßler (2014)

2012; Opaschowski, 2000; Zentes, Ney, \& Keßler, 2014). These expectations and demands are summarized in Table 3.2.

The different, professional background outlined in Section 3.2.1 suggests, that several differences might arise between brand worlds in $\mathrm{B}_{2} \mathrm{C}$ and $\mathrm{B}_{2} \mathrm{~B}$, regarding both the motives of companies operating a brand world in the $\mathrm{B}_{2} \mathrm{~B}$ context, as well as the expectations that $B_{2} B$ visitors have and the value they derive from the visit of a $\mathrm{B}_{2} \mathrm{~B}$ brand world. Numerous practical examples of $\mathrm{B}_{2} \mathrm{~B}$ brand worlds exist all over the world, implemented by a variety of companies in different industries which have already recognized the branding power of such locations. For example, in the US there are the Mack Trucks Customer Center, the Caterpillar Visitors Center, the Customer Experience Centers of General Electric and Honeywell Process Solutions, the Automation and Power Center of ABB, or the Tomahawk Customer Center of Case Construction. Examples in Europe are the Innovation Center of logistics provider DHL, the Stahlwelt of Austrian steel producer Voestalpine, or the Brand Stores and Flagship Stores of power tool manufacturer Hilti. An example from Asia is the Mitsubishi Minatomirai Industrial Museum.

\subsubsection{Experiential marketing and experiential value}

The importance of the consumption and customer experience concept is driven by an increasing need for differentiation in a commoditized world (M. B. Holbrook \& Hirschman, 1982; Pine \& Gilmore, 1999; Schmitt, 1999a; Schulze, 2005). Customer experience is characterized as a broad and holistic umbrella construct, that encompasses cognitive evaluations, affective responses, social, and physical or sensorial components (Kranzbühler et al., 2018; Lemon \& Verhoef, 2016; Verhoef et al., 2009). Customer experiences can be considered as consisting of pre-experience, core experience, and post-experience stages, and being inherently dyadic (Arnould, Price, \& Zinkhan, 2004). They are the result of various degrees of interaction between a single firm or brand and a customer, ranging from those consumption experiences which are independently constructed by consumers, to those experiences that are co-created by companies and consumers, and finally those consumption experiences which are largely 
Table 3.2: Super-ordinate expectations and demands of $\mathrm{B}_{2} \mathrm{C}$ brand world visitors

\begin{tabular}{|c|c|}
\hline $\begin{array}{l}\text { EXPECTATION / DEMAND } \\
\text { CATEGORY }\end{array}$ & CONTENT \\
\hline Entertainment & $\begin{array}{l}\text { Visitors want to spent a good time and experience something } \\
\text { new and extraordinary. The brand world has to offer a high } \\
\text { entertainment value and at the same time differentiate itself } \\
\text { from similar marketing formats via extraordinary and new } \\
\text { experiences. }\end{array}$ \\
\hline Information & $\begin{array}{l}\text { Visitors want to get to know the company, the brand and its } \\
\text { products in their own 'living room'. }\end{array}$ \\
\hline Flow & $\begin{array}{l}\text { If the brand world manages to create a positive immersion in } \\
\text { the experience which fascinates the visitors, a consistent experi- } \\
\text { ence will emerge which increases the visitors' involvement in } \\
\text { such a way, that they might even lose track of time. }\end{array}$ \\
\hline Relaxation & Visitors expect a relaxed experience which is not straining them. \\
\hline Diversity & $\begin{array}{l}\text { Target groups expect a high infotainment value from the brand } \\
\text { world, meaning a diversified, and highly experiential connec- } \\
\text { tion between entertaining and informative elements. }\end{array}$ \\
\hline Escapism & $\begin{array}{l}\text { Visitors see a visit to a brand world as welcome distraction } \\
\text { from day-to-day life. }\end{array}$ \\
\hline Community & $\begin{array}{l}\text { Visitors do not want to experience the brand world in isola- } \\
\text { tion, but value a group experience and want to interact and } \\
\text { experience the visit with others }\end{array}$ \\
\hline $\begin{array}{l}\text { Sense of well-being and appre- } \\
\text { ciation }\end{array}$ & $\begin{array}{l}\text { Visitors expect a strong appreciation of their visit and interest in } \\
\text { the brand from the operating company. The brand world should } \\
\text { thus not make the impression of a sales tool. Furthermore, } \\
\text { visitors want to be welcomed in a clean and tidy environment } \\
\text { by well-trained personnel. }\end{array}$ \\
\hline
\end{tabular}

Adapted from Kirchgeorg, Springer, and Ermer (2012), Opaschowski (2000), Zentes, Ney, and Keßler (2014)

'constructed' by organizations (Carù \& Cova, 2007). But also a whole network of firms, employees, brands, experts, or opinion leaders can influence the customer experience, and therefore they need to be investigated from both the organizational and the customer's perspective (Kranzbühler et al., 2018; Tynan \& McKechnie, 2009). Several research streams focusing on experience have evolved based on different perspectives and meanings of the term experience (for detailed reviews, please refer to Carù and Cova, 2003; Jain, Aagja, and Bagdare, 2017; Schmitt and Zarantonello, 2013). The original 'experiential view' implies that any type of consumption is not only a logical and rational process, but instead involves "a steady flow of fantasies, feelings, and fun" (Hirschman \& Holbrook, 1982, p. 132).

The core idea of experiential marketing is that in today's commoditized world of the experience society and economy, customers perceive functional features and benefits, product quality, and a positive brand image as given. They instead now want products, communications, and marketing campaigns to deliver an extraordinary experience (Pine \& Gilmore, 1999; Schmitt, 1999a; Schulze, 2005). Experiences are subjectively felt emotions that cannot be 'made' or 'guaranteed' by the 'provider'. They depend on the processing and the reception of each individual customer (Kilian, 2009). Experiential marketing thus refers to the strategies of staging and creating offerings for the purpose of facilitating these extraordinary experiences (Carù \& Cova, 2003; Pine \& Gilmore, 1999). For experience providers it is crucial to create an adequate and fitting environment which contributes to the evoking of a desirable experience, 
and their ability to create, manage, and market these experiences will strongly influence their success (Berry \& Carbone, 2002; Prahalad \& Ramaswamy, 2004; Schmitt, 1999a, 1999b; van Boven \& Gilovich, 2003). Companies' brands play an important role in the co-creation of experiences. They are not only mere identifiers facilitating the experience, but rich sources of "sensory, affective, and cognitive associations that result in memorable and rewarding brand experiences" (Schmitt, 1999a, p. 57). These brand experiences are subjective, internal consumer responses to brand-related stimuli, like sensations, feelings, emotions, and cognition (Brakus et al., 2009).

Experiential marketing and its techniques have so far mostly been discussed in the context of consumer markets. This can be explained with the focus on emotions, feelings and hedonic dimensions in $\mathrm{B}_{2} \mathrm{C}$, whereas traditionally the $\mathrm{B}_{2} \mathrm{~B}$ area is seen as more professional and rational (Rinallo et al., 2010). The existing research on experiential marketing in $\mathrm{B}_{2} \mathrm{~B}$ is mainly limited on trade shows as an important means of $\mathrm{B}_{2} \mathrm{~B}$ communication and event marketing (Kirchgeorg et al., 2010; Rinallo et al., 2010; Zarantonello \& Schmitt, 2013). The findings suggest that in that context, experiential marketing methods and tools developed in $\mathrm{B}_{2} \mathrm{C}$ can be and are applied in $\mathrm{B}_{2} \mathrm{~B}$ (Rinallo et al., 2010). Since the industrial buyer experiences in trade shows are instrumental, this preliminary understanding of experiential marketing in business markets is followed by a call for further research on other experiential marketing instruments and the determinants of their effectiveness, because some experiential marketing tactics that are based on autotelic activities and involve fantasies, feelings, and fun, and which work in consumer markets, may prove to be ineffective or even counter-productive in industrial environments (Rinallo et al., 2010).

Experiential value is defined as the value derived from an experience via interactions involving either direct usage or distanced appreciation of goods and services (Mathwick, Malhotra, \& Rigdon, 2001). This conceptualization is based on the work of M. B. Holbrook (1999), who presented a typology of consumer value designed to classify the types of value in the consumption experience along three continuous key dimensions: extrinsic vs. intrinsic value, self-oriented vs. other-oriented value, and active vs. reactive value (M. B. Holbrook, 1999). Holbrook introduced a relativistic view of consumer value, based on the notions of value being 1) comparative, as it involves a comparison among products and services, 2) personal, as it varies from person to person, and 3) situational, as it depends on the context of the experience (M. B. Holbrook, 1999). Largely based on Holbrook's seminal work, different experiential value sources or types have been identified (Gentile, Spiller, \& Noci, 2007; Schmitt \& Zarantonello, 2013; Tynan \& McKechnie, 2009; Varshneya, Das, \& Khare, 2017). We present an overview of experiential value dimensions in $\mathrm{B}_{2} \mathrm{C}$, going far beyond fantasies, feelings, and fun, in Table 3.3.

Research on experiential value in $\mathrm{B}_{2} \mathrm{~B}$ is limited. Based on both organizational and consumer value literature, recent explorative research in the $\mathrm{B}_{2} \mathrm{~B}$ context examined the value types created in the experience of visiting networking events (V.-W. Mitchell, Schlegelmilch, \& Mone, 2016). Visitors' perceived value in this event context, which is related to experiential marketing or visiting a brand world, comprise eight dimensions. They are presented in Table 3.4. These findings are in line with propositions, that a cross-fertilization between value models of $\mathrm{B}_{2} \mathrm{C}$ and $\mathrm{B}_{2} \mathrm{~B}$ will help to reciprocally fill gaps of understanding. For $\mathrm{B}_{2} \mathrm{~B}$, it is suggested to consider the role that emotions and individuals play in 
Table 3.3: $\mathrm{B} 2 \mathrm{C}$ experiential value dimensions

\begin{tabular}{|c|c|}
\hline $\begin{array}{l}\text { B2C EXPERIENTIAL } \\
\text { VALUE DIMENSIONS }\end{array}$ & AUTHORS \\
\hline Sensory & Agapito, Valle, and Mendes (2014), Schmitt (1999a, 1999b) \\
\hline Emotional & $\begin{array}{l}\text { Mathwick, Malhotra, and Rigdon (2001), Richins (1997), Sánchez, } \\
\text { Callarisa, Rodríguez, and Moliner (2006), Schmitt (1999a), Sweeney } \\
\text { and Soutar (2001) }\end{array}$ \\
\hline Functional / Utilitarian & $\begin{array}{l}\text { Arnould, Price, and Zinkhan (2004), Mathwick, Malhotra, and Rigdon } \\
\text { (2001), Sánchez, Callarisa, Rodríguez, and Moliner (2006), Sweeney } \\
\text { and Soutar (2001) }\end{array}$ \\
\hline Hedonic & Babin, Darden, and Griffin (1994), Varshneya and Das (2017) \\
\hline Relational & $\begin{array}{l}\text { Fournier (1998), Gainer (1995), Lusch, Vargo, and O'Brien (2007), McK- } \\
\text { echnie and Tynan (2008), Schmitt (1999a), Vargo and Lusch (2008) }\end{array}$ \\
\hline Social & $\begin{array}{l}\text { Andrews, Kiel, Drennan, Boyle, and Weerawardena (2007), Michaud } \\
\text { Trevinal and Stenger (2014), Sánchez, Callarisa, Rodríguez, and Mo- } \\
\text { liner (2006), Sweeney and Soutar (2001), Varshneya and Das (2017) }\end{array}$ \\
\hline $\begin{array}{l}\text { Cognitive / Informa- } \\
\text { tional }\end{array}$ & Poulsson and Kale (2004), Schmitt (1999a), Varshneya and Das (2017) \\
\hline Novelty & Poulsson and Kale (2004) \\
\hline Utopian & Maclaran and Brown (2005) \\
\hline Ethical & Varshneya and Das (2017) \\
\hline
\end{tabular}

Adapted from Tynan and McKechnie (2009), Varshneya, Das, and Khare (2017)

all stages of the buying decision process (Kemp, Borders, Anaza, \& Johnston, 2018), and to include more non-rational dimensions in the appreciation of perceived value (Mencarelli \& Rivière, 2015).

Although the possibility for $\mathrm{B}_{2} \mathrm{~B}$ companies to create flagship venues where customer visits can evolve into engaging branded experiences has also been mentioned in the literature (Gilmore \& Pine, 2002), and their emergence in business practice as outlined in Section 3.2.2, they have not so far attracted the attention of academia. To address this gap and understand the nature of this branding instrument and its experiential marketing techniques, how it is experienced and contributes to $\mathrm{B}_{2} \mathrm{~B}$, we investigate these brand worlds in the industrial marketing context.

\subsubsection{Phenomenological background}

In order to investigate and understand the nature of $\mathrm{B}_{2} \mathrm{~B}$ brand worlds and how they are experienced, we draw on the psychological stance of phenomenology, the primary focus of which are the questions of how we perceive, experience, and act in the world around us (Dourish, 2004), and which we therefore deem fruitful for the purpose of our research. Specifically, we focus on the concepts of embodiment and affordances, which we will briefly introduce here. These are not new, but have recently infused research in fields related to brand worlds, such as design (van Dijk, 2018), architectural experiences (Jelić, Tieri, de Matteis, Babiloni, \& Vecchiato, 2016), consumer and service experiences (Helkkula, Kelleher, \& Pihlström, 2012; Kelleher \& Peppard, 2011), and customer retail experiences (Yakhlef, 2015).

Current literature on experiences provides a thorough understanding of the internal, psychological, cultural, or environmental factors shaping an experi- 
Table 3.4: B2B experiential value dimensions in networking events

\begin{tabular}{|c|c|}
\hline $\begin{array}{l}\text { B2B EXPERIENTIAL } \\
\text { VALUE DIMENSIONS }\end{array}$ & DESCRIPTION \\
\hline $\begin{array}{l}\text { Leaning, epistemic, } \\
\text { and knowledge }\end{array}$ & $\begin{array}{l}\text { Value based on finding out information and practices to improve } \\
\text { activities or solve particular issues. }\end{array}$ \\
\hline Innovation & $\begin{array}{l}\text { Value which is derived from obtaining access to new markets and } \\
\text { technologies, pooling complementary skills, or speeding products to } \\
\text { markets. }\end{array}$ \\
\hline Professional & $\begin{array}{l}\text { A form of functional value which "translates into benefits for the } \\
\text { individual within the organization such as: gaining new customers, } \\
\text { business partners, suppliers which are mediated by that individual" } \\
\text { (V.-W. Mitchell, Schlegelmilch, \& Mone, 2016, p. 102). }\end{array}$ \\
\hline Reputation & $\begin{array}{l}\text { The value organizations or individuals derive from doing business } \\
\text { with high equity brands. }\end{array}$ \\
\hline Social & $\begin{array}{l}\text { Involving socializing and creating connections and relations that en- } \\
\text { hance the individual's social standing, rather than professional con- } \\
\text { nections. }\end{array}$ \\
\hline Relationship & $\begin{array}{l}\text { Seen on the individual level as "the value of knowing the person with } \\
\text { whom you on behalf of your company are transacting" (V.-W. Mitchell, } \\
\text { Schlegelmilch, \& Mone, 2016, p. 102). }\end{array}$ \\
\hline Emotional & An activation of emotions and feelings for the individuals \\
\hline $\begin{array}{l}\text { Hedonic, altruistic, en- } \\
\text { tertainment, service ex- } \\
\text { cellence }\end{array}$ & $\begin{array}{l}\text { Pleasure in the consumption is appreciated as an end in itself and } \\
\text { one's consumption behavior influences others. }\end{array}$ \\
\hline
\end{tabular}

Adapted from V.-W. Mitchell, Schlegelmilch, and Mone (2016)

ence (Berry \& Carbone, 2002; Bitner, 1990, 1992; M. B. Holbrook \& Hirschman, 1982; Verhoef et al., 2009; Yakhlef, 2015). Yet the role of the body, our medium for having a world, and the locus for actions and perceptions through which we relate to, enact, and experience our environment, is unaccounted for, and the body is instead seen as transmission device for perception, "ignoring its potential as the locus of an innovative interactive process between the agent and the environment" (Yakhlef, 2015, p. 554). In contrary to this cartesian dualism of cognitivism, which makes a strong separation between mind and body (Dourish, 2004), taking an embodied perspective means to understand the unified lived body, neither only the physical body nor the mind, as anchoring us in our environment (Merleau-Ponty, 1962). From an embodied perspective, perception, the activity of our senses, is not a window to cognition, but a bodily, emotional, and cognitive activity - perceiving is something that we actively do (Merleau-Ponty, 1962; Noë, 2006). Action, in turn, is the activity of our 'motor'-system. Embodiment implies a strong coupling between action and perception which are in constant coordination in the action-perception-cycle, so that the way people actually experience the world is dependent on this dynamic sensorimotor activity of the human organism as a whole (Jelić et al., 2016). In other words, "perception is for action, and action is for perception" (Cañal-Bruland \& van der Kamp, 2015, p. 63). This perspective makes the body necessary for experiencing the environment, including for example architecture or retail spaces, and emphasizes the intrinsic connection between these environments and human mind/body through action (Jelić et al., 2016; Yakhlef, 2015). 
With regard to this action, affordances are defined as possibilities for action which are provided to an 'animal' by its environment, as perceived by this animal (Gibson, 1986). In fields related to design, such as architecture or product design, the term affordances has been used to describe the functionality of designed artifacts in terms of the perceived usability by the user (e.g., the mobility and ergonomic properties of architectural elements and spaces) (Jelić et al., 2016). A further connection between designed affordances as action possibilities that can also invite behavior and the agent's capacities to perceive and engage with them has been put forward more recently than Gibson's original definition (Withagen, de Poel, Araújo, \& Pepping, 2012). Based on this, and the premise that affordances can be designed by, e.g., architects or other designers, the suggestion has been made recently that "people's experience of architectural environments is intrinsically structured by the possibilities for action, which is informed from both sensorimotor knowledge and motivational factors of every individual" (Jelić et al., 2016, p. 11).

\section{$3 \cdot 3$ METHODOLOGY}

\subsubsection{Expert interviews}

Given the exploratory nature of our research question, we applied a qualitative research approach using semi-standardized expert interviews to investigate the overall case of brand worlds in $\mathrm{B} 2 \mathrm{~B}$. This research method has previously proven purposeful in industrial marketing when there is scant or no existing information (e.g. Geiger, 2017; Keränen \& Jalkala, 2013), and has been deemed appropriate for research in exploratory stages (Bogner, Littig, \& Menz, 2009).

Since our goal was to gain a deeper understanding and orientation in the field of brand worlds, as well as to attain information exclusive to the experts, the interviews we conducted can be seen as a mixture of the exploratory and the systematizing variant of expert interviews (Bogner et al., 2009). Although the interviews are qualitative and explorative in nature, prior theoretical knowledge about the concepts in the area of research is fundamental (Flick, 2009). This knowledge can then be used to develop interview guidelines, while the openly formulated questions leave room for the experts to fill with their specific knowledge (Mayer, 2012). Due to the lack of literature on brand worlds in B2B, we focused on the $\mathrm{B}_{2} \mathrm{C}$ literature and the value sources of brand worlds that are described there (e.g. Borghini et al., 2009; Diamond et al., 2009; Gilmore \& Pine, 2002; Hollenbeck et al., 2008; Joy et al., 2014; Kozinets et al., 2002; Sherry, 1998; Sherry et al., 2001). Based on this prior knowledge, we developed our interview guidelines, specifically targeting the motives of operating B2B companies, the expectations and values that visitors have and derive, the constituting elements and specifics, as well as the perception of the $\mathrm{B}_{2} \mathrm{~B}$ brand worlds. Interview guidelines for all interviewee groups are provided in the Appendix in Sections A.2.1 - A.2.3.

\subsubsection{Sample}

To achieve a relevant and full understanding of brand worlds as an instrument of experiential marketing in business markets, we engaged with a compre- 
hensive and unique, multi-perspective sample. Adding to the perspective of operating companies, we triangulated our findings with samples of business visitors and exhibition designers to achieve a $360^{\circ}$ view on the co-created $\mathrm{B}_{2} \mathrm{~B}$ brand world experience, as depicted in Figure 3.1. ${ }^{1}$ In total, we base our research on 37 expert interviews with 44 informants.

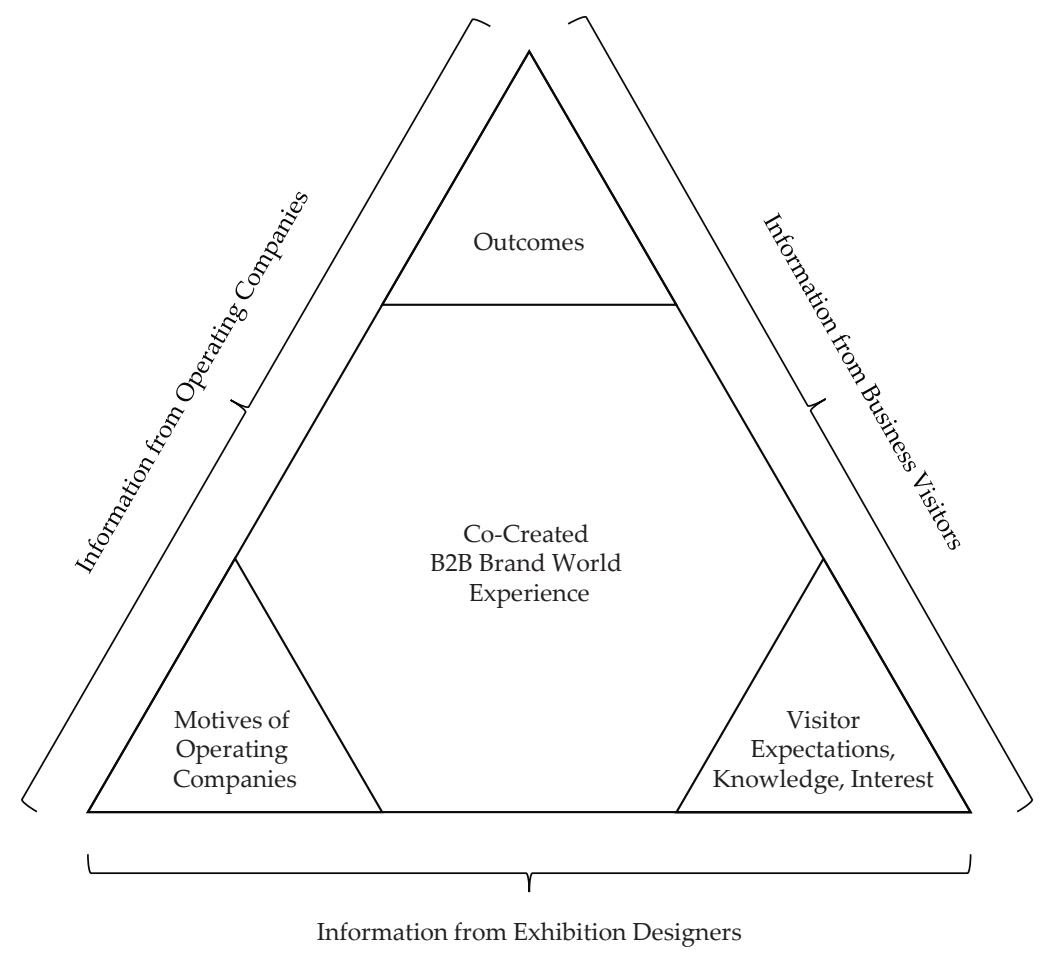

Figure 3.1: A $360^{\circ}$ view on co-created $\mathrm{B}_{2} \mathrm{~B}$ brand world experience

We carefully and thoroughly selected 17 companies operating B2B brand worlds, covering different industries and sizes from the US, Germany and Austria. We identified them through extensive online research and visiting practitioner conferences on experiential marketing and brand worlds. All participating companies operate different, outstanding, and innovative types of brand worlds - including for example Showrooms, Factory Tours, Visitor Centers, Customer Experience Centers, Museums, and Innovation Centers. One company was interviewed twice with different interviewees, because the firm operates two separate brand worlds in different locations with different goals. Where needed, we engaged both academic and private networks to establish a first contact with the selected companies via phone, and to introduce the research topic. We provided them with upfront information about the nature and the goal of the study via email. All informants were either directly

I We thank both reviewers for their suggestion to gather additional data. Especially valuable was reviewer 2's comment, that value is only perceived by the user, not the designer. This led to the addition of the visitors' and the exhibition designers' perspective, which proved to be valuable sources of additional information, helping us to improve, triangulate and validate our findings. 
managing the brand world or, if such a position did not exist, informants were closely related to the brand world and holding key informant positions such as Marketing Manager. Subsequently, we were invited to conduct 15 interviews on-site at the brand worlds and conducted three interviews by phone. In order to further ensure reliability and validity of our research, to put the interviews in context and enrich them, and to thoroughly get acquainted with all informants and components of the respective brand world, each on-site interview was preceded by an extensive tour throughout the entire brand world of roughly 1.5-2 $\mathrm{h}$. Due to the fact that the interviews were conducted directly after these extensive tours given to us by the respondents themselves, we could directly dive into the topic and start with the depth interview without the need to get acquainted during the beginning of the interviews. A detailed description of our sample of operating companies is provided in the Appendix in Table A.2.

To triangulate and enrich our findings from the company sample, and to answer our research questions regarding the expectations that business visitors have towards $\mathrm{B}_{2} \mathrm{~B}$ brand worlds and the value they derive from their $\mathrm{B}_{2} \mathrm{~B}$ brand world experience, we also conducted 14 expert interviews with business visitors of $\mathrm{B}_{2} \mathrm{~B}$ brand worlds. Informants are employed by 13 different companies in various industries and act in various buying center roles. They have visited at least one, some also several $\mathrm{B} 2 \mathrm{~B}$ brand worlds in a role as a business visitor recently before the interviews. To establish first contact, we engaged with them via the previously mentioned operating companies, or academic and private networks. 13 of the interviews were subsequently conducted via phone, one face-to-face. We provided informants with upfront information about the nature and the goal of the study, therefore we could directly start with the deep interview phase after giving another short introduction prior to the interview. A full, detailed description of our sample of business visitors is provided in the Appendix in Table A.3. To additionally triangulate and validate our findings with a third, supplementary point of view, we conducted five more interviews with exhibition designers in managing positions at different exhibition design or marketing and brand agencies. This sample was chosen based on the extensive experience of the respective informants in designing and implementing various types of brand worlds for numerous companies in both the consumer and business marketing area. We established contact, introduced ourselves and informed the respondents about the research project upfront via email and phone. Subsequently, two interviews were conducted by phone, and three interviews were conducted at the informants' offices. A full overview of our sample of exhibition designers is provided in the Appendix in Table A.4.

The overall average net duration of our interviews was 47 min of deep and relevant discussion. The overall average phone call duration was $53 \mathrm{~min}$. The overall average visit duration for on-site interviews at brand worlds or faceto-face interviews with visitors and exhibition designers was $2 \mathrm{~h}$ and $58 \mathrm{~min}$. We fully transcribed all interviews and presented them to the interviewees afterwards for validation. Where necessary, we translated the statements quoted in this study into English. 


\subsubsection{Qualitative content analysis}

We analyzed the interview material using the method of qualitative content analysis, which is a systematic, rule-bound mixed-method approach (Mayring, 2014). Specifically, we used the technique of inductive category formation to arrive directly at summarizing categories coming from the material itself, and not from theoretical considerations (Mayring, 2014). This approach is similar to Grounded Theory, yet "more systematic" (Mayring, 2014, p. 79). The a priori definitions of what the relevant parts of the material are, as well as the level of abstraction, are crucial to the analysis and are derived from the research questions (Mayring, 2014). Based on the aim of our qualitative approach, we included all material covering goals, expectations, value derived from the $\mathrm{B}_{2} \mathrm{~B}$ brand world experience, the success factors, and differences between $\mathrm{B}_{2} \mathrm{C}$ and $\mathrm{B}_{2} \mathrm{~B}$ brand worlds as relevant parts in the analysis. During the analysis process, we implemented several measures to ensure reliability and validity of our findings. We used a qualitative data management and analysis program (MaxQDA) and handled all interview transcripts with ultimate care. Two coders analyzed all data material separately, following established procedures developed for the inductive category formation technique of qualitative content analysis (Mayring, 2014). The process involves revising the emerging categories after approximately $50 \%$ of the content analysis, to arrive at a final category structure. We also investigated whether a revision of the initial coding definitions and instructions was necessary, but no issues arose during the coding process. We subsequently merged the codings based on thorough discussions between coders regarding the interpretation and categorization of individual informant statements, as well as a peer debriefing with other researchers not involved in the study (Corley \& Gioia, 2004). Additionally, exemplary informants' statements demonstrate the plausibility of our results and are presented in the Appendix in Section A.2.5.

\subsection{RESULTS}

The goal of this study is threefold. First, to answer the question of why, to investigate the motives of industrial companies to implement a brand world, and to identify expectations $B_{2} B$ visitors have, and the value they derive from the experience of a $\mathrm{B}_{2} \mathrm{~B}$ brand world visit; Second, to answer the question of what, to understand the nature of the $\mathrm{B}_{2} \mathrm{~B}$ brand world and what it is constituted of; and third, to answer the question of how, to investigate how the $\mathrm{B} 2 \mathrm{~B}$ brand world is perceived and how the experience is co-created.

\subsubsection{Motives of companies operating $B 2 B$ brand worlds}

With respect to why $\mathrm{B}_{2} \mathrm{~B}$ companies operate brand worlds, our research revealed 18 different motives. Not all of them are relevant for each type of $\mathrm{B}_{2} \mathrm{~B}$ brand world. We classified these motives based on the order of nomination by the informants, and the number of informants mentioning the specific goal. The most important goals that $\mathrm{B}_{2} \mathrm{~B}$ companies pursue with their brand worlds are product awareness, brand associations, brand awareness, and product experiences. 
Product awareness is the extent to which someone is aware of and familiar with a company's products and services, either through direct exposure or marketing efforts (Collins, 2007). Especially for organizations with a broad product portfolio, the $\mathrm{B} 2 \mathrm{~B}$ brand worlds are an effective way to provide not only the visitor, but also own employees with a full overview and knowledge of the company's offering, and to showcase both already existing as well as new products.

Brand associations refer to three distinct perspectives on the brand (D. A. Aaker, 1996b): brand-as-product (value), brand-as-person (personality), and brand-as-organization (organizational associations). The brand-as-product perspective involves functional benefits and focuses on the value proposition of the brand; the brand-as-person perspective establishes a link to the brands emotional and self-expressive benefits, and is a basis for differentiation and customer relationships; the brand-as-organization perspective, also often an important differential factor, considers the organization and its people, values, and programs which lie behind the brand, and shows that a brand represents more than products and services. It includes "having a concern for customers, being innovative, striving for high quality, being successful, having visibility, being oriented toward the community, and being a global player" (D. A. Aaker, 1996b, p. 113). All of these dimensions, but especially brand-as-person and brand-as-organization are important goals of $\mathrm{B} 2 \mathrm{~B}$ brand worlds, since $\mathrm{B}_{2} \mathrm{~B}$ business involves a high level of personal interaction and trust in those individuals and their organizations. Brand worlds, in which dedicated one-on-one time is spent with the customer, from several hours up to sometimes several days in the case of trainings in the brand world, are a unique way to create those positive brand associations for the customer, and also strongly support internal and employer branding purposes.

Product experience refers to the vivid, personal use of products, to trying them out and experiencing their capabilities first-hand (Hoch, 2002). These live experiences of touching and trying the products in a $\mathrm{B} 2 \mathrm{~B}$ brand world directly convey their value-in-use, and additionally entail a sense of excitement, joy, play, and experiential learning for the visitor, be it an engineer, a purchaser or the user of the product.

Brand awareness is "the ability for a buyer to recognize or recall that a brand is a member of a certain product category" (D. A. Aaker, 1996b, p. 61). It includes knowing what the brand stands for and having an opinion about the brand (D. A. Aaker, 1996b). For several B2B companies this is a top goal they pursue with their brand worlds, closely linked to product awareness. Informants stated for example that most purchasers know the specific product category that they are buying quite well but sometimes not in full depth; that they are not aware of the full breadth of the offerings of the company; or that they link the company to only one specific product category that they might already be buying. Brand worlds serve as a means to widen and deepen the visitor's understanding of the company's offerings, and to create awareness for companies which are sometimes perceived as niche brands but are in fact global players.

Table 3.5 presents further motives that operating companies pursue with B2B brand worlds, such as visitor's perceived quality/leadership of the brand, customer loyalty, the integration of the customer into business processes in the form of co-creation, initiating and enhancing customer relationships, initiating 
and closing sales, or internal and employer branding. They mostly build on the four aforementioned goals. For exemplary informant statements we refer to Table A.5 in the Appendix.

Table 3.5: Motives of companies operating B2B brand worlds $(n=18)$

\begin{tabular}{|c|c|c|c|c|c|}
\hline FIRST NOMINATION & $\#$ & SECOND NOMINATION & $\#$ & THIRD NOMINATION & \# \\
\hline Product Awareness & 8 & Brand Associations & 6 & $\begin{array}{l}\text { Initiate customer rela- } \\
\text { tionship }\end{array}$ & 4 \\
\hline Brand Associations & 6 & Product Experience & 4 & Initiating sales & 3 \\
\hline Brand Awareness & 5 & $\begin{array}{l}\text { Perceived Quality / } \\
\text { Leadership }\end{array}$ & 3 & Closing sales & 3 \\
\hline Product Experience & 4 & Product Awareness & 1 & Brand Associations & 2 \\
\hline Customer Integration & 1 & Customer Integration & 1 & Product Awareness & 2 \\
\hline Customer Loyalty & 1 & Customer Loyalty & 1 & $\begin{array}{l}\text { Perceived Quality / } \\
\text { Leadership }\end{array}$ & 2 \\
\hline $\begin{array}{l}\text { Product Development } \\
\text { and Testing }\end{array}$ & 1 & $\begin{array}{l}\text { Enhance customer rela- } \\
\text { tionship }\end{array}$ & 1 & $\begin{array}{l}\text { Employer / Internal } \\
\text { Branding }\end{array}$ & 2 \\
\hline \multirow[t]{6}{*}{ Transparency } & 1 & $\begin{array}{l}\text { Initiate customer rela- } \\
\text { tionship }\end{array}$ & 1 & $\begin{array}{l}\text { Enhance customer rela- } \\
\text { tionship }\end{array}$ & 2 \\
\hline & & Initiating sales & 1 & Product Experience & 1 \\
\hline & & $\begin{array}{l}\text { Employer / Internal } \\
\text { Branding }\end{array}$ & 1 & Customer Integration & 1 \\
\hline & & $\begin{array}{l}\text { Proving marketing } \\
\text { claims }\end{array}$ & 1 & Brand Awareness & 1 \\
\hline & & Differentiation & 1 & & \\
\hline & & $\begin{array}{l}\text { Provide a branded expe- } \\
\text { rience }\end{array}$ & 1 & & \\
\hline
\end{tabular}

\subsubsection{Expectations of business visitors of $B 2 B$ brand worlds}

The expectations of business visitors regarding their visit to a $\mathrm{B} 2 \mathrm{~B}$ brand world, i.e. the reasons why prior to the visit, focus on the generation of knowledge, related to the products and the operating company itself. Visitors expect to learn something new or understand something that they would not be able to understand or learn without the brand world visit, and they largely expect that this curiosity and thirst for knowledge are satisfied in a pleasant and appealing atmosphere.

This means that business visitors for example want to get to know the whole range of products and services the operating company has to offer, try the products themselves or see the products in use. Visitors also expect to see the products in a larger context, if possible, e.g. some application examples of where and how the product can be used, or to be shown how an industrial product relates to their day-to-day private life. Additionally, visitors want to be able to easily and quickly understand the technical functions and added value of complex products and services, and get some background information on the products, such as where and how they are produced, or what materials are used.

Visitors also want to get to know better the operating company, based on information such as current facts and figures on employee numbers, turnover, 
target markets, and main pillars and competencies of the company. Additionally, information on the history of the company as well as an outlook on the future development are expected, as well as references such as other major customers. Visitors also expected to get to know the corporate culture and expected to see, whether what is shown during the brand world visit matches their daily experiences in their business relationship with the operating company.

Interestingly, several business visitors also expected an emotionally appealing or even entertaining character of the brand world visit, even in the $\mathrm{B}_{2} \mathrm{~B}$ context, in a way that positive emotions such as excitement or even fun are elicited. Additionally, in general business visitors expect to feel valued by the operating company and to have a sense of wellbeing during their visit. For a full list of categories of business visitors' expectations and exemplary informant statements, we refer to Table A.6 in the Appendix.

\subsubsection{Value of the experiences at $B 2 B$ brand worlds for $B 2 B$ visitors}

Based on our analysis, we found several types of value that business visitors derive from their $\mathrm{B}_{2} \mathrm{~B}$ brand world visits, i.e. answers to the question of why they go to $\mathrm{B}_{2} \mathrm{~B}$ brand worlds subsequent to their visit. Our research shows that several specifics emerge in comparison to the value types created in $B_{2} B$ networking events as outlined in Section 3.2.3. At the same time, it shows that, bearing in mind these specifics, those general value types can be transferred to the related experiential marketing area. An overview of informants' statements supporting our findings, exemplary subordinate value dimensions, and all superordinate value dimensions is given in the Appendix in Table A.7

Little surprisingly, the learning, epistemic and knowledge value of the $\mathrm{B}_{2} \mathrm{~B}$ brand world experience plays the most important role for the respondents, alongside the closely related professional value they derive for their daily business activities from this knowledge or information. Basically, the visit to a brand world should not primarily be autotelic, meaning an end in itself, but instead value is derived from the brand world experience if it helps the visitors in their jobs. This includes gathering and generating new knowledge and information for the visitor; getting information about the company, its history, origin and vision; theoretical information about a company's products and offerings; application examples that make it possible for the visitor to grasp the functions and benefits of a complex or abstract product quickly; and also practical product trainings for users are sources of value, that are instrumental and functional in nature, and support the visitors in their daily business. In short, visitors derive value if the visits serve their business goals.

A very interesting finding though is, that business visitors also derive value from the more emotional aspects of the brand world experience. If the visit entails a sense of edutainment or infotainment, or the exhibits are linked to everyday life, this also makes it easier and more engaging for the visitor to understand otherwise complex or abstract products or services. These senses of enthusiasm, fascination for and emotional bond with products derived from these emotional encounters make it also easier for visitors to remember the features and benefits of products and services, and thus support or maybe even influence the decision-making process. Additionally, in a form of escapism, one respondent who is in the role of the user of $\mathrm{B} 2 \mathrm{~B}$ products, states that it is also 
sometimes simply nice and enjoyable to get out of the daily business and see something different and new.

Furthermore, visitors derive value from the relational dimension of the experience. Based on the time spent together in the brand world, the information about the company, its heritage, and competence, and the quality and benefits of its products that are presented there, the visit enables them to establish or strengthen a relationship and trust with the organization as a whole, but equally important with their contact persons and other individuals within that organization.

Interestingly, the hedonic, altruistic, entertainment, service excellence value dimension, which targets the experience as an end in itself, also played a role for several business visitors of $\mathrm{B}_{2} \mathrm{~B}$ brand worlds. For example, visitors derive value and a form of pleasure and fascination from the appreciation of well designed and engineered products which are on exhibition, either as a whole or as cutaway models, which allow for a more detailed examination of the way a product works. Additionally, 'wow effects' can be created by architectural or design elements which might be linked to the heritage or the products of a company, or simply by the first-hand experience created by the use of the products, or also by getting to know the overall heritage of industrial companies. At the same time though, respondents also state that they did not perceive the brand world as a kind of tourist attraction in the sense of some $\mathrm{B}_{2} \mathrm{C}$ brand worlds and made the humoristic overstatement that they would not have made the way to the $\mathrm{B}_{2} \mathrm{~B}$ brand world to spent some time there in private on a Saturday.

The innovation value business visitors derive from a brand world visit is based on the presentation of new products and also the full breadth and depth of products. Several respondents stated that in the brand world they saw products that they were not aware of, and which would help either them directly or also colleagues or their whole organization in their business endeavors.

The reputation, status, esteem, branding value dimension only played a minor role, with two respondents stating that the knowledge and product awareness generated in the brand world and the relationship with the operating company would help them to further differentiate themselves from their own competitors.

Similarly, social value was only mentioned by two respondents stating that they told their friends and family about the visit. A sense of community or enjoyment of the visit together with peers, as is the case for $\mathrm{B}_{2} \mathrm{C}$ brand worlds, was not mentioned by our respondents.

\subsubsection{The nature of the B2B brand world}

\subsubsection{1 $\quad B 2 B$ brand world contents}

Our respondents have stated in various ways, that the development of a brand world begins with what is supposed to be conveyed there: the content of the $\mathrm{B}_{2} \mathrm{~B}$ brand world. This content, which is based on information, stories, images, and other resources, has to be first investigated and then defined in detail, and should then transform into a common, golden thread leading through the brand world. It is influenced both by the motives of operating companies, as well as the expectations, knowledge, skills, and interests of the visitor. Very much in contrast to $\mathrm{B}_{2} \mathrm{C}$ brand worlds, where consumers are driven by and expect hedonic aspects, and where visits take place fully unrelated to specific purchase 
intentions and are based completely on the own intention to visit, business visitors to $\mathrm{B}_{2} \mathrm{~B}$ brand worlds are motivated by and expect more utilitarian aspects. Their visits are usually related to specific purchasing intentions or an already existing customer-brand relationship, in the process of which they are invited by the operating company to a company visit. In fact, they often do not visit the company to 'visit the brand world', but to conduct their general business activities, such as meetings, workshops, negotiations, audits, relationship maintenance, or trainings. The $\mathrm{B}_{2} \mathrm{~B}$ brand world is then rather used by the operating company as a three-dimensional 'business card', a tool where the company presents itself at a glance, or as a complementary instrument to provide the visitor with either an additional experience to present a positive, credible image, or as an extraordinary and stimulating location in which, by the provision of additional, unique information, mutual value is created and where these business activities take place. Yet, since the aforementioned expectations vary from individual to individual, the content of the visit should be highly contextual and individualized, and the focus of the entire visit should not be on presenting the company or the brand, but on the visitors, their needs, and the company's ability to satisfy those needs. Thus, the brand world visit and its content have to be easily modifiable for the demands and needs of several target groups, be them customers and their purchasing agents or product users, marketing or sales agents, top level managers, own employees or potential employees, or media and press or governmental institutions. Accordingly, high flexibility is needed to cater to the needs of the visitors, which are based on the social situatedness of the individual visitors or their organization, e.g. whether a prior relationship to the brand or the individual employee or guide of the operating company exists.

Bearing in mind this different contextual setting for the B2B brand world, several common themes have been mentioned by our respondents as content that should be conveyed in order to provide a successful B2B brand world visit for all actors involved. First of all, the brand world and its content provide the possibility to experience the brand, its core and values 'in-vivo' by making it tangible. Therefore, at the heart of the visit are the themes that define the brand, that make it special, and that also differentiate it from its competitors. By displaying the competency and ability of the brand and its products throughout history, present, and future on the one hand, and by offering an authentic, honest, consistent, and transparent view on the brand on the other hand, a certain level of trust in the operating company can be established. Furthermore, what is part of the golden thread leading through $\mathrm{B}_{2} \mathrm{~B}$ brand worlds, is the notion of positioning the brand as the right partner for the visitor, by displaying that one understands the visitors needs and problems and is also able to solve them. Furthermore, in order to fulfill the visitors needs for the visit to support them in their business activities, the content should be woven into an educational process, in which the deep, detailed, and precise explanation of technically complex products, for example by means of exemplary use cases, or in other easy and even ludic ways, play an important role. An important part of this process is also to relate the brand and its product, which might be very abstract, to the visitors daily life, to facilitate their understanding of and identification with the brand and its products. The education about the whole breadth and depth of the company's offering is also content useful for the visitors. The brand world visit should additionally provide information which 
is unique and goes beyond the content of the brands webpage. Furthermore, an important part of the content of the brand world, given its more influential role in $\mathrm{B}_{2} \mathrm{~B}$ and more complex products and services, is the personal interaction with employees of the operating company, through which the brand can actually be given a face. In its own brand world, the operating company and its employees have the chance to spend focused, face-to-face time with the business visitors Therefore, $\mathrm{B}_{2} \mathrm{~B}$ brand worlds are guided experiences, so that visitors are always accompanied by a contact person representing the brand, elaborating on the exhibits, and building a relationship with the visitors. This goes along with a much more customized visit, in which the specific areas of interest of the business visitors are discussed in much more detail and depth. At the heart of this personalized visit is also to make the visitors feel special, appreciated, and esteemed by the operating company. Furthermore, although in a $\mathrm{B}_{2} \mathrm{~B}$ context, respondents also stated that the content of the brand world should emotionalize, fascinate, and immerse the visitors - less with a hedonic goal, but more in order to support remembrance, and to evoke more serious kinds of emotions, such as trust, credibility, authenticity and reassurance. Nevertheless, also edutaining contents play an increasing role according to our respondents. Supportive informant statements on the $\mathrm{B}_{2} \mathrm{~B}$ brand world content can be found in the Appendix in Table A.8.

\subsubsection{2 $\quad$ B2B brand world experiencescape}

The contents of the $\mathrm{B}_{2} \mathrm{~B}$ brand world manifest in the $\mathrm{B}_{2} \mathrm{~B}$ brand world experiencescape. Experiencescapes are "the spaces in which experiences are staged and consumed [that] can be likened to stylized landscapes that are strategically planned, laid out, and designed. They are, in this sense, landscapes of experience" (O'Dell, 201ob, p. 16). This experiencescape comprises physical artifacts and spaces on the one hand, and the social environment and practices on the other. Both contribute to convey the contents outlined above and are the answer to the question of what the $\mathrm{B}_{2} \mathrm{~B}$ brand world consists of.

Respondents state that, in order for the artifacts and spaces which constitute the brand world physically to convey the content, they are tangible embodiments of the brand itself. The way the content is presented has to fit the brand and its spirit to provide the visitors with an authentic, and consistent image. Furthermore, the artifacts and spaces have to create an emotionally appealing, intriguing, also surprising and immersive atmosphere, and they do this by experiential techniques which appeal to all the visitors' senses of sight, hearing, taste, smell, and touch within the brand world space. Overall, respondents stated that the physical $\mathrm{B}_{2} \mathrm{~B}$ brand world space is and should be contemporary, up-to-date, and clean, as all physical aspects reflect on the brand operating the premises. Given the professional background of $\mathrm{B}_{2} \mathrm{~B}$ visitors, the artifacts and spaces are, compared to their $\mathrm{B}_{2} \mathrm{C}$ counterparts, also characterized by a generally less exhaustive orchestration, staging and hyperbolism, following the conviction of 'less is more,' and instead focusing on the relevancy for the visitor, the ease of use and the raisons d'être of each exhibit. This physical embodiment of the brand and its spirit in the $\mathrm{B}_{2} \mathrm{~B}$ brand world experiencescape culminates in what one respondent called the 'genius loci,' which is both related to the physical location of the $\mathrm{B}_{2} \mathrm{~B}$ brand world, and the designed artifacts and spaces. Regarding the location, the $\mathrm{B}_{2} \mathrm{~B}$ brand worlds are, also in contrast to many of 
their $\mathrm{B}_{2} \mathrm{C}$ counterparts such as showrooms and flagship stores, mainly situated either at locations linked to the heritage of the brand, as the founding site or the site of important inventions, or at the corporate headquarters. Both locations already imply a special feeling of visiting the origins or the roots of the brand, and as such contribute to the overall experience. Regarding the designed artifacts and spaces, these are often not only mere functional instruments to convey the content but are designed in such a way that makes linkages to the brand's core, heritage, products, or the production facilities, and thus they also contribute strongly to the overall experience within the brand world.

Regarding social environment and practices, these also represent the brand, and are designed to a certain extent by the operating company in form of behavioral branding, and the corresponding behavior of employees towards the visitors. In general, the brand world and its contents have to be 'lived' by the employees, and respondents stated that, at first glance quite generic or obvious behaviors and aspects, such as competence, friendliness, passion, professionality and again the focus on the visitors and their needs by the brand world's employees or guides are important for delivering a consistent picture. But given the more influential role of personal interaction and more complex products and services in $\mathrm{B}_{2} \mathrm{~B}$, this explicit expression of the importance of the social environment makes sense. This also leads to $\mathrm{B}_{2} \mathrm{~B}$ brand worlds being mostly guided experiences, so that visitors are always accompanied by either their specific contact person within the company, representing the brand, elaborating on the exhibits, and building a relationship with the visitors, and/or a specific guide for the brand world. This goes along with a much more customized visit, in which the specific areas of interest of the business visitor are discussed in much more detail and depth. Additionally, for visitors it is an important aspect to not only get to know their sales person better, but also to personally meet with and getting to know other employees such as for example product managers, sales managers, or service or internal sales support employees, that they normally only communicate with via email or phone. Supportive informant statements on the $\mathrm{B}_{2} \mathrm{~B}$ brand world experiencescape can be found in the Appendix in Table A.9

\section{$3 \cdot 5$ DISCUSSION AND CONCLUSION}

\subsubsection{Understanding the nature of $B 2 B$ brand worlds and how they are experienced}

Brand worlds as the apex of branding, which use experiential marketing techniques, have made their way from the consumer area into business marketing practice. Given the different $\mathrm{B}_{2} \mathrm{~B}$ context (B. P. Brown et al., 2007), the direct transfer of theories, frameworks, and knowledge from $\mathrm{B}_{2} \mathrm{C}$ to $\mathrm{B}_{2} \mathrm{~B}$ should be approached with caution. In order to understand the nature and phenomenon of brand worlds in the $\mathrm{B}_{2} \mathrm{~B}$ context and how they are experienced, we conducted exploratory empirical research with the goal to get a comprehensive view on brand worlds, and interviewed operating companies, exhibition designers, and business visitors. We now synthesize and interpret our findings and summarize our comprehensive view on $\mathrm{B} 2 \mathrm{~B}$ brand worlds in Figure 3.2.

In $\mathrm{B}_{2} \mathrm{C}$, when visiting a brand world, consumers are driven by and expect hedonic aspects. Consumer visits take place fully unrelated to specific purchase 
intentions and are based completely on consumers' own intentions to visit. In contrary, business visitors to $\mathrm{B}_{2} \mathrm{~B}$ brand worlds are motivated by and expect more utilitarian aspects. Their visits are usually related to specific purchasing intentions, initial business contacts, or an already existing customer-brand relationship, in the process of which they are invited by the operating company to a company visit. In fact, they often do not visit the company to 'visit the brand world', but to conduct their general business activities, such as meetings, workshops, negotiations, audits, relationship maintenance, or trainings. Looking at the what, namely what the $\mathrm{B} 2 \mathrm{~B}$ brand worlds consists of, its contents and the experiencescape, and further to its nature and what its purpose is in $\mathrm{B}_{2} \mathrm{~B}$, our research shows that against this professional background, it is used by the operating company as a 'business card,' a tool where the company presents itself, its core, values, identity and products at a glance for the visitors to experience. It is a complementary instrument to provide the visitors with either an additional experience to present a positive, credible image, or as an extraordinary and stimulating location in which, by the provision of additional, unique information and the possibility to experience the brand, its products and employees 'in-vivo', mutual value in the form of learning, epistemic, and knowledge, relationship, or professional value is created. Based on these relevant experiences they provide for the visitors, $\mathrm{B}_{2} \mathrm{~B}$ brand worlds are the ideal locus for or complementation to such business activities related to specific purchasing intentions, initial business contacts, or the deepening of an already existing business relationship. Looking at the why, our respondents stated that for conveying the brand's identity and portfolio in all its breadth and depth, and for the visitors to getting to know the operating company in this breadth and depth, the instrument of brand worlds is superior to any other marketing instrument based on the direct experience it provides:

"For the breadth that [the brand] has, this is a very quick way to see just how much our company can do, is capable of, how diverse our portfolio is. [...] I think [...] that this space gives that picture more effectively than anything I can think of off the top of my head." (Cara, operating company)

Reflecting on Carù and Cova's (2007) continuum of experiences - ranging from constructed by the consumer, through co-created by consumer and organization, to largely constructed by the organization - the experience at $\mathrm{B}_{2} \mathrm{~B}$ brand worlds can clearly be described as co-created by both the organization and the visitors. Looking at the underlying mechanism of how these experiences are co-created, two things are at the core of the $\mathrm{B}_{2} \mathrm{~B}$ brand world experience itself: the brand world experiencescape, reflecting the company's contribution to the co-created $\mathrm{B}_{2} \mathrm{~B}$ brand world experience; and the embodied cognition of the $\mathrm{B} 2 \mathrm{~B}$ brand world, reflecting the visitors' contribution to how they experiences the $\mathrm{B}_{2} \mathrm{~B}$ brand world. The experiencescape and its physical artifacts and spaces and social environments and practices are manifestations of the motives that the operating company wants to achieve with the content they provide to their visitors in their brand world. The success of brand worlds in general is based on the fact that these experiencescapes are largely controlled by the manufacturer itself, where the operating company can holistically and vividly present its brand (Kozinets et al., 2002). However, respondents stated that if they do not deem the information and content provided during the visit as 
relevant and useful for them, then this decreases their perceived experience in the $\mathrm{B}_{2} \mathrm{~B}$ brand world. A key finding of our research therefore is, that in order to address the varieties of different buying center members and to explain complex products, the visits have to be tailored to the specific expectations, levels of knowledge, skills, and interests of each individual visitor. On the other hand, if the brand world visit is relevant and useful for the visitors, and if it thus supports the visitors in their business activities, this leads to an enhanced brand world experience. Therefore, the operating companies tailor the content of the experience either a priori or ad-hoc during the visit, with the help of guides and interactive, multifunctional exhibits and spaces, to the specific needs of the visitors, and largely focus on those products and information, that the visitors are really interested in. Therefore, one can say that not only the motives of the operating company, but also the expectations, knowledge, skills, and interests of the visitors influence the content of the $\mathrm{B}_{2} \mathrm{~B}$ brand world visit, and it is at this point of the co-creation of the $\mathrm{B} 2 \mathrm{~B}$ brand world experience, where a first alignment between motives of the operating company and the expectations of the visitors takes place. The content then becomes manifest in the core of the $\mathrm{B}_{2} \mathrm{~B}$ brand world, the experiencescape, comprising the designed artifacts and spaces, which constitute the physical premises of the $\mathrm{B}_{2} \mathrm{~B}$ brand world, as well as the social environment and practices of employees and their behaviors at the $\mathrm{B}_{2} \mathrm{~B}$ brand world.

The involvement, immersion and interaction of the consumers with their physical environment is a part of the co-creation of extraordinary experiences (Kozinets et al., 2004). Furthermore, branding in business markets essentially is a form of communicative interaction (Ballantyne \& Aitken, 2007); especially the deep, personal interactions between employees, customers, and stakeholders evoke the co-creation of branded experiences, and are a key factor for establishing business relationships. From a phenomenological perspective, both the artifacts and spaces as well as the social environment and practices of the $\mathrm{B}_{2} \mathrm{~B}$ brand world experiencescape provide affordances for the embodied visitors to act upon and perceive, based on the application of a multitude of experiential marketing techniques which focuses on various senses. How the individual visitor does act upon and perceive these affordances is again influenced by their expectations, level of knowledge, skills, and interests. A key finding of our research is, that through their action and perception on these affordances, the visitors in turn interact with and influence both these physical artifacts and spaces, as well as the social environment. This thus leads to a joint action-perception cycle, through which the experience of the visitors at the $\mathrm{B}_{2} \mathrm{~B}$ brand world is co-created between the visitors themselves and the $\mathrm{B}_{2} \mathrm{~B}$ brand world experiencescape. Therefore, a second alignment between the operating company's motives, as expressed in the content provided through the experiencescape, and the visitors expectations takes place in this joint action-perception cycle and interaction between visitors and experiencescape. This interaction and relationship-building with subjects (i.e. the brands employees), as well as the interaction with, perception with all senses of, and immersion in the environment leads to further engagement, a personalization and co-production of the $\mathrm{B}_{2} \mathrm{~B}$ brand world experience and facilitates learning and relationship-building in the brand world. In essence, it is how the $\mathrm{B} 2 \mathrm{~B}$ brand world experience itself, and the value in it for both parties, is co-created. 
Further key findings of our research are that the factors relevancy, authenticity, and emotion directly influence this interaction between experiencescape and visitors, and as such the entire co-creation of the $\mathrm{B} 2 \mathrm{~B}$ brand world experience. As described before, the visitors have to get a functional and instrumental benefit from the brand world experience, which helps them in their business activities. Therefore, the content of the visit should be highly contextual and individualized, and the $\mathrm{B}_{2} \mathrm{~B}$ brand world has to be easily modifiable for the demands and needs of several target groups, be them customers and their purchasing agents or product users, marketing or sales agents, top level managers, own employees or potential employees, or media and press or governmental institutions. As a consequence, also all the exhibits have to serve a deeper purpose of information or education and should not be an end in themselves. The more authentically, open, and honest the brand's characteristics and identity are presented, and the more consistent this presentation in the brand world is with other brand communication instruments, and the visitors experiences with the brand in daily business, the more intense and credible is the brand experience for the visitors. If the picture that is drawn of the brand in the brand world is not authentic, inconsistent with visitors' prior experiences with the brand and its employees in their daily lives, or if information provided seems unrealistic, then the visitors feel deceived. Both relevancy and authenticity are cognitive perceptions and evaluations of what the company contributes to the co-creation of the experience, namely the content as manifested in the $\mathrm{B} 2 \mathrm{~B}$ brand world experiencescape. This evaluation is situated in the visitors. It is only possible through interaction with the experiencescape, and also influences this interaction and thus the co-creation of the entire B2B brand world experience, and the value the experience has for the visitors. If the brand world experience is not perceived as being relevant to the business visitors they derive less or even no value from it, and the visit is useless to them. Regarding this value, respondents describe $\mathrm{B}_{2} \mathrm{~B}$ brand worlds as even more effective as trade shows in presenting an overview of the full product range on offer and getting to know the brand. Providing the visitors with a real, lived experience with the brand and its products is crucial for $\mathrm{B}_{2} \mathrm{~B}$ brand worlds. The interesting and exciting experiences, encounters, interactions, and activities that $\mathrm{B}_{2} \mathrm{~B}$ brands provide in these locations - not only to externals but also to employees - simplify understanding, learning, and remembrance for the visitor. Similarly, if the overall experience in the $\mathrm{B} 2 \mathrm{~B}$ brand world is not perceived as being authentic or trustworthy, it diminishes the value derived from the experience for the visitor.

In contrast to relevancy and authenticity, emotions are not a cognitive evaluation, but affective responses to external stimuli such as adaptive problems (Ekman, 1992; Plutchik, 1980). Thus, they are not an evaluation of the company's offering in the brand world, such as perceived relevance or authenticity, but affective responses to both the co-creation composites of the company and the visitors. Since emotion and experience are two closely related concepts, emotion is a key factor for a positive experience also in $\mathrm{B}_{2} \mathrm{~B}$ brand worlds. This emotionality is less strongly pronounced compared to $\mathrm{B}_{2} \mathrm{C}$ brand worlds, but still an important aspect. These emotions entail for example a general emotional appeal, a sense of well-being and appreciation of the visitors by the operating company, communication on eye-level, but also wow-effects and fascination, for example in combination with architecture and design which 
have to represent the brand. Such emotional aspects do play an important role as a factor influencing the interaction between experiencescape and visitors, even in the business context. Engineers or technically interested visitors do react emotional, with joy or a sense of entertainment and enthusiasm, if they have the possibility to interact and get involved with the environment in the brand world, if they can try out, play with, and experience products. These emotions in turn lead to a more positive experience of the brand world. Also, the perception of impressive architecture or the interaction with employees can lead to positive emotional responses. Similarly, if employees behave in an unpleasant or unprofessional way, the premises do not meet the visitors' expectations regarding cleanliness, or the content provided is not immersive or irrelevant to the visitors, this results in a more negative experience. Furthermore, positive emotions that are evoked during the visit of the $\mathrm{B}_{2} \mathrm{~B}$ brand world facilitate and support visitors' understanding and remembrance of the information and content provided in the brand world, their decision making, and also relationship building with the brand and its employees.

In the context of business networking events, eight main experiential value dimensions have been identified (V.-W. Mitchell et al., 2016), all of which are supported by our study of the $\mathrm{B} 2 \mathrm{~B}$ brand world experience. With regard to the learning, epistemic, and knowledge dimension, learning is defined by experiential learning theorists as "the process whereby knowledge is created through the transformation of experience. Knowledge results from the combination of grasping and transforming experience" (Kolb, 1984, p. 41). The findings of our study show that with providing interactive product experiences in $\mathrm{B}_{2} \mathrm{~B}$ brand worlds, operating companies want to enable this transfer of knowledge. The products and their functions can be touched, tested and examined, and sometimes the production process is presented in a factory tour. These direct, hands-on, personal experiences that can be created with experiential marketing activities such as brand worlds will leave a deeper impression on the visitors minds, and create more knowledge than regular information materials, advertising instruments, or trade magazines. Additionally, they let the visitors directly experience the products' or services' value-in-use. The operating companies openly present their value propositions, and provide the visitors with the opportunity to directly assess these propositions interactively (Lindgreen, Hingley, Grant, \& Morgan, 2012; Woodruff, 1997). Further values derived from the experience are professional value, relationship value, emotional value, hedonic, altruistic, entertainment, and service excellence value, reputation, status, esteem, and branding value, as well as social value. Based on respondents' statements, we have also reason to hypothesize, that further outcomes of the $\mathrm{B} 2 \mathrm{~B}$ brand world experience comprise an improve in relationship outcomes, such as mutual trust and relationship commitment, an increase or positive influence on brand equity and its dimensions brand awareness, brand associations, perceived quality, and brand loyalty, as well as a positive influence on the internal branding purposes of the operating company.

\subsubsection{Theoretical implications}

To the best of our knowledge, our exploratory study is the first to investigate brand worlds as an instrument of branding, employing experiential marketing techniques, in the $\mathrm{B}_{2} \mathrm{~B}$ context. The study answers a general call for further 
Company sphere and contribution

\begin{tabular}{|ll|}
\hline \multicolumn{2}{|c|}{ Motives of Operating Companies } \\
- Brand Associations & - Customer Integration \\
- Brand Awareness & - Employer and Internal \\
- Product Awareness & Branding \\
- Product Experience & - Product development and \\
- Customer Relationship and & testing \\
Loyalty & - Proving marketing claims \\
- Initiating and closing sales & - Transparency \\
- Perceived Quality / & - Differentiation \\
Leadership & - Branded Experience \\
\hline & $\downarrow$ \\
\hline
\end{tabular}

Visitor sphere and contribution

\begin{tabular}{|c|}
\hline Visitor Expectations, Knowledge, Skills, Interests \\
\hline $\begin{array}{ll}\text { - Getting to know the } & \text { Product training } \\
\text { products and offerings } & \text { - Expectations or demands } \\
\text { - Getting to know the } & \text { regarding the design and } \\
\text { organization } & \text { environment } \\
\text { - Learning, understanding, } & \text { - Clear and open } \\
\text { curiosity } & \text { communication } \\
\text { - Good service / sense of well-- Factory visit } \\
\begin{array}{ll}\text { being and appreciation } & \text { - Emotional appeal }\end{array}\end{array}$ \\
\hline
\end{tabular}

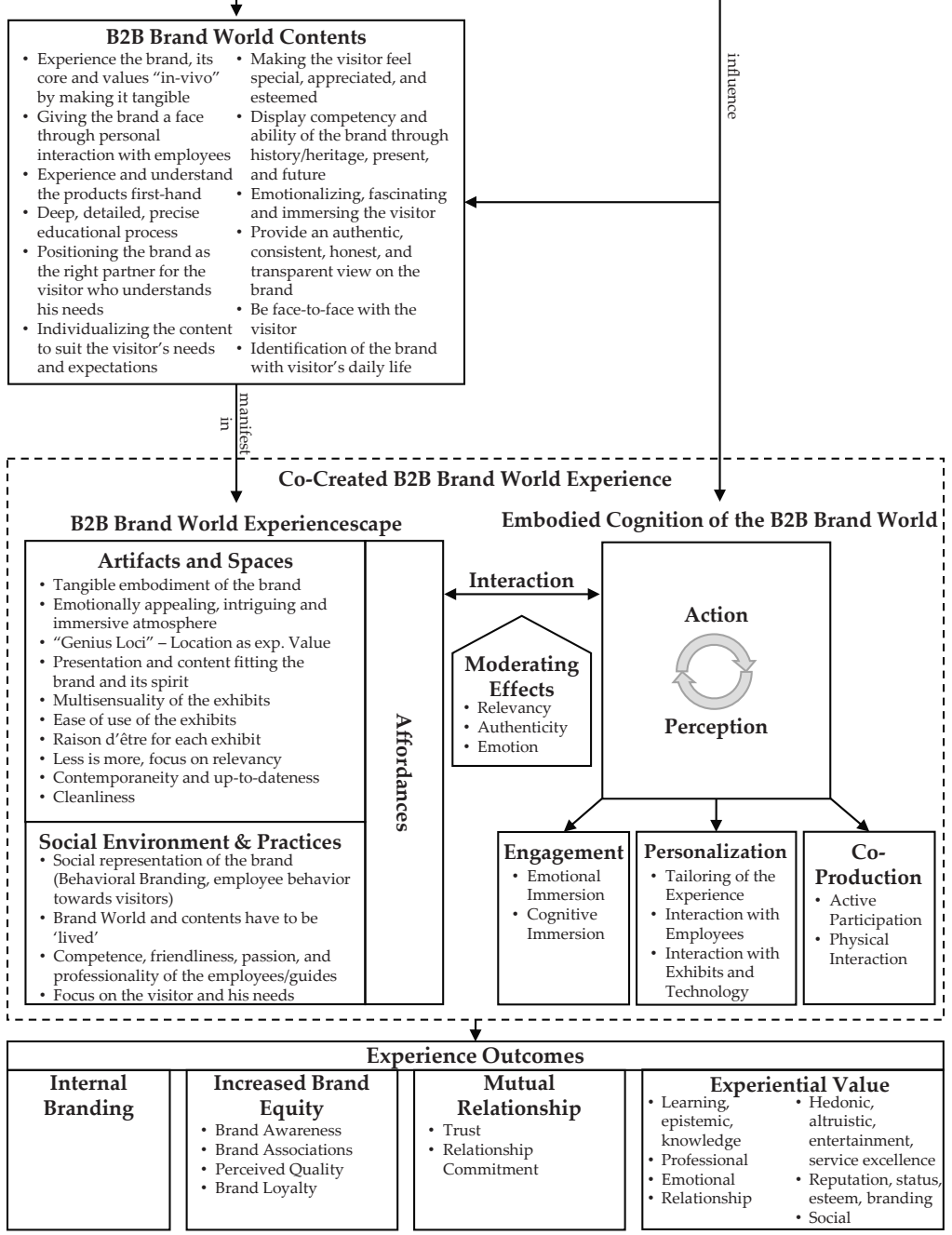

Figure 3.2: A comprehensive view on $\mathrm{B}_{2} \mathrm{~B}$ brand worlds 
research on experiential marketing activities in business markets (Rinallo et al., 2010) and contributes to the literature on the branding instrument of brand worlds specifically. By investigating it from multiple perspectives, namely the operating companies', the business visitors', and the exhibition designers', it expands the literature from merely describing its existence in B2B (Gilmore \& Pine, 2002) to a comprehensive and holistic understanding of its nature, as well as the why, what, and how of this phenomenon. Our study thus contributes to the understanding of the industrial marketing equivalent of one of the most powerful branding instruments in consumer markets (Dolbec \& Chebat, 2013). It introduces $\mathrm{B}_{2} \mathrm{~B}$ brand worlds as a valuable alternative and complementation to existing $\mathrm{B}_{2} \mathrm{~B}$ branding instruments for the operating company, but also as a valuable tool for the business visitors, based on the experience that is co-created there. Therefore, our study also contributes to the frameworks of the tactics of brand building and brand management, as well as the customer experience in business markets (Lindgreen et al., 2010; Mora Cortez \& Johnston, 2017). An interesting area of future research arises in the investigation of the specific role of $\mathrm{B}_{2} \mathrm{~B}$ brand worlds in the entire customer journey and relationship between businesses. Our findings show that the operating companies especially value the brand worlds as materialized business cards and figurehead of their brand. If one of the actors involved possesses a brand world, they often provide the inspiring and stimulating physical environment for a first personal meeting and interaction, and thus the foundation for a future relationship between the operating company and other actors on business markets. These relationships and interactions between actors are core aspects of business markets (Håkansson, 1982; Håkansson \& Snehota, 1995). Based on environmental psychology literature, we expect the brand worlds' stimuli, atmospherics and servicescapes to influence how these relationships and interactions are perceived (Bitner, 1992; Kotler, 1973; Mehrabian \& Russell, 1974). Therefore, a quantitative investigation into the impact of a $\mathrm{B}_{2} \mathrm{~B}$ brand world visit on the visitors' perception of the brand seems fruitful. Furthermore, quantitative investigations of our propositions pose interesting avenues for future research, for example in order to investigate the impact of the specific success factors on the overall experience and the value subsequently derived from the brand world visit.

Research on value in business markets highlights that the delivery of value requires loyalty and trust between partners (Lindgreen et al., 2012), which both are core goals that $\mathrm{B}_{2} \mathrm{~B}$ brands pursue with their brand worlds. The dimensions of value that business visitors derive from the experience of visiting a $\mathrm{B}_{2} \mathrm{~B}$ brand world also show a substantial overlap with experiential dimensions in the $\mathrm{B}_{2} \mathrm{C}$ context, as described for example by Gentile et al. (2007) or Lemon and Verhoef (2016). Recent research concerning perceived value in $\mathrm{B}_{2} \mathrm{~B}$ especially highlights the possible advantages of a cross-fertilization of value research in both $\mathrm{B}_{2} \mathrm{C}$ and $\mathrm{B}_{2} \mathrm{~B}$ in order to fill research gaps of the respectively other field. The authors specifically propose the inclusion of more non-rational dimensions in the appreciation of perceived value in $\mathrm{B}_{2} \mathrm{~B}$ (Mencarelli \& Rivière, 2015). These include feelings, atmosphere, or positive emotions, which are relevant in long-lasting customer relationships (Andersen \& Kumar, 2006). Our study shows that values derived from experiences in business encounters, such as the visit of a $\mathrm{B}_{2} \mathrm{~B}$ brand world, also comprises these emotional and hedonic aspects and thus contributes to the literature stream on value in business markets. 
Future research might engage in the investigation of experiential value derived from other experiences in business markets, both qualitatively and quantitively. Our research shows that by providing interactive product experiences in the brand worlds, where the products and their functions can be touched, tested and examined, and sometimes also the production process of the products is presented, visitors are able to directly experience the products' or services' value propositions and value-in-use (Lindgreen et al., 2012; Woodruff, 1997). Based on the literature on product experience in the consumer area (Hoch, 2002), an interesting question for future research that emerges from this direct product experience is whether it influences purchasing intentions or even purchasing behavior.

The role of emotions in $\mathrm{B}_{2} \mathrm{~B}$ markets has recently also gained increased attention from academia (Borders \& Kemp, 2018). Emotions play a role at all stages in the organizational buying process. Therefore, individuals, as opposed to entire organizations, should play a role in a B2B brand's marketing communications (Kemp et al., 2018). We contribute to this stream of literature by identifying that not only do visitors derive emotional value from the $\mathrm{B}_{2} \mathrm{~B}$ brand world experience, but in fact, the emotions evoked in the context the experience of $\mathrm{B}_{2} \mathrm{~B}$ brand worlds, which is highly individualized due to the close personal interaction with the brand's employees on the brand world premises, facilitate and enhance learning, remembering, and relationship-building. Emotions thus play a crucial role in the co-creation of the $\mathrm{B}_{2} \mathrm{~B}$ brand world experience, and the overall value and success of $\mathrm{B} 2 \mathrm{~B}$ brand worlds, both for the operating company as well as for the visitors. We especially deem it necessary to further investigate the role of emotions between a brand's marketing communication instruments and the outcomes of these marketing efforts on business markets.

\subsubsection{Managerial implications}

Our research has important implications for business marketing practice. In light of increasing globalization and commoditization, branding nowadays plays an important role on industrial markets. Our findings indicate that if a brand world is implemented by a B2B company, it can become its flagship, its business card, and figurehead, much as it is the case in $\mathrm{B}_{2} \mathrm{C}$. It is the materialization of the brand and invites not only customers, but also employees and a myriad of other stakeholders to visit and to getting to know the brand. By focusing on the more utilitarian aspects of the experience - and with the support of hedonic ones - the operating companies can set up the brand worlds to create a meaningful, valuable experience for their business visitors, which can leave a long-lasting positive impression and help building and maintaining a strong brand. Bearing in mind the differentiation between more autotelic experiences in $\mathrm{B}_{2} \mathrm{C}$ and more instrumental experiences in $\mathrm{B}_{2} \mathrm{~B}, \mathrm{~B} 2 \mathrm{~B}$ brand worlds can provide not only a suitable, but an extraordinary frame for business meetings, trainings, and events with (potential) customers or other stakeholders.

Regarding brand communication, brand worlds provide an environment fully controlled by the operating company. With themed experiences, where physical cues such as symbols, signals or stories are used to inspire the senses, the brand's core and values can effectively be conveyed to the visitors with almost no distorting external influences. If a company aims at increasing 
product awareness, brand worlds are for example more effective than trade shows in giving a quick yet full overview of the brands' offerings. Additionally, brand worlds in $\mathrm{B} 2 \mathrm{~B}$ are also educational tools, enhancing learning on products, processes, or the brand itself in interactive, experiential situations where visitors can for example have a live, direct, and hands-on try with the product. All these functions of the $\mathrm{B}_{2} \mathrm{~B}$ brand world eventually aim to contribute to an overarching company goal, by strengthening the brand's image, position in the market, collaboration, relationships, and interaction with other business market actors.

Our study identified not only the possible benefits of a brand word in business markets, but also how the experience is co-created. Since sometimes only minimal investments are necessary to turn factories into small-scale brand worlds, it can be a worthwhile undertaking (Kozinets et al., 2002). A museum attached to a factory, or museal aspects in a B2B brand world for example will help to demonstrate the history and experience of the brand in a certain field, which results in reduced uncertainty on the customer side and a more positive brand perception. Furthermore, interactive exhibits and information displayed in an engaging, immersive, and involving way facilitate understanding and learning for the visitors. Therefore, we encourage $\mathrm{B}_{2} \mathrm{~B}$ branding practitioners to take advantage of these strong brand experiences evoked in brand worlds and consider them as an additional instrument in their tactics of brand building and brand management.

\subsubsection{Limitations and outlook}

Our study focuses on eliciting qualitative information. While it succeeds in answering questions on what the drivers of industrial brand worlds are and which consequences can be anticipated, the actual strength of effects still remains to be determined by means of quantitative studies. Another quantitative question of utmost managerial importance is of financial nature: How much budget should a firm allocate to industrial brand worlds? In order to facilitate well-informed decisions, future research should try to quantify the return on investment yielded by industrial brand worlds. Optimally, this would lead to an indication of 'brand world elasticity,' which would allow B2B marketers to design and manage industrial brand worlds much like price, advertisement, and professional selling, for which elasticities are an established decision tool (Albers, Mantrala, \& Sridhar, 2010).

To conclude, our research shows that $\mathrm{B} 2 \mathrm{~B}$ brand worlds, based on the experiential techniques they employ, are valuable instruments for branding and relationship-building. Companies can actually present their brand and its products and services 'in the flesh.' Business visitors are provided with a variety of valuable, first-hand information, tailored to their specific needs. Furthermore, visitors can get a feel for the brand and its employees which other marketing instruments can hardly provide. Our findings also provided much confidence in that $\mathrm{B}_{2} \mathrm{~B}$ brand worlds are not a fad, but an emerging management instrument that is here to stay. They are the three-dimensional business card of a well-run business. 
Based on the qualitative information gathered in the previous chapter, the differences between brand worlds in $\mathrm{B}_{2} \mathrm{C}$ and $\mathrm{B}_{2} \mathrm{~B}$ are delineated. This provides valuable information especially for $\mathrm{B}_{2} \mathrm{~B}$ marketing practitioners operating brand worlds.

PUBLICATION HISTORY:

Initially, this chapter, written with Prof. Dr. Marc Kuhn and Prof. Dr. Jörg Henseler, was a section of the submission to Industrial Marketing Management of the previous chapter, but has been removed during the review process following the reviewers' suggestions. It is thus based on the same methodology and sample. An extended version of this section was then submitted as an extended abstract and presented at the 34th Annual Conference of the Industrial Marketing and Purchasing (IMP) Group, held in Marseille, France from September 4-7 2018. The full version of this chapter will be rewritten to be suitable for submission in a journal, probably the Journal of Business \& Industrial Marketing.

REFERENCES TO PREVIOUS PUBLICATIONS:

Österle, B., Kuhn, M. M., \& Henseler, J. (2018). Differences between Brand Worlds in $\mathrm{B}_{2} \mathrm{C}$ and $\mathrm{B}_{2} \mathrm{~B}$ : Structured Abstract. In IMP Group (Ed.), 34th Annual IMP Conference.

KEYWORDS:

Brand Worlds, interaction, relationship, B2B, experiential marketing, branding, experience 


\section{DIFFERENCES BETWEEN BRAND WORLDS IN B 2 C AND B 2 B}

\section{ABSTRACT}

Brand worlds, permanent physical branded locations, are increasingly popular venues used by marketers on consumer markets to build relationships with their customers, based on the direct, personal interactions and the extraordinary experiences they provide. Such brand museums, showrooms, or flagship stores also exist in $\mathrm{B}_{2} \mathrm{~B}$ marketing practice, but have only received limited academic attention. Differences between the context of $\mathrm{B}_{2} \mathrm{C}$ and $\mathrm{B}_{2} \mathrm{~B}$ markets raise the question of how and whether $\mathrm{B}_{2} \mathrm{~B}$ brand worlds differ from their $\mathrm{B}_{2} \mathrm{C}$ counterparts. We build on a sample of 37 expert interviews, comprising the perspectives of all relevant stakeholders: 18 interviews with 17 different operating companies, 14 interviews with business visitors from 13 companies, and five interviews with exhibition designers. Although similar and building on the same principles, we find that $\mathrm{B} 2 \mathrm{~B}$ brand worlds also differ substantially from their $\mathrm{B}_{2} \mathrm{C}$ equivalents in several dimensions. $\mathrm{B} 2 \mathrm{~B}$ companies focus more on providing live product experiences, in order to explain often complex products, and to create awareness for the whole breadth and depth of their product portfolio in their brand worlds. B2B visitors expect a visit to support them in their own business activities. Furthermore, the visits, experiences, and interactions in $\mathrm{B}_{2} \mathrm{~B}$ brand worlds are more customized, based on a strong personal interaction with the respective contact persons, sales agents or guides. Our research highlights the differences between $\mathrm{B}_{2} \mathrm{C}$ and $\mathrm{B}_{2} \mathrm{~B}$ brand worlds as three-dimensional 'business cards,' where relationships are initiated and built.

\subsection{INTRODUCTION}

The importance of relationships on business markets and the notion that interactions between actors are at the core of business relationships has been highlighted in research of the Industrial Marketing and Purchasing Group (IMP) (Håkansson, Ford, Gadde, Snehota, \& Waluszewski, 2009; Håkansson \& Snehota, 1995). These interactions can be analyzed on various levels, such as on the organizational level, or on a more micro level by looking at individual processes that can involve organizational units, single products, individuals, or certain types of activities, such as business meetings (Guercini, La Rocca, Runfola, \& Snehota, 2014).

In consumer research, the facet of the environment or servicescape and its influence on the behavior, interaction and relationship building between actors (i.e. consumers and a company) has been widely researched (Baker, Parasuraman, Grewal, \& Voss, 2002; Bitner, 1992). Building on this $\mathrm{B} 2 \mathrm{C}$ research, specific instruments of experiential marketing and live communication, namely permanent, physical branded locations such as flagship stores, brand stores, brand lands, brand museums, or customer experience centers, subsumed under the term 'brand worlds', are increasingly popular venues used by $\mathrm{B}_{2} \mathrm{C}$ companies (Kozinets et al., 2002). As "apexes of branding" (Dolbec \& Chebat, 2013, p. 460), they are not only used to communicate the brands, but also to directly and personally interact with consumers, to provide them with 
extraordinary experiences, and eventually to build relationships with them (Dolbec \& Chebat, 2013; Kozinets et al., 2002; Moore et al., 2010). These venues have also been mentioned as a possibility for $\mathrm{B}_{2} \mathrm{~B}$ companies to increase close rates, due to the relationships developed there (Gilmore \& Pine, 2002), and industrial marketing practitioners have already discovered the potential of such instruments for their own organizations. In fact, B2B brand worlds can be found all over the world, such as for example the Caterpillar Visitors Center or the Customer Experience Centers of General Electric and Honeywell Process Solutions in the US, the Innovation Center of logistics provider DHL or the Stahlwelt of Austrian steel producer Voestalpine in Europe, or the Mitsubishi Minatomirai Industrial Museum in Asia. But in contrast to their $\mathrm{B}_{2} \mathrm{C}$ counterparts, these physical environments and instruments of experiential marketing in industrial markets, and how they influence behaviors, interactions and relationships, have not attracted academic attention yet. Since researchers are advised to be cautious with the mere transfer of knowledge, theories, and frameworks from $\mathrm{B}_{2} \mathrm{C}$ to $\mathrm{B}_{2} \mathrm{~B}$, and instead to take into account the unique characteristics of $\mathrm{B}_{2} \mathrm{~B}$ markets for the development of a sound $\mathrm{B}_{2} \mathrm{~B}$ theory (Mudambi, 2002; Seyedghorban et al., 2016; Webster \& Keller, 2004), one first needs to understand the nature of $\mathrm{B}_{2} \mathrm{~B}$ brand worlds compared to their $\mathrm{B}_{2} \mathrm{C}$ counterparts in order to further investigate how business interactions and relationships might be influenced by a visit to such $\mathrm{B}_{2} \mathrm{~B}$ brand worlds. Against this background, the purpose of this paper is to identify potential differences between $\mathrm{B}_{2} \mathrm{C}$ and $\mathrm{B}_{2} \mathrm{~B}$ brand worlds.

The remainder of this manuscript is structured as follows. To provide the context for this study, we first describe brand worlds and their nature in $\mathrm{B}_{2} \mathrm{C}$, before we elaborate briefly on the core differences between consumer and business markets. Next, we describe our exploratory research approach, and present an overview of our comprehensive, multi-perspective sample. Subsequently, we present our results and draw a conclusion.

\subsection{THEORETICAL BACKGROUND}

\subsubsection{Brand Worlds}

The efforts of brandscaping - creating physical locations based on brands - are amongst the strongest means in creating brand experiences and relationships with a brand in $\mathrm{B}_{2} \mathrm{C}$, based on emotions and a non-rational approach (Riewoldt, 2002). Some examples for such locations in the consumer marketing area are the Disney Worlds, the Apple flagship stores, or the World of Coca-Cola in Atlanta, Georgia. They follow the conviction that "the glamour and power of the brand are the key weapons in the battle for target groups and customers. By staging the brand experience in flagship stores, shop designs or entire theme parks, companies communicate the image of the brand and imprint a characteristic atmosphere on the consumer consciousness" (Riewoldt, 2002, p. 8). In contrast to most classical advertising instruments, the brand becomes visible, actually tangible in such locations, and therefore a strong, real, memorable customer experience, and a relationship between the brand and the customer is created (Manlow \& Nobbs, 2013; Webb, 2012). The live experience of taking a trip to, for example, a brand park, and actually visiting the brand becomes part of one's own life and has a higher recollective value than simple advertising or 
conventional PR (Mikunda, 2004). Simply witnessing a product's production in a mere plant tour can lead to higher brand loyalty and a better relationship to the brand, based on the identification with the product, the familiarity with the production process, and the interaction with employees (M. A. Mitchell \& Orwig, 2002).

Flagship stores are titled the "apex of branding" because of their branding power (Dolbec \& Chebat, 2013, p. 460). Similar venues have been mentioned and investigated in consumer-centric academic literature, such as customer experience places, brand lands, brand museums, brandscapes, flagship stores, etc. (e.g. Borghini et al., 2009; Diamond et al., 2009; Gilmore \& Pine, 2002; Hollenbeck et al., 2008; Joy et al., 2014; Kozinets et al., 2002; Sherry, 1998; Sherry et al., 2001). We use the term 'brand worlds' as an umbrella term for such permanent branded locations that are an instrument of brand communication and experiential marketing. These brand worlds have been subject to a limited amount of academic research in the $\mathrm{B}_{2} \mathrm{C}$ environment already. For example, the goals of different types of brand worlds in various industries have been investigated, which are, to summarize, related to the image of the brand, the presentation, staging and testing of products, merchandising goals, knowledge transfer, and customer relationship goals (e.g. Borghini et al., 2009; Diamond et al., 2009; Gilmore \& Pine, 2002; Hollenbeck et al., 2008; Joy et al., 2014; Kozinets et al., 2002; Sherry, 1998; Sherry et al., 2001). In two synoptical works, several main goals that operating companies pursue with their brand worlds in $\mathrm{B} 2 \mathrm{C}$ with different priorities were identified (Kirchgeorg et al., 2012; Zentes et al., 2014): Goals with the highest priority are brand experience, brand and product presence, the determination of the own position in the competitive environment, as well as to improve, strengthen, and foster the own brand image. Medium priority goals are information, raising brand awareness, internal communication goals, the management and activation of existing customer relationships, and building trust. Lower priority goals encompass the integration of customers into business processes (e.g. co-creation), engaging with potential new customers, and generating sales turnover.

B2 $\mathrm{C}$ visitors' motivations, expectations and demands have also been subject to investigation. When they visit brand worlds, they want to experience entertainment, flow, get information about the products and the brand, relax, be distracted and escape from their day-to-day live, experience community with other visitors, and feel well and appreciated by the operating company (Kirchgeorg et al., 2012; Opaschowski, 2000; Zentes et al., 2014).

\subsubsection{Differences between $\mathrm{B}_{2} \mathrm{C}$ and $\mathrm{B} 2 \mathrm{~B}$ markets}

Core differences of $\mathrm{B}_{2} \mathrm{~B}$ markets compared to $\mathrm{B}_{2} \mathrm{C}$ comprise the nature of demand (derivative vs. primary); more technical and quantifiable value propositions; a small number of customers, but large-unit transactions; complex buying processes involving buying centers and thus group dynamics, resulting in more rational discourse and decision-making; the emphasis on corporate rather than product branding; a culture driven by manufacturing and technology, which is related to the complexity of industrial products; and the more important role of relationships, interpersonal communication or personal interaction and selling (B. P. Brown et al., 2007; B. P. Brown et al., 2012; D. Grewal et al., 1998; Kotler \& Pfoertsch, 2006; Lilien, 2016; Webster \& Keller, 
2004; Zablah et al., 2010). Furthermore, B2B buying decisions are influenced by the buying situation (e.g. Kotler \& Pfoertsch, 2006), a higher perceived risk, and the more economic and performance type of risk (B. P. Brown et al., 2007). These differences have effects on marketing communications, which are proposed to be more technical and pedagogical, but also more interactive and personal, and thus also on the branding efforts, interaction between actors and relationship-building on business markets (B. P. Brown et al., 2007). After about 40 years of research, $\mathrm{B} 2 \mathrm{~B}$ branding has evolved from irrelevance towards being important for business marketing practice, and an established field of study (Gordon et al., 1993; Interbrand, 2018; Saunders \& Watt, 1979; Seyedghorban et al., 2016; Shipley \& Howard, 1993; Sinclair \& Seward, 1988; Webster \& Keller, 2004). Nowadays, "branding is just as relevant in $\mathrm{B} 2 \mathrm{~B}$ as it is in $\mathrm{B}_{2} \mathrm{C}$ " (Kotler $\&$ Pfoertsch, 2006, p. 12). When it comes to the question of how a B2B brand can be built and communicated, the brand is conceptualized as a holistic and interactive experience, as in $\mathrm{B}_{2} \mathrm{C}$, which highlights the importance of interaction in brand building (Biedenbach \& Marell, 2010; Kotler \& Pfoertsch, 2006; Lynch \& de Chernatony, 2004). Therefore, despite the specific importance of the salesperson and personal interaction (Lynch \& de Chernatony, 2007), all customer touchpoints and elements of the marketing mix contribute to brand equity dimensions, as they do in $\mathrm{B}_{2} \mathrm{C}$ : They create awareness of the brand, link desired associations to the brand image, evoke emotions or judgements of quality, and facilitate a stronger customer-brand relationship (Biedenbach \& Marell, 2010; Kotler \& Pfoertsch, 2006).

The different, professional setting outlined here suggests, that several differences might also arise between brand worlds in $\mathrm{B}_{2} \mathrm{C}$ and $\mathrm{B}_{2} \mathrm{~B}$ regarding several aspects, such as for example the goals of operating companies, the motivation and expectations of visitors, or the general setup and design. Although the possibility for $\mathrm{B} 2 \mathrm{~B}$ companies to create flagship venues, where customer visits can evolve into engaging branded experiences and lead to a strong relationship between the actors, has also been mentioned in the literature (Gilmore \& Pine, 2002), and the emergence of $\mathrm{B} 2 \mathrm{~B}$ brand worlds in business practice, they have not so far attracted the attention of academia. To address this gap and to build the foundation for a deeper understanding of the value and contribution of $\mathrm{B} 2 \mathrm{~B}$ brand worlds to business relationships, we investigate brand worlds in the industrial marketing context and whether and how they differ from their $\mathrm{B}_{2} \mathrm{C}$ counterparts.

\subsection{METHODOLOGY AND SAMPLE}

Given the exploratory nature of our research question, we applied a qualitative research approach using semi-standardized expert interviews to investigate the differences between brand worlds in $\mathrm{B}_{2} \mathrm{C}$ and $\mathrm{B}_{2} \mathrm{~B}$. This research method has previously proven purposeful in industrial marketing when there is scant or no existing information (Geiger, 2017; Keränen \& Jalkala, 2013), and has been deemed appropriate for research in exploratory stages (Bogner et al., 2009).

Although the interviews are qualitative and explorative in nature, prior theoretical knowledge about the concepts in the area of research is fundamental (Flick, 2009). This knowledge can then be used to develop interview guidelines, while the openly formulated questions leave room for the experts to fill with their specific knowledge (Mayer, 2012). Due to the lack of literature on brand 
worlds in $\mathrm{B}_{2} \mathrm{~B}$, we focused on the $\mathrm{B}_{2} \mathrm{C}$ literature on brand worlds (Borghini et al., 2009; Diamond et al., 2009; Gilmore \& Pine, 2002; Hollenbeck et al., 2008; Joy et al., 2014; Kozinets et al., 2002; Sherry, 1998; Sherry et al., 2001). Based on this prior knowledge, we developed our interview guidelines, specifically targeting the characteristics of $\mathrm{B}_{2} \mathrm{~B}$ brand worlds, also in comparison to their $\mathrm{B}_{2} \mathrm{C}$ counterparts.

To achieve a relevant and full understanding of brand worlds in business markets, we engaged with a comprehensive and unique, multi-perspective sample. Adding to the perspective of operating companies, we triangulated our findings with samples of business visitors and exhibition designers. In total, we base our research on 37 expert interviews with 44 informants. We carefully and thoroughly selected 17 companies from the industrial sector operating B2B brand worlds, from the US, Germany and Austria, covering different industries and sizes. We identified them through extensive online research and visiting practitioner conferences on experiential marketing and brand worlds. All participating companies operate different, outstanding, and innovative types of brand worlds - including for example Showrooms, Factory Tours, Visitor Centers, Customer Experience Centers, Museums, and Innovation Centers. One company was interviewed twice with different interviewees, because the firm operates two separate brand worlds in different locations with different goals, giving us a total of 18 interviews with 17 companies. We were invited to conduct 15 interviews on-site at the brand worlds and conducted three interviews by phone. Each on-site interview was preceded by an extensive tour throughout the entire brand world of roughly $1.5-2$ hours. Due to the fact that the interviews were conducted directly after these extensive tours given to us by the respondents themselves, we could directly dive into the topic and start with the depth interview without the need to get acquainted during the beginning of the interviews. A detailed description of our sample of operating companies is provided in the Appendix in Table A.2.

To triangulate and enrich our findings from the company sample, we also conducted 14 expert interviews with business visitors of $\mathrm{B}_{2} \mathrm{~B}$ brand worlds. Informants are employed by 13 different companies in various industries and act in various buying center roles. They have visited at least one, some also several $\mathrm{B}_{2} \mathrm{~B}$ brand worlds in a role as a business visitor recently before the interviews. 13 of the interviews were conducted via phone, one face-to-face. A full, detailed description of our sample of business visitors is provided in the Appendix in Table A.3.

To additionally triangulate and validate our findings with a third, supplementary point of view, we conducted five more interviews with exhibition designers in managing positions at different exhibition design or marketing and brand agencies. This sample was chosen based on the extensive experience of the respective informants in designing and implementing various types of brand worlds for numerous companies in both the consumer and business marketing area. Two interviews were conducted by phone, and three interviews were conducted at the informants' offices. A full overview of our sample of exhibition designers is provided in the Appendix in Table A.4.

The overall average net duration of our interviews was 47 minutes of deep and relevant discussion. The overall average phone call duration was 53 minutes. The overall average visit duration for on-site interviews at brand worlds or face-to-face interviews with visitors and exhibition designers was 2 hours and 
58 minutes. We fully transcribed all interviews and presented them to the interviewees afterwards for validation. Where necessary, we translated the statements quoted in this study into English.

We analyzed the interview material using the method of qualitative content analysis. Specifically, we used the technique of inductive category formation to arrive directly at summarizing categories coming from the material itself, and not from theoretical considerations (Mayring, 2014). We used a qualitative data management and analysis program (MaxQDA) and handled all interview transcripts with ultimate care. Two coders analyzed all data material separately, following established procedures developed for the inductive category formation technique of qualitative content analysis (Mayring, 2014). The process involves revising the emerging categories after approximately $50 \%$ of the content analysis, to arrive at a final category structure. We also investigated whether a revision of the initial coding definitions and instructions was necessary, but no issues arose during the coding process, so changes were not necessary. We subsequently merged the codings based on thorough discussions between coders regarding the interpretation and categorization of individual informant statements, as well as a peer debriefing with other researchers not involved in the study (Corley \& Gioia, 2004).

\subsection{DIFFERENCES BETWEEN B2C AND B2B BRAND WORLDS}

Our findings show that despite the similarities of $\mathrm{B}_{2} \mathrm{C}$ and $\mathrm{B}_{2} \mathrm{~B}$ brand worlds, and the fact that they rely on the same principles of experiential marketing and live communication in both $\mathrm{B}_{2} \mathrm{C}$ and $\mathrm{B}_{2} \mathrm{~B}$, there are also substantial differences. Similarities also emerge because $\mathrm{B}_{2} \mathrm{~B}$ brand worlds increasingly open up to the general public, e.g. for reasons of employer branding or PR. Nevertheless, there are major differences between brand worlds in the two contexts. These are based on their role as three-dimensional 'business cards.' Furthermore, what leads to differences is their role and implementation in the $\mathrm{B}_{2} \mathrm{~B}$ purchasing process to support the visitor in their business activities, by providing deep, tailored experiences and knowledge about products and processes based on personal interaction and emotions. Also, there are differences regarding the goals of operating companies, the expectations and motivations of visitors, as well as the physical appearance and content of $\mathrm{B}_{2} \mathrm{~B}$ brand worlds compared to their $\mathrm{B}_{2} \mathrm{C}$ counterparts. An overview of these differences is given in Table 4.1.

The goals that operating companies in $\mathrm{B}_{2} \mathrm{~B}$ and $\mathrm{B}_{2} \mathrm{C}$ contexts pursue are similar in general, but the focus is slightly different. While a major goal for $\mathrm{B}_{2} \mathrm{C}$ companies is to create brand experience, $\mathrm{B}_{2} \mathrm{~B}$ companies focus more on product awareness and product experience, as well as brand awareness and associations. Additionally, the means that these goals are pursued with are different, which we will elaborate on later in this section.

A major difference between $\mathrm{B}_{2} \mathrm{C}$ and $\mathrm{B}_{2} \mathrm{~B}$ brand worlds is the motivation and expectation of the visitor. In $\mathrm{B}_{2} \mathrm{C}$, consumers are driven by and expect hedonic aspects, visits take place fully unrelated to specific purchase intentions, and are based completely on the visitors' intentions to visit. In contrary, business visitors to $\mathrm{B}_{2} \mathrm{~B}$ brand worlds are motivated by and expect more utilitarian aspects. Their visits are usually related to specific purchasing intentions or an already existing customer-brand relationship, in the process of which they are invited by the operating company to a company visit. In fact, they often 
Table 4.1: Differences between $\mathrm{B}_{2} \mathrm{C}$ and $\mathrm{B}_{2} \mathrm{~B}$ brand worlds

\begin{tabular}{|c|c|c|}
\hline DIMENSION & B2C & В2в \\
\hline \multirow[t]{2}{*}{$\begin{array}{l}\text { Goals of operating } \\
\text { company }\end{array}$} & \multicolumn{2}{|c|}{$\begin{array}{l}\text { Goals are similar in general, but importance of goals is } \\
\text { slightly different }\end{array}$} \\
\hline & $\begin{array}{l}\text { Stronger focus on brand expe- } \\
\text { rience }\end{array}$ & $\begin{array}{l}\text { Stronger focus on product } \\
\text { awareness, product experi- } \\
\text { ence, brand awareness and } \\
\text { brand associations }\end{array}$ \\
\hline $\begin{array}{l}\text { Motivation and expecta- } \\
\text { tions of the visit for the } \\
\text { visitor }\end{array}$ & $\begin{array}{l}\text { More hedonic, unrelated to } \\
\text { buying situation, motivated } \\
\text { only by the customer }\end{array}$ & $\begin{array}{l}\text { More utilitarian, related to spe- } \\
\text { cific buying situation, invited } \\
\text { visits; brand world visit rather } \\
\text { addition to business activities } \\
\text { than end in itself }\end{array}$ \\
\hline \multirow[t]{2}{*}{$\begin{array}{l}\text { Experiential value for the } \\
\text { visitor }\end{array}$} & \multicolumn{2}{|c|}{$\begin{array}{l}\text { Value derived is similar in general, but importance is } \\
\text { different }\end{array}$} \\
\hline & $\begin{array}{l}\text { More hedonic and emotional } \\
\text { value }\end{array}$ & $\begin{array}{l}\text { More learning, epistemic and } \\
\text { knowledge value, as well as } \\
\text { professional value }\end{array}$ \\
\hline $\begin{array}{l}\text { Personal interaction with } \\
\text { brand }\end{array}$ & $\begin{array}{l}\text { Usually no strong personal in- } \\
\text { teraction, except for service } \\
\text { personnel or guides }\end{array}$ & $\begin{array}{l}\text { Customized visits and experi- } \\
\text { ences; strong personal interac- } \\
\text { tion with contact person, sales } \\
\text { agent or guide }\end{array}$ \\
\hline Information & $\begin{array}{l}\text { More superficial and not as } \\
\text { technical }\end{array}$ & $\begin{array}{l}\text { Deeper, more focus on detail } \\
\text { and technical explanation }\end{array}$ \\
\hline Emotion & $\begin{array}{l}\text { Stronger focus on emotion, fas- } \\
\text { cination, entertainment and } \\
\text { edutainment }\end{array}$ & $\begin{array}{l}\text { More serious and different } \\
\text { type of emotionality. More fo- } \\
\text { cused on trust, credibility, and } \\
\text { authenticity, but edutainment } \\
\text { gains importance }\end{array}$ \\
\hline $\begin{array}{l}\text { Orchestration and stag- } \\
\text { ing }\end{array}$ & $\begin{array}{l}\text { Strong, impressive, and ludic } \\
\text { staging }\end{array}$ & $\begin{array}{l}\text { Subtler, only to support the } \\
\text { message }\end{array}$ \\
\hline Product training & Plays a minor role & $\begin{array}{l}\text { Plays a strong role, often rea- } \\
\text { son for the visit, or training is } \\
\text { conducted in the brand world } \\
\text { facilities; often occupies a big } \\
\text { portion of the size of the brand } \\
\text { world premises }\end{array}$ \\
\hline Factory tours & Sometimes attached & Often attached/incorporated \\
\hline Number of visitors & Usually higher & Usually lower \\
\hline Budget & $\begin{array}{l}\text { Usually higher in relation to } \\
\text { the size of the brand world }\end{array}$ & $\begin{array}{l}\text { Usually lower in relation to the } \\
\text { size of the brand world }\end{array}$ \\
\hline Size & \multicolumn{2}{|c|}{ No difference, can be small and large in both contexts } \\
\hline Location & $\begin{array}{l}\text { Usually in highly frequented } \\
\text { locations or at corporate head- } \\
\text { quarter }\end{array}$ & $\begin{array}{l}\text { Usually at corporate headquar- } \\
\text { ter }\end{array}$ \\
\hline
\end{tabular}


do not visit the company to 'visit the brand world,' but to conduct their general business activities, such as meetings, workshops, negotiations, audits, relationship maintenance, or trainings. The $\mathrm{B} 2 \mathrm{~B}$ brand world is then rather used by the operating company as a 'business card,' a tool where the company presents itself at a glance, or as a complementary instrument to provide the visitor with either an additional experience to present a positive, credible image, or as an extraordinary and stimulating location in which, by the provision of additional, unique information, mutual value is created and where these business activities take place and the relationship is deepened further.

The overall experiential value that visitors derive from $\mathrm{B}_{2} \mathrm{C}$ and $\mathrm{B}_{2} \mathrm{~B}$ brand worlds is also similar in general, but the focus is different, largely also due to the different motivation of the visit. While private visitors to $\mathrm{B}_{2} \mathrm{C}$ brand worlds derive stronger emotional and hedonic value from the visit, the focus of business visitors to $\mathrm{B} 2 \mathrm{~B}$ brand worlds is more on learning, epistemic and knowledge value, as well as professional value dimensions, due to the embedding of the visit in the overall $\mathrm{B}_{2} \mathrm{~B}$ customer journey.

Also, due to the more influential role of personal interaction and more complex products and services in $\mathrm{B}_{2} \mathrm{~B}, \mathrm{~B}_{2} \mathrm{~B}$ brand worlds are guided experiences, so that visitors are always accompanied by a contact person representing the brand, elaborating on the exhibits, and building a relationship with the visitor. This goes along with a much more customized visit, in which the specific areas of interest of the business visitor are discussed in much more detail and depth.

Regarding this content provided in the $\mathrm{B}_{2} \mathrm{~B}$ brand world, the level of information in general is much more detailed, more technical, and focused on the explanation of technical specifics, whereas in their $\mathrm{B}_{2} \mathrm{C}$ counterparts, the information is more superficial, and less technical and detailed. Nevertheless, by means of interactive exhibits and media, visitors to $\mathrm{B}_{2} \mathrm{C}$ brand worlds can go into deeper detail as well, so that all interests can be met.

While $\mathrm{B}_{2} \mathrm{C}$ brand worlds are focused on creating strong emotions, fascinating, entertaining and edutaining the visitor, $\mathrm{B}_{2} \mathrm{~B}$ brand worlds are not necessarily less emotional, but more serious. They try to evoke different kinds of emotions, such as trust, credibility, authenticity and reassurance. Nevertheless, also edutaining contents play an increasing role according to our respondents.

The experience created in $\mathrm{B}_{2} \mathrm{C}$ brand worlds is based on intense, impressive, and ludic orchestration and staging of the contents in the entire brand world. In $\mathrm{B}_{2} \mathrm{~B}$ brand worlds in contrast, this staging and orchestration is done much subtler, and all staging has to serve the purpose of conveying the message of the content.

The importance of product training also serves as differentiation between $\mathrm{B}_{2} \mathrm{C}$ and $\mathrm{B}_{2} \mathrm{~B}$ brand worlds. While product training only plays a minor role in $\mathrm{B}_{2} \mathrm{C}$, it often is a crucial function in or even the reason for the $\mathrm{B}_{2} \mathrm{~B}$ brand world visit, which then usually occupies a large amount of the brand world premises.

Factory tours, which are also often a part of the utilitarian visit to a B2B company and its brand world, only play a minor role in $\mathrm{B}_{2} \mathrm{C}$ brand worlds, since these are often also not located at production sites.

Another obvious difference between $\mathrm{B}_{2} \mathrm{C}$ and $\mathrm{B}_{2} \mathrm{~B}$ brand worlds is the number of visitors per year. $\mathrm{B}_{2} \mathrm{C}$ brand worlds are in general much more highly frequented. The exception to the rule are brand worlds of $\mathrm{B}_{2} \mathrm{~B}$ companies that are, intentionally or not, tourist attractions, which target at and also attract a large number of private visitors and charge entrance fees. 
The budget is usually higher in $\mathrm{B}_{2} \mathrm{C}$ brand worlds. Again, exceptions are the just mentioned brand worlds turned tourist attractions of $\mathrm{B}_{2} \mathrm{~B}$ companies, which target a private audience, or $\mathrm{B}_{2} \mathrm{~B}$ brand worlds which are large in size.

Physically, both brand worlds of $\mathrm{B}_{2} \mathrm{C}$ and $\mathrm{B}_{2} \mathrm{~B}$ companies can be rather large or small in size, which usually depends on the type and the size of the products, the level of awareness of the operating company in the general public or its industry, respectively, and the number of visitors that it aims to attract.

The location is a big success factor for some $\mathrm{B}_{2} \mathrm{C}$ brand worlds such as flagship stores (Moore \& Doherty, 2007). This aspect only plays a minor role in the context of $\mathrm{B}_{2} \mathrm{~B}$ brand worlds, where the propensity of the potential visitor to travel to the brand world is higher as in $\mathrm{B} 2 \mathrm{C}$. Therefore, they are usually situated directly at the corporate headquarter or at important production or historical sites, where the 'genius loci' comes to bear. The exception to the rule in our sample is one gateway facility situated directly in the area of a customer cluster, in order to gain access to these customers.

\section{$4 \cdot 5$ CONCLUSION}

Brand worlds as the apex of branding and an instrument of experiential marketing have made their way from the consumer area into business marketing practice. The extraordinary experiences and the direct, personal interaction that they provide also influence relationship-building on business markets (Gilmore \& Pine, 2002). Given the different B2B context (B. P. Brown et al., 2007), the direct transfer of theories, frameworks, and knowledge from $\mathrm{B}_{2} \mathrm{C}$ to $\mathrm{B}_{2} \mathrm{~B}$ should be approached with caution. In order to understand the phenomenon of brand worlds in the $\mathrm{B} 2 \mathrm{~B}$ context, and to lay the foundation for further inquiries into their influence on interactions and relations on business markets, we investigated how these marketing instruments in the $\mathrm{B}_{2} \mathrm{~B}$ context differ from their counterparts in $\mathrm{B}_{2} \mathrm{C}$.

Our findings show that $\mathrm{B}_{2} \mathrm{~B}$ brand worlds share several similarities with their $\mathrm{B}_{2} \mathrm{C}$ counterparts, and that they are using the same principles of experiential marketing, live communication, and branding in order to fulfill their goals and convey their messages. But based on the different priorities of operating companies regarding the goals, and the motivations and expectations of business visitors, also some major differences in brand worlds in $\mathrm{B}_{2} \mathrm{~B}$ compared to $\mathrm{B}_{2} \mathrm{C}$ emerge. Our results highlight these differences that have to be taken into account for the design, implementation, and operation of brand worlds in B2B. Our research thus extends the existing knowledge on brand worlds in $\mathrm{B}_{2} \mathrm{C}$.

An interesting area of future research arises in the investigation of the specific role of $\mathrm{B}_{2} \mathrm{~B}$ brand worlds in the entire customer journey, and the relationships and interactions between actors along this journey in brand worlds on a micro level, since these relationships and interactions are at the core of business markets (Håkansson, 1982; Håkansson \& Snehota, 1995). If one of the actors involved possesses a brand world, they often provide the inspiring and stimulating physical environment for a first personal meeting and interaction, and thus the foundation for a future relationship between the operating company and other actors on business markets. Based on environmental psychology literature, we expect the brand world's stimuli, atmospherics and servicescape to influence how these relationships and interactions are perceived (Baker et al., 2002; Bitner, 1992; Kotler, 1973; Mehrabian \& Russell, 1974). 
The theoretical framework developed in this chapter links recent findings on customer experiences and brand experiences, and conceptualizes the overall brand experience as dynamic. This allows for its measurement across multiple individual touchpoints and stages, and thus for the investigation of the effect of the experience created at one individual touchpoint. This framework serves as the basis for the subsequent quantitative study of whether and how industrial brand worlds work.

PUBLICATION HISTORY:

The earliest version of this chapter, written together with Prof. Dr. Marc Kuhn and Prof. Dr. Jörg Henseler, was submitted as an extended abstract and presented at the Academy of Marketing Science (AMS) World Marketing Congress 2018. The full version of this chapter will be rewritten to be suitable for submission in a journal, probably the Journal of Product \& Brand Management.

REFERENCES TO PREVIOUS PUBLICATIONS:

Österle, B., Kuhn, M. M., \& Henseler, J. (2018). The Dynamic Nature of Brand Experience. In Academy of Marketing Science (Ed.), Proceedings of the 21st World Marketing Congress.

KEYWORDS:

Brand Experience, Brand management, Customer Experience, Customer Journey, Touchpoint 


\section{THE DYNAMIC NATURE OF BRAND EXPERIENCE}

\section{ABSTRACT}

There is a need to conceptually link findings from specific experience areas, and to generalize from them to overarching principles of experiences. Building on recent syntheses and conceptualizations, we contribute to this discussion and synthesis by proposing a framework that we think answers questions regarding the role of the brand in the customer journey and the customer experience, and the measurement of overall brand experiences. Regarding the role of the brand in the customer experience and the customer journey, we follow the conceptualization that brands reflect all customer experiences with a brand along the customer journey. Thus, the experiences that brands evoke within the customer (sensory, affective, behavioral, and intellectual) represent these overall experiences that customers have with a brand along the customer journey. By linking the brand experience concept to two recent frameworks on static and dynamic experiences and the customer journey and experience, we propose that static experiences, i.e. single touchpoints, reflect the brand related stimuli that compose the overall, i.e. dynamic, brand experience. This conceptualization allows for the measurement of the overall brand experience across multiple touchpoints and multiple stages, which is an important issue for both marketing theory and practice.

\subsection{INTRODUCTION}

Customer experiences are at the center of both marketing practitioner's and academic's attention, according to a recent study commissioned by Accenture (2015) and the research priorities of the Marketing Science Institute (2016).

This importance of experiences has already been voiced in the 1950 s by Abbott (1955) with the quote that "what people really desire are not products but satisfying experiences" (Abbott, 1955, p. 39). Independently from these findings, the experiential approach was developed in the 1980s, which focuses on fantasies, feelings, and fun as key aspects of the consumption experience (Hirschman \& Holbrook, 1982; M. B. Holbrook \& Hirschman, 1982). This approach has broadened the then predominant view of customers and consumers as being purely rational and information-processing decision makers by recognizing the emotional aspects involved. Since then, it has sparked ongoing interest in both marketing practice and academia and even led to the conceptualization of the experience economy (Pine \& Gilmore, 1998).

Despite this attention already decades ago, the research area on experience in marketing is still nascent and emerging (Lemon \& Verhoef, 2016; Schmitt \& Zarantonello, 2013). Various streams of research investigated different aspects and facets of the customer experience along the customer journey more indepth (Kranzbühler et al., 2018; Lemon \& Verhoef, 2016), such as for example product experiences (Hoch, 2002), service experiences (Hui \& Bateson, 1991), shopping experiences (Kerin, Jain, \& Howard, 1992), brand experiences (Brakus et al., 2009), or the distinction between day-to-day 'ordinary' and extraordinary experiences (Carù \& Cova, 2003), and there is a need to conceptually link those findings from specific experience areas, and to generalize from them to 
overarching principles of experiences (Schmitt \& Zarantonello, 2013). In recent efforts to achieve this syntheses, and to investigate the reciprocal dependence and influence of customer experiences in different contexts and at different touchpoints on one another and the overall customer experience, academics identified that although it was initially introduced as a holistic concept, customer experience has been investigated at different levels: as static experience at various touchpoints, which represents an "individual's cognitive, affective and sensory evaluation of one or multiple touchpoints with a firm at one specific point in time" (Kranzbühler et al., 2018, p. 438), and as dynamic experience, "an individual's evolving cognitive, affective and sensory evaluation of a series of any direct or indirect touchpoints with a firm within the entire course of the customer journey" (Kranzbühler et al., 2018, p. 438). This dynamic, overall customer experience is "built up through a collection of these touch points in multiple phases of a customer's decision process or purchase journey" (Lemon \& Verhoef, 2016, pp. 70-71). Since previous experiences influence the current experience and also future experiences, and current experiences might let us see previous experiences in a different light, the customer experience process is iterative and dynamic (Lemon \& Verhoef, 2016, pp. 74-76). In sum, customer experience is a broad, multidimensional umbrella construct (Kranzbühler et al., 2018), "focusing on a customer's cognitive, emotional, behavioral, sensorial, and social responses to a firm's offerings during the customer's entire purchase journey" (Lemon \& Verhoef, 2016, pp. 70-71).

Along with these syntheses arose several questions related to the measurement of the dynamic, overall experience, and the role of the brand within this context (Lemon \& Verhoef, 2016, p. 78): "What is the role of the brand in the CX [customer experience] and customer journey? [...] How can we measure the CX construct across multiple touch points and journey stages? Are different measures needed for different stages of the journey? [...] What fast, simple metrics could provide insight? [...] What are the effects of different touch points on customer experience, conversion, and loyalty?" Our goal in this article is to bring together the literature that exists on these questions, and to propose a framework that we think might answer them. To address this, the remainder of this paper is structured as followed: First, we provide an overview of the customer experience literature, with a focus on its multilevel nature of static and dynamic experiences. Second, we focus on the individual touchpoints and different aspects of experiences and their measurement. Third, we link the concept of brands and brand experience to the multilevel nature of experiences and the individual touchpoints. We then propose our framework as an answer to the above-mentioned questions.

\subsection{CUSTOMER EXPERIENCES}

Although the experiential approach was introduced by Hirschman and Holbrook (1982) and M. B. Holbrook and Hirschman (1982), one of these authors describes that, without realizing it when they developed their approach, "a distinguished lineage for the basic concepts involved could be traced back through the work of (say) Sid Levy at Northwestern in the 196os, Wroe Alderson at Wharton in the 1950s, and the economists Lawrence Abbott in the 1950 or or Alfred Marshall in the early 190os, all the way to Adam Smith in the Eighteenth Century (e.g., Alderson, 1957; Boyd \& Levy, 1963; Woods, 1981)" 
(M. B. Holbrook, 2006, p. 715). Nevertheless, with their experiential approach they put emphasis on this view, where the customer is not only seen as rational, information-processing decision-maker, but emotions like fantasies, feelings, and fun also play a role in consumption.

As highlighted by Kranzbühler et al. (2018), following the initial works of Hirschman and Holbrook (1982) and M. B. Holbrook and Hirschman (1982), researchers investigated the impact of employees, other customers, and environmental variables such as the physical surroundings on the customer's experience at single touchpoints (Bitner, 1990, 1992; Hui \& Bateson, 1991). Also, in the context of individual touchpoints, sensory marketing recently described the use of subconscious triggers to create a sensory customer experience by appealing to the human senses (Achrol \& Kotler, 2012; Krishna, Elder, \& Caldara, 2010; Madzharov, Block, \& Morrin, 2015). In parallel, research emerged extending the concept of customer experience by considering temporal influences. Researchers recognized that experiences can also take place across a longitudinal timeframe and multiple, day-to-day, not necessarily extra-ordinary service encounters, and that past experiences determine current ones (Arnould \& Price, 1993; Carù \& Cova, 2003; Verhoef et al., 2009). Service-dominant logic further validated this temporal influence and dynamic perspective by highlighting that services and the accompanying experiences are at the core of business and the value created is subjective, contextual and experiential (Vargo \& Lusch, 2004). This perspective was extended even further by moving away from the focus on dyadic firm-customer interactions as fundament for experiences, when a broader network of firms and interactions between this network and the customer were incorporated into experience research (Patrício, Fisk, Falcão e Cunha, \& Constantine, 2011). These developments led to the conceptualization of customer experiences on two levels by Kranzbühler et al. (2018): "Static CE [customer experience] is an individual's cognitive, affective and sensory evaluation of one or multiple touchpoints with a firm at one specific point in time. Dynamic CE [customer experience], in contrast, is an individual's evolving cognitive, affective and sensory evaluation of a series of any direct or indirect touchpoints with a firm within the entire course of the customer journey" (Kranzbühler et al., 2018, p. 438). In their framework, static experiences are influenced by the customer experience design, which is under the firm's control, environmental and personal factors, and perceived through the individual's sensory, cognitive, and affective lens (Kranzbühler et al., 2018). The dynamic customer experience in turn is formed by static customer experiences created at various touchpoints with a firm (Kranzbühler et al., 2018). Their proposed framework is depicted in Figure 5.1.

A similar point of view is expressed by Lemon and Verhoef (2016). They "conceptualize customer experience as a customer's 'journey' with a firm over time during the purchase cycle across multiple touch points. We also conceptualize the total customer experience as a dynamic process" (Lemon \& Verhoef, 2016, p. 74). This dynamic and iterative process flows from prepurchase to purchase to postpurchase phases, and incorporates past experiences and purchases, as well as external factors. During this process, customers experience touchpoints in each stage, not all of which are under the firm's control (Lemon \& Verhoef, 2016). Their proposed process model for the customer journey and experience is depicted in Figure 5.2. However, due to a lack of a strong measurement for the overall customer experience along the entire customer 


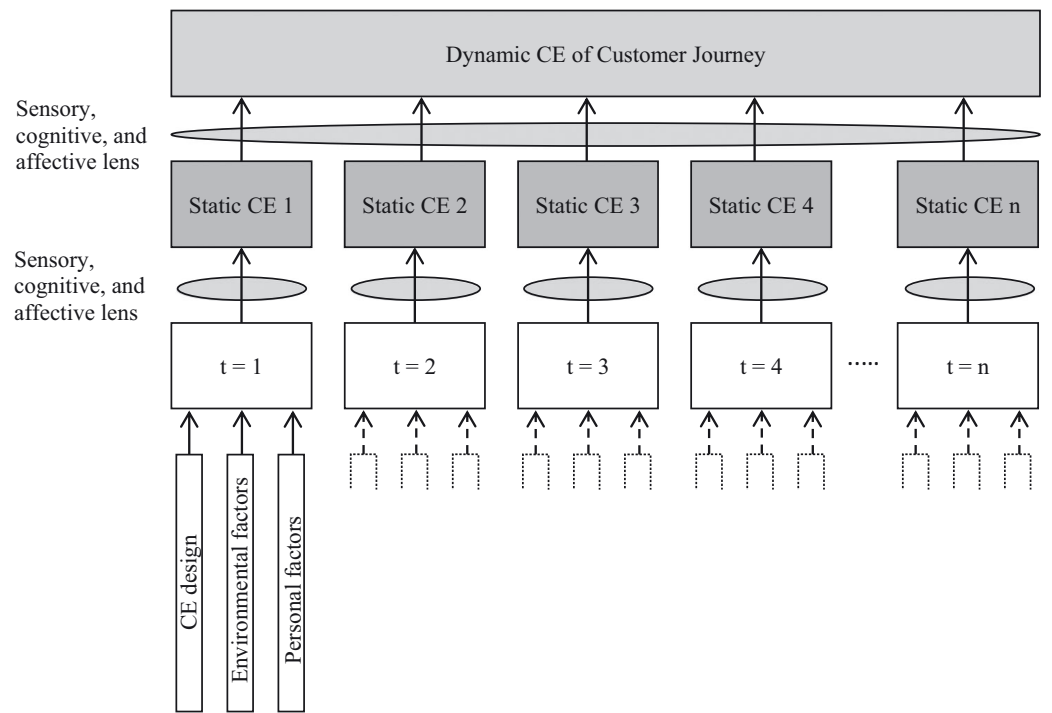

Figure 5.1: Formation of static and dynamic customer experience. Reprinted from Kranzbühler, Kleijnen, Morgan, and Teerling (2018)

journey, Lemon and Verhoef (2016) express the urgent need for the development of such a scale or scales. They describe that this field is still in development and scales on this overall customer experience are "still being evaluated and reviewed for their internal and external validity" (Lemon \& Verhoef, 2016, p. 81 ), and that established measures such as SERVQUAL might provide a good starting point (Lemon \& Verhoef, 2016).

\section{TOUCHPOINTS AND EXPERIENCES}

The management of customer touchpoints is a key issue in experience management. Customers' experiences are formed through experiencing, assessing, and evaluating individual touchpoints and entire journeys with a firm or brand through their own sensorial, emotional, and cognitive lenses (Kranzbühler et al., 2018). A touchpoint is a stimulus that induces a private, individual experience "'of' or 'about' something" (Schmitt \& Zarantonello, 2013, p. 50). The sources that an experience is of or about, and which induce these experiences are manifold, and they spread across all stages of the customer journey (Lemon \& Verhoef, 2016). These experience sources, or touchpoints, range for example from direct interaction with a product, as product experience (Hoch, 2002), to the consumption of a service, as service experience (Klaus \& Maklan, 2012), to store visits as shopping or retail experience, when customers interact with the staff, other customers, or experience the atmospherics of a store (Arnould, Price, \& Zinkhan, 2002; Verhoef et al., 2009). Additionally, all kinds of communication tools, both traditional above-the-line instruments such as advertising and below-the-line instruments such as public relations or event marketing are touchpoints, and as such sources for individual experiences with a firm at a single point in time in the customer journey (Schmitt, Brakus, \& Zaran- 


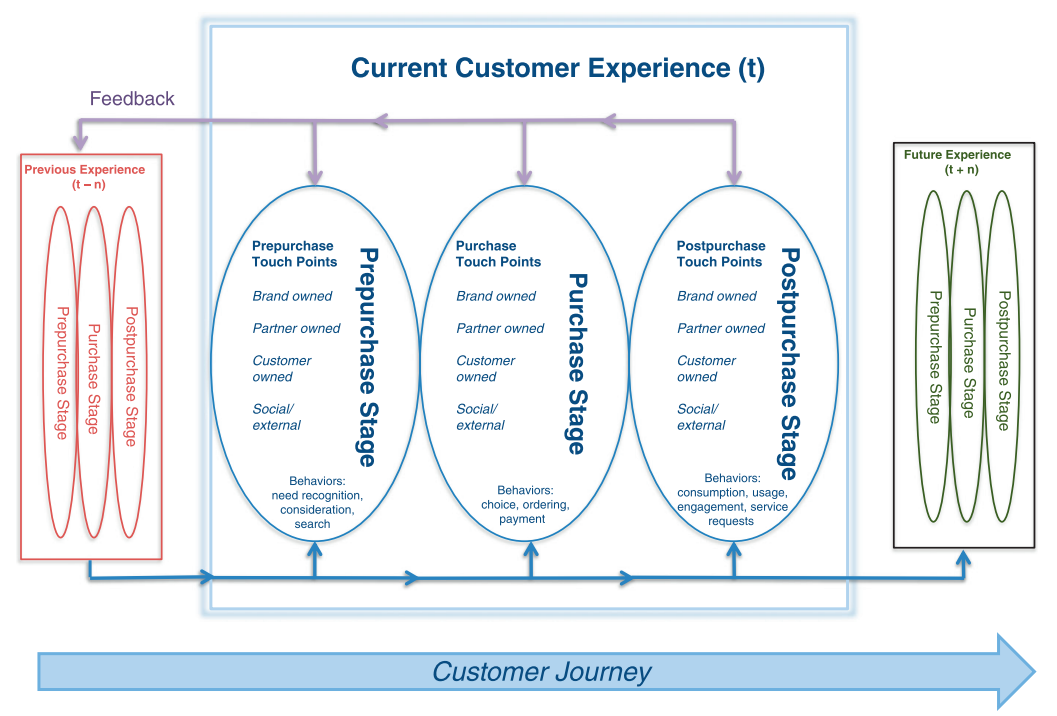

Figure 5.2: Process Model for Customer Journey and Experience. Reprinted from Lemon and Verhoef (2016)

tonello, 2014). The increasing focus on customer experience arises because of the rising complexity of the customer journey (Lemon \& Verhoef, 2016). The increased number of a myriad of touchpoints with a firm on that journey on multiple channels, customer-to-customer interactions through social media, and the increasingly social nature of these touchpoints in general, results in opportunities and challenges for companies. But in general, it becomes increasingly complex for firms to create, manage, deliver, and attempting to control customer experiences (Brynjolfsson, Hu, \& Rahman, 2013; Lemon \& Verhoef, 2016; Libai et al., 2010; Rapp, Baker, Bachrach, Ogilvie, \& Beitelspacher, 2015; Verhoef, Kannan, \& Inman, 2015). Four types of touchpoints with different levels of control by the firm have been identified, and on each stage of the experience, the customer might interact with each of these types (Lemon \& Verhoef, 2016): brand-owned, partner-owned, customer-owned, and social/external/independent touch points. Brand-owned touchpoints include those that are designed, managed, and controlled by the brand itself, such as advertising, websites, or brand-controlled elements of the marketing mix. Partner-owned touchpoints are touchpoints in the customer experience that are jointly designed, managed, or controlled by the brand and its partners, such as channel distribution partners, communication channel partners, or marketing agencies. Customer-owned touchpoints are out of the reach of the brand's control, such as customers' thinking about their desires in the prepurchase phase, or during the consumption of a product or service in the postpurchase stage. Social/external/independent touchpoints reflect the role of, e.g., other customers, peer influences, environments, or other independent information sources on the customer's experience (Lemon \& Verhoef, 2016). All of these touchpoints along the customer journey can be broken down into "experiential stimuli" (Schmitt \& Zarantonello, 2013, pp. 50-51), more specific stimuli that evoke experiences 
at that single touchpoint. For example, "typefaces, logos, colors, and shapes appear at experience touchpoints as part of the graphic designs of slogans and messages and as graphic elements on Web sites and in shopping environments" (Schmitt \& Zarantonello, 2013, pp. 50-51). The complex question remains for experience management, which of these stimuli evoke which experiences at various touchpoints, and how the dimensions or stimuli of individual touchpoints relate to the dimensions of experiences or evoke experiences (Lemon \& Verhoef, 2016; Schmitt, 2009; Schmitt \& Zarantonello, 2013).

Due to the myriad number of touchpoints and their different natures, one single scale encompassing all touchpoints and their stimuli and dimensions is barely imaginable. Instead, and although it is a complex endeavor, we argue for individual experience scales for single touchpoints which evaluate what dimensions or stimuli at this touchpoint evoke or contribute to the experience at that individual touchpoint. These could be scales for all touchpoints, where customers 'make' an experience, such as product and user experience scales, retail experience scales, service experience scales, or event marketing experience scales, to just name a few. The recent conceptualization of such scales and concepts support our case (Bustamante \& Rubio, 2017; Hassenzahl, Diefenbach, \& Göritz, 2010; Klaus \& Maklan, 2012; Tafesse, 2016).

\subsection{BRANDS AND EXPERIENCES}

Branding literature has evolved in its logic of branding and the meaning of the brand considerably. Since the early 1900s, where brands were seen as identifiers, this evolution moved towards the notion of brands as functional and symbolic images between the 1930s and the 1990s, to the logic of brands as knowledge, relationship partner and promise, towards today's status, where brands and their value are seen within dynamic and social processes (Merz, He, \& Vargo, 2009).

Around the time of the evolution towards the service-dominant logic, brands were conceptualized to "reflect the complete experience that customers have with products" (Keller \& Lehmann, 2006, p. 740). In light of the servicedominant logic, we propose that this reflection of experiences by a brand goes beyond products and includes services and all other touchpoints during the customer journey. This is in line with Brakus et al.'s 2009 conceptualization of the brand experience as "subjective, internal consumer responses (sensations, feelings, and cognition) and behavioral responses evoked by brand-related stimuli that are part of a brand's design and identity, packaging, communications and environments" (Brakus et al., 2009, p. 53). While some of the experience constructs mentioned in the previous section refer to specific phases of the customer journey, brand experience is considered to span all phases (Nysveen, Pedersen, \& Skard, 2013). According to Brakus et al.'s conceptualization of their brand experience scale, it is not measuring the experience with brands at individual touchpoints. Instead, their brand experience scale evaluates the internal experiences that are evoked by brands as sources of these experiences: "In addition, when consumers complete brand experience scales, such scales are usually not directly assessing the dynamic, 'online' experience of the consumer in the here and now; rather, such scales typically assess a lasting trace stored in long-term memory based on multiple exposures to brand-related stimuli" (Brakus et al., 2009, p. 55). Furthermore, "brand experiences arise in a 
variety of settings when consumers search for, shop for, and consume brands. Accordingly, we conceptualized brand experience as subjective consumer responses that are evoked by specific brand related experiential attributes in such settings. We demonstrated that brand experience can be broken down into four dimensions (sensory, affective, intellectual, and behavioral), which are differentially evoked by various brands" (Brakus et al., 2009, p. 65). Therefore, we propose that this internal response to a brand, evoked by brand-related stimuli or touchpoints, reflects the complete, dynamic, overall experience that customers 'have' with a brand along the customer journey as proposed by Kranzbühler et al. (2018) and Lemon and Verhoef (2016). Figure 5.3 summarizes our proposals in a holistic brand experience framework.

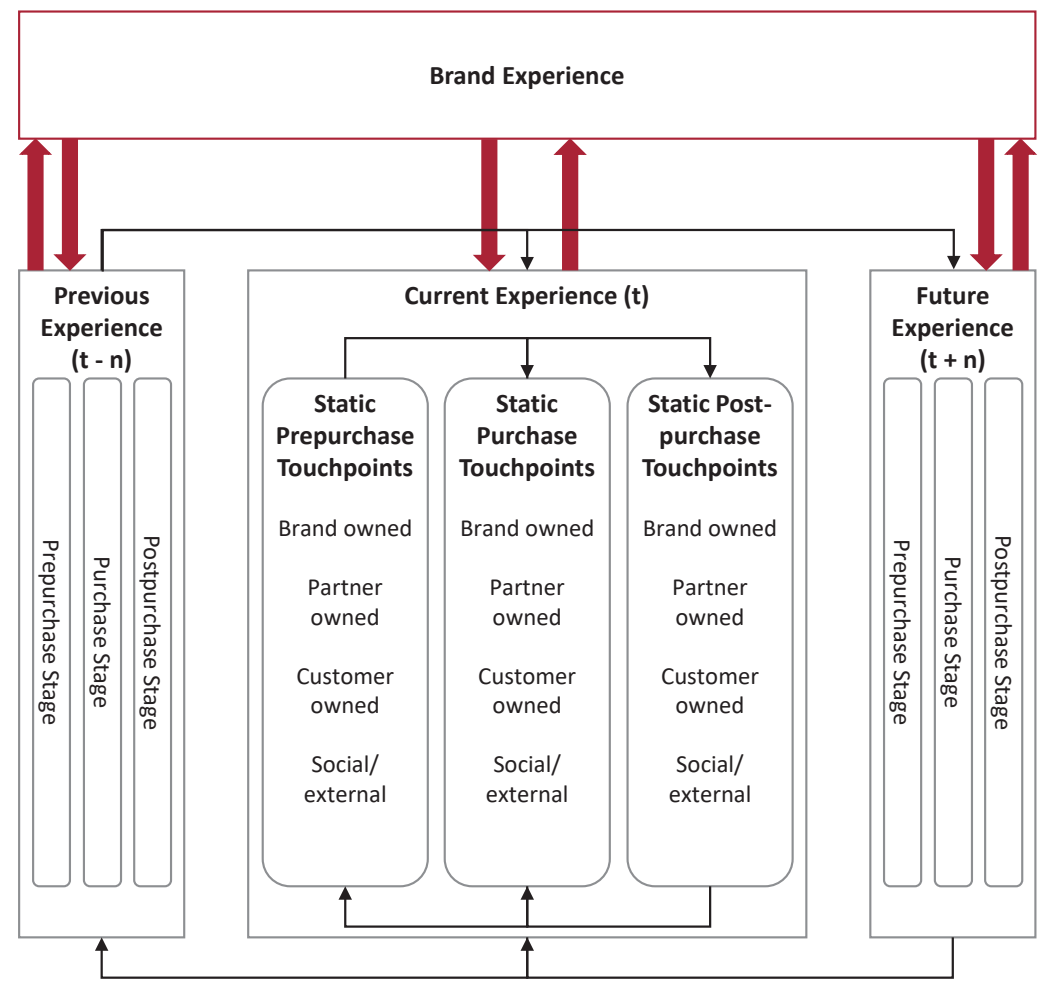

Figure 5.3: Customer Journey and Dynamic Nature of Brand Experience. Based on Lemon and Verhoef (2016) and Kranzbühler, Kleijnen, Morgan, and Teerling (2018)

\section{$5 \cdot 5$ CONCLUSION AND IMPLICATIONS}

There is a need to conceptually link findings from specific experience areas, and to generalize from them to overarching principles of experiences (Schmitt \& Zarantonello, 2013). Building on recent syntheses and conceptualizations (Kranzbühler et al., 2018; Lemon \& Verhoef, 2016), we contribute to this discus- 
sion and synthesis by proposing a framework that we think answers questions that have been put forward within that discussion.

Regarding the role of the brand in the customer experience and the customer journey, we follow the conceptualization that brands reflect all customer experiences with a brand along the customer journey (Keller \& Lehmann, 2006). Thus, the experiences that brands evoke within the customer (sensory, affective, behavioral, and intellectual) represent these overall experiences that customers have with a brand along the customer journey (Brakus et al., 2009) This conceptualization allows for the measurement of the overall brand experience across multiple touchpoints and multiple stages, and thus answers another question put forward by Lemon and Verhoef (2016). By linking the brand experience concept to the framework of static and dynamic experiences proposed by Kranzbühler et al. (2018), we propose that static experiences, i.e. single touchpoints, reflect the brand related stimuli that compose the overall, i.e. dynamic, brand experience.

With respect to future research, we suggest the empirical validation of our framework. Additionally, due to the vast amount and increasingly different nature of these individual touchpoints (e.g. product experiences vs. social media experiences related to a brand), separate measurement scales will be needed, at least for groups of similar touchpoints. Experimental and quasiexperimental research designs then allow for the investigation of the effects of different touchpoints and their experiential stimuli on the overall brand experience and its dimensions, by measuring it before and after exposure to a touchpoint.

Since Brakus et al.'s 2009 brand experience scale does not reflect the experiences at a single point in time, longitudinal studies also allow for the investigation of the effects of multiple touchpoints on each other, and on brand experience along the entire customer journey. Since the brand experience scale only measures strength and not valence of the experiences, for theoretical and managerial purposes it might be necessary to slightly reword the individual items, in order to evaluate whether the overall experience is influenced positively or negatively by various touchpoints (Brakus et al., 2009).

We have brought together two similar, but still different frameworks of the customer experience along the customer journey (Kranzbühler et al., 2018; Lemon \& Verhoef, 2016), by integrating the brand and brand experiences as the conceptual link between both. We think that our contribution to the theoretical discussion on the synthesis of the experience literature will also be valuable for marketing practice, by providing a framework that allows for the measuring and evaluation of the influence of individual touchpoints on the overall experience with the brand. 

In this chapter, whether a visit to a $\mathrm{B}_{2} \mathrm{~B}$ brand world increases the levels of the crucial branding outcomes of brand experience and brand equity, i.e. whether brand worlds work in industrial marketing, is quantitatively investigated. This step also shows how the brand world works on a macro-level from an experiential marketing perspective, by analyzing how the co-created brand world experience relates to pre-visit and post-visit brand experience and brand equity in a nomological net, using partial least squares structural equation modeling.

PUBLICATION HISTORY:

The earliest, work-in-progress version of this chapter, written together with Prof. Dr. Marc Kuhn and Prof. Dr. Jörg Henseler, was submitted as an extended abstract to the Academy of Marketing Science (AMS) Annual Conference 2019. A shortened, full paper version of this chapter, written together with Prof. Dr. Marc Kuhn and Prof. Dr. Jörg Henseler, was also submitted to the 9th BMM-EMAC Biennial International Conference on Business Market Management 2019.

REFERENCES TO PREVIOUS PUBLICATIONS:

By the time of printing this thesis, this paper was still under review.

KEYWORDS:

brand worlds, experiences, brand experience, brand equity, B2B, PLS, PLSc 


\section{ENTERING B2B BRANDS' LIVING ROOMS: HOW BRAND WORLDS CAN HELP BUILD BRAND EQUITY}

\section{ABSTRACT}

Understanding, creating and managing strong brands and favorable customer experiences are important issues for business marketing practitioners and academics. Brand worlds are amongst the strongest means of branding in $\mathrm{B}_{2} \mathrm{C}$, based on the experiential marketing techniques employed there. $\mathrm{B}_{2} \mathrm{~B}$ practitioners use these instruments for branding purposes as well. Yet, nuances of industrial marketing raise the question, whether brand worlds are effective in this different context. This article therefore investigates the impact of a brand world visit in industrial marketing on levels of brand experience and brand equity, based on a sample of 218 business visitors in a pretest-posttest quasi-experimental design. Next to a pretest-posttest comparison, we used partial least squares structural equation modeling to understand the role of the experience co-created at the brand world. We found that the visit significantly increases levels of brand experience and brand equity. The experience at the individual touchpoint of the brand world mediates the relationship between pre- and post-visit brand experience. It is not influenced by pre-visit brand equity. Yet, this brand world experience influences post-visit brand equity directly and indirectly through post-visit brand experience. Our findings thus expand the conceptualization of customer experience as a dynamic concept from $\mathrm{B}_{2} \mathrm{C}$ to $\mathrm{B}_{2} \mathrm{~B}$, and show that it also holds in this different context. This study furthermore shows that, using experiential marketing techniques, brand worlds as 'living room of the brand' are also strong branding instruments in industrial marketing.

\subsection{INTRODUCTION}

In today's world, brands are one of the most valuable, intangible assets for companies (Kotler \& Pfoertsch, 2006). They are ubiquitous and serve several important functions (see for example Kapferer, 2012; Keller, 2013). While in earlier days the relevance of brands was perceived to be limited to consumer markets, nowadays, despite the important role of functional and rational aspects in organizational buying decisions, "branding is just as relevant in B2B as it is in $\mathrm{B}_{2} \mathrm{C}^{\prime \prime}$ (Kotler \& Pfoertsch, 2006, p. 12). Some of the most valuable brands today are $\mathrm{B}_{2} \mathrm{~B}$ brands, such as GE, Cisco, or IBM (Interbrand, 2018). Yet, B2B branding research is still considered relatively novel (B. P. Brown et al., 2012; Gomes et al., 2016; Keränen et al., 2012; Leek \& Christodoulides, 2011a, 2011b; Mohan et al., 2018; Seyedghorban et al., 2016). A general finding in the consumer marketing area, which also holds for the realm of industrial marketing, is that brands are conceptualized to reflect the complete experience that customers have with products, services, marketing activities, and other brand-related stimuli along all touchpoints (Brakus et al., 2009; Keller \& Lehmann, 2006; Kotler \& Pfoertsch, 2006), or in other words, the "experience is the brand" (Prahalad, 2004, p. 23).

Improving customer experience is a top business priority for companies today (Accenture, 2015). Marketing science highlights the importance of customer experiences as well, stating that understanding, creating, and managing 
customer experiences is a top research priority, and one of the most important research challenges (Lemon \& Verhoef, 2016; Marketing Science Institute, 2014, 2016). Customer experience is described as a multidimensional concept (Lemon \& Verhoef, 2016), spanning "the customer's subjective response to the holistic direct and indirect encounter with the firm" (Lemke, Clark, \& Wilson, 2011, p. 848). The increasing importance of customer experience is not only prevalent in $\mathrm{B}_{2} \mathrm{C}$, but also in $\mathrm{B}_{2} \mathrm{~B}$ markets, where customer experiences are just as crucial, yet research on the topic is much more limited (Lemke et al., 2011; Pine \& Gilmore, 1998; Zolkiewski et al., 2017). This strong focus on customer experiences originates in the increasing number and complexity of touchpoints in multiple channels and media, through which customers interact with firms, leading to more complex customer journeys (Lemon \& Verhoef, 2016). The increasingly social nature of customer experience, for example due to the rise of social media and customer-to-customer interactions on these platforms, has made it more difficult for firms to create, manage, and attempt to control the experiences of the customer (e.g. Brynjolfsson et al., 2013; Lemon \& Verhoef, 2016; Rapp et al., 2015).

As stated before, creating customer experiences is a top research priority (Lemon \& Verhoef, 2016; Marketing Science Institute, 2014, 2016). Experiential marketing refers to the strategies of staging and creating offerings for the purpose of facilitating extraordinary experiences (Carù \& Cova, 2003; Pine \& Gilmore, 1999). Yet, since experiences are subjectively felt emotions, they cannot be made or guaranteed by companies, but only induced - they are dependent on the processing and reception of each individual customer, and are co-created (Kilian, 2009; Schmitt \& Zarantonello, 2013). It is therefore crucial for companies to create an environment which contributes to the evoking of the desired experiences within the individual (Schmitt, 1999b). Real, physical venues have been mentioned as a possibility for $\mathrm{B} 2 \mathrm{~B}$ companies to evoke strong, memorable customer experiences (Gilmore \& Pine, 2002; Pine \& Gilmore, 1999; Schmitt, 1999b), yet only trade shows have been investigated from an experiential perspective on business markets. Thus, more research on other experiential environments and the determinants of their effectiveness is necessary (Rinallo et al., 2010).

'Brand worlds' are such environments. The term brand world is an umbrella term for permanent, physical, branded spaces such as flagship stores, brand stores, brand lands, brand museums, or customer experience centers (Gilmore \& Pine, 2002; Österle, Kuhn, \& Henseler, 2018a). In essence, they are branding instruments in which experiential marketing techniques are applied (Österle et al., 2018a). Through powerful branded experiences based on the direct, highly interactive, personal, and local visitor-brand encounters, these environments can evoke a meaningful and significant image of the brand (Borghini et al., 2009; E. H. Wood, 2009; Zarantonello \& Schmitt, 2013). To add to this, these spaces are also largely under the control of the operating company and thus provide it with the opportunity to display its brand's identity in a pure and non-diluted way (Kozinets et al., 2002). As such, flagship stores have even been called the "home of the brand" (Moore et al., 2010, p. 153) and the "apex of branding" (Dolbec \& Chebat, 2013, p. 460), and it is little surprising that these spaces have gained increasing popularity amongst $\mathrm{B}_{2} \mathrm{C}$ companies. Examples include Apple with their flagship stores, car manufacturers with their brand museums or in the case of VW's Autostadt entire brand lands, or, not to forget, Disney 
and its Disney Worlds, to only name a few. Given the outlined increasing importance of branding, experiences, and also subjective evaluations, heuristics, and emotions in B2B (Casidy et al., 2018; Iyer et al., 2015; Mohan et al., 2018; Zablah et al., 2010) it is equally little surprising, that also industrial marketing practitioners have noted the potential of these instruments for their own brands. In fact, brand worlds of industrial companies can be found all over the world: General Electric, Honeywell, and ABB operate customer experience centers in the US, logistics provider DHL an Innovation Center and Austrian steel producer Voestalpine a brand land in Europe, and Mitsubishi Heavy Industries the Minatomirai Industrial Museum in Asia, for example. While their B2C counterparts have attracted some academic attention already, and their impact on brand related goals is proven (Dolbec \& Chebat, 2013), researchers call for caution when transferring findings and implications from $\mathrm{B}_{2} \mathrm{C}$ to $\mathrm{B}_{2} \mathrm{~B}$, because of the different context (Keränen et al., 2012; Seyedghorban et al., 2016). Furthermore, researchers call for further research on experiential marketing instruments in industrial markets (Rinallo et al., 2010). Brand worlds in the industrial marketing area have only been investigated recently. So far, based on qualitative, exploratory work, the motives of industrial companies to implement brand worlds, the expectations that $\mathrm{B}_{2} \mathrm{~B}$ visitors have, the value they derive from the visit, the nature of $\mathrm{B}_{2} \mathrm{~B}$ brand worlds and what they are constituted of, how they are perceived, how the experience at brand worlds is co-created, and how $\mathrm{B}_{2} \mathrm{~B}$ brand worlds differ from their $\mathrm{B}_{2} \mathrm{C}$ counterparts have been investigated (Österle et al., 2018a, 2018b).

Yet, research to date has not answered a key managerial question of utmost importance related to the effectiveness of these apexes of branding in $\mathrm{B}_{2} \mathrm{~B}$ : are the outcomes that operating companies set out to achieve with the experiences at $\mathrm{B}_{2} \mathrm{~B}$ brand worlds also actually achieved? The purpose of this research therefore is to investigate the impact of a $\mathrm{B}_{2} \mathrm{~B}$ brand world visit, and the experiences that are co-created there, on two key branding outcomes that operating companies pursue with $\mathrm{B}_{2} \mathrm{~B}$ brand worlds: brand experience and brand equity.

This research contributes to the overall understanding of the $\mathrm{B}_{2} \mathrm{~B}$ counterparts of one of the most powerful branding instruments in $\mathrm{B}_{2} \mathrm{C}$, namely brand worlds (Österle et al., 2018a). By being, to the best of our knowledge, the first study to investigate their effectiveness regarding customer experience and branding outcomes, it also contributes to the understanding of industrial customer experiences and experiential marketing in business markets (Rinallo et al., 2010), as well as to research on brand building tactics and brand management in business markets in general (Lindgreen et al., 2010). It also contributes to research on customer experience in $\mathrm{B}_{2} \mathrm{C}$ as well as in $\mathrm{B}_{2} \mathrm{~B}$, by explicating the effect of an experience at an individual touchpoint on the overall brand experience and subsequent experience outcomes (Kranzbühler et al., 2018; Lemon \& Verhoef, 2016; Zolkiewski et al., 2017). Practically, this study shows that $\mathrm{B}_{2} \mathrm{~B}$ brand worlds are indeed effective in increasing brand experience and brand equity levels, which has important implications for business marketers.

The remainder of this paper is structured as follows. To provide the context, we briefly outline the current state of research relevant for this study on $\mathrm{B} 2 \mathrm{~B}$ branding and on customer experiences, with a focus on brand equity and brand experience, respectively. We then turn to the object under investigation, namely brand worlds in industrial marketing, and elaborate on them. Subsequently, 
we develop our conceptual model and the hypotheses that are tested in this study. Next, our empirical study is described. We then present the results of our analysis, before we interpret them, relate them back to theory, and provide theoretical and managerial implications as well as future research areas in the discussion.

\subsection{BACKGROUND}

\subsection{1 $\quad B 2 B$ branding and $B 2 B$ brand equity}

Research on branding in business or industrial markets has undergone a development from being irrelevant towards a separate and acknowledged, yet still relatively nascent field of study (Kotler \& Pfoertsch, 2006; Leek \& Christodoulides, 2011b; Mohan et al., 2018; Seyedghorban et al., 2016). This can be traced back to the pressures of commoditization, growing customer power, globalization, price, and a decreasing number of personal relationships originating in digital communications, which have led companies to turn to branding to gain a sustainable competitive advantage (Baumgarth \& Schmidt, 2010; Keränen et al., 2012; Kotler \& Pfoertsch, 2007; Leek \& Christodoulides, 2011b; Mudambi et al., 1997; Walley et al., 2007). When reliability, functionality, and the quality of products are now assumed as minimum requirements (Lynch \& de Chernatony, 2007), researchers actually state that even in the industrial field, branding may represent one of the last means by which companies can create a sustainable competitive advantage (Ohnemus, 2009). This development goes hand in hand with the fact that, while functional and rational components are still important, the role of affective and emotional components, subjective evaluations and heuristics in $\mathrm{B}_{2} \mathrm{~B}$ buying decisions and relationships is more and more acknowledged by scholars (Bagozzi, 2006; Casidy et al., 2018; Iyer et al., 2015; Leek \& Christodoulides, 2012; Lynch \& de Chernatony, 2007; Mohan et al., 2018; Zablah et al., 2010).

As in the $\mathrm{B}_{2} \mathrm{C}$ area, brands in $\mathrm{B}_{2} \mathrm{~B}$ are build on the experiences that customers and other stakeholders make with the brand along all possible, direct and indirect touchpoints (Ballantyne \& Aitken, 2007; Biedenbach \& Marell, 2010; Y. J. Wang, Capon, Wang, \& Guo, 2018; Zaichkowsky, Parlee, \& Hill, 2010). Among others, benefits of strong brands in $\mathrm{B}_{2} \mathrm{~B}$ include risk and complexity reduction, an increase of perceived product quality, support in building trust and sustainable business relationships; furthermore, they enable premium pricing strategies and even improve firm financial value (Backhaus, Erichson, \& Weiber, 2011; Bendixen et al., 2004; Homburg, Klarmann, \& Schmitt, 2010; Kotler \& Pfoertsch, 2006; Leek \& Christodoulides, 2011b, 2012; Marquardt, 2013; Michell et al., 2001; Wise \& Zednickova, 2009), and investing in brands can therefore lead to potential performance benefits (Casidy et al., 2018; Mohan et al., 2018; Voss \& Mohan, 2016).

The value that a brand has for its company, brand equity, is a key concept for marketing academics and a highly important intangible asset (Christodoulides, Cadogan, \& Veloutsou, 2015; Kotler \& Pfoertsch, 2006). One of the most commonly used definitions for brand equity stems from the consumer marketing literature and describes it as assets and liabilities which are linked to a brand, its name and symbol. These contribute to or diminish the value provided by a product or service to a company or its customers (D. A. Aaker, 1991). It is 
thus understood as the customer perception of the total benefits that a brand carries, also in B2B marketing literature (D. A. Aaker, 1996a; Baumgarth \& Binckebanck, 2011; Bendixen et al., 2004; Y. J. Wang et al., 2018; Zaichkowsky et al., 2010). Although a full consensus about the conceptualization and dimensions of brand equity in B2B has not been reached yet (Biedenbach, 2012; van Riel et al., 2005; Y. J. Wang et al., 2018), D. A. Aaker's (1991, 1996a) initial brand equity conceptualization as a multidimensional concept, consisting of brand awareness, brand associations, perceived quality, and other proprietary brand assets, has widely been used and proven to be relevant in industrial environments as well (e.g. Bendixen et al., 2004; Biedenbach, 2012; Biedenbach, Bengtsson, \& Marell, 2015; Biedenbach, Bengtsson, \& Wincent, 2011; Y.-M. Chen, Su, \& Lin, 2011; Davis et al., 2008; Jensen \& Klastrup, 2008; van Riel et al., 2005; Yoo, Donthu, \& Lee, 2000; Zhang, Jiang, Shabbir, \& Du, 2015).

\subsubsection{Customer experience and brand experience}

The importance of experiences for marketing was already voiced in the 1950, with Abbott (1955) stating that "what people really desire are not products but satisfying experiences" (p. 39). This idea gained importance in marketing practice and science with the development of the experiential approach, which focuses on the important role of fantasies, feelings, and fun in the consumption experience (Hirschman \& Holbrook, 1982; M. B. Holbrook \& Hirschman, 1982), and subsequently with the developments of the experience economy and experiential marketing, up to the experience society (Pine \& Gilmore, 1998; Schmitt, 1999b; Schulze, 2005).

Customer experiences are today at the center of both marketing practitioner's and academic's attention in $\mathrm{B}_{2} \mathrm{C}$ and $\mathrm{B}_{2} \mathrm{~B}$ (Accenture, 2015; Marketing Science Institute, 2014, 2016; Zolkiewski et al., 2017). But despite the attention already decades ago, research on experiences in marketing is still nascent, emerging, and fragmented, even more so in the $\mathrm{B}_{2} \mathrm{~B}$ area than in $\mathrm{B}_{2} \mathrm{C}$ (Kranzbühler et al., 2018; Lemon \& Verhoef, 2016; Schmitt \& Zarantonello, 2013; Zolkiewski et al., 2017). In general, customer experience is defined as a multidimensional construct, focusing on a customer's subjective, cognitive, emotional, behavioral, sensorial, and social responses to the holistic direct and indirect encounter with the firm and its offerings during the entire purchase journey (Lemke et al., 2011; Lemon \& Verhoef, 2016). It thus includes but is not limited to the communication encounter, the service encounter and the consumption encounter (Lemke et al., 2011). While positive experiences in $\mathrm{B} 2 \mathrm{C}$ should be engaging, robust, compelling, and memorable (Gilmore \& Pine, 2002), positive $\mathrm{B}_{2} \mathrm{~B}$ experiences are trouble-free and reassuring, and are based on reducing customer effort (Cardozo, 1965; C. Meyer \& Schwager, 2007; Zolkiewski et al., 2017). Several streams of research have investigated the dimensions, facets and aspects of the customer experience, such as product experiences, service experiences, shopping experiences, day-to-day ordinary and extraordinary experiences, as well as brand experiences (Brakus et al., 2009; Carù \& Cova, 2003; Hoch, 2002; Hui \& Bateson, 1991; Kerin et al., 1992; Lemon \& Verhoef, 2016). Yet, there is a need to conceptually link the findings from these specific experience areas, and to generalize from them to overarching principles of experiences (Schmitt \& Zarantonello, 2013). 
Recently, researchers have therefore conceptualized the total customer experience as a dynamic process along the customer's journey with a firm across multiple touchpoints in the purchase cycle, where previously made experiences influence current and future experiences (Lemon \& Verhoef, 2016). In a similar vein, the customer experience is conceptualized as consisting of static customer experience and dynamic customer experience (Kranzbühler et al., 2018). The static customer experience is an individual's sensory, affective, and cognitive evaluation of one or several touchpoints with a company at one specific point in time. The dynamic customer experience, on the other hand, is an individual's evolving sensory, affective, and cognitive of a several direct or indirect touchpoints with a firm within the entire course of the customer journey (Kranzbühler et al., 2018).

A sound measurement scale for the measurement of the overall customer experience is lacking, research on the effects of different touch points on customer experience is, too, and the role of the brand in the customer experience and customer journey is unclear (Lemon \& Verhoef, 2016).

Yet, as stated in Section 6.2.2, brands reflect the complete experience that customers have with a firm along all touchpoints (Keller \& Lehmann, 2006). The concept of brand experience is defined as "subjective, internal consumer responses (sensations, feelings, and cognition) and behavioral responses evoked by brand-related stimuli that are part of a brand's design and identity, packaging, communications and environments" (Brakus et al., 2009, p. 53), and it entails sensory, affective, behavioral, and intellectual experience dimensions (Brakus et al., 2009). Given the similarity between the definition of brand experience and the overall customer experience, it is necessary to provide a further specification for brand experience. As outlined above, the experience that relates to a brand is one of multiple facets or aspects of the overall, multidimensional customer experience, which also comprises aspects such as technology (Lemon \& Verhoef, 2016). When it comes to measuring brand experiences, a characteristic of the most prominent brand experience measurement scale is that it does not assess the experience with a brand at an individual touchpoint (Brakus et al., 2009). Instead it evaluates a lasting trace stored in long-term memory, which dynamically evolves based on multiple exposures to and touchpoints with brand-related stimuli (Brakus et al., 2009). Furthermore, customer satisfaction with the brand increases with higher scores on the brand experience scale, i.e. the more a brand evokes multiple experience dimensions (Brakus et al., 2009). As such, while several experience scales focus on specific phases in the customer journey (i.e. shopping experience) or specific offerings and touchpoints (i.e. service experience), the brand experience concept and the related scale by Brakus et al. (2009) are seen as the broadest and most comprehensive experience construct, and could be used to measure the overall experience with a brand across all touchpoints (Lemon \& Verhoef, 2016; Nysveen et al., 2013; Zarantonello \& Schmitt, 2010). Furthermore, brand experience is increasingly recognized as important also in managerial practice, and recent research has set out to stimulate a renaissance of brand experience to further academic understanding of this central marketing concept (Andreini et al., 2018). Practically, while the concept and its measurement scale were developed in a consumer context, it is argued that the same scale can be used with other stakeholders as well (Saari \& Mäkinen, 2016). 


\subsubsection{Brand worlds in industrial marketing}

In a society where brands play an ever increasing role, brand worlds have become the new places of pilgrimage (Borghini et al., 2009; Hollenbeck et al., 2008; Riewoldt, 2002). 'Brand world' is an umbrella term for permanent branded locations, which are an instrument of branding and experiential marketing, such as flagship stores, brand museums, customer experience centers, or brand lands (Österle et al., 2018a). In the consumer marketing area, they deliver an experience much stronger than regular advertising due to their direct, highlyinteractive visitor-brand encounters, which evoke a meaningful and significant image of the brand (Borghini et al., 2009; Zarantonello \& Schmitt, 2013), and they create a unique customer experience in an environment largely controlled by the operating company (Kozinets et al., 2002). As such, locations such as the Apple flagship stores, the World of Coca-Cola in Atlanta, GA, or the Volkswagen Autostadt in Wolfsburg, GER, are one of the strongest means of brand communication in $\mathrm{B}_{2} \mathrm{C}$ (Kozinets et al., 2002), and also called "the apex of branding" (Dolbec \& Chebat, 2013, p. 460) or the "home of the brand" (Moore et al., 2010, p. 153). Within the context of the previous conceptualizations of customer experience, they are one possible touchpoint along the entire customer journey.

Such spaces also exist in various industrial markets, for example in the form of customer experience centers, visitor centers, brand museums, showrooms, or innovation centers (AB VOLVO, 2018; Caterpillar Inc., 2016; Deutsche Post DHL Group, 2016; General Electric Company, 2015; Honeywell Safety Products, 2016; Mack Trucks Inc., 2016; ZF Friedrichshafen AG, 2016). While they adapt the same underlying principles of experiential marketing and share other similarities, they also differ substantially from their $\mathrm{B}_{2} \mathrm{C}$ counterparts in several aspects (Österle et al., 2018b). B2C brand world visitors mainly seek for autotelic, hedonic, and emotional experiences based on entertainment, information, flow, relaxation, diversity, escapism, community and a general sense of well-being and appreciation by the operating company. Their visit is often unrelated to a specific buying situation and motivated mostly by the visitors themselves (Kirchgeorg et al., 2012; Opaschowski, 2000; Österle et al., 2018a, 2018b; Zentes et al., 2014). Business visitors to B2B brand worlds, on the other hand, have more utilitarian expectations. They want the visit to support them in their own business activities, rather than it being an end in itself. The visit is usually related to a specific buying situation or an addition to their business activities, such as for example meetings or negotiations, and often the visitors are invited by the operating company to the brand world (Österle et al., 2018a). The B2B brand worlds are used by their operating companies as "threedimensional business cards" (Österle et al., 2018a, p. 86), in that they give operating companies the opportunity to present their brands, values and identities, as well as their products and services in the flesh and at a glance (Österle et al., 2018a). In these extraordinary and stimulating spaces, business visitors are provided with various kinds of valuable, direct information in a personal, tailored experience catered to their specific needs. They can personally get to know the brand and get a feel for it and its employees, which other marketing instruments can hardly provide (Österle et al., 2018a). Therefore, the goals that operating companies pursue with the implementation of a brand world in an industrial marketing area are quite similar to their $\mathrm{B}_{2} \mathrm{C}$ counterparts, 
namely the provision of hands-on product experiences, as well as to increase product awareness, brand awareness, brand associations, perceived quality, and building customer relationships and loyalty - which can be summarized in an increase of brand equity (Österle et al., 2018a, 2018b). Indeed, also similar to their equivalents in $\mathrm{B}_{2} \mathrm{C}, \mathrm{B}_{2} \mathrm{~B}$ brand worlds have been reported to be superior to any other marketing instrument in conveying the brand's identity and portfolio in its full breadth and depth, due to the direct, personal, and strong brand experience they provide in this permanent branded space (Österle et al., 2018a)

Like experiences in tourism or $\mathrm{B}_{2} \mathrm{C}$ brand worlds, visitor experiences in such B2B brand worlds are co-created on-site (Campos, Mendes, Valle, \& Scott, 2015; Carù \& Cova, 2007; Dolbec \& Chebat, 2013; Kozinets et al., 2004; Österle et al., 2018a). Two things are at the core of this experience co-creation in $\mathrm{B}_{2} \mathrm{~B}$ brand worlds: the $\mathrm{B}_{2} \mathrm{~B}$ brand world experiencescape, which reflects the operating company's contribution, and the embodied cognition of the B2B brand world, reflecting the visitors' contribution to how they experience the $\mathrm{B}_{2} \mathrm{~B}$ brand world (Österle et al., 2018a). The B2B brand world experiencescape consists of two dimensions: physical artifacts and spaces on the one hand, and the social environments and practices constructed in the $\mathrm{B}_{2} \mathrm{~B}$ brand world on the other hand. They are both largely under the control of the operating company and carefully designed and managed (Österle et al., 2018a). A third dimension, which manifests in these physical artifacts and spaces in the form of the design, the exhibits, and the overall atmosphere, as well as in the employee behavior, attitude, and expertise, are the information and contents which the operating company wants to convey in the B2B brand world (Österle et al., 2018a). As such, the entire $\mathrm{B}_{2} \mathrm{~B}$ brand world itself can be seen as an artifact (Henseler, 2017a; Hollenbeck et al., 2008; Österle et al., 2018a). In a joint action-perception cycle, the overall experience of the visitor in the $\mathrm{B}_{2} \mathrm{~B}$ brand world is then cocreated based on the visitor's contribution to it, the embodied cognition. This embodied cognition encompasses the dimensions interaction, and involvement and immersion with the physical and social environment provided by the operating company in the B2B brand world experiencescape, and the visitor's subjective perception thereof (Österle et al., 2018a).

\subsubsection{Conceptual Model and hypotheses}

The dynamic nature of customer experiences and brand experiences, as outlined in Section 6.2.2, provide the framework for our conceptual model. Findings suggest that the experiences made at individual touchpoints influence the overall customer experience with a brand along the customer journey (Kranzbühler et al., 2018; Lemon \& Verhoef, 2016). The brand experience construct assesses "a lasting trace stored in long-term memory based on multiple exposures to brand-related stimuli" (Brakus et al., 2009, p. 55). The higher the brand experience, meaning the more experience dimensions are evoked by the brand, the more satisfied the consumers will be with the brand in total (Brakus et al., 2009). Brand experience is therefore seen as the most comprehensive experience construct, and to reflect the overall experience a customer has with a brand (Lemon \& Verhoef, 2016; Nysveen et al., 2013).

The branding power of brand worlds is evident in $\mathrm{B}_{2} \mathrm{C}$ (Diamond et al., 2009; Dolbec \& Chebat, 2013; Kozinets et al., 2002). Whether in $\mathrm{B}_{2} \mathrm{~B}$ or $\mathrm{B} 2 \mathrm{C}$, they are artifacts designed with the goal to induce positive brand experiences 
in the visitor (Dolbec \& Chebat, 2013; Österle et al., 2018a). Furthermore, experiential marketing instruments and the related tools of event marketing, where consumers encounter brands interactively and directly, are considered to be instruments that companies can use to generate brand experiences based on the multitude of brand-related stimuli evoked there (Wohlfeil \& Whelan, 2005, 2007; Zarantonello \& Schmitt, 2013). In fact, events are explicitly mentioned as sources and antecedents of brand experiences in various contexts (Andreini et al., 2018; Brakus et al., 2009; Fransen, van Rompay, \& Muntinga, 2013; Khan \& Fatma, 2017; Khan \& Rahman, 2016). Additionally, the environment and brand clues, such as a store, the staff and humanic clues, technologies used, or the technical quality of the offerings are sources of brand experiences (Andreini et al., 2018; Khan \& Fatma, 2017; Tafesse, 2016). In the retail environment, the more extraordinary flagship stores lead to a stronger brand experience than regular brand stores based on these clues, such as the flagship store's atmosphere and environment, the direct contact to the often better trained employees, and the higher variety and quality of the merchandise on display (Dolbec \& Chebat, 2013; Kozinets et al., 2002). Furthermore, storytelling and marketing communications are sources of brand experience (Andreini et al., 2018; Khan \& Fatma, 2017; Khan \& Rahman, 2015). Storytelling is also a key ingredient to the content of brand worlds in the consumer area (Borghini et al., 2009; Dolbec \& Chebat, 2013; Hollenbeck et al., 2008), and the more anchoring points for a brand's ideology and image are implemented in the physical environment, the more real, lively, and powerful the subjective experience co-created in such spaces will be (Borghini et al., 2009). Based on these findings, the hypothesis that the level of brand experience is significantly higher after the visit to a brand world in industrial marketing than it is before suggests itself.

H1: The level of post-visit brand experience is higher than the level of pre-visit brand experience.

As outlined in Section 6.2.3, a major goal of brand worlds in $\mathrm{B}_{2} \mathrm{~B}$ is also to increase brand equity (Österle et al., 2018a). In the consumer marketing area, the visit to a brand world is a powerful branding instrument (Borghini et al., 2009; Diamond et al., 2009; Dolbec \& Chebat, 2013; Kozinets et al., 2002). A visit to experiential flagship stores in $\mathrm{B}_{2} \mathrm{C}$, for example, has a stronger influence on brand equity than a visit to regular brand stores (Dolbec \& Chebat, 2013). Yet not only brand worlds, but also visits to other experiential marketing instruments, specifically various types of events, do in fact increase the level of brand equity (Zarantonello \& Schmitt, 2013). In general, there is evidence that branded environments influence the visitors perceptions of the brand's image and strengthen loyalty towards a brand (Borghini et al., 2009; Diamond et al., 2009; Kozinets et al., 2004). For the effect of a visit to a brand world on brand equity, the hypothesis can therefore be proposed that the level of brand equity is significantly higher after the visit to a brand world in industrial marketing than it is before.

H2: The level of post-visit brand equity is higher than the level of pre-visit brand equity.

To further understand how the experiences co-created at a $\mathrm{B}_{2} \mathrm{~B}$ brand world influences these proposed outcomes of brand experience and brand equity, 
they have to be placed in a nomological net. Within this nomological net, as outlined in Section 6.2.2, prior experiences are conceptualized to influence current and future experiences along the customer journey (Kranzbühler et al., 2018; Lemon \& Verhoef, 2016). Therefore, a sub-hypothesis about the positive direct relationship between pre-visit brand experience and post-visit brand experience can be made.

H1A: Pre-visit brand experience has a direct positive effect on post-visit brand experience.

Furthermore, it is important to control for the theoretical and predictive relationship between pre- and post-exposure measures, when trying to investigate the effect of a certain touchpoint (Simonin \& Ruth, 1998). In fact, there is evidence that the level of brand equity prior to an exposure to a brand has a strong influence on the level of brand equity after such an exposure in the event marketing context (Zarantonello \& Schmitt, 2013). Therefore, the hypothesis that pre-visit brand equity has a positive direct effect on post-visit brand equity suggests itself.

H2A: Pre-visit brand equity has a direct positive effect on post-visit brand equity.

For embedding the brand world experience in the nomological net, a look at recent research on customer experience is valuable. According to theory, a brand world in industrial marketing is a single touchpoint along the entire customer journey. Customer experience is further described as a dynamic process along this costumer journey, where previous experiences are conceptualized to influence current and future ones (Kranzbühler et al., 2018; Lemon \& Verhoef, 2016). In line with these conceptualizations, the experience at the single touchpoint of a brand world in industrial marketing should therefore be positively influenced by pre-visit brand experience, and the brand world experience itself in turn should positively influence post-visit brand experience. Thus, the hypothesis can be made that there is a positive complementary mediation of the relationship between pre-visit brand experience and post-visit brand experience by the brand world experience (Zhao, Lynch, \& Chen, 2010).

H3: The brand world experience exerts a positive complementary mediation effect on the relationship between pre-visit brand experience and postvisit brand experience.

Similarly important for the nomological net is the role of the individual experience touchpoint in relation to probable branding outcomes. As described in Section 6.2.1 and Section 6.2.2, brands reflect the complete experience that customers have with a firm along all touchpoints (Keller \& Lehmann, 2006) Individual experiences with brands provide sensory, affective, intellectual, and bodily stimulations, which increase the perceived value of a brand (Brakus et al., 2009; Pine \& Gilmore, 1998; Zarantonello \& Schmitt, 2013), and individual dimensions of brand equity, as well as brand equity itself (Andreini et al., 2018; Khan \& Fatma, 2017; Nysveen et al., 2013). On the other hand, although in different contexts, previous information about and feelings towards the brand, such as its reputation, the trust that one places in a brand, or brand love, do influence the experience with a brand at a certain touchpoint as well (Andreini et al., 2018; H.-B. Chen, Yeh, \& Huan, 2014; Morgan-Thomas \& Veloutsou, 
2013). In line with these conceptualizations, the experience at a brand world in industrial marketing should therefore be positively influenced by pre-visit brand equity, and the brand world experience in turn positively influences post-visit brand equity. Thus, the hypothesis can be made that there is a positive complementary mediation of the relationship between pre-visit brand equity and post-visit brand equity by the brand world experience (Zhao et al., 2010).

H4: The brand world experience exerts a positive complementary mediation effect on the relationship between pre-visit brand equity and post-visit brand equity.

In addition to the previous conceptualizations, the remaining relationships between the concepts within the nomological net are to be studied, in order to come to a thorough understanding of the effects between them. There is evidence for the consumer marketing area that the overall brand experience is an antecedent of different dimensions of brand equity, and of brand equity itself (Andreini et al., 2018; Khan \& Fatma, 2017; Nysveen et al., 2013). This also holds for the special context of experiential marketing instruments such as events and $\mathrm{B}_{2} \mathrm{C}$ brand worlds (Andreini et al., 2018; Brakus et al., 2009; Dolbec \& Chebat, 2013). The hypothesis can therefore be made that brand experience is also an antecedent to brand equity in the industrial context, both before and after the visit of the brand world.

H5: Pre-visit brand experience has a direct positive effect on pre-visit brand equity.

H6: Post-visit brand experience has a direct positive effect on post-visit brand equity.

Figure 6.1 depicts the conceptual model and hypotheses.

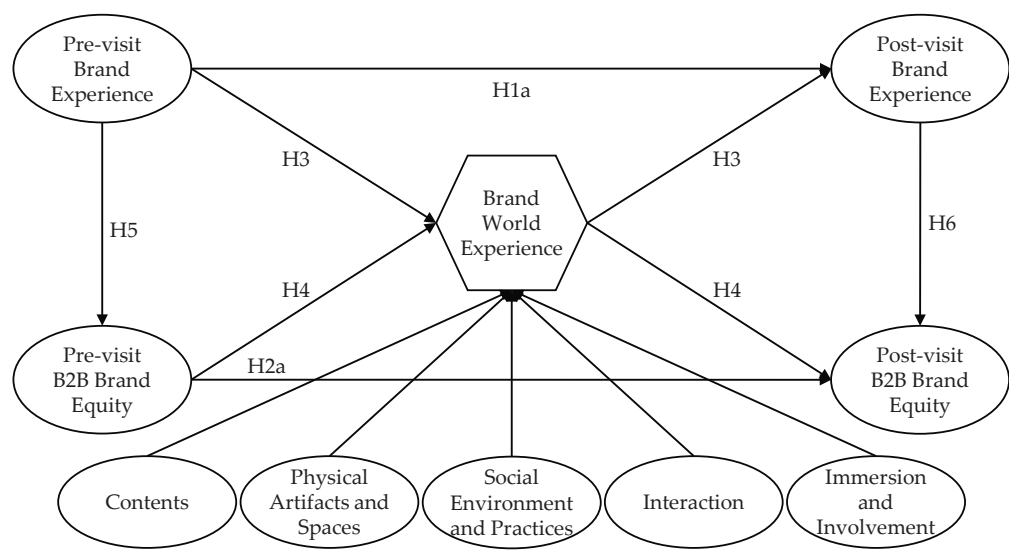

Figure 6.1: Conceptual model and hypotheses 


\subsection{EMPIRICAL STUDY}

\subsubsection{Setting and survey procedure}

In order to test these hypotheses we conducted a large-scale quantitative study within a brand world. We now first give a thorough explanation of the setting of the brand world, and the survey procedure, to provide a comprehensive overview of our empirical study design.

The study was conducted at an industrial brand world in Germany. While the operating brand is originally based in the US, the brand world under study here is located at the site of the main factory of the brand in Europe, which also houses its European headquarters. To give an indication of the relevance of the brand under investigation, it currently ranks among the 100 best global brands according to Interbrand (2018), was amongst the top 50 of worlds most admired brands in 2017 according to Fortune (2017), and amongst the 100 most reputable companies in the US in 2017 according to the Reputation Institute (2017). The factory is the largest factory of the company outside of the US, and is specialized on a specific product line of the brand, which is shipped worldwide. The brand world is open to the general public, and in a showroom current products of the brand are on display and can be experienced. Additional information, for example on technical details and the latest technical developments, possible applications, but also on the history of the brand and the factory are provided. Additionally, a small number of historical products are on display as well. In the attached brand fanshop, visitors can buy an entire range of branded merchandise and accessories, from toys to pens and pins and clothing. Children are catered for with a special section in the brand world, where model products are on display. Furthermore, a plethora of books and toys invite to playful learning. The brand world also offers four presentation rooms with a capacity of 50 persons each, and two meeting rooms with a capacity of 18 persons. These rooms are used for internal events, workshops, and meetings with business partners, but just like the entire showroom, they can also be rented and used by external entities. As such, the brand world was already the venue for a multitude of cultural and business events such as congresses, conferences, parties, or concerts.

In addition to the visit of the brand world, individual, guided factory tours in 11 different languages are offered to groups with a background in the industry, such as (potential) customers, students, vocational trainees or apprentices in the industry. Other stakeholders, such as for example private owners or collectors of historical products of the brand, municipal institutions, or suppliers are also welcome. All factory tours are by appointment only, and interested customers can arrange a tour only through a sales partner of the brand. In total, the brand world provides tours to about 20,000 visitors a year, in groups of up to 20 people. Due to the increasing interest and limited capacities, factory tours to the general public are usually not provided anymore. The tours last between 1.5 and 2 hours and lead the visitors through the entire factory. The starting and end point of each tour is the showroom of the brand world. Upon their arrival, visitors are welcomed by a brand employee at the front desk and the respective tour guide. Tours usually start in the morning, and depending on their time of arrival, a small breakfast or snacks are provided to the tour participants in the showroom, where they can also have a first look at the machinery on display. 
Subsequently, and before the tour starts, the visitors are led into one of the presentation or meeting rooms, where the tour guide gives a presentation about the background of the company, the factory, and the safety instructions for the tour itself. The tour guide then leads the visitors through the factory and explains the different manufacturing steps using a wireless tour guide audio system, and answers to questions that might arise. The tours also encompass a museum physically separated from the brand world, which is only accessible in the context of the tour. There, many more historical products of the brand are on display than in the showroom of the brand world, which rather focuses on current equipment. After the tour, the participants are usually invited to a lunch break in the factory cafeteria, before returning back to the showroom.

Within a special customer satisfaction program, customers who have bought a new machine are provided with a firsthand experience of the quality of workmanship built into their new product. They receive a private, behind-thescenes, guided tour of the factory where their equipment is manufactured. After the tour, the product they purchased awaits them in the showroom, where they are given a private explanation of the features and where they can start it for the first time. As a special gesture of gratitude, a golden key to the product is handed over to the customer, and a picture of the handover is taken. This picture is then printed on a framed certificate, which often finds its way into the offices of the customers. Furthermore, the visitors receive a special baseball cap which cannot be bought in the brand fanshops, as a souvenir to their visit of the factory. In special cases, the customers also visit with factory employees, such as product managers or sales managers. This explicitly happens for VIP customers. In addition to the factory tours and the gold key handover, these key accounts also have the opportunity to visit a virtual reality lab for R\&D that the brand operates in a private public partnership in cooperation with a local university of applied sciences.

Based on its setup and contents, this brand world can be considered as a prime, representative example of a $\mathrm{B}_{2} \mathrm{~B}$ brand world, and thus a suitable setting for our study on the experiences at brand worlds in industrial marketing and their impact.

We conducted our study in this brand world on 20 different weekdays between June and August 2018. We focused on visitors who participated in guided tours only. These were the majority of visitors, and only these experienced the full brand world contents. Our survey was first briefly introduced to the visitors by the front desk brand employee and the tour guides upon the visitors' arrival. Depending on the group size, the visitors were then led into the presentation or meeting rooms, were paper-based pre-visit questionnaires were already laid out together with branded pens of the operating company. We then gave a more thorough introduction to the survey and its goal, granted anonymity, explained GDPR regulations, and how we would use the data we collected. We made sure that respondents understood how to fill in an individual code, which had to be filled in accordingly in a second post-visit questionnaire, in order to allow us to match the pre- and post-questionnaires. Furthermore, as an incentive, the visitors could keep the pens and we explained that we would donate $1 €$ per completed post-visit questionnaire to one out of three charities of the visitors' choice. The visitors were then asked for their voluntary support and participation in the study. The pre-visit questionnaire contained brand experience and brand equity items, as well as socio-demographic questions. 
Detailed information on these measurement items is given in Section 6.3.3. It took respondents roughly about 8-10 minutes to complete the pre-visit questionnaire. Afterwards, the regular procedure as described above commenced, starting with the presentation of the tour guide. After the tour, the museum visit, the return to the showroom, visit to the merchandise shop, and, in case of Gold Key or VIP customers, after having received their golden keys and certificates or visited the virtual reality lab, the visitors were approached by us again, and asked to also fill out a post-visit questionnaire before their departure. Again, paper-based questionnaires were used, which were either laid out again in the respective rooms, or handed out by us directly. Since now additional questions on the brand world experience were introduced (see Section 6.3.3), answering the post-questionnaire took respondents about 10 minutes.

All questionnaires were prepared both in English and in German. The paperbased questionnaires have been electronically scanned using the software EvaSys SurveyGrid, which specializes in electronic data collection from paperbased surveys. The data have been checked for correct recognition of the answers provided by the participants.

\subsubsection{Research design}

The survey procedure outlined in Section 6.3.1 is a one-group, pretest-posttest quasi-experimental design (Cook \& Campbell, 1979; Reichardt, 2009; Shadish, Cook, \& Campbell, 2002). Specifically, the treatment in this quasi-experiment is the visit to an industrial brand world, which was described more closely in Section 6.3.1. In our pretest observation, we measured brand experience and brand equity, and captured socio-demographic factors as well. In the posttest observation, additionally to measuring brand experience and brand equity again, we also measured the visitor's experience at the B2B brand world itself. The measures used are described more closely in Section 6.3.3.

Such one-group, pretest-posttest quasi-experimental research designs have proven to be effective in similar contexts, such as the investigation of the impact of event marketing on brand equity (Zarantonello \& Schmitt, 2013). They were also used in different contexts in marketing research, where the influence of a treatment on evaluations of brands was investigated (e.g. Simonin \& Ruth, 1998).

This research design has the advantage that the result can be causally tied to the treatment or intervention if other possible causes explaining the result are implausible (Shadish et al., 2002). Furthermore, the comparison between pretest and posttest is very simple to derive and understand (Reichardt, 2009). A disadvantage is, that there are several threats to internal validity of one-group pretest-posttest quasi-experimental designs, which might bias the effect of the treatment and therefore the inferences on causality (Shadish et al., 2002). The most important threat for this study are unmeasured confounding variables, i.e. causes other than the treatment which might be responsible for the difference between the pretest and the posttest observation (Reichardt, 2009). We took several precautions in order to avoid or reduce the risk of impact of this specific potential bias, and also other biases related to pretest-posttest quasiexperimental designs. We conducted the pretest and posttest observations immediately before and after the treatment, to avoid 'history effects', meaning that no external event besides the treatment under study could plausibly 
produce some of the observed pretest-posttest change (Reichardt, 2009). We furthermore did not introduce a change in the measuring instruments, in order to avoid 'instrumentation effects' (Reichardt, 2009). Furthermore, due to the duration of the treatment, i.e. the brand world visit, memory effects are reduced (Shadish et al., 2002; Simonin \& Ruth, 1998).

\subsubsection{Measurement}

We measured constructs using multi-item scales adapted from prior research. We measured all constructs using seven-point Likert-type scales (" 1 - strongly disagree," and " 7 - strongly agree" if not otherwise stated). In total, we measured three constructs: brand experience, brand equity, and brand world experience, of which brand experience and brand equity have been measured in both pretest and posttest questionnaires. Naturally, brand world experience has only been measured after the treatment, in order to evaluate the visitors' experience at the brand world.

For measuring brand experience, we used the conceptualization and scale developed by Brakus et al. (2009). They specified brand experience as a fourfactor model with correlated factors, i.e. as a second-order common factor of common factors, or in other words a reflective first-order, reflective secondorder construct, or a Type I second-order specification (Brakus et al., 2009; Jarvis, MacKenzie, \& Podsakoff, 2003). The first-order common factors are the sensory, affective, behavioral, and intellectual dimension, each measured by three indicators. A pretest of our survey instrument showed, that the items with a reversed polarity in the original scale were hard for respondents to understand. In line with the recommendations of A. L. Holbrook, Krosnick, Carson, and Mitchell (2000) and Iglesias, Singh, and Batista-Foguet (2011), we therefore reworded those items so that they have the same polarity as the rest of the items in the final survey instruments used. A full list of our brand experience indicators can be found in the Appendix in Table A.1o.

For measuring the brand equity dimensions, we used the brand equity scale for $\mathrm{B}_{2} \mathrm{~B}$ settings developed by Biedenbach et al. (2011) and Biedenbach et al. (2015). It consists of the four factors brand awareness (three items), brand associations (four items), perceived quality (three items), and brand loyalty (three items). We additionally included three more items to measure brand associations from a different, more consumer-oriented perspective, adopted from (Christodoulides et al., 2015). Since we were also interested in the overall brand equity evaluation, we included three items to measure this construct, developed for B2B settings (Davis et al., 2008). A full list of our brand equity indicators can be found in the Appendix in Table A.11.

In order to measure the perception of the factors that compose the brand world experience as described in Section 6.2.3, namely of the contents, the physical artifacts and spaces, and the social environment and practices within the B2B brand world, and the visitors' interaction, and immersion and involvement with this environment and the visit, we adopted scales from related areas. We turn first to the factors of the brand world experiencescape, which are largely under the control of and contributed by the operating company. For the brand world content component, we used a four item scale developed to measure the educational dimension of experience constructs in the tourism industry $(\mathrm{Oh}$, Fiore, \& Jeoung, 2007). Similarly, we relied on two three-item scales developed 
to measure ambient conditions and design factors in the service industry, in order to measure the physical artifacts and spaces component (Brady \& Cronin, 2001). We furthermore relied on twelve items developed to measure employee attitude, behavior, and expertise in the service industry (Brady \& Cronin, 2001) to measure the social environment and practices component. Next to these factors determining the brand world experiencescape, we measured those factors outside the control of the operating company, which are thus contributed by the visitor, and in turn compose the co-created $\mathrm{B} 2 \mathrm{~B}$ brand world experience. To measure the level of interaction with subjects within the brand world, we used five items originating from the service industry (Brady \& Cronin, 2001) and research on the experience value of museum visitors as a co-creation process (Antón, Camarero, \& Garrido, 2017). To measure the level of interaction with the environment within the brand world, we adopted three items developed to measure the interaction with the environment within the context of retail stores (Foster \& McLelland, 2015). The immersion and involvement dimension was measured using three items developed to measure the involvement of visitors in theme parks (Dong \& Siu, 2013), as well as two items to measure the level of mental and physical participation in co-creation processes within experiential tourism consumption (Prebensen \& Xie, 2017). A full list of our brand world experience indicators can be found in the Appendix in Table A.12.

In total, since these dimensions together compose the $\mathrm{B}_{2} \mathrm{~B}$ brand world experience, and thus act as a prescription for dimension reduction (Dijkstra \& Henseler, 2011), we conceptualized it as a composite of common factors (van Riel, Henseler, Kemény, \& Sasovova, 2017). The first-order factors of this composite are the content provided in the industrial brand world (1), the physical artifacts and spaces (2), and the social environment and practices (3), as well as the visitor's interaction (4) and immersion and involvement (5) with and in the $\mathrm{B}_{2} \mathrm{~B}$ brand world experiencescape.

\subsubsection{Sample}

In total, we collected 329 pre-visit and 283 post-visit questionnaires in German, as well as 127 pre-visit and 93 post-visit questionnaires in English. Of the total of 376 post-questionnaires, 334 could be matched undoubtedly to prequestionnaires using the individual code filled in by the respondents on each questionnaire. Of those, we removed 37 respondents who did not state their age or were under 18 years. Furthermore, following established guidelines (Hair, Hult, Ringle, \& Sarstedt, 2017), we had to remove 72 observations with more than $15 \%$ missing values among the brand experience, brand equity, and brand world experience constructs, which were of particular interest for our study. We also checked for suspicious response patterns and removed seven respondents who straightlined more than four out of in total six item batteries (Leiner, 2013; Osborne, 2013). This led us to a final sample of 218 matched preand post-observations.

These 218 visitors are all highly relevant, mostly industrial respondents for the purpose of our study. The largest group are actual or potential industrial customers of the brand, and they attribute for $49.1 \%$ or 107 participants of our sample. Furthermore, $12.8 \%$ or 28 of the visitors in our sample are Gold Key customers, $5.5 \%$ or 12 VIP customers, $9.2 \%$ or 20 are trainees or students in the industry, and $23.4 \%$ or 51 respondents are other stakeholders. This 
latter group comprises for example local municipal institutions, suppliers, and private owners of historic products of the brand. In total, all of these groups are highly interesting stakeholders with respect to the brand under investigation, which gives us confidence that our sample is relevant for the study at hand.

$19.3 \%$ or 42 of respondents in our sample are female. Little surprisingly, with $75.7 \%$ or 165 out of the 218 respondents, the largest group of participants is from Germany. 20 participants in our sample came to visit the brand world from countries outside of Europe. For 186 respondents or $85.3 \%$ of our sample it was their first visit to the brand world. For 114 or $52.3 \%$ of our respondents, either they or their company did not own a product of the brand, for 33 or $15.1 \%$ either they or their company did own one, and for 70 or $32.1 \%$, either they or their company owned several of the brands products.

Figures 6.2 to 6.6 provide a graphical overview of our sample characteristics.

\title{
Visitor group
}

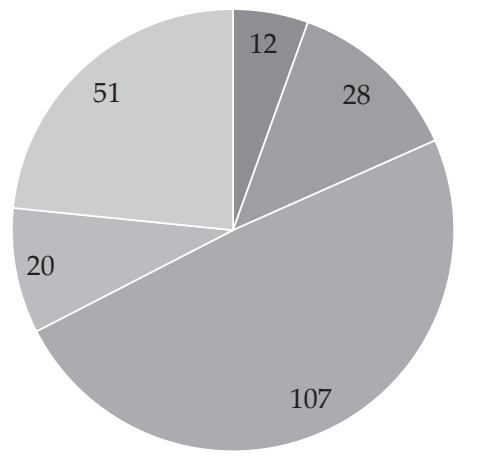

\author{
- VIP customer \\ - Gold Key \\ customer \\ - (Potential) \\ Customer \\ - Trainee / \\ student \\ Other \\ stakeholder
}

Figure 6.2: Sample distribution of visitor groups

Age

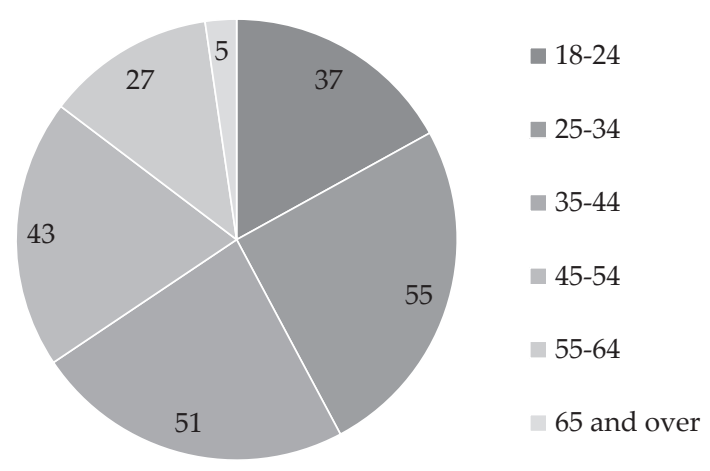

Figure 6.3: Sample distribution of age 


\section{Country}

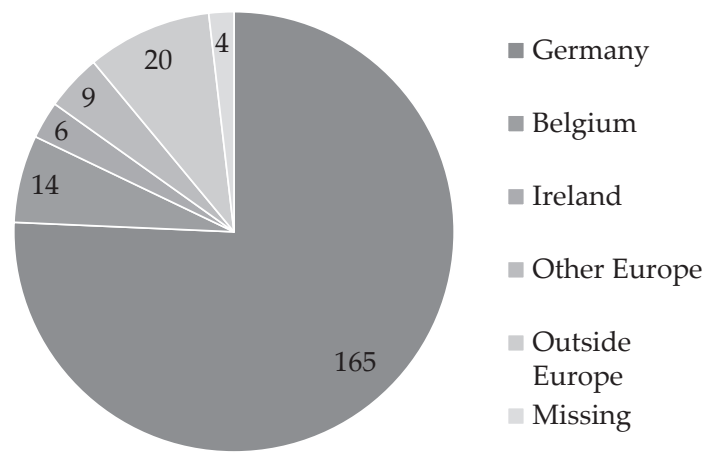

Figure 6.4: Sample distribution of country

Previous visit to the brand world

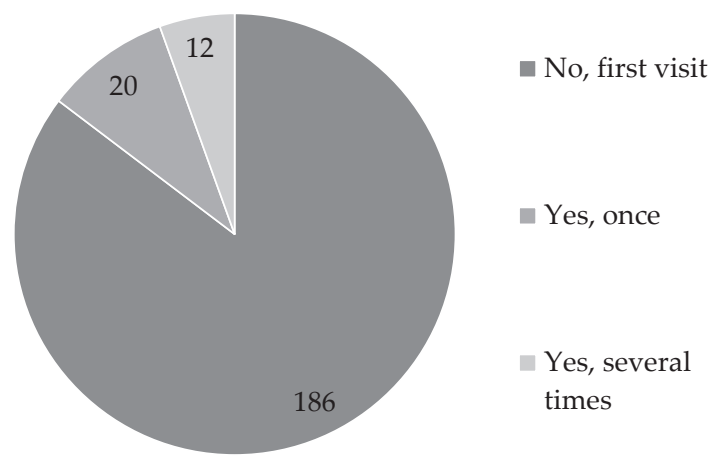

Figure 6.5: Sample distribution of previous visits to the brand world

\subsubsection{Data characteristics and analysis procedure}

IBM SPSS Statistics version 23 was used for descriptive statistics and the investigation of hypotheses 1 and 2. Initial assessments of the data characteristics of our focal constructs revealed, that according to the Kolmogorov-Smirnov test and visual inspection using histograms and Q-Q-plots, data on all our items is non-normal distributed. In general, most of our data is left-skewed, and the data on several items is leptokurtic. An overview of the statistics for all indicators is given in the Appendix in Table A.13.

Considering the brand world experience construct, this study draws on a composite of common factors model (van Riel et al., 2017). Furthermore, our research can be described as a mixture of confirmatory research and explanatory research. Confirmatory research, because we are interested in the causal relationships between pre- and post-visit brand experience and brand equity, and the $\mathrm{B}_{2} \mathrm{~B}$ brand world experience as a composite and as a whole, compared 


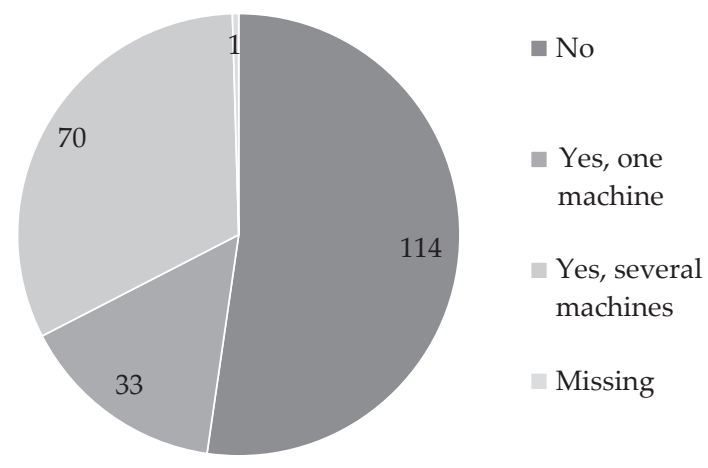

Figure 6.6: Sample distribution of ownership of the brand's products

to investigating the components of the brand world experience separately in this nomological net (Henseler, 2018). Explanatory research, because our interest lies also in understanding the mechanism behind a potential increase in brand experience and brand equity, and thus in effect sizes and inference statistics of path coefficients (Henseler, 2018). For these very reasons, we applied partial least squares structural equation modeling (Henseler, 2016, 2018) using ADANCO 2.o.1 (Henseler \& Dijkstra, 2015) to assess hypotheses 1a, 2a, and 3-6. The consistent partial least squares algorithm (PLSc) implemented in the software allows for the consistent estimation of both composites and common factors (Dijkstra \& Henseler, 2015b), goodness of fit tests and inference statistics (Dijkstra \& Henseler, 2015a; Henseler et al., 2014), as well as the consistent estimation of second-order composites of common factors (van Riel et al., 2017)

More specifically, we used the inner weighting scheme set to factor, so that the inner weights of adjacent constructs are proportional to their correlations (Henseler, Ringle, \& Sinkovics, 2009). A recent monte carlo simulation study has shown that single missing data imputation methods generally perform better with PLS-SEM and missing at random data than with for example covariance-based SEM (Kock, 2018). Arithmetic mean imputation only yields slightly biased path coefficients and mean loading estimates, and none of the tested methods induced a significant bias in standard errors when compared with a full dataset, even with as much as $30 \%$ of missing data (Kock, 2018). Therefore, we applied arithmetic mean imputation as missing value treatment. In total, our dataset had $2.82 \%$ missing values on the indicators of interest, with a maximum of $11.01 \%$ for the perceived quality indicator "How consistent is the quality of [the brand]'s products / services?" (1pql1) prior to the visit. We therefore are confident that our results are only biased to a small extend due to missing data or missing data imputation. Furthermore, we used bootstrapping with 999 bootstrap samples to provide inference statistics and the possibility to assess overall model fit (Dijkstra \& Henseler, 2015a).

Since all relevant constructs, brand experience, brand equity, and the brand world experience, are higher-order constructs based on lower-order common factors, and we conceptualized our focal construct brand world experience as 
composite of common factors, we follow the three-stage approach as proposed by van Riel et al. (2017) in order to achieve consistent estimates for our parameters. In the first stage, a model is estimated and assessed for overall model fit and measurement model fit without the second-order constructs, with the purpose to obtain construct scores and consistent correlations of the first-order constructs. In this stage, a saturated model in which all lower-order constructs can correlate freely is a recommended choice, because model misfit can then be attributed to a problem in the measurement model. In the second stage, the second-order constructs are then included in the model, specified as composites or factors, respectively, with the construct scores of the lower-order constructs as their indicators. The purpose of this stage is to obtain consistent estimates for the structural model, based on the construct reliabilities of the lower-order constructs. These are used to calculate reliabilities of the second-order constructs. In the third and last stage, consistent estimates for the structural model including the relationships between the first-order common factors and the second-order composites are obtained, by correcting the correlations of the second-order construct for attenuation (van Riel et al., 2017).

The assessment of the overall goodness-of-fit measures should be the starting point for model assessment (Henseler, 2017a, 2017b; Henseler, Hubona, \& Ray, 2016). If the model fit measures show a misfit between data and model, the estimates may be meaningless, and the conclusions drawn from them become questionable, because the misfit implies that the data contains more information than the model conveys (Henseler et al., 2016). With the unweighted least squares discrepancy $\left(\mathrm{d}_{\mathrm{ULS}}\right)$ and the geodesic discrepancy $\left(\mathrm{d}_{\mathrm{G}}\right)$, two alternatives to assess bootstrapped-based model fit are available, which both estimate the discrepancy between the empirical correlation matrix and the model-implied correlation matrix. The lower these discrepancies are in absolute terms, the better is the model fit in general. By comparing these absolute discrepancies to the bootstrapped 95\%- (HI95) or 99\%-Quantile (HI99), researchers can determine whether the discrepancy is statistically significant and the model should be rejected or not. Furthermore, with the standardized root mean squared residual $(S R M R)$, a fit index for assessing the approximate model fit is available (Dijkstra \& Henseler, 2015a; Henseler, 2017a; Henseler et al., 2016). A SRMR below 0.08 indicates a well-fitting model (Hu \& Bentler, 1999).

To assess the measurement models of common factors (reflectively specified models), one should again draw on the bootstrap-based tests of overall model fit first (Henseler, 2017b). They can indicate, whether empirical evidence speaks against the specification of the data as a factor model (Henseler, 2017b; Henseler et al., 2016). If this is not the case, one can continue to assess the reliability and validity of measurement (Henseler, 2017b). To assess the amount of random error in construct scores, their internal consistency reliability should be assessed using Dijkstra-Henseler's $\rho_{\mathrm{A}}$ (Dijkstra \& Henseler, 2015b) or Raykov's $r$ (Raykov, 1996), since they are currently the only consistent reliability measures for PLS construct scores (Henseler, 2017a; Henseler et al., 2016). Of the two, Dijkstra-Henseler's $\rho_{\mathrm{A}}$ is implemented in ADANCO 2.o.1. A minimum reliability of 0.7 is recommended (Nunnally \& Bernstein, 1994). The more traditional reliability measures, composite reliability, also called Jöreskog's $\rho_{C}$ and Cronbach's $\alpha$ refer to sum scores, not construct scores, and therefore provide inconsistent estimates (Henseler et al., 2016). To assess the degree of systematic measurement error or the validity of a measurement model, several distinct 
measures are available. First, a factor should be unidimensional, which can be assessed by its convergent validity. The average variance extracted ( $A V E)$ serves as a measure for convergent validity and should be above 0.5 (Fornell \& Larcker, 1981; Henseler, 2017a). Second, factors should exhibit discriminant validity, meaning that a pair of factors should also be statistically different if they represent theoretically different concepts. Recent simulation studies have shown that a new criterion for assessing discriminant validity, the heterotraitmonotrait ratio of correlations (HTMT, Henseler, Ringle, and Sarstedt, 2015), outperforms the more traditional Fornell-Larcker criterion (Franke \& Sarstedt, 2018; Voorhees, Brady, Calantone, \& Ramirez, 2016). A HTMT significantly smaller than 1 or clearly below 0.85 provides evidence for the discriminant validity of a pair of constructs (Henseler, 2017a; Henseler et al., 2015). Furthermore, all indicators should load sufficiently well on their own constructs, but less on other constructs in the model. Therefore, the cross-loadings of indicators should be assessed to assure that all indicators are correctly assigned (Henseler, 2017a).

To assess composite measurement models, researchers should rely on nomological validity, reliability, and the assessment of its composition by investigating the weights of the indicators for possible multicollinearity issues (Henseler, 2017a). Nomological validity can be assessed by means of confirmatory composite analysis (Henseler et al., 2014; Müller, Schuberth, \& Henseler, 2018; Schuberth, Henseler, \& Dijkstra, 2018). In essence, this statistical technique tests whether the overall model fit of a model that includes the composite in a nomological net as an entity composed of its indicators exhibits a significantly worse fit than a model in which the composite is not included, and where its indicators act within the nomological net without the proportionality constraints imposed on them by the composite (Henseler, 2017a; Henseler et al., 2014; Müller et al., 2018; Schuberth et al., 2018). If the model with the composite does not have a significantly worse fit, researchers can rely on Ockham's razor and conclude that the composite has nomological validity, that it is the composite that acts within the nomological net, rather than its individual indicators, and that it thus makes sense to create the composite (Henseler, 2017a; Henseler et al., 2016). Regarding reliability, composites will have imperfect reliability if the indicators contain a random measurement error (Henseler, 2017a). This is the case for composites of common factors, such as our brand world experience constructs. In these cases, the reliability of the composite can be calculated based on the estimated reliabilities of the lower-order common factors (van Riel et al., 2017). With respect to the weights, one can assess the sign and magnitude as well as their significance. If unexpected results occur, such as unexpected negative signs of the weights, this is most likely due to multicollinearity issues, and therefore the variance inflation factors $(V I F)$ of the indicators should be assessed as well (Cenfetelli \& Bassellier, 2009; Henseler, 2017a; Henseler et al., 2016). If problems related to multicollinearity occur, there are certain guidelines for action (Cenfetelli \& Bassellier, 2009). First, researchers should evaluate whether the indicators have conceptual overlap. If so, under the consideration that the conceptual meaning of the composite should not be altered, one of the indicators with overlap could be removed and the test for collinearity could be repeated. If removal of an indicator would alter the conceptual meaning of the composite, a guideline and discussion of the overlap and on how to improve measurement should be provided. Despite multicollinearity issues, researchers 
could still proceed with the evaluation of the structural model, yet the weights and signs of composite indicators should not be directly interpreted (Cenfetelli \& Bassellier, 2009; Hair et al., 2017).

The coefficients of determination of endogenous latent variables ( $R^{2}$ values) should be the starting point for the assessment of the structural model. They quantify how much of the variance in the construct is explained by its predictors, and their values can range from o to 1 (Henseler, 2017a). To enable comparison across models with different sample sizes and with different numbers of independent variables, the adjusted $R^{2}$ should be applied (Henseler, 2017a). The path coefficients in structural equation models should also be assessed. They quantify the influence of an independent variable on a dependent variable, and, since they are usually standardized, can be interpreted like standardized regression coefficients. This means that the path coefficient expresses the expected increase in standard deviations in the dependent variable, based on an increase of the independent variable by one standard deviation, given that all other factors remain constant (ceteris paribus) (Henseler, 2017a). Next to the size of the path coefficient, also its sign and significance (i.e. $p$-value, $t$-value, or confidence interval) are relevant, and these inference statistics are provided by means of bootstrapping as described above (Henseler et al., 2016). If path coefficients should be evaluated across models, their size is not a robust indicator for the actual size of the effect, because they are influenced by the number of other predictor variables and their correlations. Therefore, the effect size $f^{2}$ was introduced (Cohen, 1988), which should be evaluated as well (Henseler, 2017a). It indicates, how substantial a direct effect is. Effect sizes above 0.35 can be regarded as strong effects, above 0.15 as medium, and above 0.02 as weak (Cohen, 1988). For mediation analysis, first the indirect effects $(a \times b)$ and their respective inference statistics should be assessed, before determining the type of mediation by assessing the significance of direct effects and the signs of path coefficients (Nitzl, Roldán, \& Cepeda, 2016). If the indirect effect is not significant, then there is no mediation. If the indirect effect $(a \times b)$ is significant, and a) the direct effect $\left(c^{\prime}\right)$ is not, then there is full mediation; b) the direct effect is significant, then there is either i) complementary mediation, if the sign of the total effect $\left(a x b x c^{\prime}\right)$ is positive, or ii) competitive mediation, if the sign of the total effect $\left(a \times b \times c^{\prime}\right)$ is negative (Nitzl et al., 2016).

While we in general follow these guidelines on the assessment of models containing higher-order constructs (van Riel et al., 2017), we needed to implement one specific adjustment due to our research design, as outlined in Section 6.3.2. We collected data in two separate questionnaires, of which one was conducted before, and one was conducted after the visit to the industrial brand world. In such cases of longitudinal research designs, where the same indicators of factor models are measured at different points in time, one can expect the residuals between these indicators to be correlated due to systematic measurement error. In these cases, correlations between the residuals of repeated measurement indicators of factor models should therefore be allowed for a theoretically correct model specification (Hermida, 2015; Landis, Edwards, \& Cortina, 2009). While covariance-based structural equation modeling allows for a specification where indicator residuals of factor models are correlated, partial least squares structural equation modeling currently does not (Henseler et al., 2016). To solve this methodological issue, we therefore evaluated the pre-visit and the post-visit measurement model separately. We then used the 
construct scores of the first-order constructs of these separate measurement models in the subsequent stages of the evaluation of the structural model.

6.4 RESULTS

\subsubsection{Pretest-posttest comparison}

In order to test whether post-event brand experience was higher than pre-event brand experience (H1), and whether post-event brand equity was higher than pre-event brand equity $\left(\mathrm{H}_{2}\right)$, we conducted a nonparametric Wilcoxon signedrank test with pair-wise deletion, due to violation of the normality assumption of our data. We performed the test on each individual pair of pre-visit and post-visit items that we used to measure brand experience and brand equity. In order to evaluate the strength of the effects, we calculated the effect sizes $r$ as $r=\frac{z}{\sqrt{N}}$. Values of $r<.3$ can be interpreted as small effects, $.3 \leq r \leq .5$ as medium effects, and $r>.5$ as strong effects.

Our results show that for eleven out of the 12 brand experience items, the mean is higher after the brand world visit. The remaining one item exhibits the same mean after the visit as before $(M=5.10, p=.970, r=0.00)$. Out of these eleven items with a higher mean after the visit, this difference is statistically significant at $p \leq .001$ for six of them, with small to medium effect sizes (minimum $r=-.20$, maximum $r=-.37$ ), and for two more at $p \leq .1$ with small effect sizes $(r=-.12)$. Therefore we see partial support for $\mathrm{H}_{1}$, that post-event brand experience is higher than pre-event brand experience.

Regarding brand equity, out of the total of 20 brand equity items, one showed a lower mean after the visit $\left(M_{2}=6.57, S D_{2}=.627\right)$ than before $\left(M_{1}=6.68, S D_{1}=.697\right)$. Interestingly, this item is the brand awareness item "I am aware of the brand [name of the brand]." This difference is statistically significant with a small effect size $p=.000, r=-.19$. Yet, considering that the scale ranged from " 1 - strongly disagree" to " 7 - strongly agree", the level was still very high after the visit. One other brand awareness item did not show a significant change in its mean $(p=.335)$, and the third and last brand awareness item showed a significant increase in its mean from $M_{1}=6.40$ prior to the visit to $M_{2}=6.57$ after the visit at $\alpha=0.1$ with a small effect ( $p=.054, r=-.13$ ). Of the remaining 17 brand equity items, one brand associations item showed a significant increase in its mean from $M_{1}=5.42$ to $M_{2}=5.60$ at $p \leq .05$ with a small effect size $(r=-.16)$. All other items, including the three overall brand equity items, showed a significant increase in their mean after the visit with small to strong effect sizes at $p \leq .001$ (minimum $r=-.20$, maximum $r=-.56$ ). Therefore, we also see partial support for our $\mathrm{H}_{2}$ in that there was a significant increase of overall brand equity and all brand equity dimensions after the brand world visit, except for brand awareness.

An overview of the results is given in Table 6.1. 


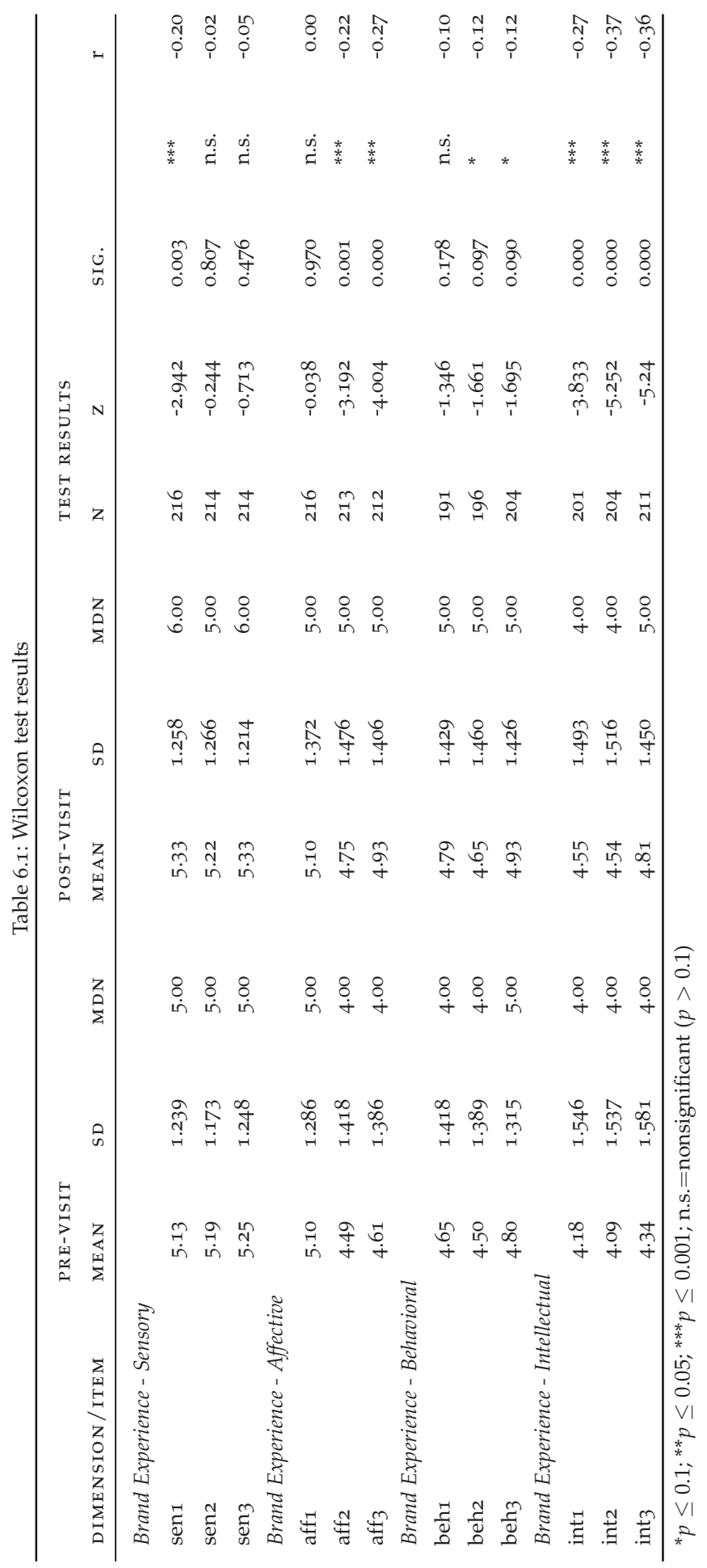




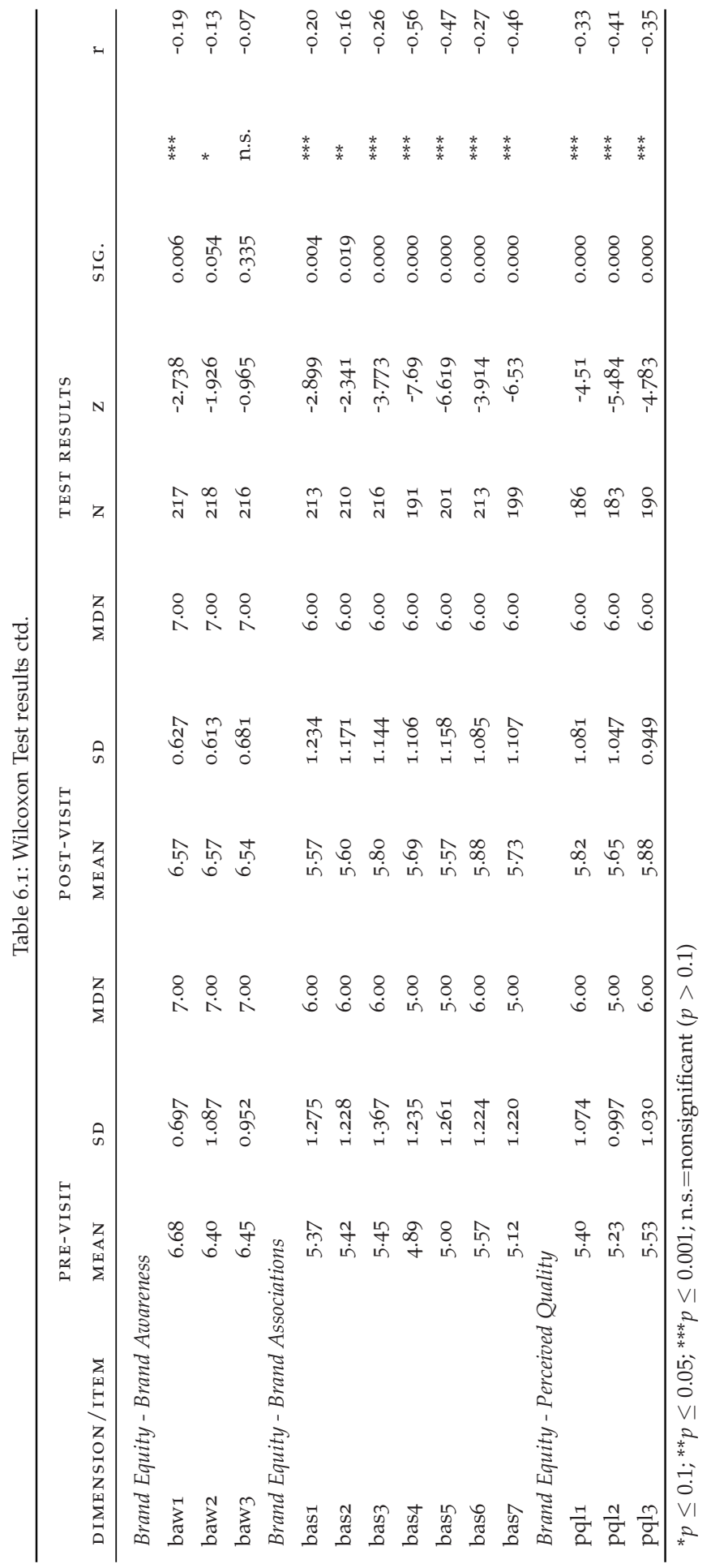




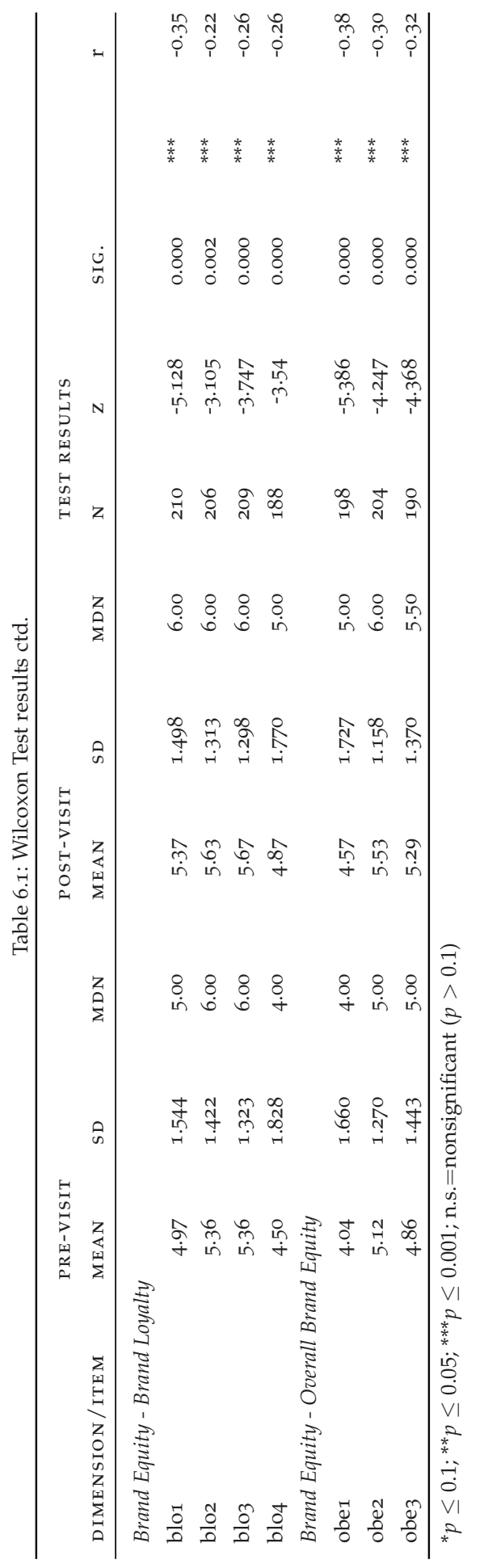




\subsubsection{Structural equation modeling}

As outlined in Section 6.3.5, the first stage of the three-stage approach for the assessment of composites of common factors originally entails the assessment of model and measurement fit for a saturated model including all first-order constructs only (van Riel et al., 2017). In this special case of a pretest-posttest quasi-experimental design, we expect the unique measurement errors of the repeated indicators of common factors to be correlated due to systematic measurement error. We therefore evaluate the saturated measurement model containing all first-order constructs measured prior to the visit and after the visit in two separate models. Table 6.2 shows for the pre-visit measurement model, that while $d_{\mathrm{ULS}}$ and $d_{\mathrm{G}}$ exceed the HI95 and HI99 thresholds, SRMR is well below 0.08 . This indicates an acceptable model fit.

Table 6.2: Model fit of the saturated model containing all first-order constructs and indicators of the pre-visit measurement

\begin{tabular}{lccc}
\hline GOF MEASURE & VAlue & HI95 & HI99 \\
\hline SRMR & 0.0466 & 0.0357 & 0.0379 \\
$\mathrm{~d}_{\mathrm{ULS}}$ & 1.1458 & 0.6714 & 0.7579 \\
$\mathrm{~d}_{\mathrm{G}}$ & 1.2126 & 0.7128 & 0.7909 \\
\hline
\end{tabular}

In the post-visit measurement model, two indicators of the content component of the brand world experience had loadings above 1.0 and created Heywood-cases. These indicators were therefore eliminated in order to be able to estimate the model. Table 6.3 shows the model fit for the saturated model of the first-order constructs of the post-visit measurement after the removal of these two indicators. Here, again $S R M R$ is well below 0.08 , and $d_{\mathrm{G}}$ is below the HI99 threshold, while $d_{\mathrm{ULS}}$ again exceeds both HI95 and HI99 thresholds. Overall, this also indicates an acceptable model fit for this post-visit measurement model.

Table 6.3: Model fit of the saturated model containing all first-order constructs and indicators of the post-visit measurement

\begin{tabular}{lccc}
\hline GOF MEASURE & VALUE & HI95 & HI99 \\
\hline SRMR & 0.0519 & 0.0410 & 0.0431 \\
$\mathrm{~d}_{\mathrm{ULS}}$ & 5.2668 & 3.2815 & 3.6316 \\
$\mathrm{~d}_{\mathrm{G}}$ & 4.0167 & 3.6543 & 4.1247 \\
\hline
\end{tabular}

Our constructs also showed good reliability in both pre-visit and post-visit measurement models. Dijkstra-Henseler's $\rho_{\mathrm{A}}$ exceeded 0.8 for all constructs, except for brand awareness and brand equity before the visit, for which it still exceeded 0.7. This speaks for a good internal consistency reliability of our construct scores. Regarding convergent validity, AVE was between 0.4 and the threshold of 0.5 for two constructs, namely brand awareness before the visit and the interaction component of the brand world experience measured 
after the visit. Regarding discriminant validity, the HTMT criterion was above 0.85 for a total of eight pairs of constructs in both measurement models, but still significantly below 1 as the HTMT inference statistic showed (see Appendix Table A.14). All loadings were significant, but two indicators from the interaction component of the brand world experience construct, measured post-visit, had loadings below 0.4 , and one other indicator from the same component cross-loaded on another construct. Bearing in mind content validity, we therefore removed those three indicators, following the guidelines of Hair et al. (2017). Removing them also increased the $A V E$ of the interaction component above the recommended threshold of 0.5. An overview of removed indicators, the reason and the effect of their removal is given in the Appendix in Table A.15

These changes to the post-visit measurement model resulted in an improvement of our reliability and validity measures, as well as the goodness-of-fit measures of the saturated first-order model for the post-visit measurement. All three goodness-of-fit measures are now even lower, $d_{\mathrm{G}}$ is still below the HI99 threshold, as is SRMR for its threshold of 0.08, see Table 6.4. Table 6.5 shows the reliability and validity measures of both our final measurement models pre-visit and post-visit. Since the $A V E$ for pre-vist brand awareness was below 0.5 , we additionally conducted an exploratory factor analysis using principal axis factoring and the direct oblimin rotation. The goal was to test, whether there are other latent factors beside brand awareness that load strongly on these items. The first extracted factor accounted for more than $60 \%$ of the indicators' variance. Therefore, we could consider our construct to exhibit convergent validity. An overview of the indicators used in these final measurement models and their loadings is given in the Appendix, in Table A.16 for pre-visit measurement, and in Table A.17 for post-visit measurement.

Table 6.4: Final model fit of the saturated post-visit measurement model

\begin{tabular}{lccc}
\hline GOF MEASURE & VALUE & HI95 & HI99 \\
\hline SRMR & 0.0506 & 0.0396 & 0.0421 \\
$\mathrm{~d}_{\mathrm{ULS}}$ & 4.5253 & 2.7730 & 3.1308 \\
$\mathrm{~d}_{\mathrm{G}}$ & 3.6935 & 3.2582 & 3.7616 \\
\hline
\end{tabular}

In order to assess how much of the variance of the overall brand equity constructs is explained by their dimensions brand awareness, brand associations, perceived quality, and brand loyalty, these were also included in the lower-order measurement models. For pre-visit overall brand equity, the variance explained was $R^{2}=0.781$, and for post-visit overall brand equity it was $R^{2}=0.880$. These are satisfactory values, so that for the next stage, we could use the estimated overall brand equity construct scores without their lower-order constructs as indicators.

In the subsequent second stage of the three-stage approach, except for brand equity for the reason mentioned above, the lower-order constructs scores are used as indicators for the second-order constructs. Again, model fit and the measurement model need to be assessed. First, to assess the composite measurement of the brand world experience, we used a minimal saturated model. This model included pre-visit and post-visit brand equity, measured with 
Table 6.5: Reliability and validity of final first-order measurement

\begin{tabular}{|c|c|c|c|c|c|c|}
\hline \multirow[b]{2}{*}{ CONSTRUCT } & \multirow[b]{2}{*}{$\rho_{\mathrm{A}}$} & \multirow[b]{2}{*}{$\rho_{\mathrm{C}}$} & \multirow[b]{2}{*}{$\alpha$} & \multirow[b]{2}{*}{ AVE } & \multicolumn{2}{|c|}{ нтмт } \\
\hline & & & & & MAX. & $95 \%$ \\
\hline \multicolumn{7}{|l|}{ Pre-visit } \\
\hline Sensory & 0.9220 & 0.9191 & 0.9185 & 0.7915 & 0.9083 & 0.9441 \\
\hline Affective & 0.8891 & 0.8888 & 0.8882 & 0.7271 & 0.9083 & 0.9441 \\
\hline Behavioral & 0.8925 & 0.8848 & 0.8868 & 0.7206 & 0.8072 & 0.8839 \\
\hline Intellectual & 0.9205 & 0.9179 & 0.9184 & 0.7888 & 0.8414 & 0.8891 \\
\hline Brand Awareness & 0.7038 & 0.6851 & 0.6693 & 0.4257 & 0.5481 & 0.6811 \\
\hline Brand Associations & 0.9070 & 0.8999 & 0.8980 & 0.5660 & 0.8879 & 0.9237 \\
\hline Perceived Quality & 0.8532 & 0.8408 & 0.8369 & 0.6405 & 0.7213 & 0.7893 \\
\hline Brand Loyalty & 0.9406 & 0.9403 & 0.9403 & 0.7975 & 0.8879 & 0.9372 \\
\hline Overall Brand Equity & 0.7875 & 0.7827 & 0.7811 & 0.5468 & 0.8780 & 0.9372 \\
\hline \multicolumn{7}{|l|}{ Post-visit } \\
\hline Contents & 0.8537 & 0.8524 & 0.8516 & 0.7429 & 0.5321 & 0.6420 \\
\hline $\begin{array}{l}\text { Physical Artifacts and } \\
\text { Spaces }\end{array}$ & 0.9075 & 0.8999 & 0.9003 & 0.6032 & 0.8475 & 0.8969 \\
\hline $\begin{array}{l}\text { Social Environment and } \\
\text { Practices }\end{array}$ & 0.9327 & 0.9260 & 0.9263 & 0.5855 & 0.6964 & 0.7627 \\
\hline Interaction & 0.8939 & 0.8791 & 0.8801 & 0.5975 & 0.8560 & 0.9134 \\
\hline $\begin{array}{l}\text { Immersion and Involve- } \\
\text { ment }\end{array}$ & 0.8631 & 0.8453 & 0.8428 & 0.5290 & 0.8560 & 0.9134 \\
\hline Sensory & 0.9470 & 0.9461 & 0.9459 & 0.8541 & 0.9264 & 0.9539 \\
\hline Affective & 0.9318 & 0.9293 & 0.9290 & 0.8146 & 0.9264 & 0.9539 \\
\hline Behavioral & 0.9142 & 0.9082 & 0.9086 & 0.7682 & 0.8330 & 0.8913 \\
\hline Intellectual & 0.9479 & 0.9473 & 0.9473 & 0.8571 & 0.8574 & 0.9038 \\
\hline Brand Awareness & 0.9198 & 0.8696 & 0.8616 & 0.7008 & 0.4825 & 0.6009 \\
\hline Brand Associations & 0.9328 & 0.9316 & 0.9314 & 0.6610 & 0.8333 & 0.8755 \\
\hline Perceived Quality & 0.9050 & 0.8942 & 0.8912 & 0.7399 & 0.7151 & 0.8257 \\
\hline Brand Loyalty & 0.9387 & 0.9385 & 0.9387 & 0.7925 & 0.9273 & 0.9650 \\
\hline Overall Brand Equity & 0.8410 & 0.8324 & 0.8274 & 0.6253 & 0.9273 & 0.9650 \\
\hline
\end{tabular}

single-indicator composite measurement by their construct scores of stage one, as predictor and outcome of the brand world experience, which is composed of the construct scores of the five brand world experience components of stage one. This minimal model is depicted in the Appendix in Figure A.1.

The only correlational constraints imposed on the data in this model are due to the composite (Schuberth et al., 2018). Hence, according to confirmatory composite analysis, if this model does not show significantly worse fit than a model without the composite, i.e. the empirical correlation matrix, then the composite has nomological validity (Schuberth et al., 2018). The goodness of fit measures for this model are displayed in Table 6.6, and they show excellent fit. Therefore, we conclude that we cannot reject the composite measurement of brand world experience, and that within the nomological net, the brand world experience acts as a new entity formed of its components (Dijkstra \& Henseler, 2011; Schuberth et al., 2018). 
Table 6.6: Model fit of the minimal model for the assessment of the second-order brand world experience composite

\begin{tabular}{lccc}
\hline GOF MEASURE & VALUE & HI95 & HI99 \\
\hline SRMR & 0.0175 & 0.0161 & 0.0192 \\
$\mathrm{~d}_{\mathrm{ULS}}$ & 0.0086 & 0.0072 & 0.0103 \\
$\mathrm{~d}_{\mathrm{G}}$ & 0.0092 & 0.0092 & 0.0130 \\
\hline
\end{tabular}

We then included pre- and post-visit brand experience in our model, according to our hypotheses. The full model showed good model fit with an SRMR smaller 0.05 and $d_{\mathrm{G}}$ below its HI95 value. Only $d_{\mathrm{ULS}}$ exceeded the HI99 threshold (see Table 6.7). It also showed reliable and valid measurement of the brand experience constructs, which are now reflectively measured by their sensory, affective, behavioral, and intellectual construct scores obtained in stage one (see Table 6.8 for reliability and validity measures, and Table 6.9 for loadings and t-values).

Table 6.7: Model fit of the final second-order model

\begin{tabular}{lccc}
\hline GOF MEASURE & VALUE & HI95 & HI99 \\
\hline SRMR & 0.0473 & 0.0435 & 0.0463 \\
$\mathrm{~d}_{\mathrm{ULS}}$ & 0.2687 & 0.2269 & 0.2570 \\
$\mathrm{~d}_{\mathrm{G}}$ & 0.2948 & 0.7135 & 1.5511 \\
\hline
\end{tabular}

Table 6.8: Reliability and validity of second-order construct measurement

\begin{tabular}{lllllll}
\hline & & & & \multicolumn{2}{c}{ HTMt } \\
Construct & $\rho_{\mathrm{A}}$ & $\rho_{\mathrm{C}}$ & $\alpha$ & AVE & MAx. & $95 \%$ \\
\hline $\begin{array}{l}\text { Pre-visit Brand Ex- } \\
\text { perience }\end{array}$ & 0.9041 & 0.9001 & 0.8983 & 0.6935 & 0.8364 & 0.8915 \\
$\begin{array}{l}\text { Post-visit Brand Ex- } \\
\text { perience }\end{array}$ & 0.9381 & 0.9358 & 0.9353 & 0.7852 & 0.8364 & 0.8915 \\
\hline
\end{tabular}

Assessing the measurement of the brand world experience composite (see Table 6.10), one can see that the sign of the social environment \& practices component $(2 s e p)$ is negative. This is unexpected, since these social environment \& practices, comprising employee's behavior, attitude, and expertise, should have a positive impact on the brand world experience, i.e. if the visitors perceived the expertise of the employees as higher, they should have a better experience. Therefore, this result points to multicollinearity issues in our measurement of the composite. Being smaller than 5, VIF values for the indicators, i.e. the lower-order construct scores, are within the acceptable threshold (Hair et al., 2017). Eliminating any of these lower-order components which are used as indicators for the $\mathrm{B}_{2} \mathrm{~B}$ brand world experience in this second stage would change 
Table 6.9: Loadings and t-values of final second-order model

\begin{tabular}{lrc}
\hline INDICATOR & LOADING & T-VALUE \\
\hline Isen & 0.8647 & 30.1540 \\
Iaff & 0.9017 & 48.4518 \\
Ibeh & 0.7609 & 20.0540 \\
Iint & 0.7964 & 22.7968 \\
2sen & 0.9256 & 47.4043 \\
2aff & 0.9280 & 45.9383 \\
2beh & 0.8235 & 23.4308 \\
2int & 0.8631 & 29.1798 \\
\hline
\end{tabular}

the conceptual meaning of our composite. We therefore did not interpret the contribution of the individual components on the overall $\mathrm{B}_{2} \mathrm{~B}$ brand world experience. We continued with the assessment of our model and followed the guidelines provided for the three-stage approach by van Riel et al. (2017) to come to our final results.

Table 6.10: Consistent weights, t-values and VIFs of final second-order model

\begin{tabular}{|c|c|c|c|}
\hline INDICATOR & CONSISTENT WEIGHT & T-VALUE & VIF \\
\hline 2 con & 0.1213 & 1.1437 & 1.3783 \\
\hline 2pas & 0.4605 & 4.4269 & 2.8680 \\
\hline 2sep & -0.1166 & -0.9095 & 1.8385 \\
\hline 2inter & 0.3300 & 2.2434 & 3.6188 \\
\hline 2imin & 0.3317 & 2.3998 & 2.5306 \\
\hline
\end{tabular}

In the process, we manually calculated a reliability for our second-order brand world experience composite of $\rho_{\mathrm{A}}=0.9526$, based on the lower-order constructs' reliabilities (van Riel et al., 2017). Furthermore, we also manually calculated consistent weights for these lower-order constructs, which now served as the indicators for the brand world experience composite. ${ }^{1}$ The final model, containing only the second-order constructs, provided us with structural model results. It is the focus of our further analysis, since it provides us with the opportunity to answer our hypotheses Hia-H6, and is depicted in the Appendix in Figure A.2.

Our model explains a substantial proportion of the variance of the focal outcome constructs post-visit brand experience, $R^{2}=.77$, Adj. $R^{2}=.76$, and

1 Contrary to the guidelines of van Riel et al. (2017), we were not able to use the reliabilities for pre-visit overall brand equity $\left(\rho_{\mathrm{A}}=0.7875\right)$ and post-visit overall brand equity $\left(\rho_{\mathrm{A}}=0.8410\right)$ to calculate our final model, because the consistent partial least squares bootstrapping algorithm would not converge. In such cases of non-convergence, literature on covariance-based structural equation modeling suggests to either impose or relax constrictions in the model (Bentler \& Chou, 1987; F. Chen Bollen, Paxton, Curran, \& Kirby, 2001; Rindskopf, 1984). Following these guidelines, we used slightly higher reliabilities of 0.85 for pre-visit overall brand equity and 0.9 for post-visit brand equity, which led to convergence of the model, yet a slight underestimation of the path coefficients. 
post-visit brand equity, $R^{2}=.78, A d j . R^{2}=.78$ (see Table 6.11). Assessing the size and significance of the structural path coefficients (see Table 6.12 for direct effects), the study demonstrates a strong, positive, significant direct effect of pre-visit brand experience on post-visit brand experience, supporting Н1a, $\beta=.65, f^{2}=1.19, p=.000,95 \% C I[0.51,0.78]$. Similarly, pre-visit brand equity has a strong, positive, significant direct effect on post-visit brand equity, supporting H2a, $\beta=.43, f^{2}=.48, p=.000,95 \% C I[0.30,0.57]$.

Table 6.11: Coefficients of determination

\begin{tabular}{llc}
\hline CONSTRUCT & $\mathrm{R}^{2}$ & ADJ. ${ }^{2}$ \\
\hline IOBE & 0.6618 & 0.6602 \\
$2 \mathrm{BWX}$ & 0.3530 & 0.3470 \\
$2 \mathrm{BEX}$ & 0.7651 & 0.7630 \\
$2 \mathrm{OBE}$ & 0.7811 & 0.7780 \\
\hline
\end{tabular}

${ }_{1} \mathrm{OBE}=$ pre-visit overall brand equity; $2 \mathrm{BWX}=$ brand world experience; $2 \mathrm{BEX}=$ post-visit brand experience; $2 \mathrm{OBE}=$ post-visit overall brand equity

Table 6.12: Direct effects

\begin{tabular}{|c|c|c|c|c|c|c|}
\hline DIRECT EFFECT & $\begin{array}{l}\text { PATH } \\
\text { CIENT }\end{array}$ & COEFFI- & $\mathrm{f}^{2}$ & $\mathrm{t}$ & $\mathrm{p}$ & $95 \%$ CI \\
\hline $1 \mathrm{BEX}->1 \mathrm{OBE}$ & & 0.81 & 1.96 & 22.80 & 0.000 & {$[0.74 ; 0.88]$} \\
\hline $1 B E X->2 B W X$ & & 0.38 & 0.08 & 2.78 & 0.006 & [0.14; 0.68] \\
\hline $1 \mathrm{BEX}->2 \mathrm{BEX}$ & & 0.65 & 1.19 & 9.52 & 0.000 & {$[0.51 ; 0.78]$} \\
\hline $1 \mathrm{OBE}->2 \mathrm{BWX}$ & & 0.24 & 0.03 & 1.64 & 0.101 & [-0.10; 0.5o] \\
\hline $1 \mathrm{OBE}->2 \mathrm{OBE}$ & & 0.43 & 0.48 & 5.87 & 0.000 & [0.30; 0.57] \\
\hline $2 \mathrm{BWX}->2 \mathrm{BEX}$ & & 0.32 & 0.30 & 4.27 & 0.000 & {$[0.18 ; 0.46]$} \\
\hline $2 \mathrm{BWX}->2 \mathrm{OBE}$ & & 0.18 & 0.07 & 2.13 & 0.033 & [0.02; 0.35] \\
\hline 2BEX $->2 \mathrm{OBE}$ & & 0.40 & 0.31 & 4.41 & 0.000 & {$[0.21 ; 0.57]$} \\
\hline
\end{tabular}

${ }_{1} \mathrm{BEX}=$ pre-visit brand experience; $\mathrm{IOBE}=$ pre-visit overall brand equity; $2 \mathrm{BWX}=$ brand world experience; $2 \mathrm{BEX}=$ post-visit brand experience; $2 \mathrm{OBE}=$ post-visit overall brand equity

The analysis of indirect effects (see Table 6.13) indicates that the relationship between pre-visit brand experience and post-visit brand experience is furthermore mediated by the brand world experience, $\beta=.19, p=.000$, $95 \%$ CI $[0.11,0.28]$. The signs of the direct effect and the indirect effect are all positive, therefore this is a complementary mediation, and $\mathrm{H}_{3}$ is supported. In contrast, the relationship between pre-visit brand equity and post-visit brand equity is not mediated by the brand world experience, since the indirect effect is not significant, $\beta=.08, p=.122,95 \% C I[-0.03,0.17]$. Therefore, $\mathrm{H}_{4}$ must be rejected. 
The direct effect of pre-visit brand experience on pre-visit brand equity is strong, positive, and significant, thus providing support for $\mathrm{H}_{5}, \beta=.81, f^{2}=$ $1.96, p=.000,95 \% C I[0.74,0.88]$. The direct effect of post-visit brand experience on post-visit brand equity is moderately strong, positive, and significant as well, thus providing support for H6, $\beta=.40, f^{2}=.31, p=$ $.000,95 \%$ CI [0.21, 0.57].

Table 6.13: Indirect effects

\begin{tabular}{|c|c|c|c|c|}
\hline INDIRECT EFFECT & PATH COEFFICIENT & $\mathrm{t}$ & $\mathrm{p}$ & $95 \% \mathrm{CI}$ \\
\hline${ }_{1} \mathrm{BEX}->2 \mathrm{BWX}$ & 0.20 & 1.62 & 0.105 & [-0.09; 0.42] \\
\hline $1 \mathrm{BEX}->$ 2BEX & 0.19 & $4 \cdot 35$ & 0.000 & {$[0.11 ; 0.28]$} \\
\hline${ }_{1} \mathrm{BEX}->2 \mathrm{OBE}$ & 0.79 & 22.86 & 0.000 & {$[0.71 ; 0.85]$} \\
\hline IOBE -> 2BEX & 0.08 & 1.57 & 0.117 & {$[-0.03 ; 0.17]$} \\
\hline $1 \mathrm{OBE}->2 \mathrm{OBE}$ & 0.08 & 1.55 & 0.122 & {$[-0.03 ; 0.17]$} \\
\hline 2BWX $->2 \mathrm{OBE}$ & 0.13 & 2.89 & 0.004 & {$[0.05 ; 0.23]$} \\
\hline
\end{tabular}

${ }_{1} \mathrm{BEX}=$ pre-visit brand experience; $1 \mathrm{OBE}=$ pre-visit overall brand equity; $2 \mathrm{BWX}=$ brand world experience; $2 \mathrm{BEX}=$ post-visit brand experience; $2 \mathrm{OBE}=$ post-visit overall brand equity

Although not being part of our hypotheses, interesting findings are also the results of our study regarding the relationships between pre-visit brand equity and brand world experience, as well as between brand world experience, postvisit brand experience and post-visit brand equity. The results do not provide evidence for a direct effect of pre-visit brand equity on brand world experience, $\beta=.24, f^{2}=.03, p=.101,95 \% C I[-0.10,0.50]$. Yet, the results do provide evidence for a weak, positive, significant direct effect of brand world experience on post-visit brand equity, $\beta=.18, f^{2}=.07, p=.033,95 \% C I[0.02,0.35]$. Also the indirect effect of brand world experience on post-visit brand equity, mediated by post-visit brand experience, is significant, $\beta=.13, p=.004,95 \% C I[0.05,0.23]$. Therefore, the results of our study indicate that the effect of the brand world experience on post-visit brand equity is complementary mediated by post-visit brand experience.

Overall, the results show that the brand world experience has a significant positive total effect on post-visit brand experience, $\beta=.32, p=.000$, $95 \% C I[0.18,0.46]$, and on post-visit brand equity, $\beta=.31, p=.000,95 \% C I$ $[0.15,0.47]$ (see Table 6.14). Furthermore, this total effect of the brand world experience on post-visit brand equity, $\beta=.31, p=.000,95 \% C I[0.15,0.47]$ amounts to more than half of the size of the total effect of pre-visit brand equity on post-visit brand equity, $\beta=50 ., p=.000,95 \% C I[0.30,0.67]$.

\subsection{Discussion}

\subsubsection{A recapitulation of our goals and findings}

Brands are one of the most valuable, intangible assets for companies today, also in industrial markets (Kotler \& Pfoertsch, 2006). Yet, knowledge on the tactics of actually building and managing brands in this context is scarce (Lindgreen 
Table 6.14: Total effects

\begin{tabular}{|c|c|c|c|c|}
\hline TOTAL EFFECT & PATH COEFFICIENT & $\mathrm{t}$ & $\mathrm{p}$ & $95 \%$ CI \\
\hline $1 \mathrm{BEX} \rightarrow{ }_{1 \mathrm{OBE}}$ & 0.81 & 22.80 & 0.000 & {$[0.74 ; 0.88]$} \\
\hline $1 \mathrm{BEX}->2 \mathrm{BWX}$ & 0.58 & 10.57 & 0.000 & {$[0.46 ; 0.68]$} \\
\hline $1 \mathrm{BEX} \rightarrow>2 \mathrm{BEX}$ & 0.83 & 22.82 & 0.000 & [0.76; 0.9o] \\
\hline $1 \mathrm{BEX} \rightarrow>2 \mathrm{OBE}$ & 0.79 & 22.86 & 0.000 & {$[0.71 ; 0.85]$} \\
\hline${ }_{1} \mathrm{OBE}->2 \mathrm{BWX}$ & 0.24 & 1.64 & 0.101 & [-0.10; 0.50$]$ \\
\hline $1 \mathrm{OBE}->2 \mathrm{BEX}$ & 0.08 & 1.57 & 0.117 & [-0.03; 0.17] \\
\hline${ }_{1} \mathrm{OBE}->2 \mathrm{OBE}$ & 0.50 & $5 \cdot 56$ & 0.000 & [0.30; 0.67$]$ \\
\hline 2BWX $->2 \mathrm{BEX}$ & 0.32 & 4.27 & 0.000 & {$[0.18 ; 0.46]$} \\
\hline 2BWX $->2 \mathrm{OBE}$ & 0.31 & 3.65 & 0.000 & {$[0.15 ; 0.47]$} \\
\hline $2 \mathrm{BEX}->2 \mathrm{OBE}$ & 0.40 & 4.41 & 0.000 & [0.21; 0.57] \\
\hline
\end{tabular}

${ }_{1} \mathrm{BEX}=$ pre-visit brand experience; $\mathrm{IOBE}=$ pre-visit overall brand equity; $2 \mathrm{BWX}=$ brand world experience; $2 \mathrm{BEX}=$ post-visit brand experience; $2 \mathrm{OBE}=$ post-visit overall brand equity

et al., 2010). While brand worlds as experiential marketing instruments have been mentioned as a possibility for $\mathrm{B} 2 \mathrm{~B}$ companies to evoke strong, memorable customer experiences with a brand (Gilmore \& Pine, 2002; Pine \& Gilmore, 1999; Schmitt, 1999b), and business marketing practitioners use them already, the actual effectiveness of these and other experiential marketing instruments in the special context of industrial markets is unclear (Rinallo et al., 2010). This research therefore set out to investigate the impact of a $\mathrm{B}_{2} \mathrm{~B}$ brand world visit, and the experiences that are co-created there, on two key branding outcomes that operating companies pursue with $\mathrm{B}_{2} \mathrm{~B}$ brand worlds: brand experience and brand equity. The results of our pretest-posttest quasi-experimental research design show that a visit to a $\mathrm{B} 2 \mathrm{~B}$ brand world does work in increasing these focal constructs. Furthermore, by analyzing the brand world experience in a nomological net of pre-test and post-test brand experience and brand equity using partial least squares structural equation modeling, the findings provide a deeper understanding on the mechanism behind this increase.

11 out of 12 indicators used to measure brand experience exhibited a significantly higher value after the visit than they did before, while the remaining indicator remained unchanged. The results for an increase in the brand awareness dimension of brand equity were inconclusive (one indicator showed a significant decrease, one indicator remained unchanged, and one indicator showed a significant increase), yet the 17 remaining indicators of brand associations, perceived quality, brand loyalty, and overall brand equity all showed a significant increase after the brand world visit compared to the observation before the visit.

The results of our structural equation model analysis show that the experience co-created at a $\mathrm{B} 2 \mathrm{~B}$ brand world as an individual touchpoint relates to the dynamic, overall brand experience, representing a lasting trace stored in long-term memory based on the exposure to the brand on multiple touchpoints. In a complementary mediation, the $\mathrm{B}_{2} \mathrm{~B}$ brand world experience is itself influ- 
enced by pre-visit brand experience, and influences post-visit brand experience. Furthermore, the co-created $\mathrm{B} 2 \mathrm{~B}$ brand world experience is not influenced by pre-visit levels of brand equity. Yet, in another complementary mediation, the experience at brand worlds does influence post-visit levels of $\mathrm{B}_{2} \mathrm{~B}$ brand equity both directly as well as indirectly through post-visit brand experience. In sum, the total effect of the brand world experience on post-visit brand equity amounts to more than half of the size of the total effect of pre-visit brand equity on post-visit brand equity. This clearly shows that brand worlds are not only effective instruments for branding and for the co-creation of strong, memorable, and extraordinary customer experiences in consumer marketing (e.g Dolbec \& Chebat, 2013), but just as much in an industrial environment. Positive customer experiences and strong brands are at the center of academic and managerial interest in $\mathrm{B}_{2} \mathrm{~B}$, and our study clearly shows the value of $\mathrm{B}_{2} \mathrm{~B}$ brand worlds for creating both.

\subsubsection{Implications for theory}

Experiential marketing instruments in general, and brand worlds in particular, have so far only been investigated qualitatively in the industrial marketing area (Österle et al., 2018a; Rinallo et al., 2010). Their usefulness in this context was unclear, and some tactics that rely on autotelic activities were regarded to be ineffective or even counter-productive (Rinallo et al., 2010).

As the, to the best of our knowledge, first quantitative research on brand worlds in industrial marketing, this study shows that brand worlds as experiential marketing and branding instruments do have a positive impact on the visitors' levels of brand experience and brand equity. An important implication for industrial marketing theory is that experiential marketing techniques and instruments can indeed be effectively applied in this different context. In the form of brand worlds they are especially valuable for brand building and brand management in business markets. Thus, this study furthers theoretical knowledge on experiential marketing and its applicability in industrial marketing in general (Rinallo et al., 2010). More specifically, this study empirically supports literature on brand worlds stating that they could also be valuable assets for industrial companies (Gilmore \& Pine, 2002). Furthermore, by providing evidence for their effectiveness, this study adds brand worlds as a complementary instrument to the strategies and tactics of building, managing, and maintaining a strong brand in industrial markets, which is seen as a major strategic objective (Lindgreen et al., 2010; Seyedghorban et al., 2016). The predominance of visitors from Germany in our sample might be an indicator, that this instrument has a rather local impact. Yet this could also be explained by the fact that the brand under investigation also operates brand worlds in other parts of the world, for example at two locations in the US.

Additionally, this study also has important implications for research on customer experiences in business markets - a top research priority and one of the most important research challenges (Lemke et al., 2011; Lemon \& Verhoef, 2016; Marketing Science Institute, 2014, 2016; Zolkiewski et al., 2017). In the context of this research, the experience co-created at a $\mathrm{B}_{2} \mathrm{~B}$ brand world as an individual touchpoint influences the dynamic, overall brand experience, representing a lasting trace stored in long-term memory based on the exposure to the brand on multiple touchpoints. Our findings are thus in line with 
recent conceptualizations in $\mathrm{B}_{2} \mathrm{C}$ of customer experience as a dynamic concept, showing that past brand experiences influence the current, static experience at an individual touchpoint, and that these current experiences in turn relate back to the overall, dynamic brand experience also in the industrial marketing context (Kranzbühler et al., 2018; Lemon \& Verhoef, 2016; Österle, Kuhn, \& Henseler, 2018c).

Furthermore, our study highlights the importance of this conceptualization of customer experiences on different levels. With respect to the relationship between the experience at a $\mathrm{B}_{2} \mathrm{~B}$ brand world, an individual touchpoint, and post-visit B2B brand equity, our study has shown that this relationship is complementary mediated by the overarching, overall, dynamic brand experience. What is more is that, in contrast to pre-visit brand experience, the levels of previsit brand equity do not influence the co-created $\mathrm{B}_{2} \mathrm{~B}$ brand world experience. This means that no matter what the B2B visitors' levels of brand awareness, brand associations, perceived quality, or brand loyalty are prior to the visit, there is a possibility for the operating company to co-create an extraordinary, strong, memorable experience for the visitor in the B2B brand world. Subsequently, this experience then influences post-visit B2B brand equity directly and indirectly through brand experiences. The total effect of this relationship between the experience at the $\mathrm{B} 2 \mathrm{~B}$ brand world and post-visit brand equity amounts to more than half of the size of the total effect of pre-visit brand equity on post-visit brand equity. This shows the important role of experiences at individual touchpoints, as well as that of the overall, dynamic brand experience for brand building purposes on industrial markets. It implies for marketing theory, that the experiences at individual touchpoints and the overarching experiences with a brand emerging from these touchpoints must be taken into consideration when trying to successfully build and manage brands in this context.

\subsubsection{Implications for practice}

The central implication of this study for marketing theory is also the most important implication for marketing practice: A visit to a brand world increases the levels of brand experience and brand equity in industrial markets. In fact, our study shows that brand worlds are powerful B2B branding instruments, since the effect of a single visit to a $\mathrm{B} 2 \mathrm{~B}$ brand world on post-visit brand equity amounts to more than half of the size of the effect of pre-visit brand equity, i.e. all the possibly negative preconceptions that the visitor had about the brand prior to the visit. This means that if the visitor prior to the visit was unaware of the brand, had negative associations with the brand, perceived it as being of low quality, or was disloyal, one single visit to a B2B brand world can compensate for more than half of these prior associations with respect to the visitors post-visit brand equity evaluation.

Additionally, the experience co-created at the $\mathrm{B}_{2} \mathrm{~B}$ brand world is not influenced by these possible preconceptions. Therefore, also visitors who are rather skeptical of the brand prior to the visit to the $\mathrm{B}_{2} \mathrm{~B}$ brand world can have a positive experience there, which in turn influences post-visit brand equity evaluations positively. Yet unfortunately, there is also a flipside: It also means that $\mathrm{B}_{2} \mathrm{~B}$ visitors who have high levels of brand awareness, brand associations, perceived quality, and brand loyalty prior to the visit do not automatically have 
a great experience at the $\mathrm{B} 2 \mathrm{~B}$ brand world. Thus, to reap the potential benefits of a brand world visit, these visits have to fulfill, if not exceed, the expectations of the visitor. Otherwise, a brand world visit which is perceived as negative by the visitor could also have a harmful impact on the overall brand experience and also on overall brand equity and its dimensions. This calls for careful management and individualization of the brand world experience to each $\mathrm{B}_{2} \mathrm{~B}$ visitor's needs, and is in line with previous findings about the importance of individualization and the creation of a visit that is relevant for the business visitor in that it supports him in his business activities (Österle et al., 2018a).

\subsubsection{Study limitations and future research directions}

We were able to show that a $\mathrm{B}_{2} \mathrm{~B}$ brand world and the experience co-created there does have a significant impact on brand experience and brand equity. A replication of our study in a different $\mathrm{B}_{2} \mathrm{~B}$ brand world setting, for example in a pure $\mathrm{B}_{2} \mathrm{~B}$ brand museum, and a different industry could further contribute to the understanding of this impact for different types of brand worlds, and what the most important brand world components are in inducing such a positive impact. Future research could also compare the impact of different experiential marketing instruments on brand experience and brand equity, such as trade shows, brand worlds, and events, in order to see which of these instruments is most effective.

The inconclusive result for brand awareness could originate in the already very high pre-visit level of brand awareness for the brand under investigation. The pre-visit mean for the indicator "I am aware of the brand [name of the brand]." was $M_{1}=6.68\left(S D_{1}=0.697\right)$, and the slight, but significant decrease lead to a post-visit mean of $M_{1}=6.57\left(S D_{1}=0.697\right)$ on a 7-point scale. Another reason might lie in the conceptualization of the construct itself, in combination with our survey procedure. Brand awareness represents the knowledge and salience (i.e. the capacity to recognize) of the brand in the respondent's mind (D. A. Aaker, 1996b). The brand name itself and the attached symbols, imagery and a brand slogan strongly influence the level of brand awareness within a given condition (D. A. Aaker, 1996b). Since the measures used in this study largely rely on the respondent's recall of the brand, and we conducted the survey under a condition where the respondent is actually physically surrounded by the brand, namely inside the $\mathrm{B}_{2} \mathrm{~B}$ brand world, this might have influenced respondents answers on the brand awareness measurement scale. Nevertheless, since the overall brand equity measures did show a significant increase due to the brand world visit, and since these measures represent all dimensions of brand equity in $\mathrm{B}_{2} \mathrm{C}$ (Yoo \& Donthu, 2001) and $\mathrm{B}_{2} \mathrm{~B}$ (Davis et al., 2008), we are confident that our overall findings hold.

The multicollinearity issues present with the measurement of the brand world experience composite on the second-order level did not allow us to interpret how influential the individual components of the brand world experience are in actually creating the $\mathrm{B}_{2} \mathrm{~B}$ brand world experience. Nevertheless, this issue does not affect the conclusions drawn from the findings in the structural model (Cenfetelli \& Bassellier, 2009; Hair et al., 2017), which were the main focus and contribution of this study. Yet, how brand world experiences are composed, and the quantitative contribution of these components to positive experiences and what possibly hinders them, is an highly important field of study, with 
implications both for academia and for managerial practice in $\mathrm{B}_{2} \mathrm{C}$ and $\mathrm{B}_{2} \mathrm{~B}$ (Lemon \& Verhoef, 2016; Zolkiewski et al., 2017). Future studies could therefore try and use or develop different measurement scales to assess the individual components and their contribution to the overall co-created experiences in brand worlds, both in $\mathrm{B}_{2} \mathrm{C}$ and in $\mathrm{B} 2 \mathrm{~B}$, with which the assessment of the influence of the individual components on the entire experience is possible. This could lead to 'recipes' explaining how the B2B brand world 'ingredients' should be composed in order to co-create the most positive experiences, which in turn would result in stronger changes in brand equity, which would have important managerial implications. Another area for future research related to such a recipe might consider the following important managerial question: If an industrial brand world is implemented, how much budget should a firm allocate to it? While our study has shown the impact that a $\mathrm{B}_{2} \mathrm{~B}$ brand world visit has on brand experience and brand equity in $\mathrm{B}_{2} \mathrm{~B}$, it did not quantify a return on investment yielded by industrial brand worlds. If future studies would lead to such an indication of 'brand world elasticity' and a recipe on how to compose the most positive brand world experience, a combination of these tools would allow $\mathrm{B}_{2} \mathrm{~B}$ marketers to design and manage $\mathrm{B}_{2} \mathrm{~B}$ brand worlds much more efficiently, and similar to price, advertisement, or professional selling (Albers et al., 2010).

In this study, we have focused on the short-term effects of the brand world visit, by measuring post-visit levels of brand experience and brand equity right after the visit of the brand world. Due to the fresh impressions of the visit, this short-term influence might be higher than the lasting long-term effect. Another possible area for future research therefore lies in the evaluation of the long-term influence of a brand world visit on brand experience and brand equity, especially since this effect on long-term memory is supposedly much stronger for such a visit than it is for regular advertising and communication instruments (Borghini et al., 2009; E. H. Wood, 2009; Zarantonello \& Schmitt, 2013).

By showing that post-visit brand experience mediates the relationship between brand world experience and brand equity, we have explained the experiential part of the mechanism behind the increase in the levels of brand equity through the visit. Yet, the direct effect between brand world experience and post-visit brand equity provides further interesting and fertile opportunities for research, because this direct effect could still be explained by other mechanisms What comes to mind when thinking about a brand world as the "home of the brand" (Moore et al., 2010, p. 153) or the metaphorical 'living room' into which the business visitor is invited, is the strong connection and relationship that can be forged there, inter-personally and also between individuals and the brand as a whole. Brands can serve as legitimate relationship partners in B2C (Fournier, 1998), and relationships and interactions are also core aspects of business marketing (Håkansson et al., 2009; Håkansson \& Snehota, 1995). The role of emotions, heuristics, and subjective evaluations is increasingly acknowledged in organizational buying behavior as well (Casidy et al., 2018; Iyer et al., 2015; Mohan et al., 2018; Zablah et al., 2010). Further research, in order to provide an explanation for this direct effect of the brand world experience on brand equity in industrial markets, might pay tribute to these emotional and subjective aspects in business markets. One of the concepts that could play a role in the relationship between brand world experience and brand equity is brand 
trust, the willingness to rely on the ability of the brand to perform its stated function (Chaudhuri \& Holbrook, 2001; Moorman, Zaltman, \& Deshpande, 1992; Morgan \& Hunt, 1994). Furthermore, brand affect, a brand's potential to evoke positive emotional responses (Chaudhuri \& Holbrook, 2001) might play a role in that relationship. Lastly, the invitation to visit the brand's 'living room' might also have an effect on brand intimacy. This concept is defined as the degree of closeness, connectedness, and bondedness with a brand (Thorbjørnsen, Supphellen, Nysveen, \& Pedersen, 2002), as the consumer having a detailed knowledge of the brand and the brand having special meaning for the consumer (Srivastava, Dash, \& Mookerjee, 2016), and as a deep understanding between the brand and the consumer through information disclosure (J. Aaker, Fournier, \& Brasel, 2004).

\subsubsection{Conclusion}

To conclude, $\mathrm{B} 2 \mathrm{~B}$ brand worlds, these permanent, interactive and extraordinary spaces largely under the control of the operating companies, where industrial brands become visible and tangible, where business visitors are presented with a variety of first-hand information tailored to their specific needs, where products and services can be experienced 'in-vivo', and where customer and brand employees meet face-to-face and forge relationships, do have a strong impact on the branding efforts of industrial companies based on the experience created there. Taking into consideration all the findings and interpretations, one can justifiably say that brand worlds might not only be the apexes of branding in $\mathrm{B}_{2} \mathrm{C}$, but also in $\mathrm{B}_{2} \mathrm{~B}$. 


\subsection{INTRODUCTION}

This research set out to investigate whether brand worlds, the apexes of branding in consumer marketing, would make sense and could also be a useful instrument for a company in industrial marketing to provide its (potential) customers or other stakeholders with unique and extraordinary experiences and, as a result of doing so, strengthen their bond to the brand. Furthermore, the goal of this research was also to understand how these brand worlds might work on industrial markets with their branding nuances. Therefore, the main goal of this $\mathrm{PhD}$ project was to answer two main research questions:

RQ1: Do brand worlds also work in industrial marketing?

And, if so:

$R Q_{2}$ : How do brand worlds work in industrial marketing?

In this final chapter, the answers to these questions are provided in the following section Section 7.2. This chapter builds on the findings of the multiple steps undertaken within this $\mathrm{PhD}$ project, as represented by the individual Chapters 2-6. It brings these individual pieces together to create a synopsis, and relates the findings from those chapters back to the main research questions in order to provide these answers. While the limitations of the findings of each individual chapter have been addressed in that very chapter, Section 7.3 discusses the limitations of this research project as a whole, and presents areas for future research based on these limitations. Section 7.4, the very last part of this thesis, delineates the key takeaways and implications from this research both for marketing theory and practice.

\subsection{Discussion}

Do brand worlds work in industrial marketing? And if so, how do they work? Answering these questions was the main purpose of the research within this $\mathrm{PhD}$ project. In the following sections, the 'red thread' described in Section 1.3 will therefore be picked up. They make the connections from the findings of the previous chapters back to these main research questions in order to answer them. Within a design science research framework, scientific research on these questions that regard brand worlds as a design artifact, gives designers and practitioners the "possibility to create, improve, orchestrate, and manage" (Henseler, 2017a, p. 178) these types of marketing instruments.

\subsubsection{Chapter 2: An Inquiry Into Experiential Marketing and Brand Worlds in Industrial Marketing}

In order to provide answers to the research questions, first a thorough understanding of the characteristics of these instruments of experiential marketing 
was needed, and an explanation of what makes them so successful in consumer marketing. Based on a systematic review of the literature on $\mathrm{B}_{2} \mathrm{C}$ brand worlds, seven main types of brand worlds in the consumer marketing area were identified in Chapter 2, namely factory tours, visitor centers, brand museums, showrooms, flagship stores, brand stores, and brand lands. Furthermore, the analysis revealed that the main goals of these consumer brand worlds are not only image based and related to branding, i.e. rather long-term oriented (Manlow \& Nobbs, 2013). These spaces also focus on the short term and have concrete retailing purposes, reflecting the extent to which they also encourage and emphasize direct purchasing decisions (Kozinets et al., 2002), for example in flagship stores or merchandising stores attached to a brand museum or a brand world. The characteristics that differentiate the various types of $\mathrm{B}_{2} \mathrm{C}$ brand worlds from each other are first related to their content and the extent to which this content is delivered in specific ways. While some spaces are more hands-on, others are purely informational or educational. Furthermore, B2C brand worlds differ in the extent to which they focus on entertainment or not, whether they showcase the entire product range or only an excerpt, the past, present or future of the brand, and the extent to which additional services are offered. Physical characteristics are also important aspects in differentiating different types of brand worlds. Their size, location, and the architecture and design varies. The latter, for example, usually is more sophisticated in flagship stores or brand lands than in brand stores. The extent to which the senses are engaged in the brand world space also fall in this physical category, as does the investment. It is usually directly linked to the size, location, and architecture and design, and which can be quite large for large brand lands, or more humble for factory tours.

Based on secondary information on existing brand worlds in industrial markets, the study shows that theoretically, several of these characteristics differentiating $\mathrm{B}_{2} \mathrm{C}$ brand worlds from each other can be transferred to the $\mathrm{B}_{2} \mathrm{~B}$ realm as well. In fact, business marketing practitioners not only successfully implement such experiential marketing techniques and instruments in the trade show industry for decades already (Rinallo et al., 2010), but also within brand worlds of companies that market industrial goods and services.

Yet, although this shows that the characteristics and benefits of brand worlds could theoretically be transferred and are in fact to a certain extent also transferred from $\mathrm{B}_{2} \mathrm{C}$ to $\mathrm{B}_{2} \mathrm{~B}$ marketing, it does not yet show that these instruments also work in this different context. Additionally, industrial marketing companies might pursue entirely different goals with their brand worlds than consumer marketing companies do, given the different nature of their customers and also the different roles, functions, and values that brands have in industrial markets (B. P. Brown et al., 2007; Leek \& Christodoulides, 2012; Seyedghorban et al., 2016; Zablah et al., 2010). Also, the difference in autotelic and instrumental experiences on consumer and business markets suggests (Rinallo et al., 2010), that business visitors to B2B brand worlds might have different expectations towards their visit to a $\mathrm{B}_{2} \mathrm{~B}$ brand world, and derive a different value from it than consumers do when they visit a $\mathrm{B}_{2} \mathrm{C}$ brand world. Therefore, this general introduction of the techniques and instruments of experiential marketing, as implemented in brand worlds, to the industrial marketing area could only serve as a first theoretical assessment and build the foundation for future research. 


\subsubsection{Chapter 3: Brand Worlds: Introducing Experiential Marketing to B2B Branding}

Rooted in the first main research question of this $\mathrm{PhD}$ project, it was therefore necessary to understand exactly what these motives of operating companies for implementing brand worlds in industrial marketing are. Only knowing these goals allows for the subsequent evaluation on whether industrial brand worlds actually work in achieving these goals. Therefore, based on the exploratory nature of this question, qualitative research -37 qualitative expert interviews with operating companies, exhibition designers, and business visitors - was conducted in order to identify these goals, as laid out in Chapter 3.

The findings show that the main objectives of industrial companies to implement brand worlds are strongly related to building their brand. More specifically, companies with broad product portfolios aim to raise product awareness, the extent to which someone is aware of and familiar with a company's products and services (Collins, 2007). Brand worlds are an effective way to provide all stakeholders, including the own employees, with a full overview and deep knowledge of the company's offerings in terms of new and existing products or services. Furthermore, a goal that industrial companies pursue with their brand worlds is to link certain associations to their brands. Brand associations refer to three distinct perspectives, namely the brand-as-product perspective, which involves functional benefits and highlights the value proposition of the brand; the brand-as-person perspective, which establishes a link to the brands emotional and self-expressive benefits; and the brand-as-organization perspective, which considers the organization and its people, values, and programs behind the brand (D. A. Aaker, 1996b). Especially the brand-as-person and the brand-as-organization perspective are important goals that the operating companies pursue with their brand worlds. The industrial buying context still involves a high degree of personal interactions and trust in those individuals and the organizations behind them (e.g. Lilien, 2016). Brand worlds are unique and strong ways to enable these personal interactions and establish this trust. This is based therein that the visitor's are basically invited into the brand's 'home' and 'living room', the brand world, and they spend dedicated one-onone time with the individuals of the respective organization there, from several hours to even several days, in which these positive brand associations can be built.

Regarding direct sales and profit, brand worlds in industrial marketing are clearly also seen as sales instruments, which contribute to relationship building and the entire customer journey. Yet, they are only expected to increase sales further down the road, in line with the fact that the entire buying process in $\mathrm{B}_{2} \mathrm{~B}$ is more complex than in B2C (R. Grewal \& Lilien, 2012).

These findings give first qualitative support describing that brand worlds do actually 'work' also in industrial marketing from the operating company's perspective. Informants in fact stated that brand worlds are more effective than any other marketing instruments in providing an overview of the products and capabilities of a brand.

In the same study, the expectations that business visitors have towards, and the value they derive from a visit to a brand world in industrial marketing were investigated. This provided first, qualitative information on whether brand worlds 'work' not only for the operating company, but also for the visitors. In line with the literature (Rinallo et al., 2010), business visitors expect that 
the visit to a brand world in industrial markets first of all helps them in their own business endeavors, i.e. that it is instrumental in nature. Business visitors expect to learn something new with respect to the operating company or its products and services, or to understand something that they would not be able to understand or learn without the brand world visit. They largely expect that this curiosity and thirst for knowledge are satisfied in a pleasant and appealing atmosphere. Furthermore, they generally expect to feel valued and welcomed by the operating company during their visit, and, interestingly, they partly also expect an emotionally appealing or even entertaining character of the brand world visit. These more emotional and hedonic expectations towards the $\mathrm{B}_{2} \mathrm{~B}$ brand world visit add to and expand previous findings that affections, emotions, heuristics, and subjective evaluations do play a role in the industrial context as well (Bagozzi, 2006; Casidy et al., 2018; Iyer et al., 2015; Leek \& Christodoulides, 2012; Lynch \& de Chernatony, 2007; Mohan et al., 2018; Zablah et al., 2010). In the context of brand worlds in industrial marketing, they do not only play a role, but they are even expected. The values that business visitors derive from their $\mathrm{B} 2 \mathrm{~B}$ brand world visit are similar to the ones identified in the context of $\mathrm{B}_{2} \mathrm{~B}$ networking events (V.-W. Mitchell et al., 2016). This indicates that those values can be transferred to the related experiential marketing area in business markets. The most important of these values of a brand world visit is, in line with the main expectation that visitors have, the learning, epistemic, and knowledge value dimension. It comprises generating and gathering new knowledge and information about the brand, as well as theoretical information about the products, their production, and use cases, as well as practical, hands-on trainings and experiences, for example for product users. Furthermore, professional value is derived if the visit provides value for the own company or the visitors themselves in some general way that helps in their business lives, and serves a purposes in general, i.e. it provides functional/utilitarian value. Yet, again also emotional value is derived in the form of edutainment or enthusiasm, or if the aforementioned expectation of appreciation and well-being is fulfilled. A highly interesting finding is that an emotional way of presenting information in a $\mathrm{B}_{2} \mathrm{~B}$ brand world also increases the value of the visit, because these emotions act as a support for remembrance and decision-making. In the same vein, value is derived from the visit if the $\mathrm{B}_{2} \mathrm{~B}$ brand worlds provides a connection of the $\mathrm{B}_{2} \mathrm{~B}$ product or service to the daily life of the visitor. The brand world visit also provides value for business visitors by being a way of escapism from their daily job, and also by simply providing the visitor with hedonic, altruistic, and entertaining experiences. These findings also expand previous literature in the $\mathrm{B} 2 \mathrm{~B}$ area which points to the relevance of emotional aspects and heuristics in the $\mathrm{B}_{2} \mathrm{~B}$ buying process (Casidy et al., 2018; Iyer et al., 2015; Mohan et al., 2018; Zablah et al., 2010). Furthermore, the brand world visit also provides value for the visitors because it allows them to build a relationship and trust with the organization, and getting to know the human beings behind this organization.

Thus, these findings provide first qualitative support for the statement that a visit to a well-designed industrial brand world not only 'works' for the operating company, but is also a valuable experience for the business visitor.

Looking at research question two, how brand worlds work in industrial marketing, the qualitative research in Chapter 3 also aimed at understanding what the nature of brand worlds in industrial markets is and what they are 
constituted of, how they are perceived and how the experiences at these brand world visits are co-created.

Therefore, not only operating companies and business visitors, but also exhibition designers were interviewed. This approach allowed us to triangulate their views in a comprehensive, multi-perspective sample. The study drew on the psychological stance of phenomenology, the primary focus of which are the questions of how we perceive, experience, and act in the world around us (Dourish, 2004). The understanding of the nature of brand worlds in industrial marketing begins with the contents the operating company wants to convey there. These are, on the one hand, rooted in the operating company's goals, but on the other hand also influenced by the varying expectations of the individual business visitors. Therefore, these contents should be highly contextual and individualized, in order to provide value for the business visitor The contents in turn manifest in the $\mathrm{B}_{2} \mathrm{~B}$ brand world experiencescape, just as in the consumer marketing area ( $\mathrm{O}^{\prime}$ Dell, 2010a). These experiencescapes are strategically planned, laid out, and designed spaces in which experiences are staged and consumed ( $\mathrm{O}^{\prime}$ Dell, 2010a). They comprise both the physical artifacts and spaces such as the architecture, design, and exhibits, which form a tangible embodiment of the brand, as well as the social environments and practices in the brand world, the behavior of the employees, their competence and attitude, i.e. the social representation of the brand. This $\mathrm{B}_{2} \mathrm{~B}$ brand world experiencescape describes the nature of the $\mathrm{B}_{2} \mathrm{~B}$ brand world and what it is. Thus, it consists of the physical artifacts and spaces, and the social environments and practices and affordances that these two components provide alone and in combination. These $\mathrm{B}_{2} \mathrm{~B}$ brand world experiencescapes are largely under the control of the operating companies, and thus are their contribution to the $\mathrm{B} 2 \mathrm{~B}$ brand world experience. Yet, affordances are action possibilities that invite behavior based on the visitor's capacities to perceive and engage with them (Withagen et al., 2012). Therefore, when looking at how the experiences are co-created at industrial brand worlds, and thus how these spaces work, two main components have to be considered: On the one hand, the $\mathrm{B}_{2} \mathrm{~B}$ brand world experiencescape, reflecting the company's contribution to the co-created $\mathrm{B}_{2} \mathrm{~B}$ brand world experience; and on the other hand the embodied cognition of the $\mathrm{B}_{2} \mathrm{~B}$ brand world, reflecting the visitor's contribution to how he perceives and interacts with the affordances provided within the $\mathrm{B}_{2} \mathrm{~B}$ brand world experiencescape, and thus how he experiences it. Through their actions and perceptions on these affordances, the visitors interact with and influence both the physical artifacts and spaces, as well as the social environment. This thus leads to a joint action-perception cycle, through which the experience of visitors at the $\mathrm{B}_{2} \mathrm{~B}$ brand world is co-created between the visitors themselves and the $\mathrm{B} 2 \mathrm{~B}$ brand world experiencescape.

These perceptions of and interactions and relationship-building processes with subjects (i.e. the brands employees), as well as the interactions with, perceptions of, and immersion in the physical environment leads to further engagement, a personalization and co-production of the $\mathrm{B}_{2} \mathrm{~B}$ brand world experience and facilitates learning and relationship-building in the brand world. To conclude, it is how the $\mathrm{B} 2 \mathrm{~B}$ brand world experience itself, and the value in it for both parties, is co-created, and thus describes how brand worlds work on the micro-level. 


\subsubsection{Chapter 4: Differences Between Brand Worlds in $B_{2} C$ and $B 2 B$}

Based on the study of Chapter 3, its 37 qualitative expert interviews and the findings derived from them, Chapter 4 delineates how brand worlds in industrial marketing differ from their counterparts in consumer marketing. While they build on the same principles of experiential marketing, $\mathrm{B}_{2} \mathrm{~B}$ companies focus more on providing live product experiences, in order to explain often complex products, and to create awareness for the whole breadth and depth of their product portfolio in their brand worlds. B2B visitors expect a visit to support them in their own business activities. Furthermore, the visits, experiences, and interactions in $\mathrm{B}_{2} \mathrm{~B}$ brand worlds are more customized, based on a strong personal interaction with the respective contact persons, sales agents or guides. These differences have to be taken into account for the design, implementation, and operation of brand worlds in industrial marketing, and therefore this chapter can serve as the basis for possible design improvements of these artifacts within the design science research paradigm. Furthermore, industrial brand worlds often provide the physical environments where first interactions take place and relationships are initiated and built. Given the importance of relationships in business markets, and the interactions between actors which are at the core of these relationships (Håkansson et al., 2009; Håkansson \& Snehota, 1995), it is therefore worthwhile for companies to further investigate how individual processes and interactions that can involve organizational units, individuals, or certain business activities such as business meetings, influence the overall relationship (Guercini et al., 2014). The stimuli provided in a brand world and its atmosphere and servicescape might, based on the findings of environmental psychology literature (Baker et al., 2002; Bitner, 1992; Kotler, 1973; Mehrabian \& Russell, 1974), influence how the relationships and interactions built and conducted within those spaces are perceived. This serves as an outline for future research and investigations within the design science perspective, which could provide useful information for the design, implementation and operation of brand worlds in industrial marketing.

Yet, after having established how brand worlds in industrial marketing work on a micro level in Chapter 3, the question still remains how they work on a macro level? Or in other words, how do the experiences co-created at this single touchpoint relate to the operating companies' goals in a nomological network and along the entire customer journey? Furthermore, in addition to the first qualitative support in Chapter 3, a quantitative evaluation of whether brand worlds actually do work in industrial markets is needed. In investigating these question, a focus is laid on the impacts of a $\mathrm{B}_{2} \mathrm{~B}$ brand world visit and the experiences co-created there on two concepts, which span large parts of the goals of operating companies identified in Chapter 3 . They are furthermore core concepts for branding and experiential marketing, both for marketing science and practice: brand experience and brand equity (Andreini et al., 2018; Mudambi, 2002; Seyedghorban et al., 2016).

\subsubsection{Chapter 5: The Dynamic Nature of Brand Experience}

Chapter 5 delineates the dynamic nature of brand experiences, which are sensations, feelings, and cognition as well as behavioral responses evoked by brand-related stimuli such as a brand's identity, design, communication and 
environments (Brakus et al., 2009). Brand experience is not evaluating the experience with brands at a certain touchpoint, but instead these subjective, internal consumer responses and behaviors represent the overall brand experience due to multiple exposures to brand-related stimuli and the lasting trace stored in long-term memory based on these exposures on individual touchpoints (Brakus et al., 2009). Based on this conceptualization and recent literature on the nature of customer experiences in general (Kranzbühler et al., 2018; Lemon \& Verhoef, 2016), a framework was developed in Chapter 5 that allows for the investigation of the effects of different touchpoints and their experiential stimuli on the overall brand experience and its dimensions. According to this framework, pretest-posttest quasi-experimental designs can be used to assess the impact of an individual touchpoint on brand experience, by measuring brand experience before and after exposure to this very touchpoint.

\subsubsection{Chapter 6: Entering B2B Brands' Living Rooms: How Brand Worlds Can Help Build Brand Equity}

In line with previous work conducted in the branding and event marketing area (Simonin \& Ruth, 1998; Zarantonello \& Schmitt, 2013), the dynamic brand experience framework developed in Chapter 5 was then combined with a pretest-posttest measurement of brand equity. This combination forms the basis for the quantitative evaluation of the two main research questions of this thesis, whether brand worlds work in industrial marketing, and how they work.

Based on a sample of 218 business visitors, Chapter 6 shows that a visit to a $\mathrm{B}_{2} \mathrm{~B}$ brand world does indeed significantly increase the levels of 11 out of 12 indicators used to measure brand experience, while the remaining indicator remained unchanged. Furthermore, while the results for an increase in the brand awareness dimension were inconclusive (one indicator showed a significant decrease, one indicator remained unchanged, and one indicator showed a significant increase), the 17 remaining indicators of brand associations, perceived quality, brand loyalty, and overall brand equity all showed a significant increase after the brand world visit compared to the observation before the visit. Thus, brand worlds work in industrial marketing regarding an increase in the levels of these two core constructs, and therefore they are not only effective instruments for branding in the consumer marketing area (Dolbec \& Chebat, 2013), but also in industrial markets.

Furthermore, the study gives insights about the mechanism of how these artifacts work on a macro-level, within a nomological network that investigates the experience co-created at the brand world and its relationship to behavioral constructs. It shows that the experiences created at the individual touchpoint, the brand world, are influenced by previous brand experiences, and in turn influence post-visit brand experiences through a complementary mediation. This supports the framework developed in Chapter 5, and the dynamic conceptualizations of customer experiences along the entire customer journey in general (Kranzbühler et al., 2018; Lemon \& Verhoef, 2016). It furthermore highlights the importance of these conceptualizations of customer experiences at different levels of the individual touchpoint and the overall experience: The study shows that the experience co-created at the individual touchpoint, the 
$\mathrm{B}_{2} \mathrm{~B}$ brand world, influences the intended branding outcome of brand equity both directly, as well as indirectly through post-visit brand experience.

Additionally, an important finding is that pre-visit brand equity levels have no influence on the experience co-created in the B2B brand world. Therefore, regardless of the levels of brand awareness, brand associations, perceived quality, or brand loyalty the business visitors have prior to their visit, there is a possibility for the operating company to co-create an extraordinary, strong, memorable experience for the visitor in the brand world, which then influences post-visit B2B brand equity directly and indirectly through post-visit brand experiences.

A finding that underlines the power that these designed artifacts have for branding purposes is that the total effect of the $\mathrm{B}_{2} \mathrm{~B}$ brand world experience on post-visit brand equity amounts to more than half of the size of the total effect of pre-visit brand equity on post-visit brand equity. One the one hand, this means that if the visitor was unaware of the brand, had negative associations with the brand, perceived it as being of low quality, or was disloyal to the brand prior to the visit, one single visit to a $\mathrm{B}_{2} \mathrm{~B}$ brand world can compensate for half of these possible preconceptions with respect to the visitors post-visit brand equity evaluation. On the other hand, it also means that visitors who have high levels of brand equity prior to the visit do not necessarily also have a great experience at the brand world. If the visitors are in fact disappointed by the experience at this individual touchpoint, it can also have a negative effect on their levels of post-visit brand experience and on post-visit brand equity. Thus, to reap the potential benefits of brand worlds in industrial marketing, operating companies have to fulfill, if not exceed, the expectations of their visitors. This calls for careful management and an individualization of the brand world experience to each B2B visitor's needs, and is in line with the findings about the importance of individualization and the creation of a visit that is relevant for the business visitor in that it supports him in his business activities.

Understanding how the visitors' experiences are co-created in these spaces (Chapter 3), and how these designed artifacts differ from their counterparts in the consumer marketing area (Chapter 4), provides industrial marketing practitioners with the first tools for the successful design, management, and operation of their brand worlds, in order to fully benefit from this powerful branding instrument (Chapter 6).

\section{$7 \cdot 3$ LIMITATIONS}

In this last chapter, the main research questions, which provided the red thread for this dissertation, have been answered. Yet regardless of the due care paid during the entire process, this dissertation comes with some limitations and areas for improvement, as does all research. While in each individual chapter, the specific limitations of the respective chapter have been addressed, this section now assesses the overall limitations of the results of this $\mathrm{PhD}$ project.

First, by adopting a mixed methods approach with systematic literature reviews, qualitative expert interviews, and quantitative surveys as data collection methods, and taking precautions regarding validity and reliability in each of these individual studies, the necessary efforts were made to benefit 
from the strengths of these individual research methods while at the same time containing their weaknesses in the overall research project.

As described in Chapter 6, although being a representative example for brand worlds in industrial markets in the eyes of the author, only one brand world was used to assess quantitatively, whether they work or not and how they work on a macro level. A valuable point for further validation of the findings would therefore be the replication of the quantitative study in the context of other settings and also other cultures, in order to investigate whether these instruments not only work in this specific industry or culture. The qualitative study in Chapter 3 provides first qualitative support for this.

Furthermore, this dissertation showed quantitatively that brand worlds in industrial markets work in increasing brand experience and brand equity, two core concepts in marketing science and practice, and key motives of operating companies to implement brand worlds. Yet, also other goals of operating companies were identified in Chapter 3. It would be worthwhile to also examine whether and how brand worlds in industrial markets work in achieving these different goals, such as customer integration, employer and internal branding, or initiating and closing sales.

Additionally, in the quantitative study in Chapter 6, this thesis focused on the effectiveness of brand worlds in industrial marketing from the operating companies perspective. For a full understanding of this marketing instrument it would also be worthwhile to combine these findings with the visitors perspective, as done in the qualitative study in Chapter 3. Further research could quantitatively investigate the usefulness of brand worlds in industrial marketing from the visitors' perspective, regarding whether and which of their expectations are met, and to what extent value is derived from the visit. This could also provide further quantitative information on how these expectations can be met and which factors are most important for customers in the co-creation of a valuable experience.

An important question that remains unanswered by this $\mathrm{PhD}$ project is one that is not only of interest for theory, but especially for marketing practice. It has also been asked in the context of many other marketing instruments, specifically for trade shows, the one area where experiential marketing was already introduced to industrial markets (Gopalakrishna, Lilien, Williams, \& Sequeira, 1995; Rinallo et al., 2010): Do they pay off? Answering this question would be highly beneficial for operating companies. Yet, so far it is not only also unanswered for brand worlds in consumer markets. In general, evaluating which one of various touchpoints along the entire customer journey 'caused' a customer to buy, or its contribution to a sale, is difficult to evaluate for the offline world (Lemon \& Verhoef, 2016). Therefore, the quantitative evaluation of a KPI such as a 'return on investment' for brand worlds might be difficult to achieve.

\section{$7 \cdot 4$ IMPLICATIONS}

Similar to the limitations, the key takeaways of each individual chapter of this dissertation were described in that respective chapter. This final section of this thesis will describe what the key findings related to the main research questions of this dissertation mean for theory and practice. 


\subsubsection{Implications for marketing theory}

Adopting a design science perspective, this dissertation is an ex-post evaluation of an existing and already implemented design artifact (van Aken et al., 2016), namely of brand worlds in industrial marketing. By showing that they work in increasing the behavioral constructs brand experience and brand equity, this thesis scientifically justifies their use and shows the effectiveness of these experiential marketing instruments for branding purposes in the industrial context. Furthermore, by showing how these brand worlds work in industrial markets on a micro-level (how the $\mathrm{B} 2 \mathrm{~B}$ brand world experience is co-created) and on a macro-level (how the $\mathrm{B} 2 \mathrm{~B}$ brand world experience works in a nomological net of pre- and post-visit brand experience and brand equity) this dissertation allows for further improvements of the design, implementation and management of these marketing instruments (Holmström et al., 2009; G. G. Meyer et al., 2014; Peffers et al., 2007; van Aken et al., 2016). These findings underscore the general usefulness of the design science perspective and its processes for marketing research (Henseler, 2017a).

This dissertation also makes several contributions that have implications to the important yet under-researched field of customer experiences in industrial markets (Zolkiewski et al., 2017). It introduces experiential marketing in general, and specifically brand worlds as an experiential marketing instrument, to the $\mathrm{B}_{2} \mathrm{~B}$ branding literature and shows that this instrument actually also works in this context. In doing so, it answers a call for further research on experiential marketing instruments and their effectiveness in B2B markets (Rinallo et al., 2010).

This thesis furthermore first transferred recent conceptualizations on the multilevel and dynamic nature of customer experiences from the consumer marketing area (Kranzbühler et al., 2018; Lemon \& Verhoef, 2016) to industrial marketing. Second, it linked these conceptualizations with the concept of brand experiences and conceptualized brand experiences as a concept with a dynamic nature as well, thus contributing to recent academic developments on brand experiences (Andreini et al., 2018). Third, by showing that the experiences co-created at the individual touchpoint of the $\mathrm{B} 2 \mathrm{~B}$ brand world are influenced by pre-visit brand experience and themselves influence post-visit brand experience, it also empirically supported this dynamic conceptualization of brand experiences.

Furthermore, in our use of the brand experience scale of Brakus et al. (2009) in the $\mathrm{B}_{2} \mathrm{~B}$ brand world setting, we have shown that it can also be reliably and validly used in this industrial marketing context. This supports recent arguments in this direction (Saari \& Mäkinen, 2016).

Additionally, the use of a phenomenological perspective within this dissertation has provided explanations for how the experiences at $\mathrm{B}_{2} \mathrm{~B}$ brand worlds are co-created. This contributes to the research stream that uses a phenomenological characterization of experiences (Helkkula, 2011), and shows that this perspective and its conceptualizations of affordances and embodiment are useful for understanding how we perceive, experience, and act in the world around us not only as consumers, but also as individuals within the role of our job.

Lastly, with respect to the research stream of experiences in industrial markets, this thesis has shown that visitors not only derive instrumental value 
from a $\mathrm{B}_{2} \mathrm{~B}$ brand world visit, but that also the emotional and hedonic aspects of the experience play a role and are valuable in the industrial context. This is on the one hand contradictory to findings which suggest that industrial buyer experiences are not autotelic but exclusively instrumental, no matter how entertaining they might be (Rinallo et al., 2010). On the other hand, it supports recent findings which show that subjective evaluations, heuristics, and emotions do play a role for business buyers as well (Bagozzi, 2006; Casidy et al., 2018; Iyer et al., 2015; Leek \& Christodoulides, 2012; Lynch \& de Chernatony, 2007; Mohan et al., 2018; Zablah et al., 2010).

These emotional aspects lead to the second large research stream that this dissertation has implications for, namely branding in the industrial marketing context. This dissertation has furthered the knowledge on brand building strategies and tactics by introducing the concept of experiential marketing to the $\mathrm{B}_{2} \mathrm{~B}$ branding area and investigating it. It has shown that and how brand worlds, as an instrument of experiential marketing and the apexes of branding in consumer marketing, work in this different context. In fact, when looking at the focal outcome of most branding efforts, the levels of brand equity, the effect of one single visit to a $\mathrm{B}_{2} \mathrm{~B}$ brand world amounts to more than half of the size of the effect of the levels of brand equity that the visitors had before their visit. This highlights how powerful and useful brand worlds can also be for branding purposes in the industrial context. Given the importance of research on brand building and brand management tactics in business markets (Lindgreen et al., 2010), this can be seen as a useful step forward for B2B branding theory.

Furthermore, what comes to mind when thinking about a brand world as the "home of the brand" (Moore et al., 2010, p. 153) or the metaphorical 'living room' into which the business visitor is invited, is the strong connection and relationship that can be forged there, inter-personally and also between individuals and the brand as a whole. Brands can serve as legitimate relationship partners in $\mathrm{B}_{2} \mathrm{C}$ (Fournier, 1998), and relationships and interactions are also core aspects of business marketing (Håkansson et al., 2009; Håkansson \& Snehota, 1995). The role of emotions, heuristics, and subjective evaluations is also increasingly acknowledged in organizational buying behavior as well (Casidy et al., 2018; Iyer et al., 2015; Mohan et al., 2018; Zablah et al., 2010). Further research might pay tribute to these emotional and subjective aspects in business markets, and especially in brand worlds as living room of the brand. One of these concepts that could be involved here is the important role of trust or brand trust especially in industrial markets (Doney \& Cannon, 1997), the willingness to rely on the ability of the brand to perform its stated function (Chaudhuri \& Holbrook, 2001; Moorman et al., 1992; Morgan \& Hunt, 1994). One could imagine that an invitation and the visit to the 'living room' of a brand can contribute to building this trust. Furthermore, brand affect, a brand's potential to evoke positive emotional responses (Chaudhuri \& Holbrook, 2001) might play a role in the visit. Lastly, the invitation to visit the brands 'living room' might also have an effect on brand intimacy. This concept is defined as the degree of closeness, connectedness, and bondedness with a brand (Thorbjørnsen et al., 2002), as the consumer having a detailed knowledge of the brand and the brand having special meaning for the consumer (Srivastava et al., 2016), and as a deep understanding between the brand and the consumer through information disclosure (J. Aaker et al., 2004). In brand worlds, where visitors are provided with detailed, transparent, authentic, and first-hand information 
in a live, on-site experience, such an intimacy might even develop in industrial markets.

\subsubsection{Implications for marketing practice}

While some $\mathrm{B}_{2} \mathrm{~B}$ practitioners are still skeptical about the role of brands and branding in industrial markets, and convinced that only objective and functional attributes matter in the organizational buying process (Amonini, McCollKennedy, Soutar, \& Sweeney, 2010), empirical evidence in research increasingly points to the contrary (e.g. B. P. Brown, Zablah, Bellenger, \& Johnston, 2011; Casidy et al., 2018; Chang, Wang, \& Arnett, 2018; Iyer et al., 2015; Leek \& Christodoulides, 2012; Lynch \& de Chernatony, 2007; Mohan et al., 2018; Y. J. Wang et al., 2018; Zablah et al., 2010). Branding researchers even claim that branding is just as important in industrial markets as it is in consumer markets (Kotler \& Pfoertsch, 2006). Brands are in fact important and valuable intangible assets not only in B2C, but also in B2B (Kotler \& Pfoertsch, 2007). Yet, despite this importance, relatively little is known about brand building and brand management in business markets. Especially, research about strategic and tactical issues related to building, managing, and refreshing brands is nascent (Lindgreen et al., 2010), and therefore industrial marketers remain uncertain about how to build their brands (Sheth \& Sinha, 2015). The differences between consumer and industrial markets imply that the tactics to achieve a strong brand are likely to differ for the two contexts (Lindgreen et al., 2010).

While some companies in the industrial marketing area have already made use of the branding instruments which are called the apexes of branding in consumer markets (Dolbec \& Chebat, 2013) and implemented different types of brand worlds, it has so far not been investigated scientifically, whether these spaces actually work in this different context or not. Researchers even stated that some of the experiential marketing tactics that work in consumer marketing and which are motivated by autotelic activities for the visitors, such as fantasies, feelings, and fun, might be ineffective or even counter-productive in business markets (Rinallo et al., 2010).

The research within the scope of this dissertation has proven that brand worlds do work also in industrial marketing, and that they are actually powerful instruments for the operating companies to build strong brands. Now, one might argue that these spaces are only viable for large multinational corporations which can afford the immense costs that come with the implementation of such brand worlds. Yet, our sample in Chapter 3 shows, that even small and medium enterprises with around 200 employees and 40 million $€$ in sales turnover per year make use of these instruments and are successful with them. Sometimes even minimal investments can turn mere factories into museumlike showcases and engaging brand worlds, just as in consumer marketing (Kozinets et al., 2002). Furthermore, these branded spaces can be valuable additions to existing marketing communication instruments. In a way, they can be permanent forms of trade show booths, and the exhibits could be used in both the brand world and the trade show format.

The research within this dissertation has also shown how brand worlds work in industrial marketing. In this context, several important general aspects and also differences in comparison to their $\mathrm{B}_{2} \mathrm{C}$ counterparts have been identified which are relevant for the design, implementation, management, and operation 
of these spaces. First, the experiences at $\mathrm{B}_{2} \mathrm{~B}$ brand worlds are co-created by both the operating company and the visitor. While the operating company provides the content which manifests in the $\mathrm{B}_{2} \mathrm{~B}$ brand world experiencescape, i.e. the physical artifacts and spaces, as well as the social environments and practices, the visitor perceives and acts upon the affordances that this experiencescape provides. The more relevant, authentic, and also emotionally appealing the content presented in the $\mathrm{B}_{2} \mathrm{~B}$ brand world experiencescape is for the visitor, the stronger is the interaction in a joint action-perception cycle. This originates in the probably most important difference to brand worlds in the consumer marketing area, namely that business visitors expect a visit to support them in their own business activities. Thus, it is crucial for the operating company to tailor and customize the visits to the expectations, needs, and interests of the respective visitors, in order for them to perceive them as relevant and derive value from them. This can be achieved through a strong personal interaction with the respective contact persons, sales agents or guides during the brand world visit, who have to adapt to those expectations, needs, and interests.

But next to these functional aspects that support the visitors in their business needs, also emotional and hedonic components do play a role even for business visitors to brand worlds in industrial marketing, and should not be forgotten or neglected. In order to explain often complex products, and to create awareness for the whole breadth and depth of their product portfolio in their brand worlds, industrial companies should for example focus on providing live product experiences, link the products and experiences to the visitors' everyday lives, and try to immerse them in the experience. These more autotelic aspects also help visitors to understand and to remember the experience, and, based on heuristics, simplify decision making for them.

Yet, the way the brand presents itself and its products and services within the brand world should always be authentic, transparent, and true. To illustrate this with a quote:

"Advertising great Bill Bernbach said, 'The most powerful element in advertising is the truth.' If you make a promise about your organization, it should be something that can't be disputed when people walk through your doors. The promise can be aspirational or even transformational, but you have to live up to what you're claiming in the marketplace." Dunham (2015)

In brand worlds, people literally walk through your doors. They are the home of the brand, its metaphorical living room. Not only has it to be true what is claimed outside those doors in the marketplace, one also has to live up to what is promised inside these doors. Ultimately, the visit to a brand world in industrial marketing can then lead to an increase of brand equity, and to a stronger, mutual, and possibly even 'intimate' relationship between the visitor and the brand, and benefit both parties. 

APPENDIX

A.1 APPENDIX CHAPTER 2 


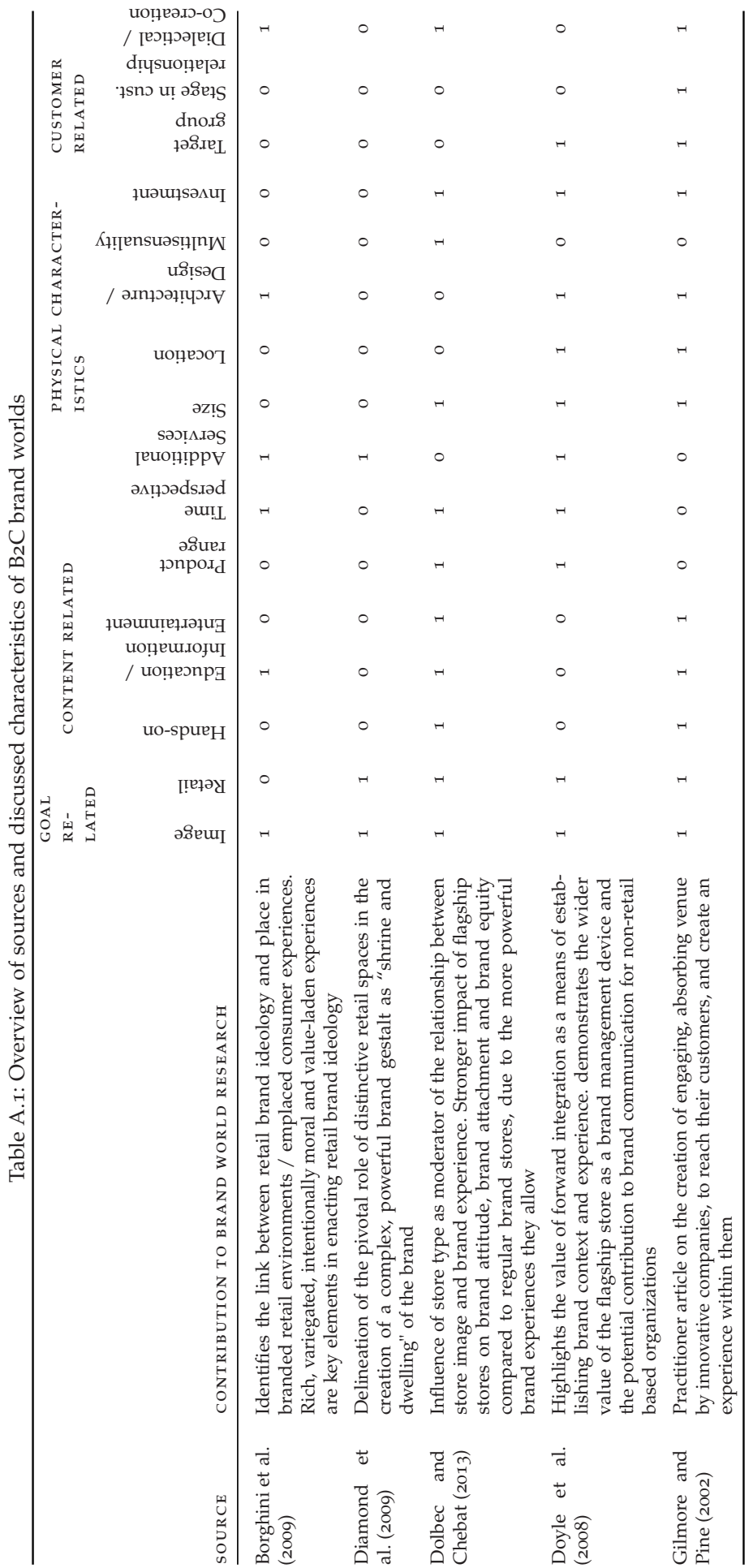




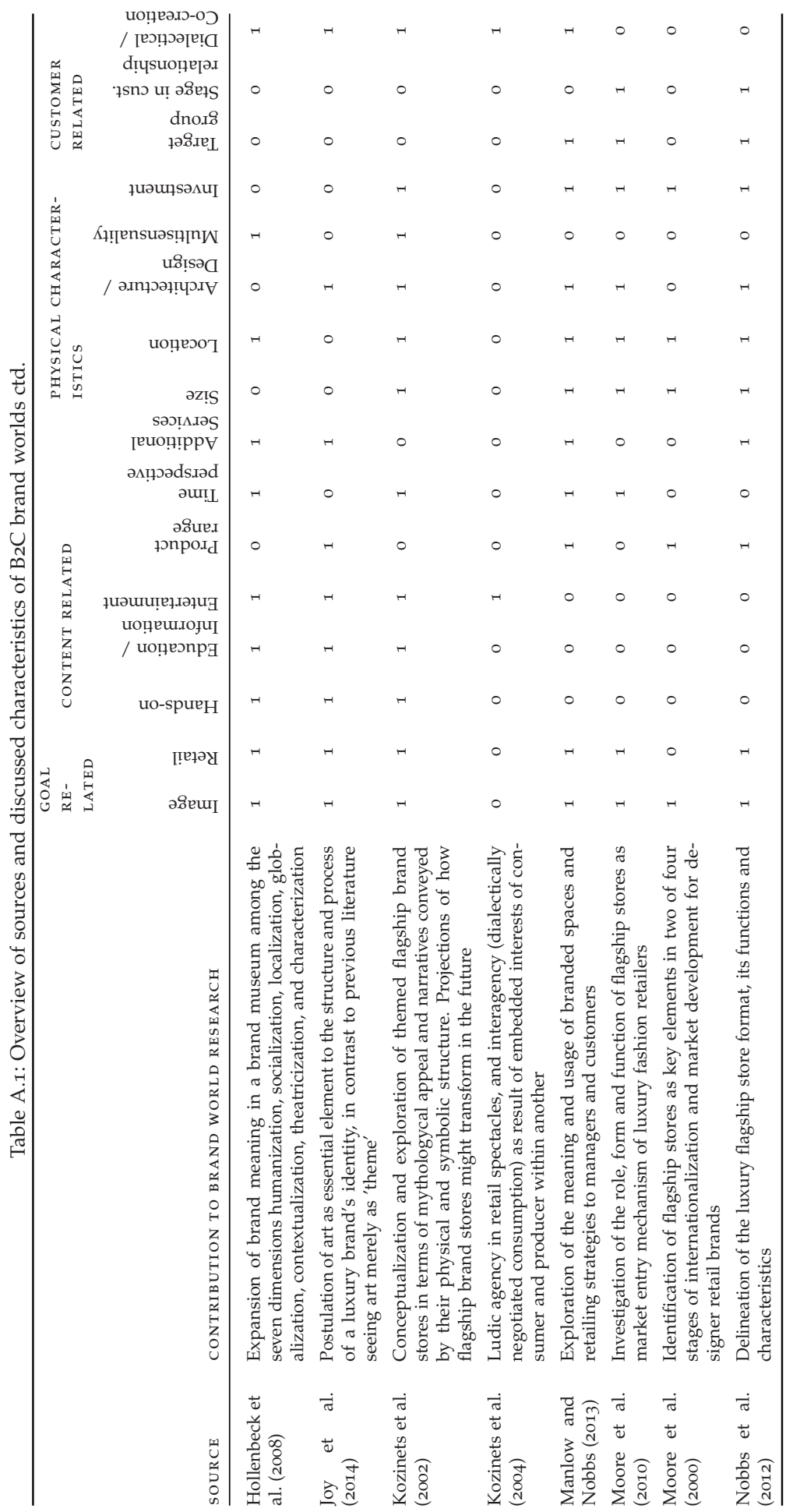




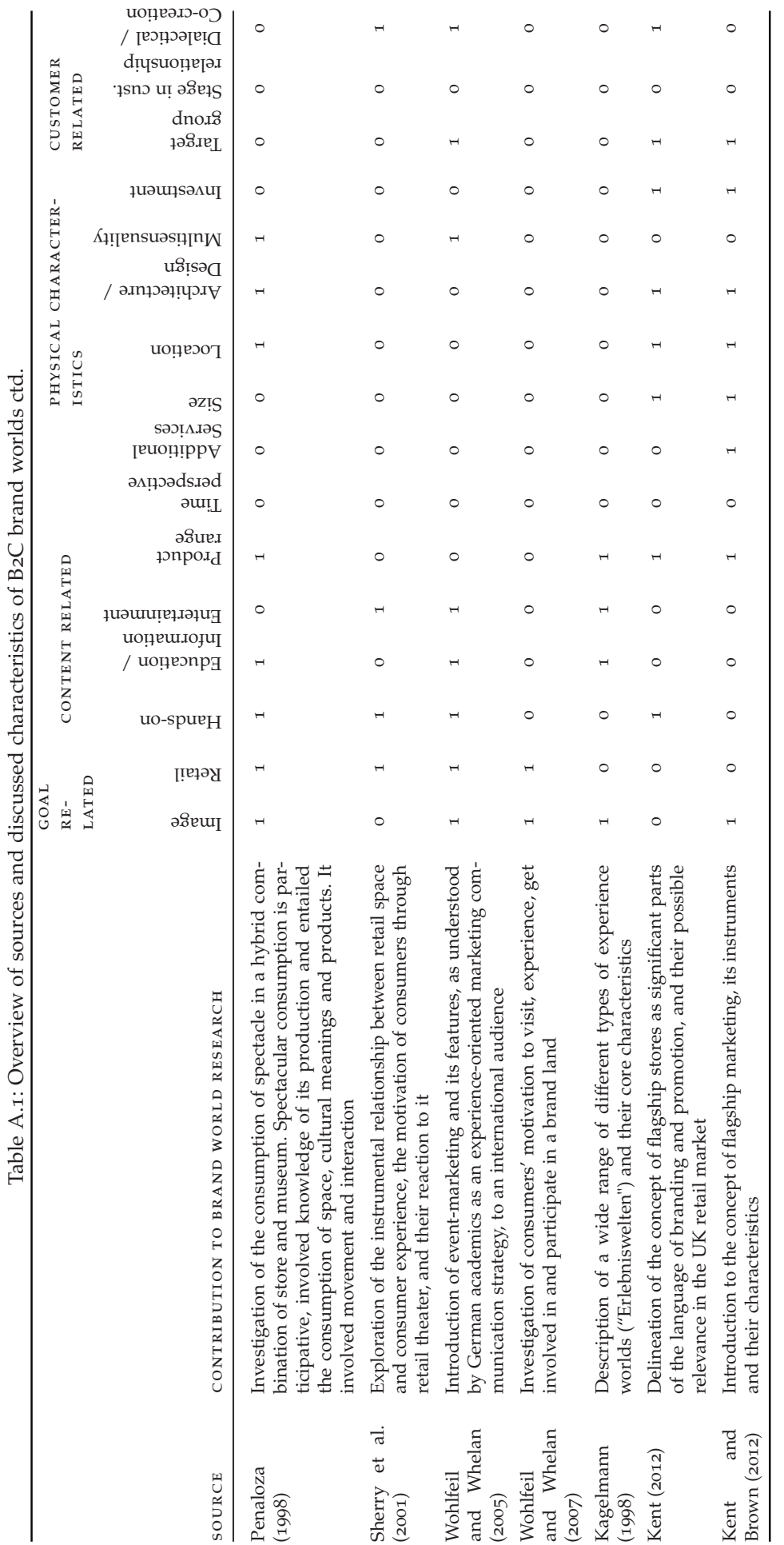




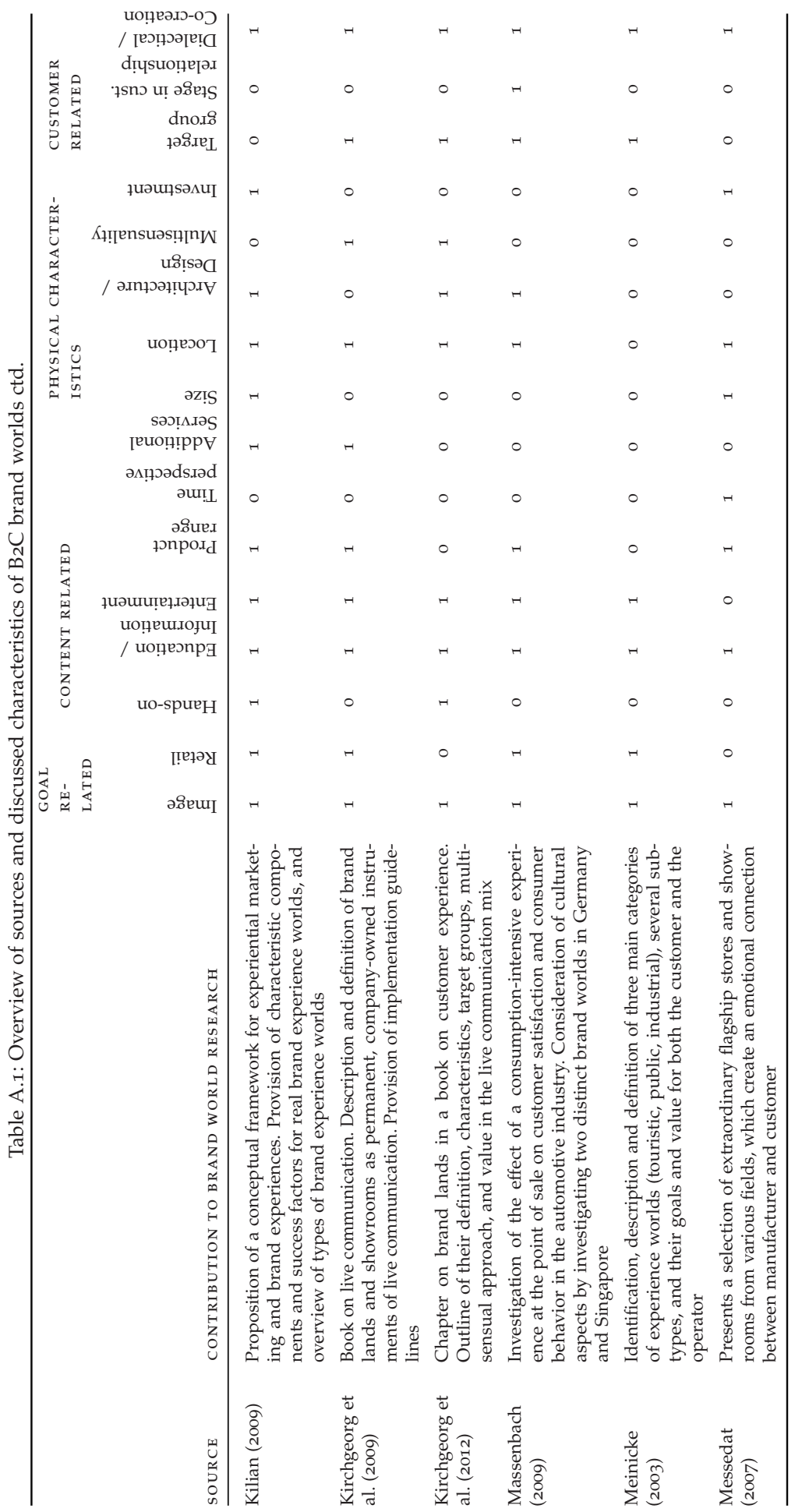




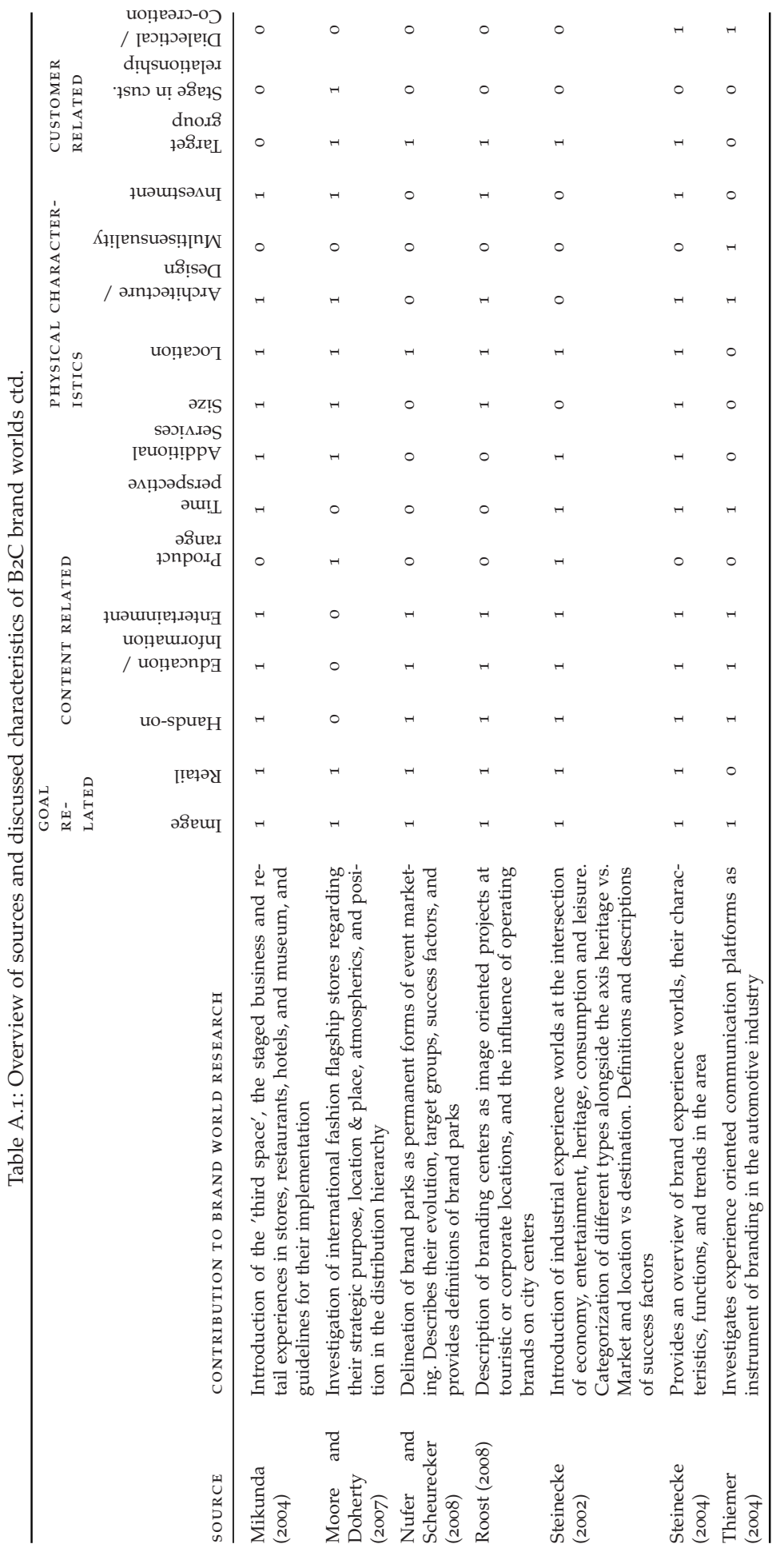




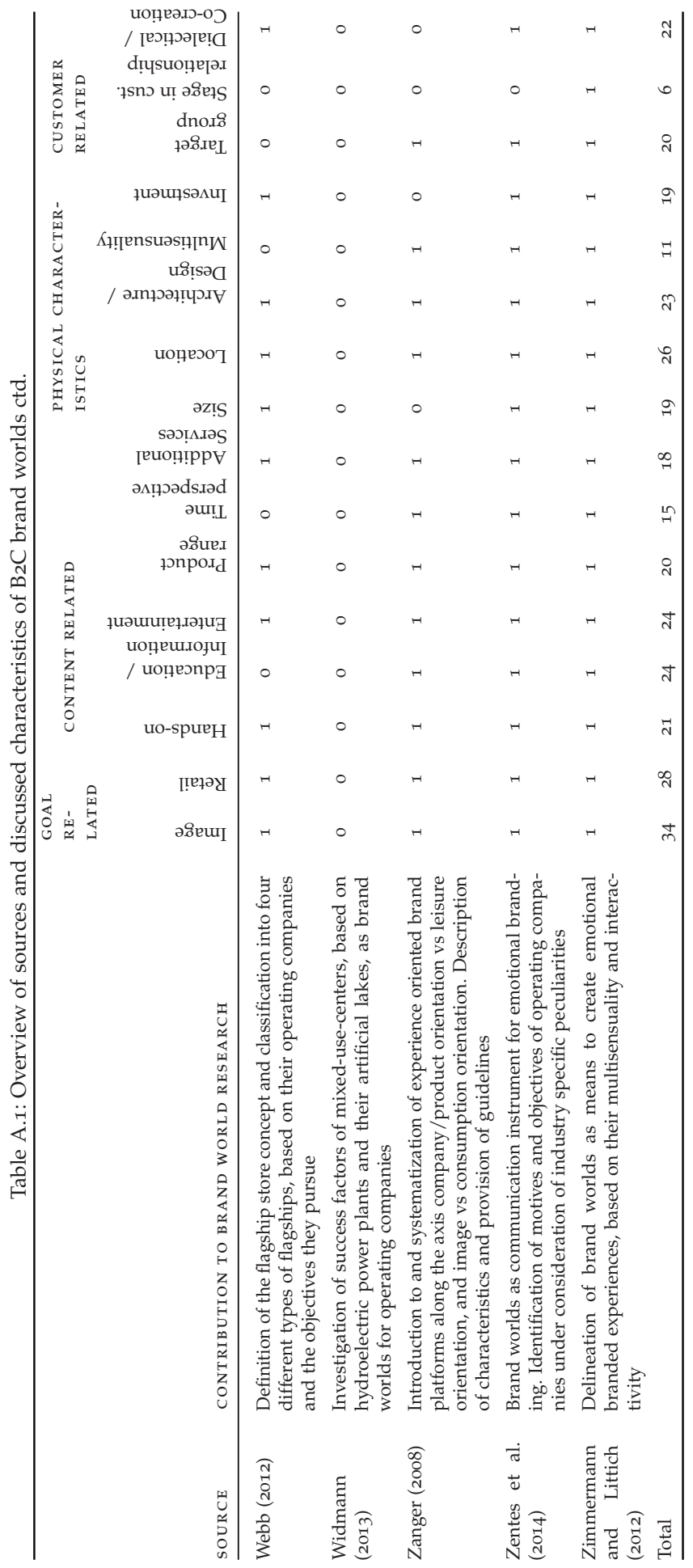




\section{A.2 APPENDIX CHAPTER 3 AND 4}

\section{A.2.1 Interview guideline for operating companies}

(Sub-questions only asked in case of further inquiries)

1. What are special features of this Brand World?

a) What are special content-related features of the Brand World?

i. Related to the practical / hands-on experience of the visitor?

ii. Related to the education or information of the visitor?

iii. Related to the entertainment of the visitor?

iv. Related to the product range on display in the Brand World?

v. Related to the time perspective of the Brand World? (Display of present / past / future developments)

vi. Related to additional services for the visitors?

b) What are special physical features of the Brand World?

i. Related to the size?

ii. Related to the location?

iii. Related to the architecture and the design?

iv. Related to the multisensuality of the Brand World?

v. Related to the investment?

c) What are special customer related features of the Brand World?

i. What target groups are addressed with the Brand World?

ii. What phase of the customer relationship does the Brand World aim at? (New or existing customers?)

iii. What forms of interaction are there between visitor and company within the Brand World? (Dialectical / Co-Creation)

2. Thinking about the Brand World: What objectives are pursued from the company's perspective?

a) What goals are pursued regarding the company image?

b) What goals are pursued regarding the customer relationships?

c) What goals are pursued regarding the innovations?

d) What monetary goals are pursued?

e) What goals are pursued regarding collaboration with customers / stakeholders?

f) What goals are pursued regarding knowledge transfer?

3. What value do you want to provide your visitors with the visit of the brand world?

a) What value do you want the visitor to derive from the visit?

b) To what extent do you want the visit to help the visitor in his business activities?

c) To what extent do you want the visit itself be valuable?

d) To what extent do you want the visit to influence the visitor himself?

e) To what extent do you want the visit to influence other people than the visitor, e.g. within his organization?

f) To what extent do you want the visitor to be active during the visit?

g) To what extent do you want the visitor to be reactive and rather perceive and observe?

4. From the company's perspective, what are the success factors to achieve these goals with the Brand World?

a) What is important to achieve the image related goals?

b) What is important to achieve the goals related to the customer relationship?

c) What is important to achieve the goals related to innovations?

d) What is important to achieve the monetary goals?

e) What is important to achieve the goals related to the collaboration with customers / Stakeh.?

f) What is important to achieve the goals related to the knowledge transfer?

g) What, in total, makes your Brand World successful?

h) Why does your Brand World "work" better than other / competitor's Brand Worlds?

i) Which aspect of your Brand World are you especially proud of?

j) What part of your Brand World would you change or improve? 


\section{A.2.2 Interview guideline for business visitors}

(Sub-questions only asked in case of further inquiries)

1. Which $\mathrm{B}_{2} \mathrm{~B}$ brand worlds have you visited as a customer/visitor so far?

2. Please describe these $\mathrm{B}_{2} \mathrm{~B}$ brand worlds briefly

3. What was the reason for your visit to these $\mathrm{B}_{2} \mathrm{~B}$ brand worlds?

4. When was your last visit to such a $B_{2} B$ brand world?

5. What are your expectations of a $\mathrm{B} 2 \mathrm{~B}$ brand world from the customer perspective?

6. What did you perceive during your visit and how did you perceive it? (in case of visits of various brand worlds:)

a) How do the brand worlds that you visited differ from each other? (related to the content)

i. Related to the practical / hands-on experience of the visitor?

ii. Related to the education or information of the visitor?

iii. Related to the entertainment of the visitor?

iv. Related to the product range on display in the Brand World?

v. Related to the time perspective of the Brand World? (Display of present / past / future developments)

vi. Related to additional services for the visitors?

vii. Related to the size?

viii. Related to the location?

ix. Related to the architecture and the design?

$x$. Related to the multisensuality of the Brand World?

7. Which value do business visitors derive from the visit of a $\mathrm{B}_{2} \mathrm{~B}$ brand world of a company?

a) What makes the visit valuable for the visitor?

b) To what extent did the visit help you in your business activities?

c) To what extent was the visit itself valuable to you?

d) To what extent did your visit influence yourself?

e) To what extent did your visit influence other people, e.g. within your organization?

f) To what extent were you active during the visit?

g) To what extent were you reactive, perceiving, or observing?

8. From the visitor's perspective, what are the success factors of $\mathrm{B}_{2} \mathrm{~B}$ brand worlds?

a) What did you like about the brand world especially?

i. Related to the practical / hands-on experience of the visitor? (content)

ii. Related to the education or information of the visitor?

iii. Related to the entertainment of the visitor?

iv. Related to the product range on display in the Brand World?

v. Related to the time perspective of the Brand World? (Display of present / past / future developments)

vi. Related to additional services for the visitors?

vii. Related to the size? (physical features)

viii. Related to the location?

ix. Related to the architecture and the design?

x. Related to the multisensuality of the Brand World?

b) What would you change or improve?

i. Related to the practical / hands-on experience of the visitor? (content)

ii. Related to the education or information of the visitor?

iii. Related to the entertainment of the visitor?

iv. Related to the product range on display in the Brand World?

v. Related to the time perspective of the Brand World (Display of present / past / future developments)

vi. Related to additional services for the visitors?

vii. Related to the size? (physical features)

viii. Related to the location?

ix. Related to the architecture and the design?

x. Related to the multisensuality of the Brand World?

c) What has to be done to fulfill your expectations towards a B2B brand world?

i. What has to be done to exceed your expectations towards a B2B brand world?

9. If you have visited several brand worlds: If so, why did the brand world of one company "work" better than the one of another company? 


\section{A.2.3 Interview guideline for exhibition designers}

(Sub-questions only asked in case of further inquiries)

1. Which $\mathrm{B}_{2} \mathrm{C}$ and $\mathrm{B}_{2} \mathrm{~B}$ brand worlds have you worked on as an exhibition designer so far?

2. Please describe these $\mathrm{B}_{2} \mathrm{~B}$ brand worlds briefly

3. What are the differences between $\mathrm{B}_{2} \mathrm{C}$ and $\mathrm{B}_{2} \mathrm{~B}$ brand worlds?

a) Content-related?

b) Related to physical features?

c) Which differences emerge from the different contexts of $\mathrm{B}_{2} \mathrm{C}$ and $\mathrm{B}_{2} \mathrm{~B}$ ?

4. Which objectives and motives do $\mathrm{B}_{2} \mathrm{C}$ companies have with their brand worlds?

a) What goals are pursued regarding the company image?

b) What goals are pursued regarding the customer relationships?

c) What goals are pursued regarding the innovations?

d) What monetary goals are pursued?

e) What goals are pursued regarding collaboration with customers / stakeholders?

f) What goals are pursued regarding knowledge transfer?

5. Which objectives and motives do $\mathrm{B}_{2} \mathrm{~B}$ companies have with their brand worlds?

a) What goals are pursued regarding the company image?

b) What goals are pursued regarding the customer relationships?

c) What goals are pursued regarding the innovations?

d) What monetary goals are pursued?

e) What goals are pursued regarding collaboration with customers / stakeholders?

f) What goals are pursued regarding knowledge transfer?

6. What value do $\mathrm{B}_{2} \mathrm{C}$ companies want to offer their visitors with their brand worlds?

a) What value do they want the visitor to derive from the visit?

b) To what extent do they want the visit to help the visitor in achieving a goal?

c) To what extent do they want the visit itself be valuable?

d) To what extent do they want the visit to influence the visitor himself?

e) To what extent do they want the visit to influence other people than the visitor, e.g. within his environment?

f) To what extent do they want the visitor to be active during the visit?

g) To what extent do they want the visitor to be reactive and rather perceive and observe?

7. What value do $\mathrm{B}_{2} \mathrm{~B}$ companies want to offer their visitors with their brand worlds?

a) What value do they want the visitor to derive from the visit?

b) To what extent do they want the visit to help the visitor in achieving a goal?

c) To what extent do they want the visit itself be valuable?

d) To what extent do they want the visit to influence the visitor himself?

e) To what extent do they want the visit to influence other people than the visitor, e.g. within his environment?

f) To what extent do they want the visitor to be active during the visit?

g) To what extent do they want the visitor to be reactive and rather perceive and observe?

8. From the exhibition designer's perspective, what are the success factors of $\mathrm{B} 2 \mathrm{~B}$ brand worlds?

a) Related to the practical / hands-on experience of the visitor? (content)

b) Related to the education or information of the visitor?

c) Related to the entertainment of the visitor?

d) Related to the product range on display in the Brand World?

e) Related to the time perspective of the Brand World? (Display of present / past / future developments)

f) Related to additional services for the visitors?

g) Related to the size? (physical features)

h) Related to the location?

i) Related to the architecture and the design?

j) Related to the multisensuality of the Brand World?

9. What specifics have to be taken into account in the design of $\mathrm{B}_{2} \mathrm{~B}$ brand worlds?

a) Related to the practical / hands-on experience of the visitor? (content) 
b) Related to the education or information of the visitor?

c) Related to the entertainment of the visitor?

d) Related to the product range on display in the Brand World?

e) Related to the time perspective of the Brand World? (Display of present / past / future developments)

f) Related to additional services for the visitors?

g) Related to the size? (physical features)

h) Related to the location?

i) Related to the architecture and the design?

j) Related to the multisensuality of the Brand World?

10. What difficulties arise when designing B2B brand worlds? 
150

APPENDIX

A.2.4 Sample 


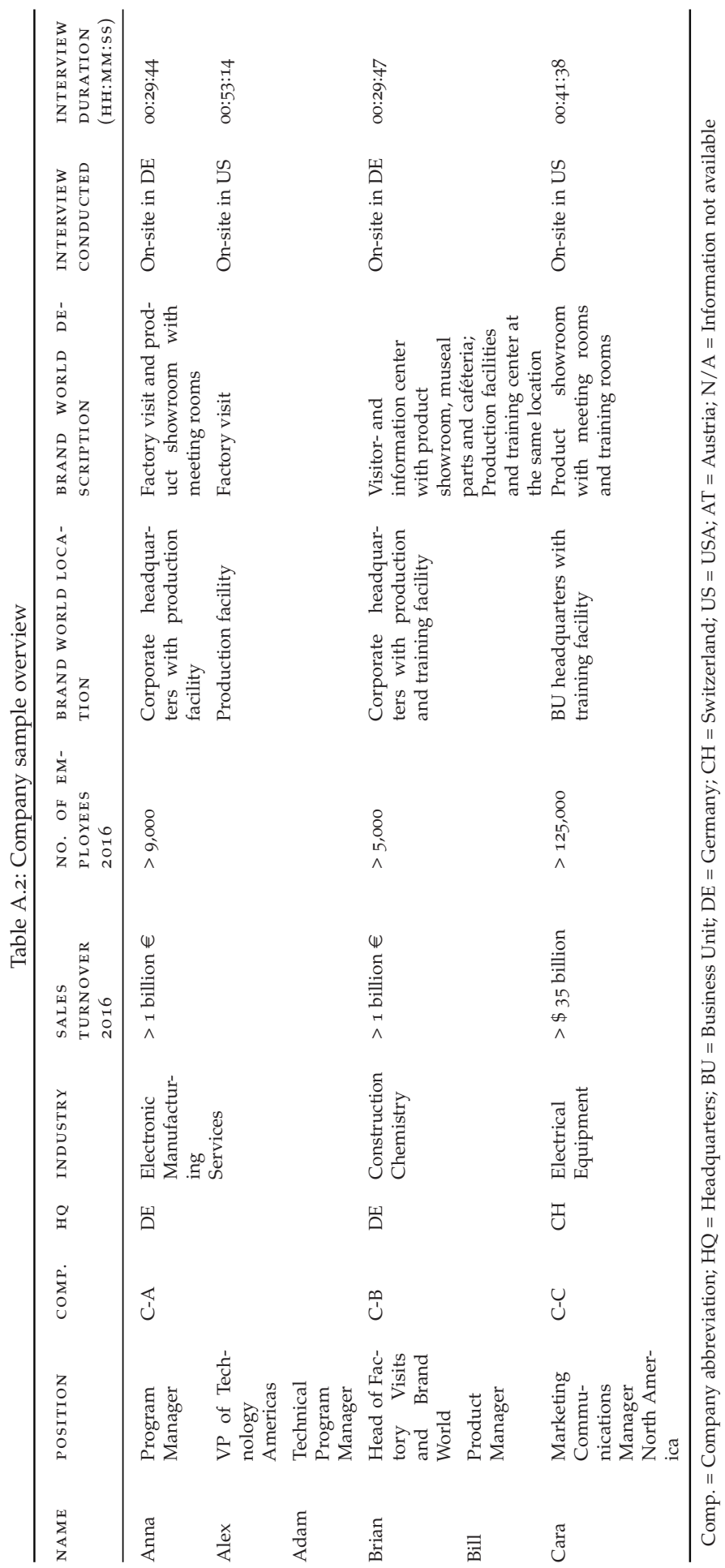




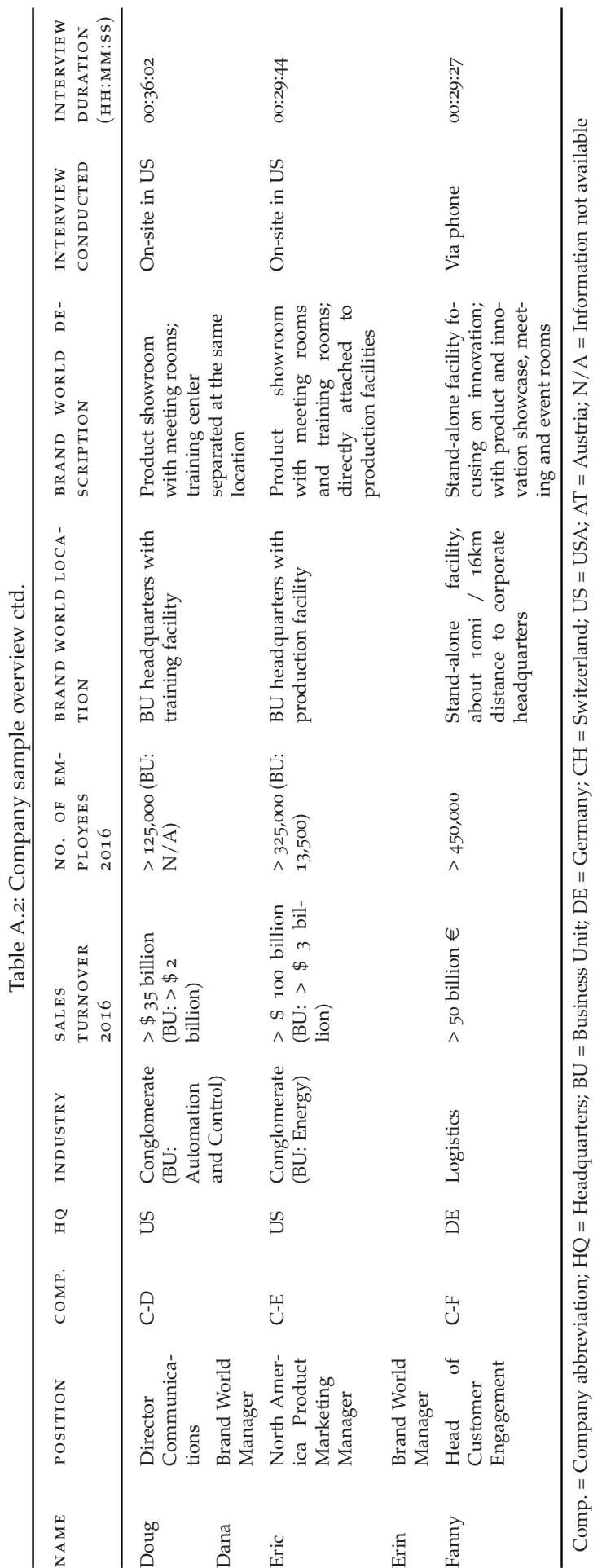




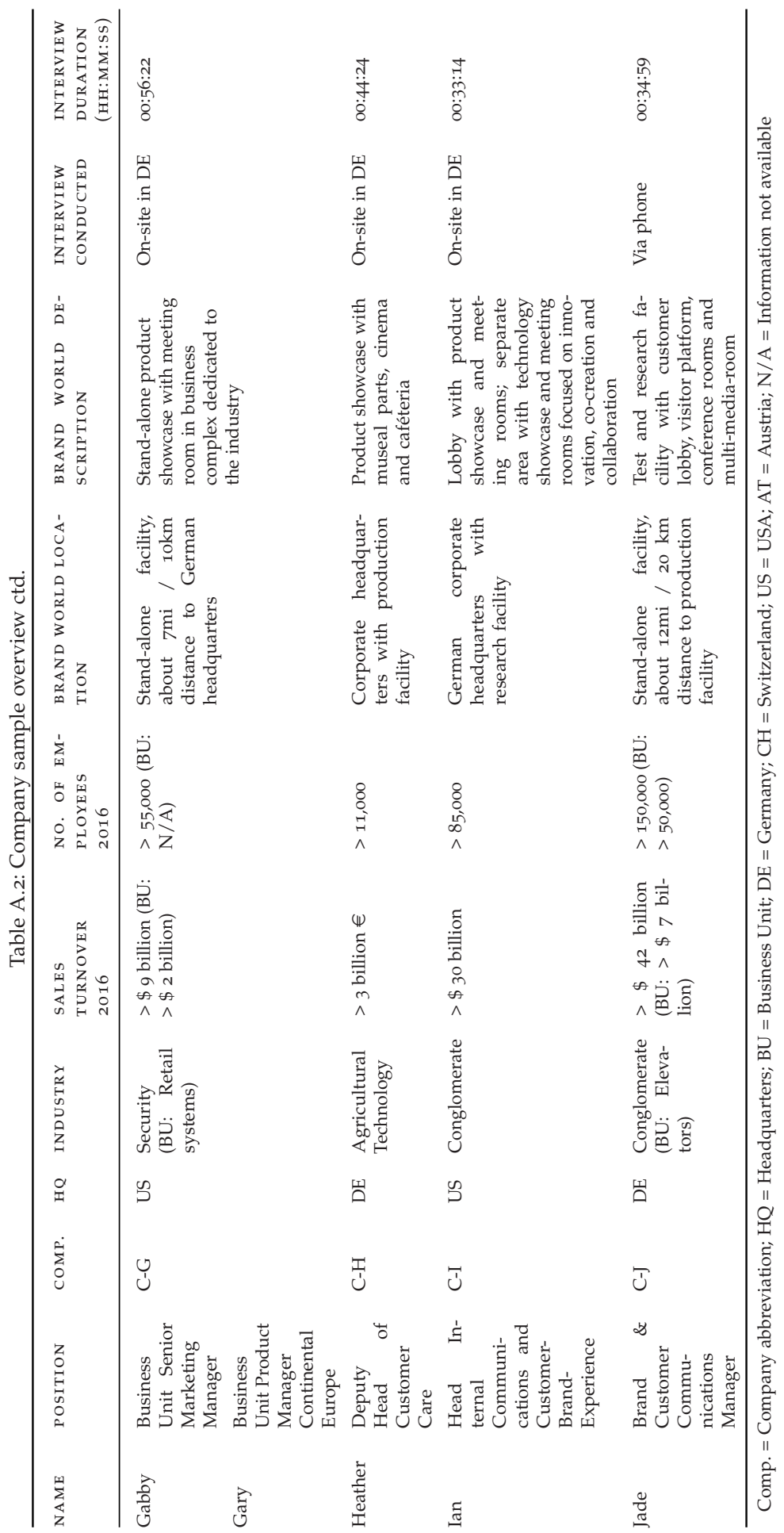




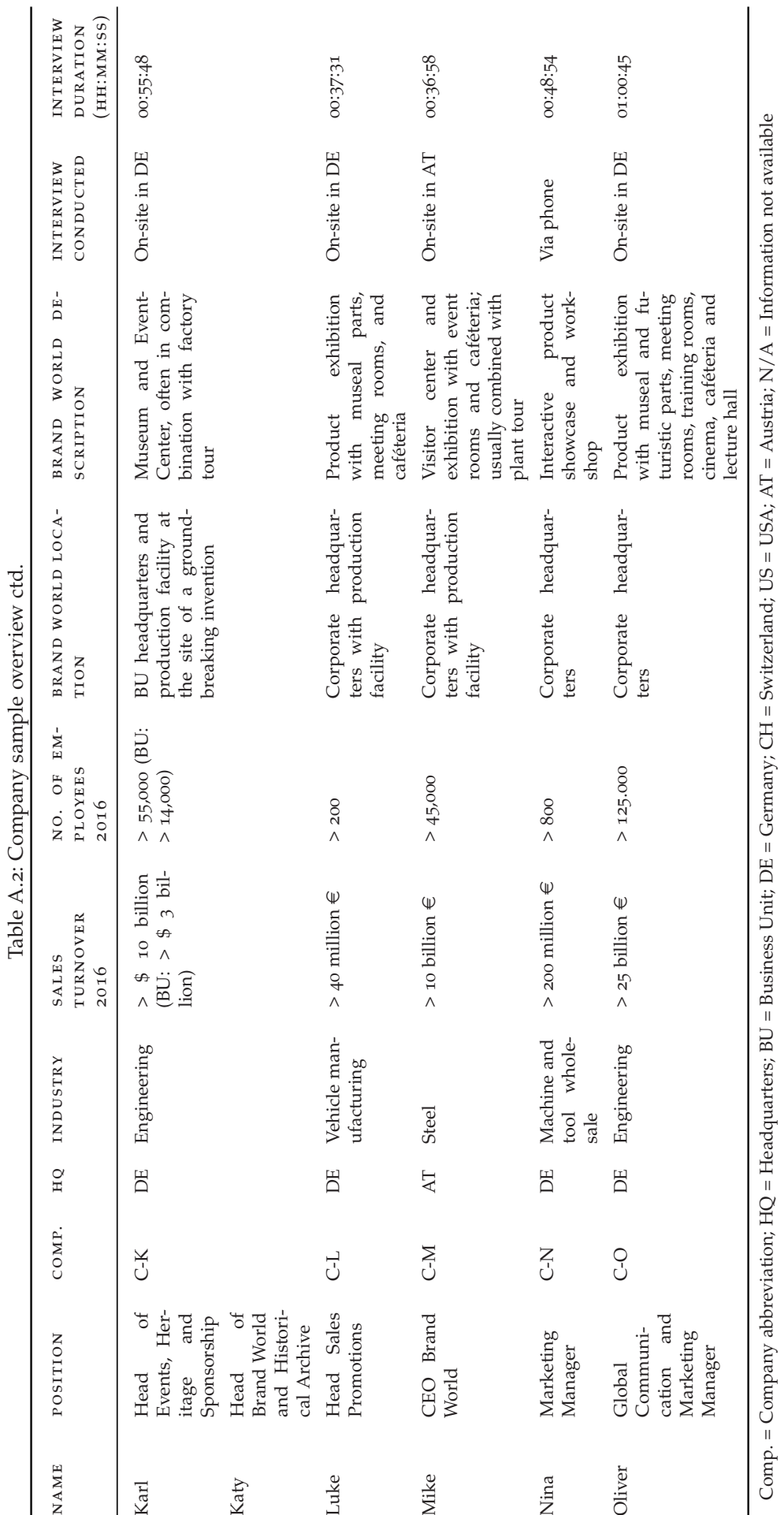




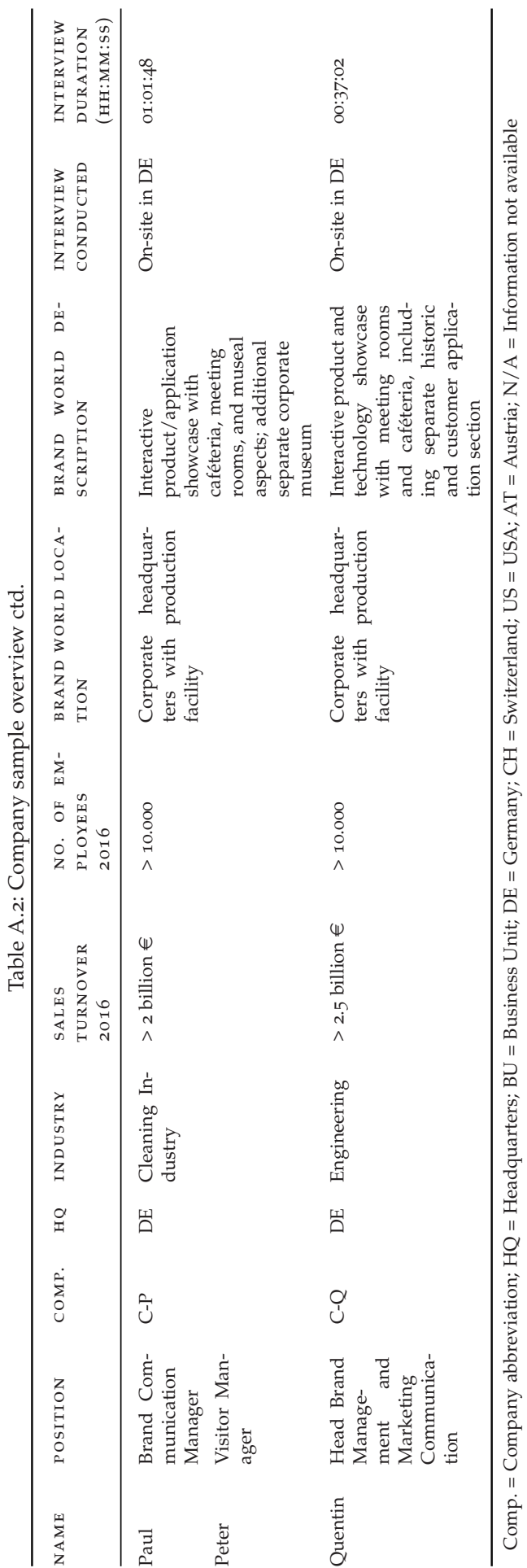




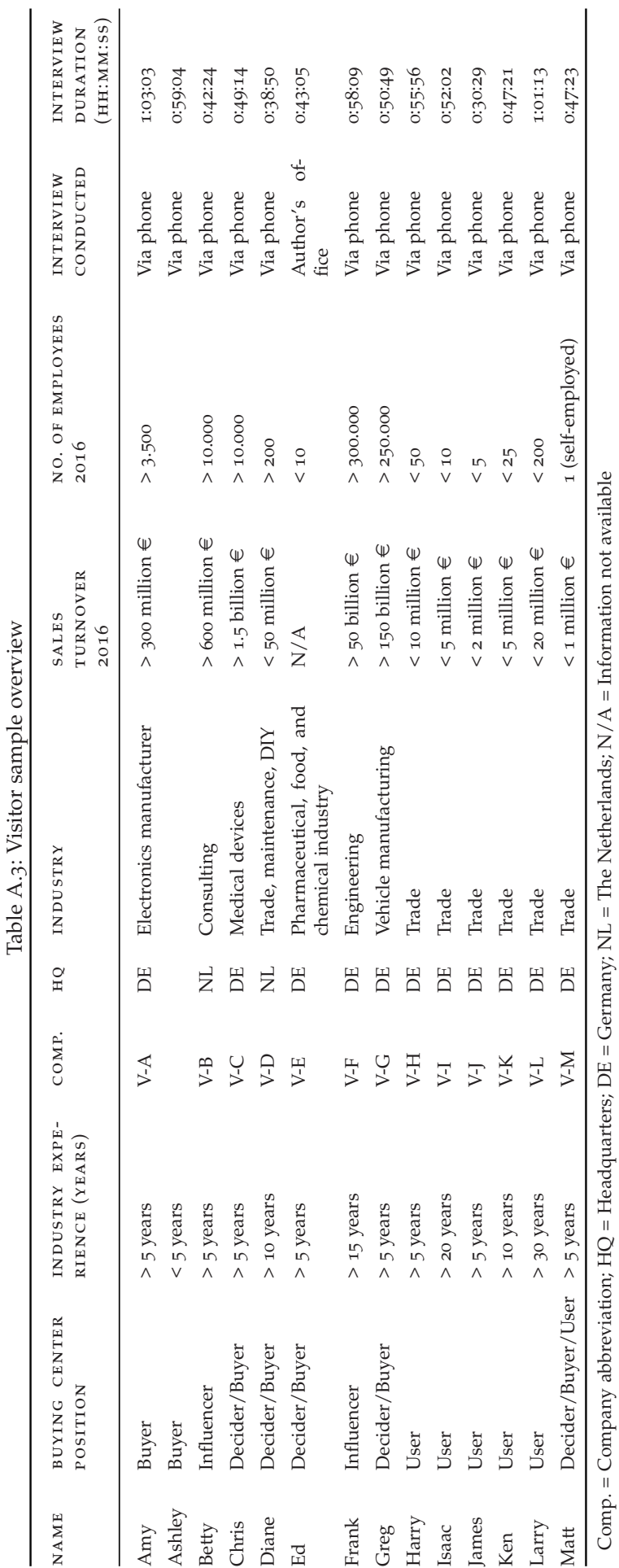




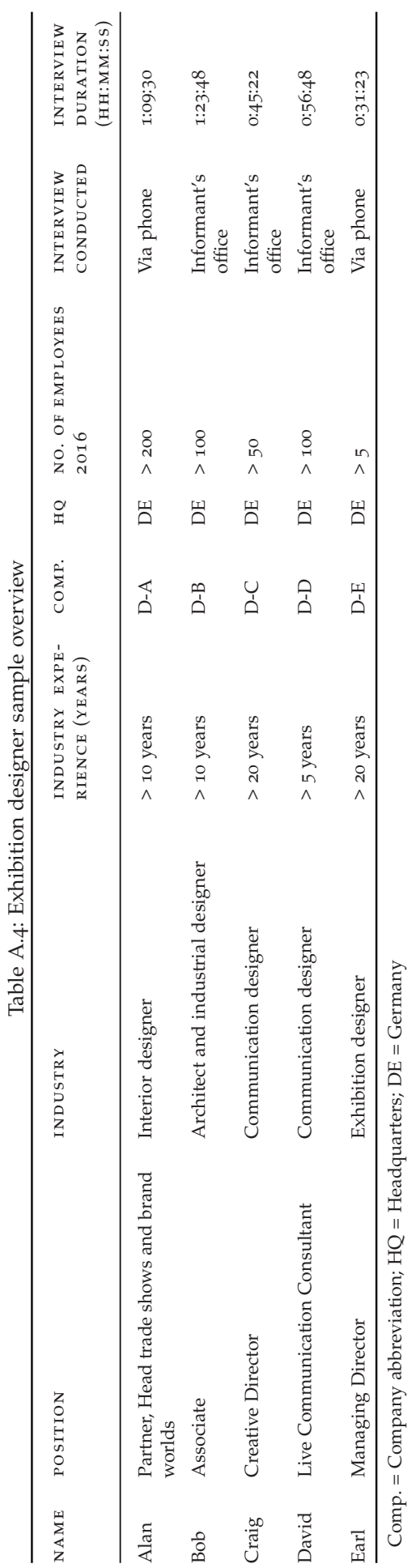


APPENDIX

A.2.5 Informant statements 
Table A.5: Company informant statements and motive categories $(n=18)$

\begin{tabular}{|c|c|}
\hline INFORMANT STATEMENTS & $\begin{array}{l}\text { MOTIVE } \\
\text { GORY }\end{array}$ \\
\hline $\begin{array}{l}\text { "So, we typically want to highlight and show off our global offering, and } \\
\text { maybe the customers come here to speak about one piece of equipment } \\
\text { and then we expand their horizons to the whole portfolio." (Eric, operating } \\
\text { company) }\end{array}$ & \multirow[t]{2}{*}{$\begin{array}{l}\text { Product } \\
\text { Awareness }\end{array}$} \\
\hline $\begin{array}{l}\text { "And what are we doing? Maybe we're feeding the imagination on that to } \\
\text { say: 'Oh, I didn't even know you had that.' Okay, great, that's all we need. } \\
\text { It's planting the seeds." (Doug, operating company) }\end{array}$ & \\
\hline $\begin{array}{l}\text { "Especially, for some of those who are maybe in procurement for some of } \\
\text { our customer companies, or that they're in the engineering portion, but } \\
\text { not the operations portion. So, they may work day in day out in terms of } \\
\text { specifying this product, or they're seeing this equipment on the computer } \\
\text { screen or on paperwork or things. But they may literally never have seen it } \\
\text { in real life." (Cara, operating company) }\end{array}$ & \multirow[t]{2}{*}{$\begin{array}{l}\text { Product } \\
\text { Experience }\end{array}$} \\
\hline $\begin{array}{l}\text { "So, they can go play with it [the product] and see what it sounds like } \\
\text { when it opens and closes and you're gonna have, you're gonna immerse } \\
\text { yourself in a much better experience that way. Better learning. [... ] We're } \\
\text { after a certain experience and we want to do that globally. Kind of like at } \\
\text { Disney. [...] And this is Disney World for [our industry]." (Eric, operating } \\
\text { company) }\end{array}$ & \\
\hline $\begin{array}{l}\text { "That is very, I would say, very important to project [the brand] as the } \\
\text { reliable partner in [our industry]." (Alex, operating company) }\end{array}$ & \multirow[t]{4}{*}{$\begin{array}{l}\text { Brand } \\
\text { Associations }\end{array}$} \\
\hline $\begin{array}{l}\text { "In the } \mathrm{B}_{2} \mathrm{~B} \text { area, especially in our industry, aspects such as durability, } \\
\text { reliability, and the fact that we developed our competence over many years, } \\
\text { are extremely important. And we just convey these aspects this way. [...] } \\
\text { And this really is the core aspect that we bring to bear during our brand } \\
\text { world tours." (Karl, operating company) }\end{array}$ & \\
\hline $\begin{array}{l}\text { "It's also a bit of sizing each other up and inspecting each other, and it is, } \\
\text { let's say, like at the beginning of a private relationship. You have to get to } \\
\text { know each other and get a feel for each other, and I think when someone } \\
\text { sees us at work here, then they can get a feel for us quite well." (Anna, } \\
\text { operating company) }\end{array}$ & \\
\hline $\begin{array}{l}\text { "It is about giving the brand and the company a face. With the employees } \\
\text { who are here. So, this is [the brand] in the flesh. [...] It is supposed to make } \\
\text { [the brand] tangible and also perceptible here at the site for someone who } \\
\text { maybe only knows the product." (Heather, operating company) }\end{array}$ & \\
\hline $\begin{array}{l}\text { "I mean I would say the awareness... Awareness is the starting point and it } \\
\text { certainly drives everything else." (Cara, operating company) }\end{array}$ & \multirow[t]{2}{*}{ Brand Awareness } \\
\hline $\begin{array}{l}\text { "And it's a very... for the breadth that [the brand] has, this is a very quick } \\
\text { way to see just how much our company can do, is capable of, how diverse } \\
\text { our portfolio is. And I don't think anybody looking at the website or } \\
\text { watching one of our many fine YouTube videos... And even it's really hard } \\
\text { to show that even at our trade show. But I think [...] that this space gives } \\
\text { that picture more effectively than anything I can think of off the top of my } \\
\text { head." (Cara, operating company) }\end{array}$ & \\
\hline
\end{tabular}


Table A.6: Expectations and demands of B2B brand world business visitors $(n=14)$

$\begin{array}{ll}\text { INFORMANT STATEMENTS } & \text { EXPECTATION / } \\ & \text { DEMAND CATE- } \\ & \text { GORY }\end{array}$
"To get a good overview of the supplier's products in a short amount
of time." (Diane, visitor)

"I would then want to get a very good overview of the whole portfolio the brand has on offer, that at least, let's say, all product families, maybe not all product variants in the smallest details, but all product families are presented to me. And I would want to see these products in their application as well, if possible." (Ashley, visitor)

"Basically, my expectations as purchasing agent, I want to, I go visit the supplier and I want to understand who the supplier is, what he's capable of and where his strengths are." (Chris, visitor)

"So, for me, the history is important, because that in the end is also the root of what they're doing today. 'Where do I come from, where do I want to go?' And this has to fit together also, in my opinion. Therefore, it does play role for me. This also has to do with authenticity. [...] In the end again to get an understanding and to see, whether this brand is actually authentic for the company, and whether you can have trust in them. And history for me is a part of that." (Frank, visitor)

"That means that what I want is a fun, learning gain in understanding along the lines of 'Oh cool, now I also know how that works.'" (Betty, visitor)

"So first I have the expectation that the brand world addresses me emotionally, even if it is about a B2B product." (Betty, visitor)

"The first thing that comes to my mind: I, as a customer, want to feel good. So, I want to feel appreciated, also that I am allowed to go in there, so to say. So, a good personal care then on-site." (Ed, visitor)

"Well my expectations, the main thing was just to learn some new [applications in product training]." (Isaac, visitor)

"Well, for one that it looks inviting in the sense of a clear spatial design, really based on the first impression, that it is bright and that there is nothing that distracts me from the products." (Ashley, visitor)

"Part of the products are really complex and sometimes you don't even know how the products interact and collude with each other So, a well-arranged and clear communication of what the products can do, and also somehow in action, in the best case." (Amy, visitor)

"And of course, I expect to see the production process, which production technologies do they use." (Chris, visitor)
Getting to know the products and offerings

Getting to know the organization

Learning, understanding, curiosity

Emotional appeal

Good service / Sense of wellbeing and appreciation

Product training

Expectations regarding the design and environment

Clear and open communication

Factory visit

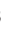


Table A.7: Value of the B2B brand world experience for business visitors $(n=14)$

\begin{tabular}{|c|c|c|c|}
\hline \multirow[t]{2}{*}{ INFORMANT STATEMENTS } & \multirow{2}{*}{$\begin{array}{l}\text { SUB- } \\
\text { ORDINATE } \\
\text { VALUE DI- } \\
\text { MENSION }\end{array}$} & \multirow{2}{*}{$\begin{array}{l}\text { SUPER- } \\
\text { ORDINATE } \\
\text { VALUE DI- } \\
\text { MENSION }\end{array}$} & \multirow[t]{2}{*}{ \# } \\
\hline & & & \\
\hline $\begin{array}{l}\text { "Like I said, for me, the acquisition of information and } \\
\text { the view on the products are important. Of course, it } \\
\text { is great if this is all nicely illuminated and well done, } \\
\text { then I feel good as a human being. But as a purchasing } \\
\text { agent, I am interested in the information and the facts } \\
\text { in there." (Greg, visitor) }\end{array}$ & \multirow[t]{2}{*}{$\begin{array}{l}\text { Generating } \\
\text { and gathering } \\
\text { information } \\
\text { in general }\end{array}$} & \multirow[t]{6}{*}{$\begin{array}{l}\text { Learning, } \\
\text { epistemic, } \\
\text { knowledge }\end{array}$} & \multirow[t]{6}{*}{14} \\
\hline $\begin{array}{l}\text { "What I am always interested in is the history, clearly, } \\
\text { where does it come from, including and outlook, where } \\
\text { does it go or what's the vision, because as a customer, } \\
\text { you want to have a good partner." (Ed, visitor) }\end{array}$ & & & \\
\hline $\begin{array}{l}\text { "Very important to me is, I go there and I can precisely } \\
\text { and quickly see, okay, they can produce this and that, } \\
\text { the company has these sites, is set up like that, and } \\
\text { presents itself in this manner. And that is the explicit } \\
\text { value for me as a purchasing agent, that I can super } \\
\text { quickly gather information apart from the products, } \\
\text { like social skills or soft facts about the company." (Greg, } \\
\text { visitor) }\end{array}$ & \multirow[t]{2}{*}{$\begin{array}{l}\text { Information } \\
\text { about the } \\
\text { company }\end{array}$} & & \\
\hline $\begin{array}{l}\text { "Of course, when I go to a showroom, I can touch } \\
\text { everything and see, whether that is something I want to } \\
\text { sell to my customers, in terms of quality and function. I } \\
\text { can hardly evaluate that with an excel sheet in a quote." } \\
\text { (Diane, visitor) }\end{array}$ & & & \\
\hline $\begin{array}{l}\text { "It was worth the long trip despite the fact that we only } \\
\text { buy one product and have a small purchasing volume so } \\
\text { far, because [...] he also offers other product categories } \\
\text { that we can source from him. And we would have never } \\
\text { realized that, if we wouldn't have driven there and have } \\
\text { seen these products standing there." (Amy, visitor) }\end{array}$ & $\begin{array}{l}\text { Theoretical } \\
\text { information } \\
\text { about the } \\
\text { products, } \\
\text { their pro- } \\
\text { duction, and } \\
\text { exemplary } \\
\text { use cases }\end{array}$ & & \\
\hline $\begin{array}{l}\text { "Well the information from the product training do help } \\
\text { on the job. You know how to exactly use the product. } \\
\text { [... A Again, trying, testing, touching, pressing, hearing, } \\
\text { feeling. That helps a lot of people." (Larry, visitor) }\end{array}$ & $\begin{array}{l}\text { Practical } \\
\text { training for } \\
\text { product users }\end{array}$ & & \\
\hline $\begin{array}{l}\text { "For me personally and my goals it is very positive, } \\
\text { because I can easily gather information there, also for } \\
\text { negotiations for example. [...] So, for my own attain- } \\
\text { ment it is extremely effective, but also for the company. } \\
\text { Because my personal goals of course flow into the cor- } \\
\text { porate goals." (Greg, visitor) }\end{array}$ & \multirow[t]{2}{*}{$\begin{array}{l}\text { Value for } \\
\text { the own } \\
\text { company } \\
\text { and the own } \\
\text { customers }\end{array}$} & \multirow[t]{3}{*}{ Professional } & \multirow[t]{3}{*}{14} \\
\hline $\begin{array}{l}\text { "The visit has to serve a purpose. Because otherwise I } \\
\text { my time is too valuable for doing this globetrotter thing } \\
\text { and looking at something." (Chris, visitor) }\end{array}$ & & & \\
\hline $\begin{array}{l}\text { "For me as a purchaser it's not so much about prices, } \\
\text { but rather about what the company is capable of. Be- } \\
\text { cause we are also instructed to minimize the number } \\
\text { of suppliers, and if I don't know what they are capable } \\
\text { of, then it does help me to see it with my own eyes and } \\
\text { have presented nicely what else there is in the supplier." } \\
\text { (Amy, visitor) }\end{array}$ & $\begin{array}{l}\text { Functional/ } \\
\text { utilitarian } \\
\text { value }\end{array}$ & & \\
\hline
\end{tabular}


Table A.7: Value of the B2B brand world experience for business visitors ctd.

\begin{tabular}{|c|c|c|c|}
\hline \multirow[t]{2}{*}{ INFORMANT STATEMENTS } & \multirow{2}{*}{$\begin{array}{l}\text { SUB- } \\
\text { ORDINATE } \\
\text { VALUE DI- } \\
\text { MENSION }\end{array}$} & \multirow{2}{*}{$\begin{array}{l}\text { SUPER- } \\
\text { ORDINATE } \\
\text { VALUE DI- } \\
\text { MENSION }\end{array}$} & \multirow[t]{2}{*}{ \# } \\
\hline & & & \\
\hline $\begin{array}{l}\text { "It has to appeal to me emotionally. [... It doesn't only } \\
\text { have to be fun and nice, but I also have to be given } \\
\text { information. Ideally in a way so that I do understand } \\
\text { something quickly, that I wouldn't have understood as } \\
\text { quickly without the brand world. [...] An increase in } \\
\text { my enthusiasm for the products, let's say enthusiasm." } \\
\text { (Betty, visitor) }\end{array}$ & $\begin{array}{l}\text { Edutainment } \\
\text { / Enthusiasm }\end{array}$ & Emotional & 11 \\
\hline \multicolumn{4}{|l|}{$\begin{array}{l}\text { "To be honest, it was also an appreciation that they took } \\
\text { the time for us to show us the brand world." (Betty, } \\
\text { visitor) }\end{array}$} \\
\hline $\begin{array}{l}\text { "I feel treated well and I feel appreciated as a customer } \\
\text { and partner." (Ed, visitor) }\end{array}$ & $\begin{array}{l}\text { Sense of } \\
\text { apprecia- } \\
\text { tion and } \\
\text { well-being }\end{array}$ & & \\
\hline \multicolumn{4}{|l|}{$\begin{array}{l}\text { "It's a kind of emotional bond somehow. I think that } \\
\text { when you have tried the products yourself, you emo- } \\
\text { tionally bind to that product much more. [...] Yes, af- } \\
\text { terwards it was really easy for me to make a product } \\
\text { choice. That was really quick then. Before, I got some } \\
\text { excel-sheets from a lot of suppliers where everything } \\
\text { was listed, and I was going back and forth through } \\
\text { them, but couldn't really bring myself to make a deci- } \\
\text { sion. And after the showroom, that's relatively easy." } \\
\text { (Diane, visitor) }\end{array}$} \\
\hline $\begin{array}{l}\text { "Yes, trying out stays on your mind much more than } \\
\text { just looking at some products." (Amy, visitor) }\end{array}$ & $\begin{array}{l}\text { Emotions as } \\
\text { support for } \\
\text { remembrance } \\
\text { and decision- } \\
\text { making }\end{array}$ & & \\
\hline $\begin{array}{l}\text { "But it's just nice also to do some other things than at } \\
\text { work, where you sometimes only do dreary things [...]. } \\
\text { And then you can just do something else for once. And } \\
\text { for that, I think these product trainings are also really } \\
\text { nice and good. You really get to see something else." } \\
\text { (Ken, visitor) }\end{array}$ & Escapism & & \\
\hline $\begin{array}{l}\text { "The integration of a } \mathrm{B}_{2} \mathrm{~B} \text { product in a } \mathrm{B}_{2} \mathrm{C} \text { product } \\
\text { is something you see a lot, and it is of course highly } \\
\text { emotional, when you then see what you do actually have } \\
\text { in daily use. I think everyone links this to his own life a } \\
\text { bit then. 'Where have I seen that product already, where } \\
\text { did I experience it and where not?"' (Greg, visitor) }\end{array}$ & $\begin{array}{l}\text { Connection to } \\
\text { daily life }\end{array}$ & & \\
\hline $\begin{array}{l}\text { "I just get a feel for it and this trust is just important, } \\
\text { that you know where they come from, what was their } \\
\text { idea, to what extent did they keep up and develop } \\
\text { themselves further. So, it's about building trust and } \\
\text { minimizing risk." (Amy, visitor) }\end{array}$ & & & \\
\hline $\begin{array}{l}\text { "For me the goal is to get to know the supplier better } \\
\text { and to understand, what he does, how he does it, and } \\
\text { also does he live up to his promises. Because one thing } \\
\text { is the spoken word, but how do they put it, 'walk the } \\
\text { talk', so what is really behind all that." (Chris, visitor) }\end{array}$ & Building trust & Relationship & 9 \\
\hline $\begin{array}{l}\text { "That I just get a first impression that signals me 'okay', } \\
\text { or that I can make an assessment whether that company } \\
\text { is relevant for me or not. Along the lines of 'do I want } \\
\text { to establish a customer relationship with them or rather } \\
\text { not?"' (Ashley, visitor) }\end{array}$ & $\begin{array}{l}\text { Building a re- } \\
\text { lationship }\end{array}$ & & \\
\hline
\end{tabular}


Table A.7: Value of the B2B brand world experience for business visitors ctd.

\begin{tabular}{|c|c|c|c|}
\hline \multirow[t]{2}{*}{ INFORMANT STATEMENTS } & \multirow{2}{*}{$\begin{array}{l}\text { SUB- } \\
\text { ORDINATE } \\
\text { VALUE DI- } \\
\text { MENSION }\end{array}$} & \multirow{2}{*}{$\begin{array}{l}\text { SUPER- } \\
\text { ORDINATE } \\
\text { VALUE DI- } \\
\text { MENSION }\end{array}$} & \multirow[t]{2}{*}{ \# } \\
\hline & & & \\
\hline $\begin{array}{l}\text { "Yes, I mean in the end, usually I'm accompanied when } \\
\text { I go to a showroom or look at the products. And simply } \\
\text { this positive aspect to get into a conversation with the } \\
\text { company employees, just to get a feel interpersonally, } \\
\text { that is positive for me." (Ashley, visitor) }\end{array}$ & $\begin{array}{l}\text { Getting to } \\
\text { know the hu- } \\
\text { man beings }\end{array}$ & & \\
\hline $\begin{array}{l}\text { "As I just mentioned, because I rejoice in technically } \\
\text { complex products, well designed products, honestly } \\
\text { also because of the respect that I have for good en- } \\
\text { gineering. And I just rejoice in seeing that someone } \\
\text { thought about a good product and that it turned out } \\
\text { like that as well. That did play a role. But I did not see } \\
\text { it as a tourist attraction, like the typical visitor to an } \\
\text { [automotive museum], in that sense." (Betty, visitor) }\end{array}$ & & & \\
\hline $\begin{array}{l}\text { "I am just someone who likes to try things herself really, } \\
\text { and that can lead to me having, when it is a really good } \\
\text { product which is good to use, it can lead to me having } \\
\text { a real wow factor." (Diane, visitor) }\end{array}$ & & & \\
\hline $\begin{array}{l}\text { "That I'm just sold on them showing me all that. Just } \\
\text { for them to differentiate themselves and to impress me } \\
\text { with it." (Ashley, visitor) }\end{array}$ & & $\begin{array}{l}\text { Hedonic, } \\
\text { altruistic, en- } \\
\text { tertainment, }\end{array}$ & 9 \\
\hline $\begin{array}{l}\text { "For me it's just really important to visit these show- } \\
\text { rooms once a year per supplier, at least, just to have } \\
\text { been there and to really see all the new products there } \\
\text { again." (Diane, visitor) }\end{array}$ & & $\begin{array}{l}\text { service } \\
\text { excellence }\end{array}$ & \\
\hline $\begin{array}{l}\text { "I mainly thought, 'well, they will just sell the [products } \\
\text { they are well-known for]'. Like that, what you know. } \\
\text { But then it emerged that they do [other product groups] } \\
\text { as well, and everything that comes with it. And that } \\
\text { was really something where I thought, 'oh okay, I didn't } \\
\text { know that you can also buy that from them."' (Matt, } \\
\text { visitor) }\end{array}$ & & Innovation & 4 \\
\hline $\begin{array}{l}\text { "Based on that you can expand your own offer, if you } \\
\text { know what else is out there. And then you can just } \\
\text { differentiate yourself more." (Ken, visitor) }\end{array}$ & & $\begin{array}{l}\text { Reputation, } \\
\text { status, es- } \\
\text { teem, brand- } \\
\text { ing }\end{array}$ & 2 \\
\hline $\begin{array}{l}\text { "Well I first told my wife about it. [... ] So, she was the } \\
\text { first, and then I also told my father, because he ... I did } \\
\text { train as a [job] at his company and worked for him as } \\
\text { well. And that was also really interesting for him, the } \\
\text { things that I heard and learned there." (Matt, visitor) }\end{array}$ & & Social & 2 \\
\hline
\end{tabular}


Table A.8: Informant statements on the B2B brand world content

INFORMANT STATEMENTS

CONTENT CATE-

GORY

"So, this is [the brand] in the flesh. [...] It is supposed to make [the brand] tangible and also perceptible here at the site for someone who maybe only knows the product." (Heather, operating company)

"Coming back to the [credo of the company], I mean, the content basically is on the one hand, the brand itself, its core and values, everything the brand has so far in this respect. And you just have to live up to that and the content is basically everything that the brand has to offer." (Bob, exhibition designer)

"It is about giving the brand and the company a face. With the employees who are here." (Heather, operating company)

"These locations also give the opportunity for personal interactions. I am able to retreat into a lounge and have a coffee upstairs, and those are often also the things that are much more exciting with regards to testing and establishing a relationship, than just directly next to some product highlights. And there also has to be time for that, because these personal relationships are the alpha and omega of not only a purchase, but also a repurchase and a recommendation, continuous collaboration and consistent joint growth." (Quentin, operating company)

"[Personal experience] plays a huge role. [... ] Customers can't please us more as than to actually demand this, being willing to do it and also doing it in the end, testing the products, and wanting to work with them. And there is nothing that can replace that experience. No brochure, no video, no picture, no text. Only the personal experience can do that." (Peter, operating company)

"Then this hands-on practical experience, definitely. Everything I can do myself or touch is good. I can feel the materials, get a feeling for the quality, whether everything is well built and the workmanship is good." (Ashley, visitor)

"This knowledge transfer also plays a role in there. Training customers in dedicated training centers, but also 'how the products are used properly', and 'how certain processes are executed'. That's a big thing. And when I think about [one brand world] to convey this knowledge to the visitor, to even make them understand complex connections. [...] And if I as a customer realize that I really learn something when I go there, then I really take something out of it and that of course also strengthens the customer relationship." (Craig, exhibition designer)

"On the one hand, we have the finished product right here, with a problem solution, but we also have the base product right there. So, I can exactly see how it is build and how the components are put together. And if someone wants to get more into the details, we can access the production lines, so it is a very transparent thing for the customer. I think that that is an important success factor." (Luke, operating company)

"That is very, I would say, very important to project [the brand] as the reliable partner in [our industry]." (Alex, operating company)

"And the goal is then, I would say, to convince the visitor that you are the right partner. That means that you cannot just superficially present what you can do, but you really have to go into the details." (Bob, exhibition designer)

"The sales guys know their audience quite well, they know that one guy likes this more and another that. For example, what I like to do is that I consciously split up groups. And then I go see one thing with the purchasing agents and let the quality managers go play with our quality managers. They really go into our production lines then, wear gloves, crawl into our lines and so on, and with the purchasing agents we only do a rough overview, so that they get an idea for the costs or something like that. And it really has to be individualized for everyone." (Anna, operating company)

Experience the brand, its core and values "in-vivo" by making it tangible

Giving the brand a face through personal interaction with employees

Experience and understand the products firsthand

Deep, detailed, precise educational process

Positioning the brand as the right partner for the visitor who understands his needs

Individualizing the content to suit the visitor's needs and expectations 
Table A.8: Informant statements on the B2B brand world content ctd.

"An individual approach in the sense, I'm a purchasing agent for two product groups. And I don't need to see production lines from products I don't buy. Doesn't interest me. That's a waste of time for me, I don't have any stakes in that." (Chris, visitor)

"I think you need to look at the target group intensively, and what kind of people they are. [...] A typical example, whether I have an engineer visiting me or a marketing person. They have completely different needs and also a different eye, as they put it. Meaning that they perceive things differently, the same object differently. And therefore, I also have to tell them different things." (David, exhibition designer)

"It's about exemplary things, the relevant things. I think that's a big success factor we can put above everything, relevance. If it doesn't affect me personally and doesn't bring me forward, then I can just chuck it in the dustbin. Then I don't even need to come. I would go out on a limb for this here." (Craig, exhibition designer)

"The first thing that comes to my mind: I, as a customer, want to feel good. So, I want to feel appreciated, also that I am allowed to go in there, so to say. So, a good personal care then on-site." (Ed, visitor)

"First of all, I think that it is important that the customer feels that he is being courted, so to say. He has to be able to feel well, and also to let go to a certain extent. You can talk extensively about everything. So that the visitor gets the feeling that you take the time for him". (Luke, operating company

"In the B2B area, especially in our industry, aspects such as durability, reliability, and the fact that we developed our competence over many years, are extremely important. And we just convey these aspects this way. [...] And this really is the core aspect that we bring to bear during our brand world tours." (Karl, operating company)

"So, for me, the heritage is indeed important, because it shows the origin basically of what they do today, as well. Where do I come from, where do I want to go? And I think that the two have to fit together, somehow, and that is why it plays an important role for me. That also has something to do with authenticity." (Frank, visitor)

"The center does the work for us. Especially if you've got somebody who's an engineer or if they're working in a company that we're dealing with doing the types of work that they're going to be in here for, this stuff is going to catch their attention. This is the stuff that's cool. This is the reason that they went into the business that they went into and took the life path that they took. This gets their attention. And even if they only stop for a second to look at it on their way back, you still planted that seed." (Cara, operating company)

"So first I have the expectation that the brand world addresses me emotionally, even if it is about a B2B product." (Betty, visitor)

"I think for industrial companies, when we talk about adding emotional appeal, it is really really essential, also if maybe not as essential as in $\mathrm{B}_{2} \mathrm{C}$, but it nevertheless has to be there." (Craig, exhibition designer)

"It really first and foremost is about immersing and getting involved in a topic, as opposed to just being presented with it." (Craig, exhibition designer)

"The first thing is the immersive experience. The opportunity we have with this multidimensional, spatial communication which brand worlds belong to... you just have to try and exploit it. Nowhere else you have this opportunity of being that much face-to-face with the customer as you are in the brand world. [...] And then you're only successful if you achieve this, to immerse people, involve them, get their interest, so that the things stick." (Alan, exhibition designer)

Making the visitor feel special, appreciated, and esteemed

Display competency and ability of the brand through history/heritage, present, and future

Emotionalizing, fascinating and immersing the visitor 
Table A.8: Informant statements on the B2B brand world content ctd.

"Authenticity, trust, and I think in the setting of customer visits, to get in touch with different departments, it provides the opportunity to personally interact and getting to know people and to see, how trustworthy the things are that we tell." (Bill, operating company)

"I would say, the more authentic I can describe a brand, the better I can identify myself with it and the more trust I develop towards this brand. [... When I achieve that, to create authenticity in a good way, I think then they accomplished a lot." (Frank, visitor)

"Well, it has to do with the entire story that I build, the space that I build, the design I create, that all this combines into an authentic overall picture. Most of the time, authenticity is the most important thing." (Bob, exhibition designer)

"Nowhere else do you have this opportunity of being that much face-to-face with the customer as you are in the brand world. From all formats, beginning with TV advertising where you reach millions of people, but of course also the sustainability is lower. Then on the other side of the spectrum you have these brand worlds, or the face-to-face product presentation, where you stand face-to-face with your customer or your visitor, and where you can pull out all the stops." (Alan, exhibition designer)

"And I think a brand world or a showroom offers that definitely, this chance, and it has this power, because I really do have the customer in my 'world', and he doesn't see the competitor logo shimmer through somewhere. He really is completely with me." (David, exhibition designer)

"Since we're talking about industrial goods, it is about presenting them short, succinct, and let's also really say sexy. Sexy meaning that it has to be presented in a way that you understand the reason behind it, and why you need it. Basic selling. And industrial goods are even slightly more interesting, when they are integrated in their final purpose. So, when we make a consumer good out of it and present there where the parts go into." (Greg, visitor)

"For example, when I present [a certain product], it really looks quite unspectacular by itself, and it might also be hard to understand, or even to have an interest, what this really is. When I now put this product into a final use case that I know as a consumer, though, or even better into a working cutaway model, and present it like that, then it is much easier for me to understand, to be interested, and also to even get excited about it." (Frank, visitor)
Provide an authentic, consistent, honest, and transparent view on the brand

Be face-to-face with the visitor

Identification of the brand with visitor's daily life 
Table A.9: Informant statements on the B2B brand world experiencescape

\begin{tabular}{|c|c|c|c|}
\hline \multirow[t]{2}{*}{ INFORMANT STATEMENTS } & EXPERIENCE- & \multicolumn{2}{|c|}{ EXPERIENCE- } \\
\hline & $\begin{array}{l}\text { SCAPE SUB- } \\
\text { CATEGORY }\end{array}$ & $\begin{array}{l}\text { SCAPE } \\
\text { GORY }\end{array}$ & CATE- \\
\hline $\begin{array}{l}\text { "It has to be a harmonious overall picture, where I say } \\
\text { 'Oh, sure, I can feel the brand"” (Craig, exhibition de- } \\
\text { signer) }\end{array}$ & $\begin{array}{l}\text { Tangible em- } \\
\text { bodiment of the } \\
\text { brand }\end{array}$ & $\begin{array}{l}\text { Artifacts } \\
\text { spaces }\end{array}$ & and \\
\hline \multicolumn{4}{|l|}{$\begin{array}{l}\text { "Best case scenario, the brand world really fits the sup- } \\
\text { plier." (Greg, visitor) }\end{array}$} \\
\hline $\begin{array}{l}\text { "Architecture and design, I think are definitely success } \\
\text { factors. That's just a thing of fascination, I transport } \\
\text { a lot of brand attributes with it, and the whole range } \\
\text { of fascination, wow-effects so to say, to the point of } \\
\text { authenticity." (Craig, exhibition designer) }\end{array}$ & $\begin{array}{l}\text { Emotionally ap- } \\
\text { pealing, intrigu- } \\
\text { ing and immer- } \\
\text { sive atmosphere }\end{array}$ & & \\
\hline \multicolumn{4}{|l|}{$\begin{array}{l}\text { "The first thing is the immersive experience. The op- } \\
\text { portunity we have with this multidimensional, spatial } \\
\text { communication which brand worlds belong to... you just } \\
\text { have to try and exploit it. (Alan, exhibition designer) }\end{array}$} \\
\hline $\begin{array}{l}\text { "And then of course with respect to the location, there } \\
\text { are several aspects. For one, like with [exemplary com- } \\
\text { pany I or exemplary company 2], I arrive at the corpo- } \\
\text { rate headquarters and the origin of the brand, and then } \\
\text { of course I get a totally different impression, as when I } \\
\text { arrived at a dull production facility in some other city. So, } \\
\text { really just visiting these roots and origins of a brand. I } \\
\text { think a lot of understanding and identification happens } \\
\text { there, this 'genius loci' just does play a role." (Craig, } \\
\text { exhibition designer) }\end{array}$ & $\begin{array}{l}\text { "Genius Loci" - } \\
\text { Location as exp. } \\
\text { Value }\end{array}$ & & \\
\hline $\begin{array}{l}\text { "Well, it has to do with the entire story that I build, } \\
\text { the space that I build, the design I create, that all this } \\
\text { combines into an authentic overall picture. Most of the } \\
\text { time, authenticity is the most important thing." (Bob, } \\
\text { exhibition designer) }\end{array}$ & $\begin{array}{l}\text { Presentation } \\
\text { and content } \\
\text { fitting the brand } \\
\text { and its spirit }\end{array}$ & & \\
\hline $\begin{array}{l}\text { "Well, it really is decisive for the experience, this mul- } \\
\text { tisensory marketing, I would say, that we try to touch } \\
\text { the visitors on all channels. With videos, the visitor can } \\
\text { touch, can try out, and so on. (Ian, operating company) }\end{array}$ & $\begin{array}{l}\text { Multisensuality } \\
\text { of the exhibits }\end{array}$ & & \\
\hline $\begin{array}{l}\text { "These exhibits are really very close to cutting edge } \\
\text { technology, which are not 'learned' out there. People } \\
\text { simply don't know how to use those things. So, you } \\
\text { may not overdo it at that point. If the things are too } \\
\text { complicated, it's frustrating, and they won't be used. } \\
\text { And of course, it should never be frustrating." (Alan, } \\
\text { exhibition designer) }\end{array}$ & $\begin{array}{l}\text { Ease of use of } \\
\text { the exhibits }\end{array}$ & & \\
\hline $\begin{array}{l}\text { "There is not too much technology in both spaces, every- } \\
\text { thing is easy to use, and it is trying to reduce complex } \\
\text { facts and circumstances to a minimum and to a simpler } \\
\text { level." (Ian, operating company) }\end{array}$ & & & \\
\hline $\begin{array}{l}\text { "But it may also not distract too much so that you get } \\
\text { the feeling that maybe all these effects and the staging } \\
\text { cover up the fact that maybe my machines are not that } \\
\text { great. So, it may only support, it may never degenerate } \\
\text { into being an end in itself." (Bob, exhibition designer) }\end{array}$ & $\begin{array}{l}\text { Raison d'être for } \\
\text { each exhibit }\end{array}$ & & \\
\hline $\begin{array}{l}\text { "Every exhibit should have the goal to convey a process } \\
\text { or a product and should end with a learning outcome. } \\
\text { That it is easier with this or that product, or only works } \\
\text { this and that way. Like in a training. Never as an end in } \\
\text { itself." (Alan, exhibition designer) }\end{array}$ & & & \\
\hline
\end{tabular}


Table A.9: Informant statements on the $\mathrm{B}_{2} \mathrm{~B}$ brand world experiencescape ctd.

\begin{tabular}{lll}
\hline INFORMANT STATEMENTS & EXPERIENCE- & EXPERIENCE- \\
& SCAPE SUB- & SCAPE CATE- \\
& CATEGORY & GORY \\
\hline
\end{tabular}

"There was one [brand world] which I really thought was cluttered. It was a huge room, really too big already, with all the products standing there in line, every possible version there is. And I got really clobbered over the head with that and it did not help me at all. It rather confused me, because it was just too much. Then there also was a different [brand world], where it was really presented nicely. With use cases, the products which are really relevant next to each other, so that you could also compare the products. That really helped. [...] So, I really think that less is more." (Diane, visitor)

"We built multiple rooms that can do really different things. And there we don't have the differentiation of the entire setting. The invest is the same for $\mathrm{B}_{2} \mathrm{C}$ and $\mathrm{B}_{2} \mathrm{~B}$ visitors, but the variation is different, to cater to the needs of the target group. [...] So we built multi-functional rooms with elements that can present different kinds of information or environments. [...] And when you have the $\mathrm{B}_{2} \mathrm{~B}$ mode, then they will of course display information for the B2B visitors, if they have customers there." (Alan, exhibition designer)

"Just the overall impression, from the outside and the inside, should be innovative." (Jade, operating company)

"So, one point I just mentioned is about the general appearance. That it is contemporary and up-to-date, and just appealing in total. The entire setting should just be appealing." (David, exhibition designer)

"Then of course also the cleanliness. How do I enter, how clean is it, is everything working, the exhibitions and so on." (Mike, operating company)

"And then I also have the personal demand, that the supplier also presents the products nicely. Although sometimes it might be subjective, I generalize that to the entire company. If he does not take care of his showroom, whether new or old, if that is not taken care of, then how does it look like in production, in storage, how do the products arrive at my facility, how do they pack, how are the logistics? So, I do think that you can infer things, from a tidy front room or a messy one." (Greg, visitor)

"Well, of course the things have to be authentic and consistent there. From the optics, to the visual design, to the way we present things there, but of course also how we treat our visitors. So, including corporate behavior [...]. It is our personal matter, to treat these visitors individually and personally, of course. That is important. (Jade, operating company)

"And our guides are former employees who are now in pension. And they are not grouchy or annoyed, but in contrary, they are happy to be there. So, this representation, they are like ambassadors of our brand. It is about giving the brand and the company a face. With the employees who are here." (Heather, operating company)

"So, we really look for guides who first of all do this on a voluntary basis, who have fun doing it, who are supporters or fans of our company, and where you can see the sparkle in their eyes when they talk about our products." (Ian, operating company)
Less is more, focus on relevancy

Contemporaneity and up-todateness

Cleanliness

Social representation of the brand (Behavioral Branding, employee behavior towards visitors)

Brand World and contents have to be 'lived'
Social environment and practices 
Table A.9: Informant statements on the B2B brand world experiencescape ctd.

\begin{tabular}{lll}
\hline INFORMANT STATEMENTS & EXPERIENCE- & EXPERIENCE- \\
& SCAPE SUB- & SCAPE CATE- \\
CATEGORY & GORY \\
\hline
\end{tabular}

"I really think all of us stand behind all of this. We do it with a passionate heart and soul, and I hope one can tell that in me as well." (Luke, operating company)

"So, besides the competence and scrupulousness in the doing, our guides also need to have the passion to work in this field" (Brian, operating company)

"But in B2B, you really get a guide normally, or someone as a contact person, who explains everything, presents things, and who is just another level to answer questions, as well. Because all this competency cannot be conveyed on a medial level with images and texts, and you cannot present and cover this competency otherwise" (Bob, exhibition designer)

"I think it's incredibly important to have someone there who is experienced in presenting something like that. There are people who are able to do that, and there are people who are not. [...] I think that is important. Someone who gives you a lot of information, but also not too much, but just the right information and the important information, succinct, presented with the product."

Competence, friendliness, passion, and professionality of the employees/guides

Focus on the visitor and his needs (Diane, visitor) 


\section{A.3 APPENDIX CHAPTER 6}

Table A.10: Brand experience indicators

\begin{tabular}{|c|c|c|c|}
\hline DIMENSION / INDICATOR WORDING & ABВR. & & SOURCE \\
\hline Sensory & $\begin{array}{l}\text { 1SEN } \\
\text { 2SEN }\end{array}$ & / & \\
\hline The brand [the brand] makes a strong impression on my senses. & $\begin{array}{l}1 \text { sen } 1 \\
2 \operatorname{sen} 1\end{array}$ & / & $\begin{array}{l}\text { Brakus et al. } \\
(2009)\end{array}$ \\
\hline I find [the brand] interesting in a sensory way. & $\begin{array}{l}1 \text { sen } 2 \\
2 \operatorname{sen} 2\end{array}$ & / & \\
\hline [The brand] does appeal to my senses. & $\begin{array}{l}1 \operatorname{sen} 3 \\
2 \operatorname{sen} 3\end{array}$ & / & \\
\hline Affective & $\begin{array}{l}\text { 1AFF } \\
\text { 2AFF }\end{array}$ & / & \\
\hline [The brand] induces positive feelings and sentiments. & $\begin{array}{l}\text { 1affi } \\
\text { 2aff1 }\end{array}$ & / & \\
\hline I have strong emotions for [the brand]. & $\begin{array}{l}1 \text { aff2 } \\
\text { 2aff2 }\end{array}$ & / & \\
\hline [The brand] is an emotional brand. & $\begin{array}{l}1 \mathrm{Iff}_{3} \\
\text { 2aff }_{3}\end{array}$ & / & \\
\hline Behavioral & $\begin{array}{l}1 \mathrm{BEH} \\
2 \mathrm{BEH}\end{array}$ & / & \\
\hline $\begin{array}{l}\text { I engage in physical actions and behaviors when I use [the } \\
\text { brand]. }\end{array}$ & $\begin{array}{l}\text { 1behi } \\
\text { 2behi }\end{array}$ & / & \\
\hline [The brand] results in bodily experiences. & $\begin{array}{l}\text { 1beh2 } \\
2 \text { beh2 }\end{array}$ & / & \\
\hline [The brand] is action oriented. & $\begin{array}{l}\text { Ibeh3 }_{3} \\
\text { 2beh3 }\end{array}$ & / & \\
\hline Intellectual & $\begin{array}{l}\text { IINT } \\
\text { 2INT }\end{array}$ & / & \\
\hline I engage in a lot of thinking when I encounter [the brand]. & $\begin{array}{l}\text { 1int1 } \\
\text { 2int1 }\end{array}$ & / & \\
\hline [The brand] makes me think. & $\begin{array}{l}\text { iint2 } \\
\text { 2int2 }\end{array}$ & / & \\
\hline [The brand] stimulates my curiosity and problem solving. & $\begin{array}{l}\text { int3 } \\
\text { 2int3 }\end{array}$ & / & \\
\hline
\end{tabular}


Table A.11: Brand equity indicators

\begin{tabular}{|c|c|c|c|}
\hline DIMENSION / INDICATOR WORDING & АввR. & & SOURCE \\
\hline Brand Awareness & $\begin{array}{l}\text { 1BAW } \\
\text { 2BAW }\end{array}$ & I & \multirow{4}{*}{$\begin{array}{l}\text { Biedenbach et al. } \\
\text { (2015); } \\
\text { Biedenbach et al. } \\
\text { (2011) }\end{array}$} \\
\hline I am aware of [the brand]. & $\begin{array}{l}\text { 1baw1 } \\
\text { 2baw1 }\end{array}$ & & \\
\hline I can quickly recall the logo of [the brand]. & $\begin{array}{l}\text { 1baw2 } \\
\text { 2baw2 }\end{array}$ & & \\
\hline $\begin{array}{l}\text { I can recognize the logo of [the brand] among other competing } \\
\text { brands. }\end{array}$ & $\begin{array}{l}\text { 1baw3 } \\
\text { 2baw3 }\end{array}$ & 1 & \\
\hline Brand Associations & $\begin{array}{l}\text { 1BAS } \\
\text { 2BAS }\end{array}$ & / & \multirow{4}{*}{$\begin{array}{l}\text { Christodoulides } \\
\text { et al. (2015) }\end{array}$} \\
\hline [The brand] has strong associations. & $\begin{array}{l}1 \text { basi } \\
2 \text { basi }\end{array}$ & / & \\
\hline [The brand] has favourable associations. & $\begin{array}{l}\text { 1bas2 } \\
2 \text { bas2 }\end{array}$ & I & \\
\hline It is clear what [the brand] stands for. & $\begin{array}{l}\text { 1bas3 } \\
2 \text { bas3 }\end{array}$ & / & \\
\hline [Brand] show empathy. & $\begin{array}{l}1 \text { bas4 } \\
2 \text { bas4 }\end{array}$ & I & \multirow{4}{*}{$\begin{array}{l}\text { Biedenbach et al. } \\
\text { (2015); } \\
\text { Biedenbach et al. } \\
\text { (2011) }\end{array}$} \\
\hline [Brand] are flexible. & $\begin{array}{l}\text { 1bas5 } \\
\text { 2bas5 }\end{array}$ & / & \\
\hline [Brand] are reliable. & $\begin{array}{l}1 \text { bas6 } \\
2 \text { bas6 }\end{array}$ & / & \\
\hline [Brand] are pragmatic. & $\begin{array}{l}\text { 1bas7 } \\
2 \text { bas7 }\end{array}$ & / & \\
\hline Perceived Quality & $\begin{array}{l}1 \mathrm{PQL} \\
{ }_{2} \mathrm{PQL}\end{array}$ & / & \multirow{4}{*}{$\begin{array}{l}\text { Biedenbach et al. } \\
\text { (2015); } \\
\text { Biedenbach et al. } \\
\text { (2011) }\end{array}$} \\
\hline $\begin{array}{l}\text { How consistent is the quality of [the brand]'s products / ser- } \\
\text { vices? }\end{array}$ & $\begin{array}{l}\text { ipqli } \\
\text { 2pqli }\end{array}$ & / & \\
\hline $\begin{array}{l}\text { How would you evaluate the quality of [the brand]'s products / } \\
\text { services compared to the quality of products / services provided } \\
\text { by their competitors? }\end{array}$ & $\begin{array}{l}\text { Ipql2 } \\
\text { 2pql2 }\end{array}$ & / & \\
\hline $\begin{array}{l}\text { How would you evaluate the overall quality of [the brand]'s } \\
\text { products / services? }\end{array}$ & $\begin{array}{l}\text { 1pql3 } \\
\text { 2pql3 }\end{array}$ & / & \\
\hline Brand Loyalty & $\begin{array}{l}1 \mathrm{BLO} \\
2 \mathrm{BLO}\end{array}$ & / & \multirow{5}{*}{$\begin{array}{l}\text { Biedenbach et al. } \\
(2015) \text {; } \\
\text { Biedenbach et al. } \\
\text { (2011) }\end{array}$} \\
\hline $\begin{array}{l}\text { [The brand] would be the first choice if my company would } \\
\text { need one of their products / services. }\end{array}$ & $\begin{array}{l}\text { 1blo1 } \\
2 \text { blo1 }\end{array}$ & / & \\
\hline I would use [the brand]'s products / services (again). & $\begin{array}{l}\text { 1blo2 } \\
2 \text { blo2 }\end{array}$ & / & \\
\hline I would recommend [the brand]'s products / services to others. & $\begin{array}{l}\text { 1blo3 } \\
2 \text { blo3 }\end{array}$ & / & \\
\hline I consider myself to be loyal to [the brand]. & $\begin{array}{l}\text { 1blo4 } \\
2 \text { blo4 }\end{array}$ & / & \\
\hline Overall Brand Equity & $\begin{array}{l}\text { 1OBE } \\
2 \mathrm{OBE}\end{array}$ & / & \multirow{4}{*}{$\begin{array}{l}\text { Davis et al. } \\
(2008)\end{array}$} \\
\hline $\begin{array}{l}\text { I am willing to pay more for a [brand] product than for a } \\
\text { competitor's product. }\end{array}$ & $\begin{array}{l}\text { 1obe1 } \\
\text { 2obe1 }\end{array}$ & / & \\
\hline [The brand]'s brand is different from other providers. & $\begin{array}{l}1 \text { obe2 } \\
2 \text { obe2 }\end{array}$ & / & \\
\hline $\begin{array}{l}\text { The brand of [the brand] gives them an advantage over other } \\
\text { providers in their industry. }\end{array}$ & $\begin{array}{l}1 \text { obe3 } \\
2 \text { obe } 3\end{array}$ & / & \\
\hline
\end{tabular}


Table A.12: Brand world experience indicators

\begin{tabular}{|c|c|c|}
\hline COMPONENT / INDICATOR WORDING & АввR. & SOURCE \\
\hline Contents & $2 \mathrm{CON}$ & \multirow{5}{*}{ Oh et al.(2007) } \\
\hline The visit has made me more knowledgeable. & $2 \operatorname{con} 1$ & \\
\hline I learned a lot. & $2 \operatorname{con} 2$ & \\
\hline It stimulated my curiosity to learn new things. & $2 \operatorname{con}_{3}$ & \\
\hline It was a real learning experience. & 2 con 4 & \\
\hline Physical Artifacts and Spaces & 2PAS & \multirow{7}{*}{$\begin{array}{l}\text { Brady et al. } \\
(2001)\end{array}$} \\
\hline $\begin{array}{l}\text { At the [Brand World], you can rely on there being a good } \\
\text { atmosphere. }\end{array}$ & 2pas1 & \\
\hline $\begin{array}{l}\text { The [Brand World]'s ambiance is what I'm looking for in such a } \\
\text { facility. }\end{array}$ & 2pas2 & \\
\hline $\begin{array}{l}\text { [The brand] understands that its atmosphere at the [Brand } \\
\text { World] is important to me. }\end{array}$ & 2pas3 & \\
\hline The [Brand World]'s layout never fails to impress me. & 2pas4 & \\
\hline The [Brand World]'s layout serves my purpose. & 2pas5 & \\
\hline $\begin{array}{l}\text { [The brand] understands that the design of the [Brand World] } \\
\text { is important to me. }\end{array}$ & 2pas6 & \\
\hline Social Environment and Practices & 2SEP & \multirow{10}{*}{$\begin{array}{l}\text { Brady et al. } \\
(2001)\end{array}$} \\
\hline $\begin{array}{l}\text { You can count on the employees at the [Brand World] being } \\
\text { friendly. }\end{array}$ & 2sepat1 & \\
\hline $\begin{array}{l}\text { The attitude of the [Brand World] employees demonstrates their } \\
\text { willingness to help me. }\end{array}$ & 2sepat2 & \\
\hline $\begin{array}{l}\text { The attitude of the [Brand World] employees shows me that } \\
\text { they understand my needs. }\end{array}$ & 2sepat3 & \\
\hline $\begin{array}{l}\text { I can count on the [Brand World] employees taking actions to } \\
\text { address my needs. }\end{array}$ & 2sepbe1 & \\
\hline The [Brand World] employees respond quickly to my needs. & 2sepbez & \\
\hline $\begin{array}{l}\text { The behavior of the [Brand World] employees indicates to me } \\
\text { that they understand my needs. }\end{array}$ & 2sepbe3 & \\
\hline $\begin{array}{l}\text { You can count on the [Brand World] employees knowing their } \\
\text { jobs. }\end{array}$ & 2sepexi & \\
\hline $\begin{array}{l}\text { The [Brand World] employees are able to answer my questions } \\
\text { quickly. }\end{array}$ & 2sepex2 & \\
\hline $\begin{array}{l}\text { The employees at the [Brand World] understand that I rely on } \\
\text { their knowledge to meet my needs. }\end{array}$ & 2 sepex 3 & \\
\hline Interaction & 2INTER & \multirow{4}{*}{$\begin{array}{l}\text { Foster et al. } \\
(2015)\end{array}$} \\
\hline $\begin{array}{l}\text { When I visit the [Brand World], I feel fully engaged in the } \\
\text { environment. }\end{array}$ & 2inten 1 & \\
\hline $\begin{array}{l}\text { When I visit the [Brand World], I feel connected with the visitors' } \\
\text { space. }\end{array}$ & 2inten 2 & \\
\hline $\begin{array}{l}\text { When I visit the [Brand World], I feel that it is a very interactive } \\
\text { experience. }\end{array}$ & 2inten 3 & \\
\hline $\begin{array}{l}\text { Overall, I'd say the quality of my interaction with the employees } \\
\text { is excellent. }\end{array}$ & 2intsui & \multirow[t]{2}{*}{$\begin{array}{l}\text { Brady et al. } \\
(2001)\end{array}$} \\
\hline $\begin{array}{l}\text { I would say that the quality of my interaction with the [Brand } \\
\text { World]'s employees is high. }\end{array}$ & 2intsu2 & \\
\hline I have interacted with other visitors in some activities. & 2intsu3 & \multirow{3}{*}{$\begin{array}{l}\text { Antón et al. } \\
(2016)\end{array}$} \\
\hline I have interacted with the employees in some activities. & 2intsu4 & \\
\hline During the visit, there were experts who gave me information. & 2intsu5 & \\
\hline Immersion/Involvement & 2IMIN & \multirow{3}{*}{$\begin{array}{l}\text { Prebensen et al. } \\
(2017)\end{array}$} \\
\hline I was an active participant in this experience. & 2imin 1 & \\
\hline I was interested in this experience. & 2imin 2 & \\
\hline I was totally involved in the experience. & 2imin 3 & \multirow{3}{*}{$\begin{array}{l}\text { Dong et al. } \\
(2013)\end{array}$} \\
\hline I felt quite absorbed in this experience. & 2imin 4 & \\
\hline I nearly forgot the time when I was visiting. & 2imin 5 & \\
\hline
\end{tabular}




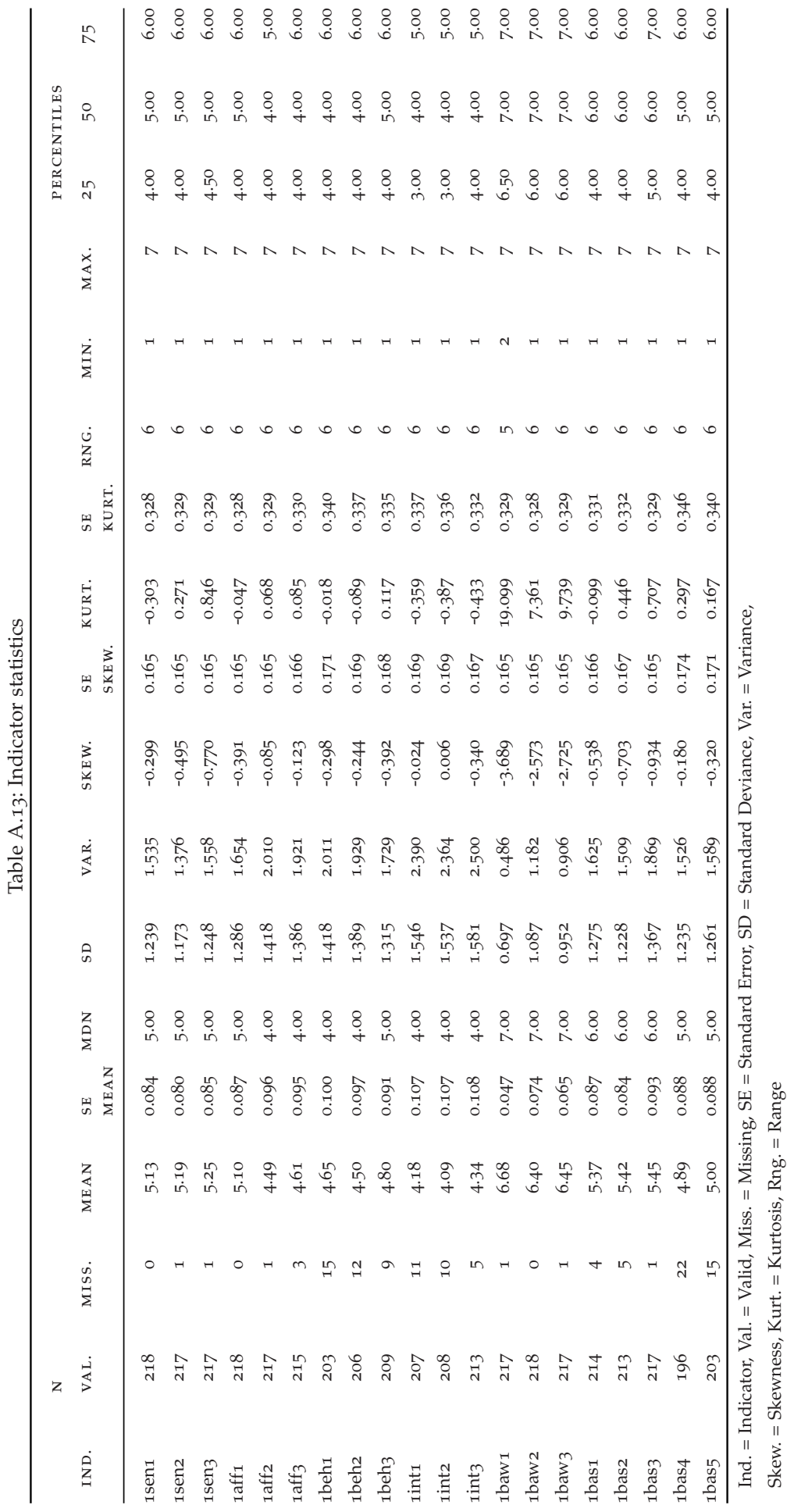




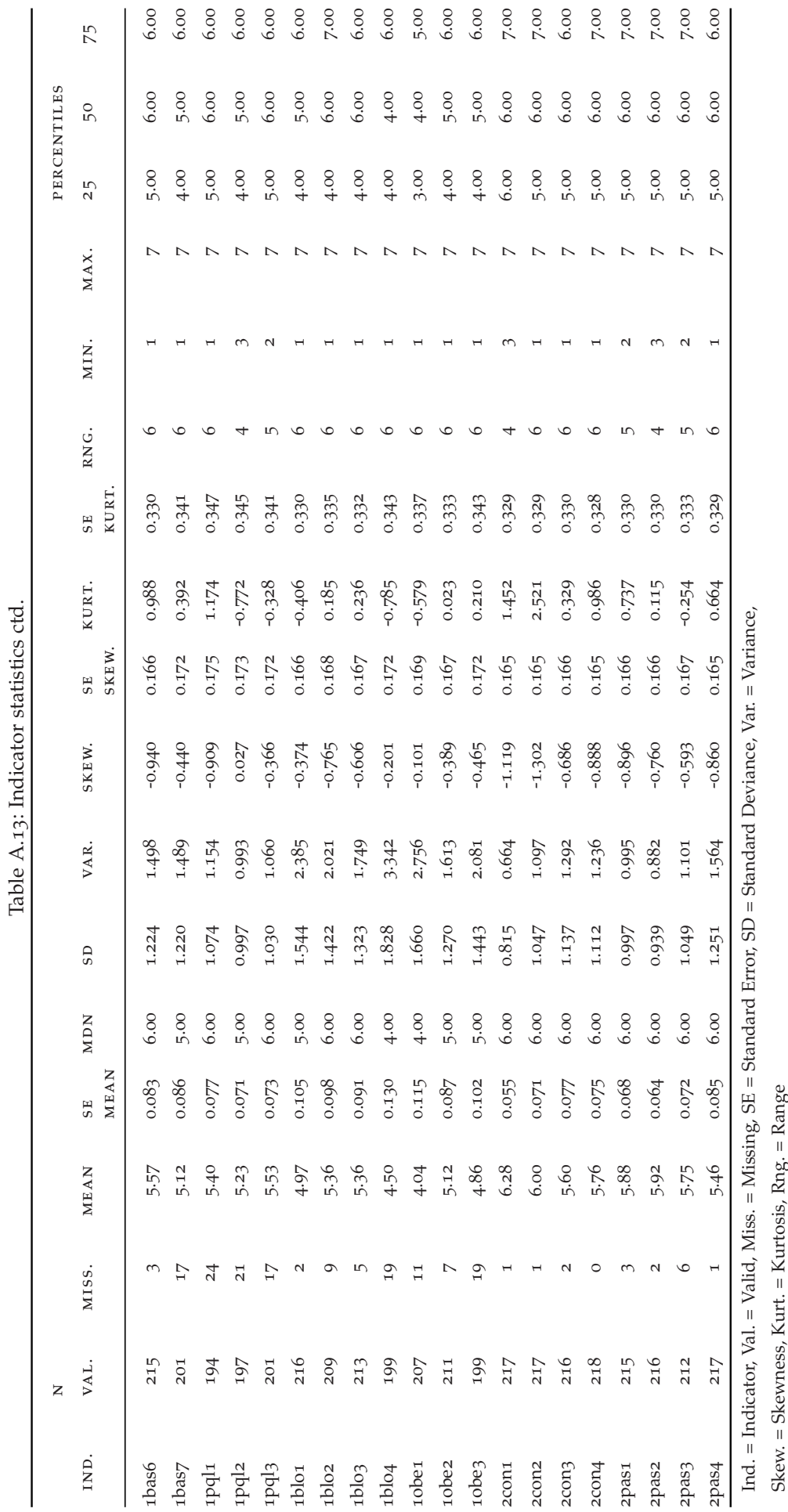




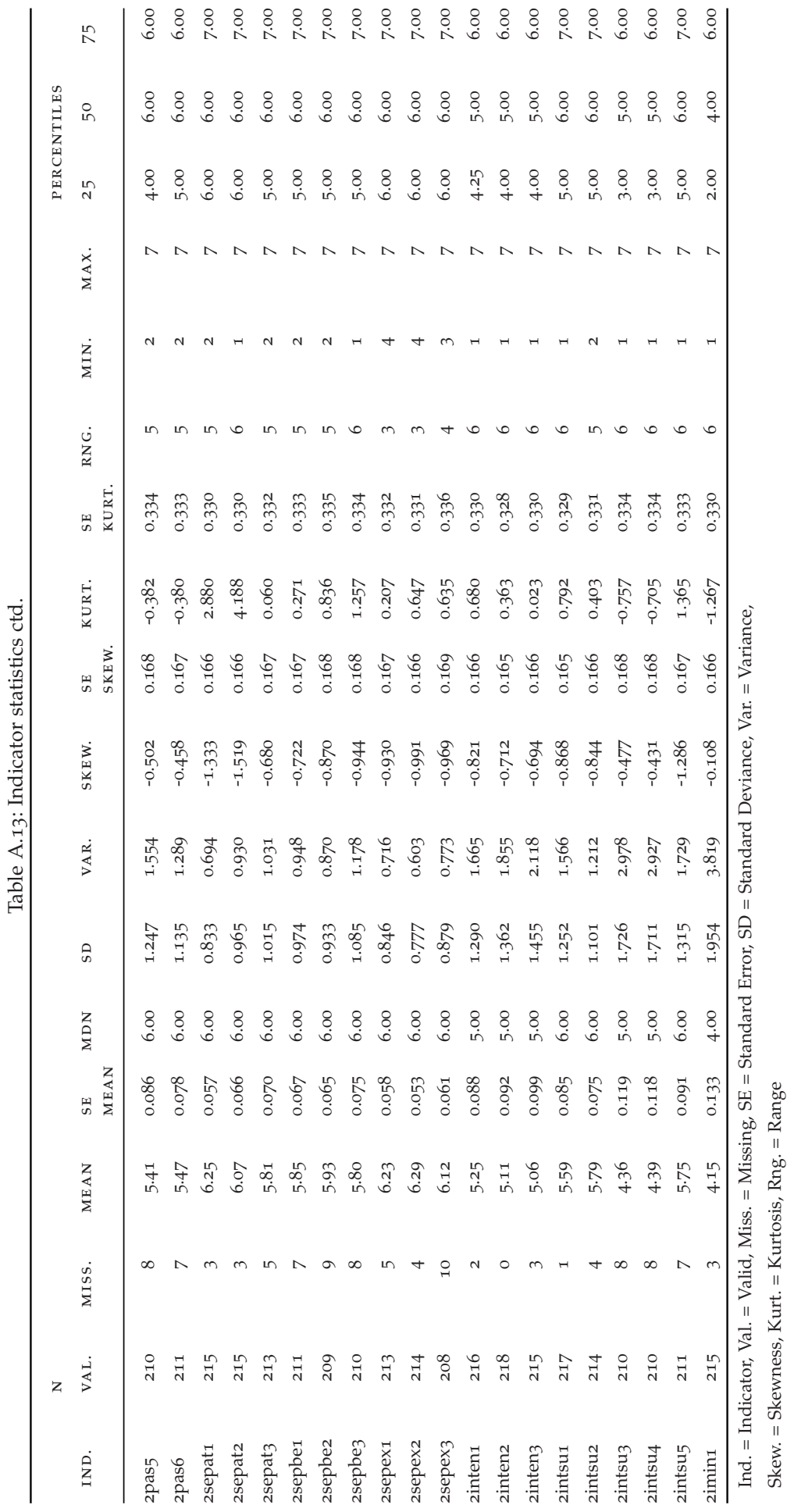




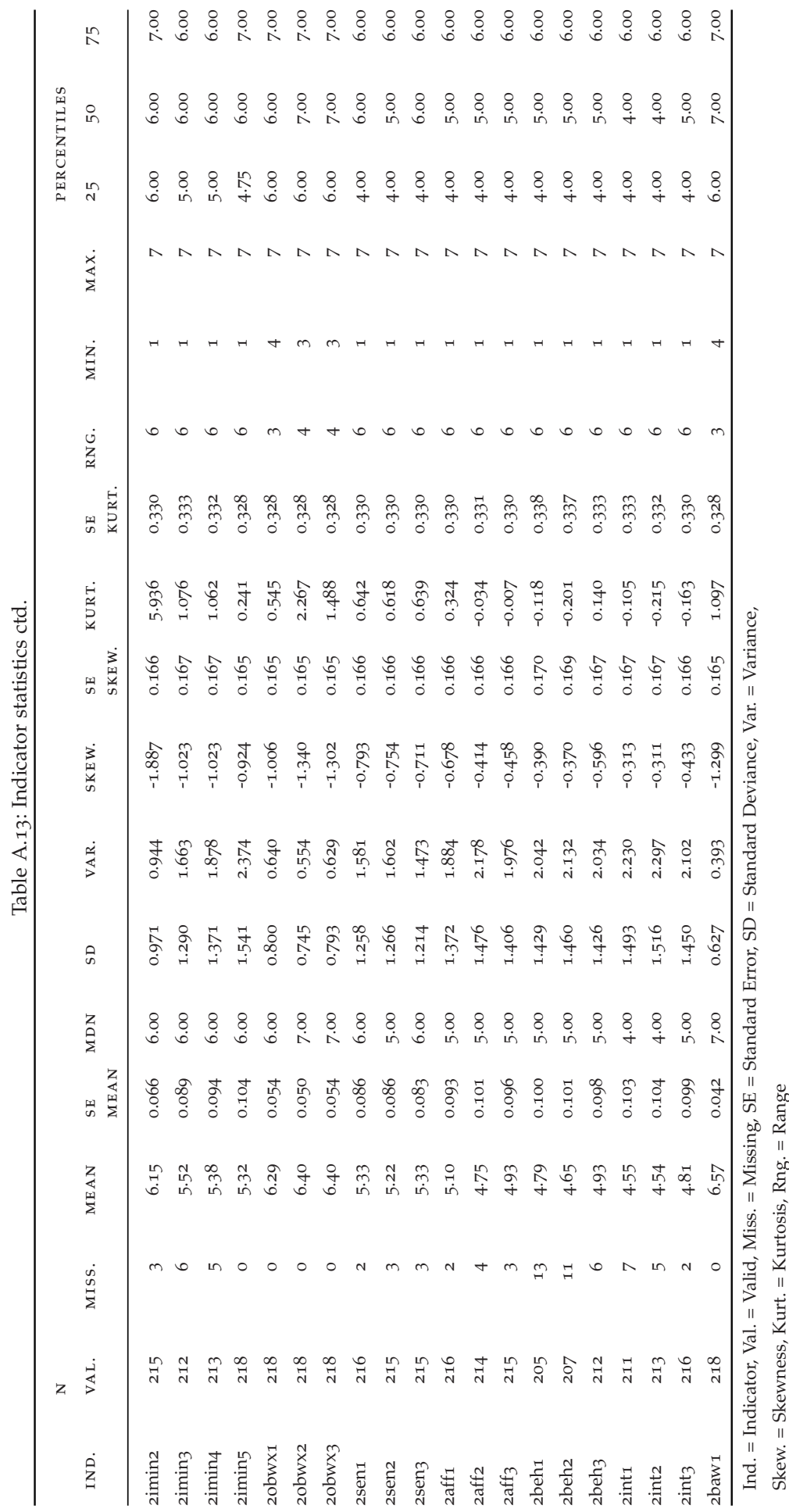




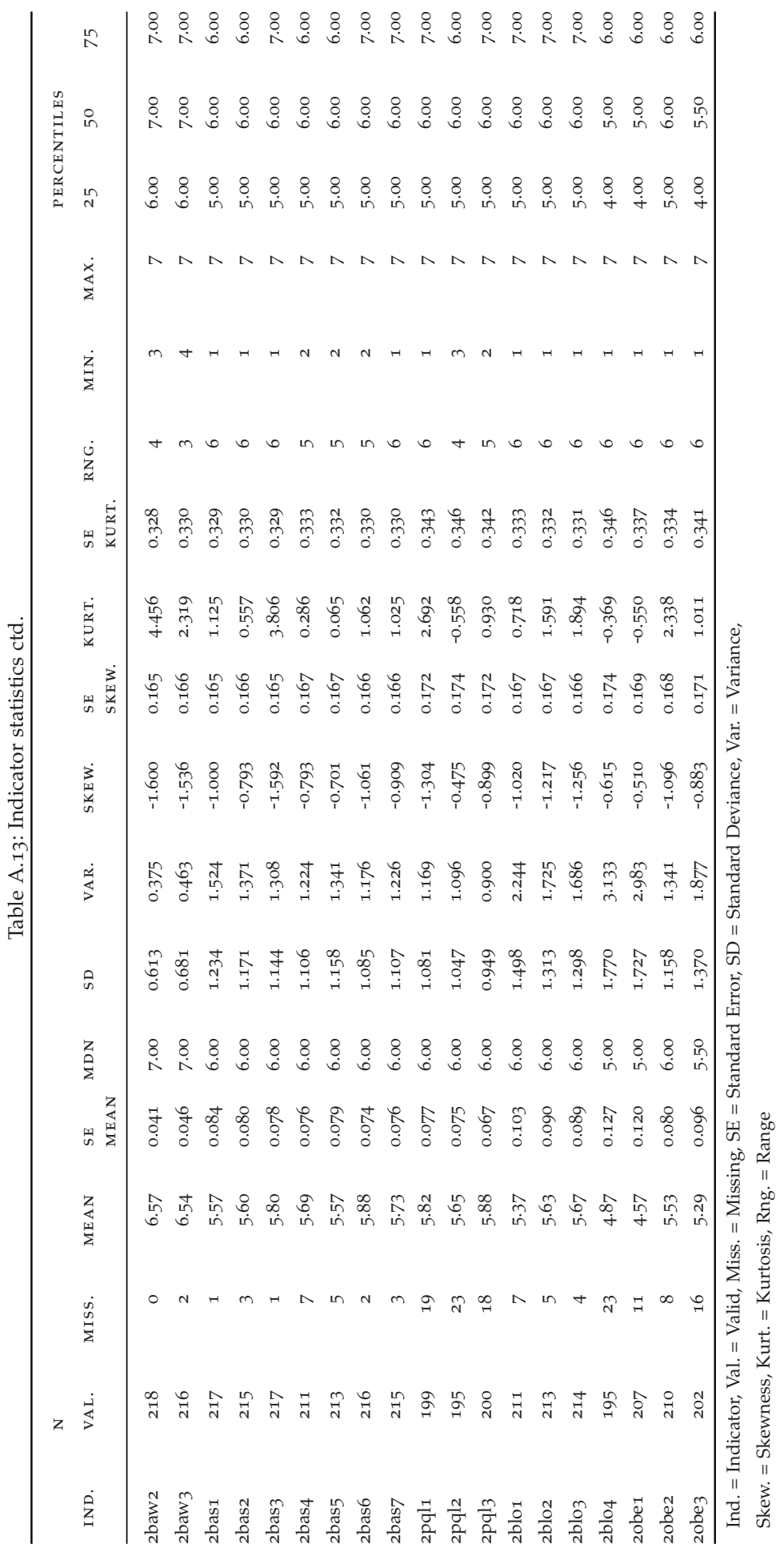


Table A.14: Reliability and validity of initial first-order measurement

\begin{tabular}{|c|c|c|c|c|c|c|}
\hline \multirow[b]{2}{*}{ CONSTRUCT } & \multirow[b]{2}{*}{$\rho_{\mathrm{A}}$} & \multirow[b]{2}{*}{$\rho_{\mathrm{C}}$} & \multirow[b]{2}{*}{$\alpha$} & \multirow[b]{2}{*}{ AVE } & \multicolumn{2}{|c|}{ нтмт } \\
\hline & & & & & MAX. & $95 \%$ \\
\hline \multicolumn{7}{|l|}{ Pre-visit } \\
\hline Sensory & 0.9220 & 0.9191 & 0.9185 & 0.7915 & 0.9083 & 0.9441 \\
\hline Affective & 0.8891 & 0.8888 & 0.8882 & 0.7271 & 0.9083 & 0.9441 \\
\hline Behavioral & 0.8925 & 0.8848 & 0.8868 & 0.7206 & 0.8072 & 0.8839 \\
\hline Intellectual & 0.9205 & 0.9179 & 0.9184 & 0.7888 & 0.8414 & 0.8891 \\
\hline Brand Awareness & 0.7038 & 0.6851 & 0.6693 & 0.4257 & 0.5481 & 0.6811 \\
\hline Brand Associations & 0.9070 & 0.8999 & 0.8980 & 0.5660 & 0.8879 & 0.9237 \\
\hline Perceived Quality & 0.8532 & 0.8408 & 0.8369 & 0.6405 & 0.7213 & 0.7893 \\
\hline Brand Loyalty & 0.9406 & 0.9403 & 0.9403 & 0.7975 & 0.8879 & 0.9372 \\
\hline Overall Brand Equity & 0.7875 & 0.7827 & 0.7811 & 0.5468 & 0.8780 & 0.9372 \\
\hline \multicolumn{7}{|l|}{ Post-visit } \\
\hline Contents & 0.8536 & 0.8523 & 0.8516 & 0.7428 & 0.5284 & 0.6420 \\
\hline Physical Artifacts and Spaces & 0.9074 & 0.8999 & 0.9003 & 0.6032 & 0.8511 & 0.8990 \\
\hline Social Environment and Practices & 0.9326 & 0.9260 & 0.9263 & 0.5855 & 0.6964 & 0.7627 \\
\hline Interaction & 0.8973 & 0.8576 & 0.8549 & 0.4505 & 0.8532 & 0.9099 \\
\hline Immersion and Involvement & 0.8630 & 0.8452 & 0.8428 & 0.5289 & 0.8532 & 0.9099 \\
\hline Sensory & 0.9471 & 0.9461 & 0.9459 & 0.8541 & 0.9264 & 0.9539 \\
\hline Affective & 0.9317 & 0.9293 & 0.9290 & 0.8146 & 0.9264 & 0.9539 \\
\hline Behavioral & 0.9141 & 0.9082 & 0.9086 & 0.7682 & 0.8330 & 0.8913 \\
\hline Intellectual & 0.9479 & 0.9473 & 0.9473 & 0.8571 & 0.8574 & 0.9038 \\
\hline Brand Awareness & 0.9195 & 0.8696 & 0.8616 & 0.7007 & 0.4825 & 0.6009 \\
\hline Brand Associations & 0.9328 & 0.9316 & 0.9314 & 0.6610 & 0.8333 & 0.8755 \\
\hline Perceived Quality & 0.9053 & 0.8943 & 0.8912 & 0.7400 & 0.7151 & 0.8257 \\
\hline Brand Loyalty & 0.9387 & 0.9385 & 0.9387 & 0.7924 & 0.9273 & 0.9650 \\
\hline Overall Brand Equity & 0.8408 & 0.8323 & 0.8274 & 0.6252 & 0.9273 & 0.9650 \\
\hline
\end{tabular}


Table A.15: Removed indicators

\begin{tabular}{|c|c|c|c|}
\hline STEP & INDICATOR & REASON & EFFECT \\
\hline 1 & $2 \operatorname{con} 3$ & Heywood case, loading $>1.0$ & \\
\hline 2 & 2 con 4 & Heywood case, loading $>1.0$ & \\
\hline 3 & 2intsu3 & $\begin{array}{l}\text { Low loading }(.3867) \text { and low AVE } \\
\text { of 2INTER }(.4505)\end{array}$ & $\begin{array}{l}\text { Increase AVE 2INTER from } .4505 \\
\text { to } .4876\end{array}$ \\
\hline 4 & 2intsu 5 & $\begin{array}{l}\text { Low loading }(.3910) \text { and low AVE } \\
\text { of 2INTER }(.4876)\end{array}$ & $\begin{array}{l}\text { Increase AVE 2INTER from } .4876 \\
\text { to } .5468\end{array}$ \\
\hline 5 & 2intsu4 & $\begin{array}{l}\text { Loading .4976, cross-loads on } \\
2 \text { PAS }(.5043)\end{array}$ & $\begin{array}{l}\text { Increase AVE 2INTER from } .5468 \\
\text { to } .5975\end{array}$ \\
\hline
\end{tabular}

Table A.16: Loadings and t-values of final first-order pre-visit measurement

\begin{tabular}{|c|c|c|c|}
\hline PRE-VISIT CONSTRUCT & INDICATOR & LOADING & T-VALUE \\
\hline \multirow[t]{3}{*}{ Sensory } & 1sen 1 & 0.9386 & 44.8263 \\
\hline & 1sen 2 & 0.8960 & 35.4102 \\
\hline & 1 sen 3 & 0.8311 & 15.6594 \\
\hline \multirow[t]{3}{*}{ Affective } & Iaff 1 & 0.8362 & 26.6826 \\
\hline & 1aff2 & 0.8689 & 38.0957 \\
\hline & $\mathrm{Iaff}_{3}$ & 0.8528 & 35.2705 \\
\hline \multirow[t]{3}{*}{ Behavioral } & IbehI & 0.9093 & 20.1001 \\
\hline & 1beh2 & 0.7463 & 13.0396 \\
\hline & Ibeh3 $_{3}$ & 0.8820 & 19.9048 \\
\hline \multirow[t]{3}{*}{ Intellectual } & Iint1 & 0.8888 & 28.4728 \\
\hline & tint2 & 0.8357 & 16.3749 \\
\hline & int3 & 0.9370 & 29.4533 \\
\hline \multirow[t]{3}{*}{ Brand Awareness } & Ibaw1 & 0.5324 & 7.2462 \\
\hline & Ibaw2 & 0.6368 & $7 \cdot 9040$ \\
\hline & 1baw3 & 0.7670 & 11.3501 \\
\hline \multirow[t]{7}{*}{ Brand Associations } & Ibasi & 0.8213 & 22.0835 \\
\hline & 1bas2 & 0.8279 & 24.7562 \\
\hline & 1bas3 & 0.5466 & 10.4947 \\
\hline & 1bas4 & 0.6997 & 14.8649 \\
\hline & Ibas5 & 0.7569 & 17.7917 \\
\hline & 1bas6 & 0.7733 & 22.5464 \\
\hline & 1bas7 & 0.8016 & 22.0714 \\
\hline \multirow[t]{3}{*}{ Perceived Quality } & Ipqli & 0.6698 & 11.0752 \\
\hline & 1pql2 & 0.8508 & 18.9935 \\
\hline & 1pql3 & 0.8656 & 22.6693 \\
\hline \multirow[t]{4}{*}{ Brand Loyalty } & Iblo1 & 0.9111 & 46.4654 \\
\hline & 1blo2 & 0.8671 & 36.7330 \\
\hline & 1blo3 & 0.9006 & 41.8762 \\
\hline & Iblo4 & 0.8927 & 38.2836 \\
\hline \multirow[t]{3}{*}{ Overall Brand Equity } & 1obe1 & 0.7571 & 18.3334 \\
\hline & 1obe2 & 0.6659 & 11.0700 \\
\hline & 1obe3 & 0.7898 & 17.9223 \\
\hline
\end{tabular}


Table A.17: Loadings and t-values of final first-order post-visit measurement

\begin{tabular}{|c|c|c|c|}
\hline POST-VISIT CONSTRUCT & INDICATOR & LOADING & T-VALUE \\
\hline \multirow[t]{2}{*}{ Contents } & $2 \operatorname{con} 1$ & 0.8367 & 11.1804 \\
\hline & $2 \operatorname{con} 2$ & 0.8864 & 20.7027 \\
\hline \multirow[t]{6}{*}{ Physical Artifacts and Spaces } & 2pasi & 0.8282 & 24.1396 \\
\hline & 2pas2 & 0.5692 & 8.9380 \\
\hline & 2 pas3 & 0.7804 & 19.4668 \\
\hline & 2pas4 & 0.8469 & 27.4131 \\
\hline & 2 pas5 & 0.7971 & 19.6907 \\
\hline & 2pas6 & 0.8045 & 21.6336 \\
\hline \multirow[t]{9}{*}{ Social Environment and Practices } & 2sepati & 0.5950 & $7 \cdot 3064$ \\
\hline & 2sepat2 & 0.6937 & 12.2990 \\
\hline & 2sepat3 & 0.8534 & 16.9537 \\
\hline & 2sepbei & 0.8750 & 20.1836 \\
\hline & 2sepbez & 0.7826 & 14.1373 \\
\hline & 2sepbe3 & 0.8496 & 17.0438 \\
\hline & 2sepexi & 0.7966 & 11.1966 \\
\hline & 2sepex 2 & 0.6199 & 6.8071 \\
\hline & 2 sepex3 & 0.7663 & 10.3963 \\
\hline \multirow[t]{5}{*}{ Interaction } & 2inten 1 & 0.8680 & 28.3717 \\
\hline & 2inten 2 & 0.9078 & 28.6266 \\
\hline & 2inten 3 & 0.7606 & 22.1633 \\
\hline & 2intsu1 & 0.6291 & 12.1353 \\
\hline & 2intsu2 & 0.6601 & 13.0762 \\
\hline \multirow[t]{5}{*}{ Immersion and Involvement } & 2imin 1 & 0.7002 & 12.2021 \\
\hline & 2imin 2 & 0.5128 & 6.9830 \\
\hline & 2 imin 3 & 0.7556 & 15.6415 \\
\hline & 2imin 4 & 0.8819 & 27.8388 \\
\hline & 2imin 5 & 0.7368 & 15.5772 \\
\hline \multirow[t]{3}{*}{ Sensory } & $2 \operatorname{sen} 1$ & 0.8884 & $33 \cdot 5945$ \\
\hline & $2 \operatorname{sen} 2$ & 0.9327 & 66.0248 \\
\hline & $2 \operatorname{sen} 3$ & 0.9503 & 57.9055 \\
\hline \multirow[t]{3}{*}{ Affective } & $2 \mathrm{aff} 1$ & 0.9342 & 57.5285 \\
\hline & 2aff2 & 0.9268 & 48.0600 \\
\hline & $2 \mathrm{aff}_{3}$ & 0.8439 & 29.3315 \\
\hline \multirow[t]{3}{*}{ Behavioral } & 2beh1 & 0.9077 & 30.0931 \\
\hline & 2beh2 & 0.7844 & 14.4010 \\
\hline & 2beh3 & 0.9303 & 32.5085 \\
\hline \multirow[t]{3}{*}{ Intellectual } & 2 int 1 & 0.9513 & 53.8577 \\
\hline & 2int2 & 0.9005 & 41.0581 \\
\hline & 2int 3 & 0.9248 & 33.6617 \\
\hline \multirow[t]{3}{*}{ Brand Awareness } & 2baw1 & 0.5527 & $4 \cdot 5489$ \\
\hline & 2baw2 & 0.9111 & 18.1753 \\
\hline & 2baw3 & 0.9832 & 17.5295 \\
\hline \multirow[t]{4}{*}{ Brand Associations } & 2basi & 0.8344 & 24.9281 \\
\hline & 2bas2 & 0.8560 & 26.8338 \\
\hline & 2 bas3 & 0.7237 & 18.9729 \\
\hline & 2 bas4 & 0.8031 & 21.5941 \\
\hline
\end{tabular}


Table A.17: Loadings and t-values of final first-order post-visit measurement ctd.

\begin{tabular}{|c|c|c|c|}
\hline POST-VISIT CONSTRUCT & INDICATOR & LOADING & T-VALUE \\
\hline & 2bas5 & 0.8265 & 25.0827 \\
\hline & 2bas6 & 0.8263 & 24.4276 \\
\hline & 2bas7 & 0.8146 & $25.115^{8}$ \\
\hline \multirow[t]{3}{*}{ Perceived Quality } & 2pqli & 0.7544 & 11.1419 \\
\hline & 2pql2 & 0.9575 & 24.7164 \\
\hline & $2 \mathrm{pql}_{3}$ & 0.8566 & $25 \cdot 4873$ \\
\hline \multirow[t]{4}{*}{ Brand Loyalty } & 2blo1 & 0.9014 & 35.2731 \\
\hline & 2blo2 & 0.8766 & $34.728 \mathrm{o}$ \\
\hline & 2blo3 & o.8798 & 32.9273 \\
\hline & 2blo4 & 0.9027 & 30.7863 \\
\hline \multirow[t]{3}{*}{ Overall Brand Equity } & 2obe1 & 0.7860 & 19.9602 \\
\hline & 2obe2 & 0.7011 & 14.7655 \\
\hline & 2obe3 & 0.8754 & 35.7289 \\
\hline
\end{tabular}

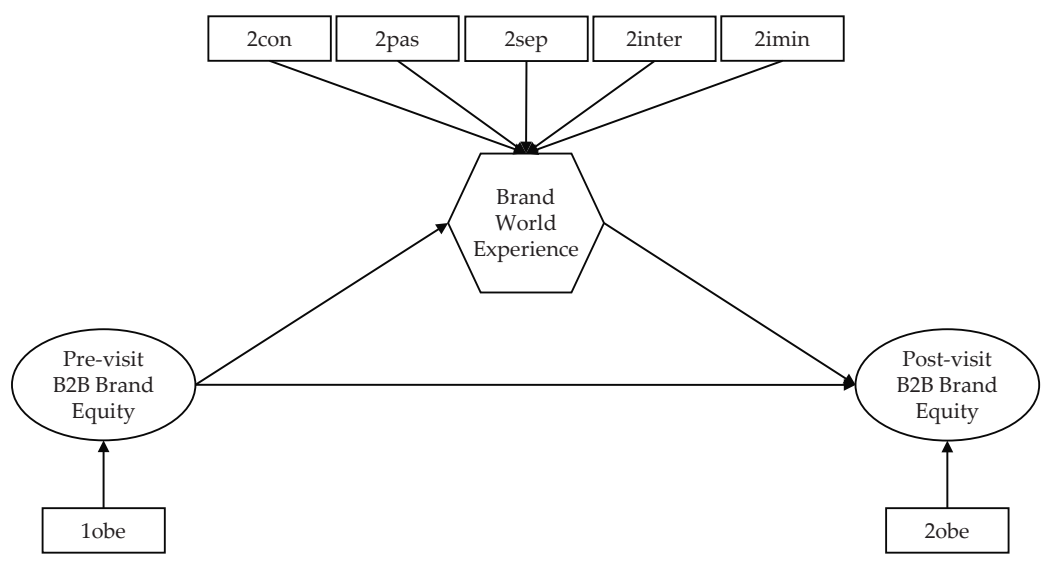

Figure A.1: Minimal model for assessment of composite brand world experience measurement 


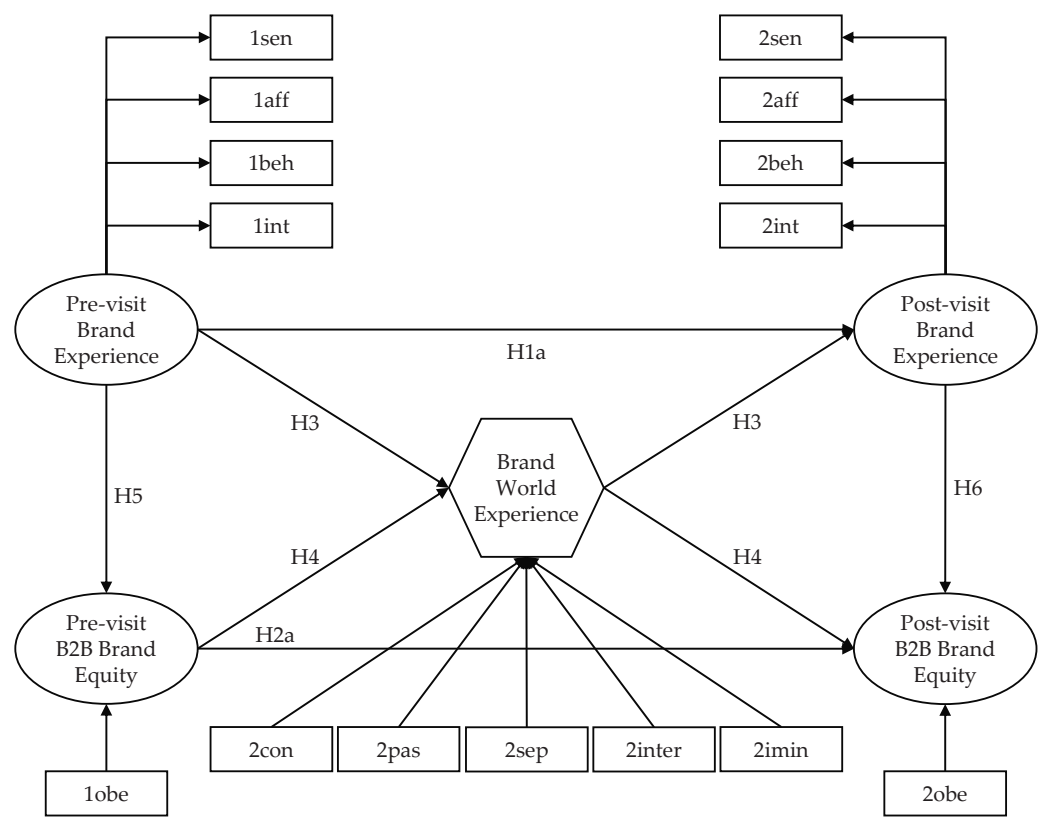

Figure A.2: Final second-order model 
Aaker, D. A. (1991). Managing brand equity: Capitalizing on the value of a brand name. New York: Free Press, Maxwell Macmillan Canada, and Maxwell Macmillan International.

Aaker, D. A. (1996a). Building strong brands. New York: Free Press.

Aaker, D. A. (1996b). Measuring brand equity across products and markets. California Management Review, 38(3), 102-120.

Aaker, J., Fournier, S., \& Brasel, S. A. (2004). When Good Brands Do Bad. Journal of Consumer Research, 31(1), 1-16. doi:10.1086/383419

AB VOLVO. (2018). Customer Center, Eskilstuna: Providing a unique brand experience. A meeting place where customers can experience Volvo Construction Equipment. Retrieved November 13, 2018, from https:/ / www.volvoce.com/europe/en/about-us/customer-center/

Abbott, L. (1955). Quality and competition. New York: Columbia Univ. Pr. Retrieved from https: / / babel.hathitrust.org / cgi / pt?id=uc1.b3428044 ; view=1up;seq $=11$; size $=125$

Accenture. (2015). Improving Customer Experience is Top Business Priority for Companies Pursuing Digital Transformation, According to Accenture Study. press release. Retrieved November 10, 2018, from https: //newsroom.accenture.com/news/improving-customer-experience-istop-business-priority-for-companies-pursuing-digital-transformationaccording-to-accenture-study.htm

Achrol, R. S., \& Kotler, P. (2012). Frontiers of the marketing paradigm in the third millennium. Journal of the Academy of Marketing Science, 40(1), 35-52. doi:10.1007/s11747-011-0255-4

Addis, M., \& Holbrook, M. B. (2001). On the conceptual link between mass customisation and experiential consumption: An explosion of subjectivity. Journal of Consumer Behaviour, 1(1), 50-66. doi:10.1002/cb.53

Agapito, D., Valle, P. O. d., \& Mendes, J. (2014). The sensory dimension of tourist experiences: Capturing meaningful sensory-informed themes in Southwest Portugal. Tourism Management, 42, 224-237. doi:10.1016/j. tourman.2013.11.011

Albers, S., Mantrala, M. K., \& Sridhar, S. (2010). Personal Selling Elasticities: A Meta-Analysis. Journal of marketing research, 47(5), 840-853. doi:10.1509 /jmkr.47.5.840

Amonini, C., McColl-Kennedy, J. R., Soutar, G. N., \& Sweeney, J. C. (2010). How professional service firms compete in the market: An exploratory study. Journal of marketing management, 26(1-2), 28-55. doi:10.1080/026725709035 34662

Andersen, P. H., \& Kumar, R. (2006). Emotions, trust and relationship development in business relationships: A conceptual model for buyerseller dyads. Industrial Marketing Management, 35(4), 522-535. doi:10.1016 /j.indmarman.2004.10.010

Andreini, D., Pedeliento, G., Zarantonello, L., \& Solerio, C. (2018). A renaissance of brand experience: Advancing the concept through a multi-perspective 
analysis. Journal of Business Research, 91, 123-133. doi:10.1016/j.jbusres.20 18.05.046

Andrews, L., Kiel, G., Drennan, J., Boyle, M. V., \& Weerawardena, J. (2007). Gendered perceptions of experiential value in using web-based retail channels. European Journal of Marketing, 41(5/6), 640-658. doi:10.1108/030 90560710737660

Anisimova, T., \& Mavondo, F. (2014). Aligning Company and Dealer Perspectives in Corporate Branding: Implications for Dealer Satisfaction and Commitment. Journal of Business-to-Business Marketing, 21(1), 35-56. doi:10.1080/1051712X.2014.857501

Antón, C., Camarero, C., \& Garrido, M.-J. (2016). The Experience Value of Visitors: A Co-Creation Process. In Association for Cultural Economics International (Ed.), 19th International Conference on Cultural Economics.

Antón, C., Camarero, C., \& Garrido, M.-J. (2017). Exploring the experience value of museum visitors as a co-creation process. Current Issues in Tourism, 61(4), 1-20. doi:10.1080/13683500.2017.1373753

Arnould, E. J., \& Price, L. L. (1993). River Magic: Extraordinary Experience and the Extended Service Encounter. Journal of Consumer Research, 20(1), 24 doi:10.1086/209331

Arnould, E. J., Price, L. L., \& Zinkhan, G. M. (2002). Consumers (1st ed.). Boston: McGraw-Hill.

Arnould, E. J., Price, L. L., \& Zinkhan, G. M. (2004). Consumers (2. ed.). McGrawHill/Irwin series in marketing. Boston, Mass.: McGraw-Hill/Irwin.

Babin, B. J., Darden, W. R., \& Griffin, M. (1994). Work and/or Fun: Measuring Hedonic and Utilitarian Shopping Value. Journal of Consumer Research, 20(4), 644. doi:10.1086/209376

Backhaus, K., Erichson, B., \& Weiber, R. (2011). Fortgeschrittene multivariate Analysemethoden: Eine anwendungsorientiere Einführung. Springer-Lehrbuch. Berlin: Springer.

Backhaus, K., Steiner, M., \& Lügger, K. (2011). To invest, or not to invest, in brands? Drivers of brand relevance in B2B markets. Industrial Marketing Management, 40(7), 1082-1092. doi:10.1016/j.indmarman.2011.09.002

Bagozzi, R. P. (2006). The role of social and self-conscious emotions in the regulation of business-to-business relationships in salesperson-customer interactions. Journal of Business $\mathcal{E}$ Industrial Marketing, 21(7), 453-457. doi:10.1108/08858620610708948

Baker, J., Parasuraman, A., Grewal, D., \& Voss, G. B. (2002). The Influence of Multiple Store Environment Cues on Perceived Merchandise Value and Patronage Intentions. Journal of Marketing, 66(2), 120-141. doi:10.1509 /jmkg.66.2.120.18470

Ballantyne, D., \& Aitken, R. (2007). Branding in B2B markets: Insights from the service-dominant logic of marketing. Journal of Business $\mathcal{E}$ Industrial Marketing, 22(6), 363-371. doi:10.1108/08858620710780127

Baumgarth, C., \& Binckebanck, L. (2011). Sales force impact on B-to-B brand equity: Conceptual framework and empirical test. Journal of Product $\mathcal{E}$ Brand Management, 20(6), 487-498. doi:10.1108/10610421111166630

Baumgarth, C., \& Schmidt, M. (2010). How strong is the business-to-business brand in the workforce? An empirically-tested model of 'internal brand equity' in a business-to-business setting. Industrial Marketing Management, 39(8), 1250-1260. doi:10.1016/j.indmarman.2010.02.022 
Bendixen, M., Bukasa, K. A., \& Abratt, R. (2004). Brand equity in the businessto-business market. Industrial Marketing Management, 33(5), 371-380. doi:1 0.1016/j.indmarman.2003.10.001

Bengtsson, A., \& Servais, P. (2005). Co-branding on industrial markets. Industrial Marketing Management, 34(7), 706-713. doi:10.1016/j.indmarman.2005.06 .004

Bentler, P. M., \& Chou, C.-P. (1987). Practical issues in structural modeling. Sociological Methods \& Research, 16(1), 78-117.

Berry, L. L., \& Carbone, L. P. (2002). Managing the total customer experience. MIT Sloan Management Review, 43(3), 85-89.

Beverland, M. B., Napoli, J., \& Lindgreen, A. (2007). Industrial global brand leadership: A capabilities view. Industrial Marketing Management, 36(8), 1082-1093. doi:10.1016/j.indmarman.2006.08.007

Biedenbach, G. (2012). Brand equity in the business-to-business context: Examining the structural composition. Journal of Brand Management, 19(8), 688-701. doi:10.1057/bm.2011.60

Biedenbach, G., Bengtsson, M., \& Marell, A. (2015). Brand equity, satisfaction, and switching costs: An examination of effects in the business-to-business setting. Marketing Intelligence \& Planning, 33(2), 164-178. doi:10.1108/MIP03-2014-0059

Biedenbach, G., Bengtsson, M., \& Wincent, J. (2011). Brand equity in the professional service context: Analyzing the impact of employee role behavior and customer-employee rapport. Industrial Marketing Management, 4o(7), 1093-1102. doi:10.1016/j.indmarman.2011.09.007

Biedenbach, G., \& Marell, A. (2010). The impact of customer experience on brand equity in a business-to-business services setting. Journal of Brand Management, 17(6), 446-458. doi:10.1057/bm.2009.37

Bitner, M. J. (1990). Evaluating Service Encounters: The Effects of Physical Surroundings and Employee Responses. Journal of Marketing, 54(2), 69. doi:10.2307/1251871

Bitner, M. J. (1992). Servicescapes: The Impact of Physical Surroundings on Customers and Employees. Journal of Marketing, 56(2), 57. doi:10.2307/12 52042

Bogner, A., Littig, B., \& Menz, W. (Eds.). (2009). Experteninterviews: Theorie, Methoden, Anwendungsfelder. Wiesbaden: Verl. für Sozialwiss.

Borders, A. L., \& Kemp, E. A. (2018). Guest editorial. Journal of Business \& Industrial Marketing, 33(1), 1-2. doi:10.1108/JBIM-06-2017-0126

Borghini, S., Diamond, N., Kozinets, R. V., McGrath, M. A., Muñiz, A. M., \& Sherry, J. F., Jr. (2009). Why Are Themed Brandstores So Powerful? Retail Brand Ideology at American Girl Place. Journal of Retailing, 85(3), 363-375. doi:10.1016/j.jretai.2009.05.003

Brady, M. K., \& Cronin, J. J. (2001). Some New Thoughts on Conceptualizing Perceived Service Quality: A Hierarchical Approach. Journal of Marketing, 65(3), 34-49. doi:10.1509/jmkg.65·3.34.18334

Brakus, J. J., Schmitt, B. H., \& Zarantonello, L. (2009). Brand Experience: What Is It? How Is It Measured? Does It Affect Loyalty? Journal of Marketing, 73(3), 52-68. doi:10.1509/jmkg.73.3.52

Brown, B. P., Bellenger, D. N., \& Johnston, W. J. (2007). The Implications of Business-to-Business and Consumer Market Differences for B2B Branding 
Strategy. Journal of business market management, 1(3), 209-230. doi:10.1007 /s12087-007-0011-x

Brown, B. P., Zablah, A. R., Bellenger, D. N., \& Donthu, N. (2012). What factors influence buying center brand sensitivity? Industrial Marketing Management, 41(3), 508-520. doi:10.1016/j.indmarman.2011.06.008

Brown, B. P., Zablah, A. R., Bellenger, D. N., \& Johnston, W. J. (2011). When do $B_{2} B$ brands influence the decision making of organizational buyers? An examination of the relationship between purchase risk and brand sensitivity. International Journal of Research in Marketing, 28(3), 194-204. doi:10.1016/j.ijresmar.2011.03.004

Brynjolfsson, E., Hu, Y. J., \& Rahman, M. S. (2013). Competing in the age of omnichannel retailing. MIT Sloan Management Review, 54(4), 23.

Bustamante, J. C., \& Rubio, N. (2017). Measuring customer experience in physical retail environments. Journal of Service Management, 28(5), 884-913. doi:10.1108/JOSM-06-2016-0142

Campos, A. C., Mendes, J., Valle, P. O. d., \& Scott, N. (2015). Co-creation of tourist experiences: A literature review. Current Issues in Tourism, 21(4), 369-400. doi:10.1080/13683500.2015.1081158

Cañal-Bruland, R., \& van der Kamp, J. (2015). Embodied Perception: A Proposal to Reconcile Affordance and Spatial Perception. i-Perception, 6(2), 63-66. doi:10.1068/io709jc

Cardozo, R. N. (1965). An Experimental Study of Customer Effort, Expectation, and Satisfaction. Journal of marketing research, 2(3), 244. doi:10.2307/31501 82

Carù, A., \& Cova, B. (2003). Revisiting Consumption Experience: A More Humble but Complete View of the Concept. Marketing Theory, 3(2), 267286. doi:10.1177/14705931030032004

Carù, A., \& Cova, B. (2007). Consuming Experiences: An Introduction. In A. Carù \& B. Cova (Eds.), Consuming experience (pp. 3-16). London: Routledge.

Casidy, R., Nyadzayo, M. W., Mohan, M., \& Brown, B. (2018). The relative influence of functional versus imagery beliefs on brand sensitivity in B2B professional services. Industrial Marketing Management, 72, 26-36. doi:10.1016/j.indmarman.2018.01.021

Caterpillar Inc. (2016). Caterpillar Visitors Center. Retrieved November 13, 2018, from http:/ / www.caterpillar.com/en/company/visitors-center.html

Cenfetelli, R. T., \& Bassellier, G. (2009). Interpretation of Formative Measurement in Information Systems Research. MIS Quarterly, 33(4), 689-707. doi:10.2307/20650323

Chang, Y., Wang, X., \& Arnett, D. B. (2018). Enhancing firm performance: The role of brand orientation in business-to-business marketing. Industrial Marketing Management, 72, 17-25. doi:10.1016/j.indmarman.2018.01.031

Chaudhuri, A., \& Holbrook, M. B. (2001). The Chain of Effects from Brand Trust and Brand Affect to Brand Performance: The Role of Brand Loyalty. Journal of Marketing, 65(2), 81-93. doi:10.1509/jmkg.65.2.81.18255

Chen, F., Bollen, K. A., Paxton, P., Curran, P. J., \& Kirby, J. B. (2001). Improper solutions in structural equation models: Causes, consequences, and strategies. Sociological Methods \& Research, 29(4), 468-508.

Chen, H.-B., Yeh, S.-S., \& Huan, T.-C. (2014). Nostalgic emotion, experiential value, brand image, and consumption intentions of customers of nostalgic- 
themed restaurants. Journal of Business Research, 67(3), 354-360. doi:10.101 6/j.jbusres.2013.01.003

Chen, Y.-M., Su, Y.-F., \& Lin, F.-J. (2011). Country-of-origin effects and antecedents of industrial brand equity. Journal of Business Research, 64(11), 1234-1238. doi:10.1016/j.jbusres.2011.06.029

Christodoulides, G., Cadogan, J. W., \& Veloutsou, C. (2015). Consumer-based brand equity measurement: Lessons learned from an international study. International Marketing Review, 32(3/4), 307-328. doi:10.1108/IMR-10-201 3-0242

Cohen, J. (1988). Statistical power analysis for the behavioral sciences (Second edition). Erlbaum Associates, Hillsdale.

Collins, C. J. (2007). The interactive effects of recruitment practices and product awareness on job seekers' employer knowledge and application behaviors. The Journal of applied psychology, 92(1), 180-190. doi:10.1037/0021-9010.92 .1 .180

Cook, T. D., \& Campbell, D. T. (1979). Quasi-experimentation: Design and analysis for field settings. Rand McNally Chicago.

Corley, K. G., \& Gioia, D. A. (2004). Identity Ambiguity and Change in the Wake of a Corporate Spin-off. Administrative Science Quarterly, 49(2), 173208. doi:10.2307/4131471

Cova, B., \& Salle, R. (2007). The industrial/consumer marketing dichotomy revisited: A case of outdated justification? Journal of Business $\mathcal{E}$ Industrial Marketing, 23(1), 3-11. doi:10.1108/08858620810841443

Cretu, A. E., \& Brodie, R. J. (2007). The influence of brand image and company reputation where manufacturers market to small firms: A customer value perspective. Industrial Marketing Management, 36(2), 230-240. doi:10.1016 /j.indmarman.2005.08.013

Davis, D. F., Golicic, S. L., \& Marquardt, A. J. (2008). Branding a B2B service: Does a brand differentiate a logistics service provider? Industrial Marketing Management, 37(2), 218-227. doi:10.1016/j.indmarman.2007.02.003

Deutsche Post DHL Group. (2016). The DHL Innovation Center. Bonn. Retrieved November 13, 2018, from https: / / www.dhl.de / en / ueberuns/innovation/dhl_innovation_center.html

Diamond, N., Sherry, J. F., Jr., Muñiz, A. M., McGrath, M. A., Kozinets, R. V., \& Borghini, S. (2009). American Girl and the Brand Gestalt: Closing the Loop on Sociocultural Branding Research. Journal of Marketing, 73(3), 118-134. doi:10.1509/jmkg.73.3.118

Dijkstra, T. K., \& Henseler, J. (2011). Linear indices in nonlinear structural equation models: Best fitting proper indices and other composites. Quality E Quantity, 45(6), 1505-1518. doi:10.1007/s11135-010-9359-Z

Dijkstra, T. K., \& Henseler, J. (2015a). Consistent and asymptotically normal PLS estimators for linear structural equations. Computational Statistics $\mathcal{E}$ Data Analysis, 81, 10-23. doi:10.1016/j.csda.2014.07.008

Dijkstra, T. K., \& Henseler, J. (2015b). Consistent Partial Least Squares Path Modeling. MIS Quarterly, 39(2), 297-316.

Dolbec, P.-Y., \& Chebat, J.-C. (2013). The Impact of a Flagship vs. a Brand Store on Brand Attitude, Brand Attachment and Brand Equity. Journal of Retailing, 89(4), 460-466. doi:10.1016/j.jretai.2013.06.003 
Doney, P. M., \& Cannon, J. P. (1997). An Examination of the Nature of Trust in Buyer-Seller Relationships. Journal of Marketing, 61(2), 35. doi:10.2307/125 1829

Dong, P., \& Siu, N. Y.-M. (2013). Servicescape elements, customer predispositions and service experience: The case of theme park visitors. Tourism Management, 36, 541-551. doi:10.1016/j.tourman.2012.09.004

Dourish, P. (2004). Where the action is: The foundations of embodied interaction (1. MIT Press paperback ed.). A Bradford book. Cambridge, Mass.: MIT Press.

Doyle, S. A., Moore, C. M., Doherty, A. M., \& Hamilton, M. (2008). Brand context and control: The role of the flagship store in B\&B Italia. International Journal of Retail \& Distribution Management, 36(7), 551-563. doi:10.1108/o9 590550810880589

Dunham, D. (2015). Nothing Kills a Bad Product Faster than Good Advertising. Retrieved December 8, 2018, from https://www.varsitybranding.com/20 15/05/14/nothing-kills-a-bad-product-faster-than-good-advertising/

Ekman, P. (1992). An argument for basic emotions. Cognition \& emotion, 6(3-4), 169-200.

Ernst, H., Hoyer, W. D., \& Rübsaamen, C. (2010). Sales, Marketing, and Researchand-Development Cooperation Across New Product Development Stages: Implications for Success. Journal of Marketing, 74(5), 80-92. doi:10.1509 /jmkg.74.5.80

Fishbein, M., \& Ajzen, I. (1975). Belief, attitude, intention and behavior: An introduction to theory and research. Addison-Wesley series in social psychology. Reading, Mass.: Addison-Wesley.

Flick, U. (2009). An introduction to qualitative research (4. ed., rev., expanded and updated.). Los Angeles, Calif.: Sage Publications.

Fornell, C., \& Larcker, D. F. (1981). Evaluating Structural Equation Models with Unobservable Variables and Measurement Error. Journal of marketing research, 18(1), 39-50. doi:10.2307/3151312

Fortune. (2017). World's most admired companies 2017. Retrieved December 18, 2018, from http://fortune.com/worlds-most-admired-companies/ 2017

Foster, J., \& McLelland, M. A. (2015). Retail atmospherics: The impact of a brand dictated theme. Journal of Retailing and Consumer Services, 22, 195205. doi:10.1016/j.jretconser.2014.07.002

Fournier, S. (1998). Consumers and Their Brands: Developing Relationship Theory in Consumer Research. Journal of Consumer Research, 24(4), 343353. doi:10.1086/209515

Franke, G., \& Sarstedt, M. (2018). Heuristics Versus Statistics in Discriminant Validity Testing: A Comparison of Four Procedures. Internet Research, forthcoming.

Fransen, M. L., van Rompay, T. J. L., \& Muntinga, D. G. (2013). Increasing sponsorship effectiveness through brand experience. International Journal of Sports Marketing and Sponsorship, 14(2), 37-50. doi:10.1108/IJSMS-14-022013-Boo4

Gainer, B. (1995). Ritual and relationships: Interpersonal influences on shared consumption. Journal of Business Research, 32(3), 253-260. doi:10.1016/014 8-2963(94)00050-O 
Geiger, I. (2017). A model of negotiation issue-based tactics in business-tobusiness sales negotiations. Industrial Marketing Management, 64, 91-106. doi:10.1016/j.indmarman.2017.02.003

General Electric Company. (2015). GE Celebrates Grand Opening of MebaneBased Customer Experience Center; Showcases Advanced Manufacturing. Retrieved March 28, 2016, from http://www.geindustrial.com/news/gecelebrates-grand-opening-mebane-based-customer-experience-centershowcases-advanced

Gentile, C., Spiller, N., \& Noci, G. (2007). How to Sustain the Customer Experience. European Management Journal, 25(5), 395-410. doi:10.1016/j.emj.2007 .08 .005

Gibson, J. J. (1986). The ecological approach to visual perception. New York: Psychology Press.

Gilmore, J. H., \& Pine, B. J. (2002). Customer experience places: The new offering frontier. Strategy \& Leadership, 30(4), 4-11. doi:10.1108/10878570210435306

Gomes, M., Fernandes, T., \& Brandão, A. (2016). Determinants of brand relevance in a B2B service purchasing context. Journal of Business $\mathcal{E}$ Industrial Marketing, 31(2), 193-204. doi:10.1108/JBIM-08-2014-0151

Gopalakrishna, S., Lilien, G. L., Williams, J. D., \& Sequeira, I. K. (1995). Do Trade Shows Pay off? Journal of Marketing, 59(3), 75. doi:10.2307/1252121

Gordon, G. L., Calantone, R. J., \& Di Benedetto, C. A. (1993). Brand Equity in the Business-to-Business Sector. Journal of Product $\mathcal{E}$ Brand Management, 2(3), 4-16. doi:10.1108/10610429310046689

Grewal, D., Krishnan, R., Baker, J., \& Borin, N. (1998). The effect of store name, brand name and price discounts on consumers' evaluations and purchase intentions. Journal of Retailing, 74(3), 331-352. doi:10.1016/Soo22-4359(99 80099-2

Grewal, R., \& Lilien, G. L. (2012). Business-to-business marketing: looking back, looking forward. In G. L. Lilien \& R. Grewal (Eds.), Handbook of business-to-business marketing (pp. 3-12). Cheltenham, UK: Edward Elgar.

Guercini, S., La Rocca, A., Runfola, A., \& Snehota, I. (2014). Interaction behaviors in business relationships and heuristics: Issues for management and research agenda. Industrial Marketing Management, 43(6), 929-937. doi:10.1016/j.indmarman.2014.05.007

Hair, J. F., Hult, G. T. M., Ringle, C. M., \& Sarstedt, M. (2017). A primer on partial least squares structural equation modeling (PLS-SEM) (Second edition). Los Angeles: Sage Publications.

Håkansson, H. (Ed.). (1982). International marketing and purchasing of industrial goods: An interaction approach (repr). New York: John Wiley \& Sons.

Håkansson, H., Ford, D., Gadde, L.-E., Snehota, I., \& Waluszewski, A. (2009). Business in networks. Chichester: Wiley.

Håkansson, H., \& Snehota, I. (Eds.). (1995). Developing relationships in business networks (1. ed., 1. publ). London u.a.: Routledge.

Hassenzahl, M., Diefenbach, S., \& Göritz, A. (2010). Needs, affect, and interactive products - Facets of user experience. Interacting with Computers, 22(5), 353-362. doi:10.1016/j.intcom.2010.04.002

Helkkula, A. (2011). Characterising the concept of service experience. Journal of Service Management, 22(3), 367-389. doi:10.1108/09564231111136872 
Helkkula, A., Kelleher, C., \& Pihlström, M. (2012). Characterizing Value as an Experience. Journal of Service Research, 15(1), 59-75. doi:10.1177/10946705 11426897

Henseler, J. (2016). New developments in PLS path modeling. Industrial Management $\mathcal{E}$ Data Systems, 116(9), 1842-1848. doi:10.1108/IMDS-09-2016-0366

Henseler, J. (2017a). Bridging Design and Behavioral Research With VarianceBased Structural Equation Modeling. Journal of Advertising, 46(1), 178-192. doi:10.1080/00913367.2017.1281780

Henseler, J. (2017b). Partial least squares path modeling. In P. S. H. Leeflang, J. E. Wieringa, T. H. Bijmolt, \& K. H. Pauwels (Eds.), Advanced Methods for Modeling Markets (pp. 361-381). International Series in Quantitative Marketing. doi:10.1007/978-3-319-53469-5\{ \textunderscore $\} 12$

Henseler, J. (2018). Partial least squares path modeling: Quo vadis? Quality $\mathcal{E}$ Quantity, 52(1), 1-8. doi:10.1007/s11135-018-0689-6

Henseler, J., \& Dijkstra, T. K. (2015). ADANCO 2.o. Kleve, Germany: Composite Modeling.

Henseler, J., Dijkstra, T. K., Sarstedt, M., Ringle, C. M., Diamantopoulos, A., Straub, D. W., ... Calantone, R. J. (2014). Common Beliefs and Reality About PLS. Organizational Research Methods, 17(2), 182-209. doi:10.1177/1 094428114526928

Henseler, J., Hubona, G., \& Ray, P. A. (2016). Using PLS path modeling in new technology research: Updated guidelines. Industrial Management $\mathcal{E}$ Data Systems, 116(1), 2-20. doi:10.1108/IMDS-09-2015-0382

Henseler, J., Ringle, C. M., \& Sarstedt, M. (2015). A new criterion for assessing discriminant validity in variance-based structural equation modeling. Journal of the Academy of Marketing Science, 43(1), 115-135. doi:10.1007/s11 747-014-0403-8

Henseler, J., Ringle, C. M., \& Sinkovics, R. R. (2009). The Use of Partial Least Squares Path Modeling in International Marketing. Advances in International Marketing, 20, 277-319. doi:10.1108/S1474-7979(2009)0oooo20014

Hermida, R. (2015). The problem of allowing correlated errors in structural equation modeling: concerns and considerations. Computational Methods in Social Sciences, 3(1), 5-17.

Hines, T., \& Bruce, M. (Eds.). (2007). Fashion marketing: Contemporary issues (2nd ed.). Amsterdam: Butterworth-Heinemann.

Hirschman, E. C., \& Holbrook, M. B. (1982). Hedonic Consumption: Emerging Concepts, Methods and Propositions. Journal of Marketing, 46(3), 92. doi:1 $0.2307 / 1251707$

Hoch, S. J. (2002). Product Experience Is Seductive. Journal of Consumer Research, 29(3), 448-454. doi:10.1086/344422

Holbrook, A. L., Krosnick, J. A., Carson, R. T., \& Mitchell, R. C. (2000). Violating Conversational Conventions Disrupts Cognitive Processing of Attitude Questions. Journal of Experimental Social Psychology, 36(5), 465-494. doi:10 .1006/jesp.1999.1411

Holbrook, M. B. (1999). Introduction to Consumer Value. In M. B. Holbrook (Ed.), Consumer value (pp. 1-28). Routledge interpretive marketing research series. London u.a.: Routledge.

Holbrook, M. B. (2006). Consumption experience, customer value, and subjective personal introspection: An illustrative photographic essay. Journal of Business Research, 59(6), 714-725. doi:10.1016/j.jbusres.2006.01.008 
Holbrook, M. B., \& Hirschman, E. C. (1982). The Experiential Aspects of Consumption: Consumer Fantasies, Feelings, and Fun. Journal of Consumer Research, 9(2), 132. doi:10.1086/208906

Hollenbeck, C. R., Peters, C., \& Zinkhan, G. M. (2008). Retail Spectacles and Brand Meaning: Insights from a Brand Museum Case Study. Journal of Retailing, 84(3), 334-353. doi:10.1016/j.jretai.2008.05.003

Holmström, J., Ketokivi, M., \& Hameri, A.-P. (2009). Bridging Practice and Theory: A Design Science Approach. Decision Sciences, 40(1), 65-87. doi:1 $0.1111 /$ j.1540-5915.2008.00221.x

Homburg, C., Klarmann, M., \& Schmitt, J. (2010). Brand awareness in business markets: When is it related to firm performance? International Journal of Research in Marketing, 27(3), 201-212. doi:10.1016/j.ijresmar.2010.03.004

Honeywell Safety Products. (2016). Honeywell Life Safety Training \& Customer Experience Center. Retrieved November 13, 2018, from http: / / www. honeywellsafety.com/USA/Training/CEC/

Hu, L. t., \& Bentler, P. M. (1999). Cutoff criteria for fit indexes in covariance structure analysis: Conventional criteria versus new alternatives. Structural Equation Modeling: A Multidisciplinary Journal, 6(1), 1-55. doi:10.1080 /10705519909540118

Hui, M. K., \& Bateson, J. E. G. (1991). Perceived Control and the Effects of Crowding and Consumer Choice on the Service Experience. Journal of Consumer Research, 18(2), 174. doi:10.1086/209250

Hüttinger, L., Schiele, H., \& Veldman, J. (2012). The drivers of customer attractiveness, supplier satisfaction and preferred customer status: A literature review. Industrial Marketing Management, 41(8), 1194-1205. doi:10.1016 /j.indmarman.2012.10.004

Hutton, J. G. (1997). A study of brand equity in an organizational-buying context. Journal of Product \& Brand Management, 6(6), 428-439. doi:10.1108 /10610429710190478

Iglesias, O., Singh, J. J., \& Batista-Foguet, J. M. (2011). The role of brand experience and affective commitment in determining brand loyalty. Journal of Brand Management, 18(8), 570-582. doi:10.1057/bm.2010.58

Interbrand. (2016). Best Global Brands 2016: Anatomy of Growth. Retrieved March 8, 2017, from www.bestglobalbrands.com

Interbrand. (2018). Best Global Brands 2018: Activating Brave. Retrieved November 8, 2018, from www.bestglobalbrands.com

Iyer, G. R., Hong Xiao, S., Sharma, A., \& Nicholson, M. (2015). Behavioral issues in price setting in business-to-business marketing: A framework for analysis. Industrial Marketing Management, 47, 6-16. doi:10.1016/j. indmarman.2015.02.001

Jain, R., Aagja, J., \& Bagdare, S. (2017). Customer experience - a review and research agenda: A review and research agenda. Journal of Service Theory and Practice, 27(3), 642-662. doi:10.1108/JSTP-03-2015-0064

Jarvis, C. B., MacKenzie, S. B., \& Podsakoff, P. M. (2003). A Critical Review of Construct Indicators and Measurement Model Misspecification in Marketing and Consumer Research. Journal of Consumer Research, 30(2), 199-218. doi:10.1086/376806

Jelić, A., Tieri, G., de Matteis, F., Babiloni, F., \& Vecchiato, G. (2016). The Enactive Approach to Architectural Experience: A Neurophysiological 
Perspective on Embodiment, Motivation, and Affordances. Frontiers in psychology, 7, 481. doi:10.3389/fpsyg.2016.00481

Jensen, M. B., \& Klastrup, K. (2008). Towards a B2B customer-based brand equity model. Journal of Targeting, Measurement and Analysis for Marketing, 16(2), 122-128. doi:10.1057/jt.2008.4

Joy, A., Wang, J. J., Chan, T.-S., Sherry, J. F., Jr., \& Cui, G. (2014). M(Art)Worlds: Consumer Perceptions of How Luxury Brand Stores Become Art Institutions. Journal of Retailing, 90(3), 347-364. doi:10.1016/j.jretai.2014.01.002

Kagelmann, H. J. (1998). Grundlegende Bemerkungen zum organisierten Vergnügen. In M. Rieder, R. Bachleitner, \& H. J. Kagelmann (Eds.), ErlebnisWelten (Vol. Bd. 4, pp. 58-94). Reihe tourismuswissenschaftliche Manuskripte. München [u.a.]: Profil.

Kapferer, J.-N. (2012). The new strategic brand management: Advanced insights and strategic thinking (5. ed.). London: Kogan Page. Retrieved from http: //site.ebrary.com/lib/alltitles/docDetail.action?docID=10538221

Kelleher, C., \& Peppard, J. (2011). Consumer Experience of Value Creation-a Phenomenological Perspective. ACR European Advances.

Keller, K. L. (2013). Strategic brand management: Building, measuring, and managing brand equity (Fourth edition, global edition). Always learning. Boston, Mass.: Pearson. Retrieved from http:/ /lib.myilibrary.com/detail.asp?id=5 23713

Keller, K. L., \& Lehmann, D. R. (2006). Brands and Branding: Research Findings and Future Priorities. Marketing Science, 25(6), 740-759. doi:10.1287/mksc. 1050.0153

Kemp, E. A., Borders, A. L., Anaza, N. A., \& Johnston, W. J. (2018). The heart in organizational buying: Marketers' understanding of emotions and decision-making of buyers. Journal of Business $\mathcal{E}$ Industrial Marketing, 33(1), 19-28. doi:10.1108/JBIM-06-2017-0129

Kent, T. (2012). Concepts of flagships. In T. Kent \& R. Brown (Eds.), Flagship Marketing (pp. 8-19). Routledge.

Kent, T., \& Brown, R. (Eds.). (2012). Flagship Marketing: Concepts and Places. Routledge.

Keränen, J., \& Jalkala, A. M. (2013). Towards a framework of customer value assessment in B2B markets: An exploratory study. Industrial Marketing Management, 42(8), 1307-1317. doi:10.1016/j.indmarman.2013.06.010

Keränen, J., Piirainen, K. A., \& Salminen, R. T. (2012). Systematic review on B2B branding: Research issues and avenues for future research. Journal of Product \& Brand Management, 21(6), 404-417. doi:10.1108/10610421211264 892

Kerin, R. A. (1996). In Pursuit of an Ideal: The Editorial and Literary History of the Journal of Marketing. Journal of Marketing, 60(1), 1-13.

Kerin, R. A., Jain, A., \& Howard, D. J. (1992). Store shopping experience and consumer price-quality-value perceptions. Journal of Retailing, 68(4), 376.

Khan, I., \& Fatma, M. (2017). Antecedents and outcomes of brand experience: An empirical study. Journal of Brand Management, 24(5), 439-452. doi:10.1 057/s41262-017-0040-X

Khan, I., \& Rahman, Z. (2015). Brand experience anatomy in retailing: An interpretive structural modeling approach. Journal of Retailing and Consumer Services, 24, 60-69. doi:10.1016/j.jretconser.2015.02.003 
Khan, I., \& Rahman, Z. (2016). Retail brand experience: Scale development and validation. Journal of Product \& Brand Management, 25(5), 435-451. doi:10.1108/JPBM-07-2015-0943

Kilian, K. (2009). Experiential Marketing and Brand Experiences: A Conceptual Framework. In A. Lindgreen, J. Vanhamme, \& M. B. Beverland (Eds.), Memorable customer experiences (pp. 25-44). Farnham: Gower.

Kirchgeorg, M., Springer, C., \& Brühe, C. (2009). Live Communication Management: Ein strategischer Leitfaden zur Konzeption, Umsetzung und Erfolgskontrolle (1. Aufl.). Wiesbaden: Gabler.

Kirchgeorg, M., Springer, C., \& Ermer, B. (2012). Brand Lands - Inszenierung begehbarer Erlebniswelten für den Kunden. In M. Bruhn \& K. Hadwich (Eds.), Customer Experience (pp. 296-316). Wiesbaden: Gabler Verlag.

Kirchgeorg, M., Springer, C., \& Kästner, E. (2010). Objectives for successfully participating in trade shows. Journal of Business $\mathcal{E}$ Industrial Marketing, 25(1), 63-72. doi:10.1108/08858621011009164

Klaus, P., \& Maklan, S. (2012). EXQ: A multiple-item scale for assessing service experience. Journal of Service Management, 23(1), 5-33. doi:10.1108/095642 31211208952

Kock, N. (2018). Single missing data imputation in PLS-based structural equation modeling. Journal of Modern Applied Statistical Methods, 17(1). doi:10.2 2237/jmasm/1525133160

Kolb, D. A. (1984). Experiential learning: Experience as the source of learning and development. Englewood Cliffs NJ: Prentice-Hall.

Kotler, P. (1973). Atmospherics as a Marketing Tool. Journal of Retailing, 49(4), 48-64.

Kotler, P., \& Pfoertsch, W. (2006). B2B brand management. Berlin: Springer.

Kotler, P., \& Pfoertsch, W. (2007). Being known or being one of many: the need for brand management for business-to-business (B2B) companies. Journal of Business \& Industrial Marketing, 22(6), 357-362.

Kozinets, R. V., Sherry, J. F., Jr., DeBerry-Spence, B., Duhachek, A., Nuttavuthisit, K., \& Storm, D. (2002). Themed flagship brand stores in the new millennium. Journal of Retailing, 78(1), 17-29. doi:10.1016/Soo22-4359(01)00063-X

Kozinets, R. V., Sherry, J. F., Jr., Storm, D., Duhachek, A., Nuttavuthisit, K., \& DeBerry-Spence, B. (2004). Ludic Agency and Retail Spectacle. Journal of Consumer Research, 31(3), 658-672. doi:10.1086/425101

Kranzbühler, A.-M., Kleijnen, M. H., Morgan, R. E., \& Teerling, M. (2018). The Multilevel Nature of Customer Experience Research: An Integrative Review and Research Agenda. International Journal of Management Reviews, 20(2), 433-456. doi:10.1111/ijmr.12140

Krishna, A., Elder, R. S., \& Caldara, C. (2010). Feminine to smell but masculine to touch? Multisensory congruence and its effect on the aesthetic experience. Journal of Consumer Psychology, 20(4), 410-418. doi:10.1016/j.jcps.201 0.06.010

Kuhn, K. A. L., Alpert, F., \& Pope, N. K. L. (2008). An application of Keller's brand equity model in a $\mathrm{B} 2 \mathrm{~B}$ context. Qualitative Market Research: An International Journal, 11(1), 40-58. doi:10.1108/13522750810845540

Kumar, V. (2015). Evolution of Marketing as a Discipline: What Has Happened and What to Look Out For. Journal of Marketing, 79(1), 1-9. doi:10.1509 /jm.79.1.1 
Landis, R. S., Edwards, B. D., \& Cortina, J. M. (2009). On the Practice of Allowing Correlated Residuals Among Indicators in Structural Equation Models. In C. E. Lance \& R. J. Vandenberg (Eds.), Statistical and methodological myths and urban legends (pp. 193-215). New York: Routledge.

Lee, C. H., \& Kim, S. Y. (2008). Differential effects of determinants on multidimensions of trade show performance: By three stages of pre-show, at-show, and post-show activities. Industrial Marketing Management, 37(7), 784-796. doi:10.1016/j.indmarman.2008.01.006

Leek, S., \& Christodoulides, G. (2011a). A literature review and future agenda for B2B branding: Challenges of branding in a $\mathrm{B}_{2} \mathrm{~B}$ context. Industrial Marketing Management, 40(6), 830-837. doi:10.1016/j.indmarman.2011.06 .006

Leek, S., \& Christodoulides, G. (2011b). Brands: Just for consumers? Introduction to the special issue on $\mathrm{B} 2 \mathrm{~B}$ branding. Industrial Marketing Management. doi:10.1016/j.indmarman.2011.09.019

Leek, S., \& Christodoulides, G. (2012). A framework of brand value in B2B markets: The contributing role of functional and emotional components. Industrial Marketing Management, 41(1), 106-114. doi:10.1016/j.indmarman. 2011.11.009

Leiner, D. J. (2013). Too Fast, Too Straight, Too Weird: Post Hoc Identification of Meaningless Data in Internet Surveys. SSRN Electronic Journal. doi:10.2 139/ssrn.2361661

Leischnig, A., \& Enke, M. (2011). Brand stability as a signaling phenomenon - An empirical investigation in industrial markets. Industrial Marketing Management, 4O(7), 1116-1122. doi:10.1016/j.indmarman.2011.09.001

Lemke, F., Clark, M., \& Wilson, H. (2011). Customer experience quality: An exploration in business and consumer contexts using repertory grid technique. Journal of the Academy of Marketing Science, 39(6), 846-869. doi:10.1007/s11747-010-0219-0

Lemon, K. N., \& Verhoef, P. C. (2016). Understanding Customer Experience Throughout the Customer Journey. Journal of Marketing, 8o(6), 69-96. doi:10.1509/jm.15.0420

Libai, B., Bolton, R., Bügel, M. S., de Ruyter, K., Götz, O., Risselada, H., \& Stephen, A. T. (2010). Customer-to-Customer Interactions: Broadening the Scope of Word of Mouth Research. Journal of Service Research, 13(3), 267-282. doi:10.1177/1094670510375600

Lilien, G. L. (2016). The B2B Knowledge Gap. International Journal of Research in Marketing, 33(3), 543-556. doi:10.1016/j.ijresmar.2016.01.003

Lindgreen, A., Beverland, M. B., \& Farrelly, F. (2010). From strategy to tactics: Building, implementing, and managing brand equity in business markets. Industrial Marketing Management, 39(8), 1223-1225. doi:10.1016 /j.indmarman.2010.02.018

Lindgreen, A., Hingley, M. K., Grant, D. B., \& Morgan, R. E. (2012). Value in business and industrial marketing: Past, present, and future. Industrial Marketing Management, 41(1), 207-214. doi:10.1016/j.indmarman.2011.11 .025

Lusch, R. F., Vargo, S. L., \& O'Brien, M. (2007). Competing through service: Insights from service-dominant logic. Journal of Retailing, 83(1), 5-18. doi:10.1016/j.jretai.2006.10.002 
Lynch, J., \& de Chernatony, L. (2004). The power of emotion: Brand communication in business-to-business markets. Journal of Brand Management, 11(5), 403-419. doi:10.1057/palgrave.bm.2540185

Lynch, J., \& de Chernatony, L. (2007). Winning Hearts and Minds: Business-toBusiness Branding and the Role of the Salesperson. Journal of marketing management, 23(1-2), 123-135. doi:10.1362/026725707 X178594

Mack Trucks Inc. (2016). Customer Center. Retrieved November 13, 2018, from http://www.macktrucks.com/about-mack/customer-center/

Maclaran, P., \& Brown, S. (2005). The Center Cannot Hold: Consuming the Utopian Marketplace: Figure 1. Journal of Consumer Research, 32(2), 311323. doi:10.1086/432240

Madzharov, A. V., Block, L. G., \& Morrin, M. (2015). The Cool Scent of Power: Effects of Ambient Scent on Consumer Preferences and Choice Behavior. Journal of Marketing, 79(1), 83-96. doi:10.1509/jm.13.0263

Manlow, V., \& Nobbs, K. (2013). Form and function of luxury flagships. Journal of Fashion Marketing and Management: An International Journal, 17(1), 49-64. doi:10.1108/13612021311305137

Marketing Science Institute. (2014). Research Priorities 2014-2016. Cambridge, MA. Retrieved November 10, 2018, from http://www.msi.org/uploads/ files/MSI_RP14-16.pdf

Marketing Science Institute. (2016). Research Priorities 2016-2018. Cambridge, MA. Retrieved September 30, 2017, from http://www.msi.org/uploads/ articles/MSI_RP16-18.pdf

Marquardt, A. J. (2013). Relationship quality as a resource to build industrial brand equity when products are uncertain and future-based. Industrial Marketing Management, 42(8), 1386-1397. doi:10.1016/j.indmarman.2013.0 7.017

Massenbach, F. v. (2009). Automobile Erlebniswelten als Kommunikationsmittel: Eine verhaltenswissenschaftliche Analyse am Beispiel des Premiummarktes in Deutschland und Singapur (1. Aufl). VS Research : Europäische Kulturen in der Wirtschaftskommunikation. Wiesbaden: VS Verlag für Sozialwissenschaften.

Mathwick, C., Malhotra, N. K., \& Rigdon, E. E. (2001). Experiential value: Conceptualization, measurement and application in the catalog and Internet shopping. Journal of Retailing, 77(1), 39-56. doi:10.1016/Soo22-43 59(00)00045-2

Mayer, H. O. (2012). Interview und schriftliche Befragung: Grundlagen und Methoden empirischer Sozialforschung (6., überarbeitete Auflage). München: Oldenbourg.

Mayring, P. (2014). Qualitative content analysis: theoretical foundation, basic procedures and software solution. Klagenfurt. Retrieved, from http:// nbn-resolving.de/urn:nbn:de:o168-ssoar-395173

McKechnie, S., \& Tynan, C. (2008). Halloween in a material world: Trick or treat? Journal of marketing management, 24(9-10), 1011-1023. doi:10.1362/o $26725708 X_{3} 82028$

Mehrabian, A., \& Russell, J. A. (1974). An approach to environmental psychology. Cambridge Mass. u.a.: MIT Press.

Meinicke, B. (2003). Erlebniswelten als Instrument der Kundenbindung: Neue Wege der deutschen Automobilindustrie. Beiträge zur angewandten Sozialgeographie. Augsburg: Selbstverlag GeoAnwender Zentrum. 
Mencarelli, R., \& Rivière, A. (2015). Perceived value in B2B and B2C. Marketing Theory, 15(2), 201-220. doi:10.1177/1470593114552581

Merleau-Ponty, M. (1962). Phenomenology of perception, trans. Colin Smith. London: Routledge and Kegan Paul.

Merz, M. A., He, Y., \& Vargo, S. L. (2009). The evolving brand logic: A servicedominant logic perspective. Journal of the Academy of Marketing Science, 37(3), 328-344. doi:10.1007/s11747-009-0143-3

Messedat, J. (2007). Best designed flagship stores: Shops, showrooms, brand centers (1. ed). Ludwigsburg u.a.: avedition [u.a.]

Meyer, C., \& Schwager, A. (2007). Customer experience. Harvard Business Review, $85(2), 116-126$.

Meyer, G. G., Buijs, P., Szirbik, N. B., \& Wortmann, J. C. (2014). Intelligent products for enhancing the utilization of tracking technology in transportation. International Journal of Operations \& Production Management, 34(4), 422-446. doi:10.1108/IJOPM-11-2012-0530

Michaud Trevinal, A., \& Stenger, T. (2014). Toward a conceptualization of the online shopping experience. Journal of Retailing and Consumer Services, 21(3), 314-326. doi:10.1016/j.jretconser.2014.02.009

Michell, P., King, J., \& Reast, J. (2001). Brand Values Related to Industrial Products. Industrial Marketing Management, 30(5), 415-425. doi:10.1016/So 019-8501(99)00097-8

Mikunda, C. (2004). Brand lands, hot spots \& cool spaces. Welcome to the third place and the total marketing experience. London: Kogan Page.

Mitchell, M. A., \& Orwig, R. A. (2002). Consumer experience tourism and brand bonding. Journal of Product \& Brand Management, 11(1), 30-41. doi:10.1108/10610420210419531

Mitchell, V.-W., Schlegelmilch, B. B., \& Mone, S.-D. (2016). Why should I attend? The value of business networking events. Industrial Marketing Management, 52, 100-108. doi:10.1016/j.indmarman.2015.05.014

Mohan, M., Brown, B. P., Sichtmann, C., \& Schoefer, K. (2018). Perceived globalness and localness in B2B brands: A co-branding perspective. Industrial Marketing Management, 72, 59-70. doi:10.1016/j.indmarman.2018.03.014

Moore, C. M., \& Doherty, A. M. (2007). The international flagship stores of luxury fashion retailers. In T. Hines \& M. Bruce (Eds.), Fashion marketing (pp. 277-296). Amsterdam: Butterworth-Heinemann.

Moore, C. M., Doherty, A. M., \& Doyle, S. A. (2010). Flagship stores as a market entry method: The perspective of luxury fashion retailing. European Journal of Marketing, 44(1/2), 139-161. doi:10.1108/03090561011008646

Moore, C. M., Fernie, J., \& Burt, S. (2000). Brands without boundaries - The internationalisation of the designer retailer's brand. European Journal of Marketing, 34(8), 919-937. doi:10.1108/03090560010331414

Moorman, C., Zaltman, G., \& Deshpande, R. (1992). Relationships between providers and users of market research: The dynamics of trust. Journal of marketing research, 29(3), 314-328.

Mora Cortez, R., \& Johnston, W. J. (2017). The future of B2B marketing theory: A historical and prospective analysis. Industrial Marketing Management, 66, 90-102. doi:10.1016/j.indmarman.2017.07.017

Morgan-Thomas, A., \& Veloutsou, C. (2013). Beyond technology acceptance: Brand relationships and online brand experience. Journal of Business Research, 66(1), 21-27. doi:10.1016/j.jbusres.2011.07.019 
Morgan, R. M., \& Hunt, S. D. (1994). The Commitment-Trust Theory of Relationship Marketing. Journal of Marketing, 58(3), 20. doi:10.2307/1252308

Mudambi, S. (2002). Branding importance in business-to-business markets. Industrial Marketing Management, 31(6), 525-533. doi:10.1016/Soo19-8501 (02)00184-0

Mudambi, S., Doyle, P., \& Wong, V. (1997). An exploration of branding in industrial markets. Industrial Marketing Management, 26(5), 433-446. doi:1 0.1016/Soo19-8501(96)00151-4

Müller, T., Schuberth, F., \& Henseler, J. (2018). PLS path modeling - a confirmatory approach to study tourism technology and tourist behavior. Journal of Hospitality and Tourism Technology, 9(3), 249-266. doi:10.1108/JHTT-o92017-0106

Nitzl, C., Roldán, J. L., \& Cepeda, G. (2016). Mediation analysis in partial least squares path modeling. Industrial Management \& Data Systems, 116(9), 1849-1864. doi:10.1108/IMDS-07-2015-0302

Nobbs, K., Moore, C. M., \& Sheridan, M. (2012). The flagship format within the luxury fashion market. International Journal of Retail $\mathcal{E}$ Distribution Management, 40(12), 920-934. doi:10.1108/09590551211274928

Noë, A. (2006). Action in perception (1. MIT Press paperback ed.). Representation and mind. Cambridge, Mass.: MIT Press.

Nufer, G., \& Scheurecker, V. (2008). Brand Parks als Form des dauerhaften EventMarketing. Reutlinger Diskussionsbeiträge zu Marketing \& Management. Tübingen: Universitätsbibliothek.

Nunnally, J. C., \& Bernstein, I. H. (1994). Psychometric Theory (McGraw-Hill Series in Psychology). McGraw-Hill New York.

Nysveen, H., Pedersen, P. E., \& Skard, S. (2013). Brand experiences in service organizations: Exploring the individual effects of brand experience dimensions. Journal of Brand Management, 20(5), 404-423. doi:10.1057/bm.20 12.31

O'Dell, T. (2010a). Experiencescapes: Blurring Borders and Testing Connections. In T. O'Dell (Ed.), Experiencescapes (pp. 11-33). Frederiksberg: Copenhagen Business School Press.

O'Dell, T. (Ed.). (2010b). Experiencescapes: Tourism, culture and economy (1. ed., 2. impr). Frederiksberg: Copenhagen Business School Press.

Oh, H., Fiore, A. M., \& Jeoung, M. (2007). Measuring Experience Economy Concepts: Tourism Applications. Journal of Travel Research, 46(2), 119-132. doi:10.1177/0047287507304039

Ohnemus, L. (2009). B2B branding: A financial burden for shareholders? Business horizons, 52(2), 159-166. doi:10.1016/j.bushor.2008.10.004

Oinonen, M., \& Jalkala, A. M. (2015). Divergent goals in supplier-customer co-development process: An integrated framework. The journal of business $\mathcal{E}$ industrial marketing, 30(3/4), 290-301.

Opaschowski, H. W. (2000). Kathedralen und Ikonen des 21. Jahrhunderts: Zur Faszination von Erlebniswelten. In A. Steinecke (Ed.), Erlebnis- und Konsumwelten (pp. 44-54). München: Oldenbourg.

Osborne, J. W. (2013). Best practices in data cleaning: A complete guide to everything you need to do before and after collecting your data. Los Angeles, Calif.: Sage Publications.

Österle, B., Kuhn, M. M., \& Henseler, J. (2016). An Inquiry into Brand Worlds in Industrial Marketing. In IMP Group (Ed.), 32nd Annual IMP Conference. 
Österle, B., Kuhn, M. M., \& Henseler, J. (2018a). Brand worlds: Introducing experiential marketing to $\mathrm{B} 2 \mathrm{~B}$ branding. Industrial Marketing Management, 72, 71-98. doi:10.1016/j.indmarman.2018.04.015

Österle, B., Kuhn, M. M., \& Henseler, J. (2018b). Differences between Brand Worlds in $\mathrm{B}_{2} \mathrm{C}$ and $\mathrm{B}_{2} \mathrm{~B}$ : Extended Abstract. In IMP Group (Ed.), 34th Annual IMP Conference.

Österle, B., Kuhn, M. M., \& Henseler, J. (2018c). The Dynamic Nature of Brand Experience. In Academy of Marketing Science (Ed.), Proceedings of the 21st World Marketing Congress.

Patrício, L., Fisk, R. P., Falcão e Cunha, J., \& Constantine, L. (2011). Multilevel Service Design: From Customer Value Constellation to Service Experience Blueprinting. Journal of Service Research, 14(2), 180-200. doi:10.1177/10946 70511401901

Peffers, K., Tuunanen, T., Rothenberger, M. A., \& Chatterjee, S. (2007). A Design Science Research Methodology for Information Systems Research. Journal of Management Information Systems, 24(3), 45-77. doi:10.2753/MISo742-122 2240302

Penaloza, L. (1998). Just Doing It: A Visual Ethnographic Study of Spectacular Consumption Behavior at Nike Town. Consumption, Markets and Culture, 2(4), 337-465.

Pine, B. J., \& Gilmore, J. H. (1998). Welcome to the Experience Economy. Harvard Business Review, 76(4), 97-105.

Pine, B. J., \& Gilmore, J. H. (1999). The experience economy: Work is theatre \& every business a stage. Boston: Harvard Business School Press.

Plutchik, R. (1980). A general psychoevolutionary theory of emotion. Theories of emotion, 1(3-31), 4 .

Poulsson, S. H., \& Kale, S. H. (2004). The Experience Economy and Commercial Experiences. The Marketing Review, 4(3), 267-277. doi:10.1362/1469347042 223445

Prahalad, C. K. (2004). The Cocreation of Value: Invited Commentaries on "Evolving to a New Dominant Logic for Marketing". Journal of Marketing, 68(1), 23. doi:10.1509/jmkg.68.1.18.24035

Prahalad, C. K., \& Ramaswamy, V. (2004). Co-creation experiences: The next practice in value creation. Journal of Interactive Marketing, 18(3), 5-14. doi:10.1002/dir.20015

Prebensen, N. K., \& Xie, J. (2017). Efficacy of co-creation and mastering on perceived value and satisfaction in tourists' consumption. Tourism Management, 60, 166-176. doi:10.1016/j.tourman.2016.12.001

Raddats, C., \& Easingwood, C. (2010). Services growth options for B2B productcentric businesses. Industrial Marketing Management, 39(8), 1334-1345. doi:10.1016/j.indmarman.2010.03.002

Rapp, A., Baker, T. L., Bachrach, D. G., Ogilvie, J., \& Beitelspacher, L. S. (2015). Perceived customer showrooming behavior and the effect on retail salesperson self-efficacy and performance. Journal of Retailing, 91(2), 358-369. doi:10.1016/j.jretai.2014.12.007

Raykov, T. (1996). Estimation of Composite Reliability for Congeneric Measures. Applied Psychological Measurement, 21(2), 173-184. doi:10.1177/0146621697 0212006 
Reichardt, C. S. (2009). Quasi-Experimental Design. In R. Millsap \& A. MaydeuOlivares (Eds.), The Sage Handbook of Quantitative Methods in Psychology (pp. 46-71). doi:10.4135/9780857020994.n3

Reputation Institute. (2017). 2017 US RepTrak 100: The Most Reputable Companies in the US. Reputation Institute.

Richins, M. L. (1997). Measuring Emotions in the Consumption Experience. Journal of Consumer Research, 24(2), 127-146. doi:10.1086/209499

Riewoldt, O. (2002). Brandscaping: Worlds of experience in retail design: Erlebnisdesign für Einkaufswelten. Basel: Birkhauser-Publishers for Architecture.

Rinallo, D., Borghini, S., \& Golfetto, F. (2010). Exploring visitor experiences at trade shows. Journal of Business \& Industrial Marketing, 25(4), 249-258. doi:10.1108/08858621011038207

Rindskopf, D. (1984). Structural equation models: Empirical identification, Heywood cases, and related problems. Sociological Methods \& Research, 13(1), 109-119.

Roost, F. (2008). Branding Center: Über den Einfluss globaler Markenkonzerne auf die Innenstädte: [Branding Center: On the Influence of global brand enterprises on city centers] (1. Aufl). SpringerLink : Bücher. Wiesbaden: VS, Verl. für Sozialwiss.

Saari, U. A., \& Mäkinen, S. J. (2016). Study on the capability to measure stakeholders' brand experiences with a consumer-centric measurement framework. In Bridging Asia and the World: Global Platform for Interface between Marketing and Management (pp. 1034-1035). Global marketing conference proceeding. doi:10.15444/GMC2016.07.07.03

Sánchez, J., Callarisa, L., Rodríguez, R. M., \& Moliner, M. A. (2006). Perceived value of the purchase of a tourism product. Tourism Management, 27(3), 394-409. doi:10.1016/j.tourman.2004.11.007

Saunders, J. A., \& Watt, F. (1979). Do brand names differentiate identical industrial products? Industrial Marketing Management, 8(2), 114-123. doi:1 0.1016/0019-8501(79)90051-8

Schmitt, B. H. (1999a). Experiential Marketing. Journal of marketing management, 15(1-3), 53-67. doi:10.1362/026725799784870496

Schmitt, B. H. (1999b). Experiential marketing: How to get customers to sense, feel, think, act and relate to your company and brands. New York NY: Free Press.

Schmitt, B. H. (2009). The concept of brand experience. Journal of Brand Management, 16(7), 417-419. doi:10.1057/bm.2009.5

Schmitt, B. H., Brakus, J. J., \& Zarantonello, L. (2014). The current state and future of brand experience. Journal of Brand Management, 21(9), 727-733. doi:10.1057/bm.2014.34

Schmitt, B. H., \& Zarantonello, L. (2013). Consumer Experience and Experiential Marketing: A Critical Review. In R. W. Belk (Ed.), Qualitative Consumer Research (Vol. 10, pp. 25-61). Review of Marketing Research. doi:10.1108 /S1548-6435(2013)0000010006

Schuberth, F., Henseler, J., \& Dijkstra, T. K. (2018). Confirmatory Composite Analysis. Frontiers in Psychology, 9, 317. doi:10.3389/fpsyg.2018.02541

Schulze, G. (2005). The experience society. London: Sage Publications.

Seyedghorban, Z., Matanda, M. J., \& LaPlaca, P. (2016). Advancing theory and knowledge in the business-to-business branding literature. Journal of Business Research, 69(8), 2664-2677. doi:10.1016/j.jbusres.2015.11.002 
Shachar, R., Erdem, T., Cutright, K. M., \& Fitzsimons, G. J. (2011). Brands: The Opiate of the Nonreligious Masses? Marketing Science, 30(1), 92-110. doi:10.1287/mksc.1100.0591

Shadish, W. R., Cook, T. D., \& Campbell, D. T. (2002). Experimental and quasiexperimental designs for generalized causal inference. Belmont, Calif.: Wadsworth Cengage Learning.

Sherry, J. F., Jr. (1998). The Soul of the Company Store: Nike Town Chicago and the Emplaced Brandscape. In J. F. Sherry Jr. (Ed.), Servicescapes (pp. 109146). Lincolnwood, Ill.: NTC Business Books.

Sherry, J. F., Jr., Kozinets, R. V., Storm, D., Duhachek, A., Nuttavuthisit, K., \& DeBerry-Spence, B. (2001). Being in the Zone. Journal of Contemporary Ethnography, 30(4), 465-510. doi:10.1177/089124101030004005

Sheth, J. N., \& Sinha, M. (2015). B2B branding in emerging markets: A sustainability perspective. Industrial Marketing Management, 51, 79-88. doi:10.101 6/j.indmarman.2015.06.002

Shipley, D., \& Howard, P. (1993). Brand-naming industrial products. Industrial Marketing Management, 22(1), 59-66. doi:10.1016/o019-8501(93)90021-X

Simonin, B. L., \& Ruth, J. A. (1998). Is a Company Known by the Company It Keeps? Assessing the Spillover Effects of Brand Alliances on Consumer Brand Attitudes. Journal of marketing research, 35(1), 30. doi:10.2307/31519 28

Sinclair, S. A., \& Seward, K. E. (1988). Effectiveness of branding a commodity product. Industrial Marketing Management, 17(1), 23-33. doi:10.1016/oo198501(88)90023-5

Srivastava, N., Dash, S. B., \& Mookerjee, A. (2016). Determinants of brand trust in high inherent risk products. Marketing Intelligence \& Planning, 34(3), 394-420. doi:10.1108/MIP-01-2015-0004

Steinecke, A. (2002). Industrieerlebniswelten zwischen Heritage und Markt. Konzepte - Modelle - Trends. In A. Steinecke (Ed.), Tourismusforschung in Nordrhein-Westfalen (Vol. 15, pp. 143-159). Paderborner geographische Studien zu Tourismusforschung und Destinationsmanagement. Paderborn: Selbstverl. des Faches Geographie, FB 1, Univ. Paderborn.

Steinecke, A. (2004). Zur Phänomenologie von Marken-Erlebniswelten. In A. Brittner-Widmann, H.-D. Quack, \& H. Wachowiak (Eds.), Von Erholungsräumen zu Tourismusdestinationen (Vol. 27, pp. 201-220). Trierer geographische Studien. Trier: Selbstverl. der Geographischen Ges. [u.a.]

Sweeney, J. C., \& Soutar, G. N. (2001). Consumer perceived value: The development of a multiple item scale. Journal of Retailing, 77(2), 203-220. doi:10.1016/Soo22-4359(01)00041-o

Tafesse, W. (2016). Conceptualization of Brand Experience in an Event Marketing Context. Journal of Promotion Management, 22(1), 34-48. doi:10.1080/1 0496491.2015.1107007

Thiemer, J. (2004). Erlebnisbetonte Kommunikationsplattformen als mögliches Instrument der Markenführung: Dargestellt am Beispiel der Automobilindustrie. Kassel: Kassel University Press.

Thorbjørnsen, H., Supphellen, M., Nysveen, H., \& Pedersen, P. E. (2002). Building brand relationships online: A comparison of two interactive applications. Journal of Interactive Marketing, 16(3), 17-34. doi:10.1002/dir.10034

Tranfield, D., Denyer, D., \& Smart, P. (2003). Towards a Methodology for Developing Evidence-Informed Management Knowledge by Means of 
Systematic Review. British Journal of Management, 14(3), 207-222. doi:10.1 $111 / 1467-8551.00375$

Tynan, C., \& McKechnie, S. (2009). Experience marketing: A review and reassessment. Journal of marketing management, 25(5-6), 501-517. doi:10.1362 /o26725709X461821

van Aken, J., Chandrasekaran, A., \& Halman, J. (2016). Conducting and publishing design science research. Journal of Operations Management, 47-48, 1-8. doi:10.1016/j.jom.2016.06.004

van Boven, L., \& Gilovich, T. (2003). To do or to have? That is the question. Journal of Personality and Social Psychology, 85(6), 1193-1202. doi:10.1037/o 022-3514.85.6.1193

van Dijk, J. (2018). Designing for Embodied Being-in-the-World: A Critical Analysis of the Concept of Embodiment in the Design of Hybrids. Multimodal Technologies and Interaction, 2(1), 7. doi:10.3390/mti2010007

van Riel, A. C., Henseler, J., Kemény, I., \& Sasovova, Z. (2017). Estimating hierarchical constructs using consistent partial least squares: The case of second-order composites of common factors. Industrial Management $\mathcal{E}$ Data Systems, 117(3), 459-477. doi:10.1108/IMDS-07-2016-0286

van Riel, A. C., Pahud de Mortanges, C., \& Streukens, S. (2005). Marketing antecedents of industrial brand equity: An empirical investigation in specialty chemicals. Industrial Marketing Management, 34(8), 841-847. doi:1 0.1016/j.indmarman.2005.01.006

Vargo, S. L., \& Lusch, R. F. (2004). Evolving to a New Dominant Logic for Marketing. Journal of Marketing, 68(1), 1-17. doi:10.1509/jmkg.68.1.1.24036

Vargo, S. L., \& Lusch, R. F. (2008). Service-dominant logic: Continuing the evolution. Journal of the Academy of Marketing Science, 36(1), 1-10. doi:10.1 007/s11747-007-0069-6

Varshneya, G., \& Das, G. (2017). Experiential value: Multi-item scale development and validation. Journal of Retailing and Consumer Services, 34, 48-57. doi:10.1016/j.jretconser.2016.09.010

Varshneya, G., Das, G., \& Khare, A. (2017). Experiential value: A review and future research directions. Marketing Intelligence \& Planning, 35(3), 339357. doi:10.1108/MIP-05-2016-0075

Verhoef, P. C., Kannan, P. K., \& Inman, J. J. (2015). From Multi-Channel Retailing to Omni-Channel Retailing. Journal of Retailing, 91(2), 174-181. doi:10.101 6/j.jretai.2015.02.005

Verhoef, P. C., Lemon, K. N., Parasuraman, A., Roggeveen, A., Tsiros, M., \& Schlesinger, L. A. (2009). Customer Experience Creation: Determinants, Dynamics and Management Strategies. Journal of Retailing, 85(1), 31-41. doi:10.1016/j.jretai.2008.11.001

Voorhees, C. M., Brady, M. K., Calantone, R., \& Ramirez, E. (2016). Discriminant validity testing in marketing: An analysis, causes for concern, and proposed remedies. Journal of the Academy of Marketing Science, 44(1), 119-134. doi:10.1007/s11747-015-0455-4

Voss, K., \& Mohan, M. (2016). Good times, bad times: The stock market performance of firms that own high value brands. European Journal of Marketing, 50(5/6), 670-694. doi:10.1108/EJM-12-2013-0716

Walley, K., Custance, P., Taylor, S., Lindgreen, A., \& Hingley, M. K. (2007). The importance of brand in the industrial purchase decision: A case study 
of the UK tractor market. Journal of Business E Industrial Marketing, 22(6), 383-393. doi:10.1108/o8858620710780145

Wang, G., Wang, X., Long, Y., Hou, W. C., \& Ching, L. A. (2015). Buyer Loyalty in Business Markets: Can the Firm and Salesperson Get What They Truly Desire? Journal of Business-to-Business Marketing, 22(3), 197-210. doi:10.10 80/1051712X.2015.1081018

Wang, Y. J., Capon, N., Wang, V. L., \& Guo, C. (2018). Building industrial brand equity on resource advantage. Industrial Marketing Management, 72, 4-16. doi:10.1016/j.indmarman.2017.11.009

Webb, B. (2012). A Classification approach to flagship stores. In T. Kent \& R. Brown (Eds.), Flagship Marketing (pp. 20-31). Routledge.

Webster, F. E., \& Keller, K. L. (2004). A roadmap for branding in industrial markets. Journal of Brand Management, 11(5), 388-402. doi:10.1057/palgrave. bm. 2540184

Widmann, T. (2013). Erfolgsfaktoren für Marken-Erlebniswelten außerhalb der Konsumgüterindustrie - dargestellt am Beispiel ausgewählter HydroenergieErzeuger. In H.-D. Quack \& K. Klemm (Eds.), Kulturtourismus zu Beginn des 21. Jahrhunderts: Festschrift für Albrecht Steinecke (pp. 213-230). München: Oldenbourg.

Wind, Y. (2006). Blurring the lines: Is there a need to rethink industrial marketing? Journal of Business $\mathcal{E}$ Industrial Marketing, 21(7), 474-481. doi:10.1108 /o8858620610708975

Wise, R., \& Zednickova, J. (2009). The rise and rise of the B2B brand. Journal of Business Strategy, 30(1), 4-13. doi:10.1108/02756660910926911

Withagen, R., de Poel, H. J., Araújo, D., \& Pepping, G.-J. (2012). Affordances can invite behavior: Reconsidering the relationship between affordances and agency. New Ideas in Psychology, 30(2), 250-258. doi:10.1016/j . newideapsych.2011.12.003

Wohlfeil, M., \& Whelan, S. (2005). Event-Marketing as Innovative Marketing Communications: Reviewing the German experience. Journal of Customer Behaviour, 4(2), 181-207. doi:10.1362/1475392054797214

Wohlfeil, M., \& Whelan, S. (2007). Like being a drop in a freshly-poured Guinness pint: Consumer motivations to participate in the "Guinness Storehouse". The Marketing Review, 7(3), 283-300. doi:10.1362/146934707 X230103

Wood, D. M., \& Ball, K. (2013). Brandscapes of control? Surveillance, marketing and the co-construction of subjectivity and space in neo-liberal capitalism. Marketing Theory, 13(1), 47-67. doi:10.1177/1470593112467264

Wood, E. H. (2009). Evaluating Event Marketing: Experience or Outcome? Journal of Promotion Management, 15(1-2), 247-268. doi:10.1080/104964909 02892580

Woodruff, R. B. (1997). Customer value: The next source for competitive advantage. Journal of the Academy of Marketing Science, 25(2), 139-153. doi:10.100 7/BFo2894350

Xie, C., \& Haugland, S. (2016). Formation of Reputation in Business Markets. Journal of Business-to-Business Marketing, 23(1), 25-45. doi:10.1080/105171 2X.2016.1148445

Yakhlef, A. (2015). Customer experience within retail environments: An embodied, spatial approach. Marketing Theory, 15(4), 545-564. doi:10.1177/1 470593115569016 
Yoo, B., \& Donthu, N. (2001). Developing and validating a multidimensional consumer-based brand equity scale. Journal of Business Research, 52(1), 1-14. doi:10.1016/So148-2963(99)ooo98-3

Yoo, B., Donthu, N., \& Lee, S. (2000). An Examination of Selected Marketing Mix Elements and Brand Equity. Journal of the Academy of Marketing Science, 28(2), 195-211. doi:10.1177/0092070300282002

Zablah, A. R., Brown, B. P., \& Donthu, N. (2010). The relative importance of brands in modified rebuy purchase situations. International Journal of Research in Marketing, 27(3), 248-260. doi:10.1016/j.ijresmar.2010.02.005

Zaichkowsky, J. L., Parlee, M., \& Hill, J. (2010). Managing industrial brand equity: Developing tangible benefits for intangible assets. Industrial Marketing Management, 39(5), 776-783. doi:10.1016/j.indmarman.2010.02.017

Zanger, C. (2008). Entstehung und Systematisierung von erlebnisorientierten Markenplattformen. In N. O. Herbrand (Ed.), Schauplätze dreidimensionaler Markeninszenierung (pp. 69-84). Stuttgart: Ed. Neues Fachwissen.

Zarantonello, L., \& Schmitt, B. H. (2010). Using the brand experience scale to profile consumers and predict consumer behaviour. Journal of Brand Management, 17(7), 532-540. doi:10.1057/bm.2010.4

Zarantonello, L., \& Schmitt, B. H. (2013). The impact of event marketing on brand equity: The mediating roles of brand experience and brand attitude. International Journal of Advertising, 32(2), 255-280. doi:10.2501/IJA-32-2-2 $55-280$

Zentes, J., Ney, B., \& Keßler, D. (2014). Markenwelten: Multisensualität und Markenidentität. Saarbrücken: H.I.MA., Inst. für Handel \& Internationales Marketing.

ZF Friedrichshafen AG. (2016). ZF Forum - Sneak Peek into Future Trends. Retrieved from https://www.zf.com/site/zfforum/en/homepage/zf_ forum.html

Zhang, J., Jiang, Y., Shabbir, R., \& Du, M. (2015). Building industrial brand equity by leveraging firm capabilities and co-creating value with customers. Industrial Marketing Management, 51, 47-58. doi:10.1016/j.indmarman.201 5.05.016

Zhao, X., Lynch, J. G., \& Chen, Q. (2010). Reconsidering Baron and Kenny: Myths and Truths about Mediation Analysis. Journal of Consumer Research, 37(2), 197-206. doi:10.1086/651257

Zimmermann, L., \& Littich, M. (2012). Markenwelten als Schauplatz für Markenerlebnisse. In H. H. Bauer, D. Heinrich, \& M. Samak (Eds.), Erlebniskommunikation (pp. 223-235). Berlin, Heidelberg: Springer-Verlag Berlin Heidelberg.

Zolkiewski, J., Story, V., Burton, J., Chan, P., Gomes, A., Hunter-Jones, P., ... Robinson, W. (2017). Strategic B2B customer experience management: The importance of outcomes-based measures. Journal of Services Marketing, 31(2), 172-184. doi:10.1108/JSM-10-2016-0350 
